Portland State University

PDXScholar

\title{
Development of a Technology Transfer Score for Evaluating Research Proposals: Case Study of Demand Response Technologies in the Pacific Northwest
}

Judith Estep

Portland State University

Follow this and additional works at: https://pdxscholar.library.pdx.edu/open_access_etds

Part of the Engineering Commons, and the Technology and Innovation Commons Let us know how access to this document benefits you.

\section{Recommended Citation}

Estep, Judith, "Development of a Technology Transfer Score for Evaluating Research Proposals: Case Study of Demand Response Technologies in the Pacific Northwest" (2017). Dissertations and Theses. Paper 3479.

https://doi.org/10.15760/etd.5363

This Dissertation is brought to you for free and open access. It has been accepted for inclusion in Dissertations and Theses by an authorized administrator of PDXScholar. Please contact us if we can make this document more accessible: pdxscholar@pdx.edu. 
Development of a Technology Transfer Score for Evaluating Research Proposals: Case Study of Demand Response Technologies in the Pacific Northwest

by

\title{
Judith Estep
}

A dissertation submitted in partial fulfillment of the requirements for the degree of

\author{
Doctor of Philosophy \\ in \\ Technology Management
}

\author{
Dissertation Committee: \\ Tugrul Daim, Chair \\ Dundar Kocaoglu, Co-Chair \\ Jisun Kim \\ Loren Lutzenhiser
}

Portland State University

2017 


\section{ABSTRACT}

Investment in Research and Development $(R \& D)$ is necessary for innovation, allowing an organization to maintain a competitive edge. The U.S. Federal Government invests billions of dollars, primarily in basic research technologies to help fill the pipeline for other organizations to take the technology into commercialization. However, as Lewis Duncan suggests, it is not about just investing in innovation, it is about converting that research into application. A cursory review of the research proposal evaluation criteria suggests that there is little to no emphasis placed on the transfer of research results. This effort is motivated by a need to move research into application.

One segment that is facing technology challenges is the energy sector. Historically, the electric grid has been stable and predictable; therefore, there were no immediate drivers to innovate. However, an aging infrastructure, integration of renewable energy, and aggressive energy efficiency targets are motivating the need for research and to put promising results into application. Many technologies exist or are in development but the rate at which they are being adopted is slow.

The goal of this research is to develop a decision model that can be used to identify the technology transfer potential of a research proposal. An organization can use the model to select the proposals whose research outcomes are more likely to move into application. The model begins to close the chasm between research and application - otherwise known as the "valley of death". 
A comprehensive literature review was conducted to understand when the idea of technology application or transfer should begin. Next, the attributes that are necessary for successful technology transfer were identified. The emphasis of successful technology transfer occurs when there is a productive relationship between the researchers and the technology recipient. A hierarchical decision model, along with desirability curves, was used to understand the complexities of the researcher and recipient relationship, specific to technology transfer. In this research, the evaluation criteria of several research organizations were assessed to understand the extent to which the success attributes that were identified in literature were considered when reviewing research proposals. While some of the organizations included a few of the success attributes, none of the organizations considered all of the attributes. In addition, none of the organizations quantified the value of the success attributes.

The effectiveness of the model relies extensively on expert judgments to complete the model validation and quantification. Subject matter experts ranging from senior executives with extensive experience in technology transfer to principal research investigators from national labs, universities, utilities, and non-profit research organizations were used to ensure a comprehensive and cross-functional validation and quantification of the decision model.

The quantified model was validated using a case study involving demand response (DR) technology proposals in the Pacific Northwest. The DR technologies were selected based on their potential to solve some of the region's most prevalent 
issues. In addition, several sensitivity scenarios were developed to test the model's response to extreme case scenarios, impact of perturbations in expert responses, and if it can be applied to other than demand response technologies. In other words, is the model technology agnostic? In addition, the flexibility of the model to be used as a tool for communicating which success attributes in a research proposal are deficient and need strengthening and how improvements would increase the overall technology transfer score were assessed. The low scoring success attributes in the case study proposals (e.g. project meetings, etc.) were clearly identified as the areas to be improved for increasing the technology transfer score. As a communication tool, the model could help a research organization identify areas they could bolster to improve their overall technology transfer score. Similarly, the technology recipient could use the results to identify areas that need to be reinforced, as the research is ongoing.

The research objective is to develop a decision model resulting in a technology transfer score that can be used to assess the technology transfer potential of a research proposal. The technology transfer score can be used by an organization in the development of a research portfolio. An organization's growth, in a highly competitive global market, hinges on superior R\&D performance and the ability to apply the results. The energy sector is no different. While there is sufficient research being done to address the issues facing the utility industry, the rate at which technologies are adopted is lagging. The technology transfer score has the potential to increase the success of crossing the chasm to successful application by helping an organization make informed and deliberate decisions about their research portfolio. 


\section{DEDICATION}

"All great achievements require time."

\section{- Maya Angelou}

This research is dedicated to patience...those who have it, those who need it, and those who are learning it. 


\section{ACKNOWLEDGEMENTS}

This research represents an effort that could not be done in isolation. The list of those who supported me is remarkable, and I'm certain to leave someone out. However, here I am, crossing the finish line and I only have thanks and gratitude to express.

I am grateful for my family that endured missed soccer practices and track meets, and delayed vacations so that I could pursue my passion. Craig, Sophia, and Samuel, your tolerance and patience with me are unsurpassed. I am in awe! Of course, there is my extended family in California, Washington, Texas, and Oregon that told me I could - and I did.

To my committee members, I appreciate your support, encouragement, and most of all brainstorming with me to narrow my research topic. It resulted in a perfect complement to my work environment. This synergy made my research more meaningful knowing the model can have an immediate impact on how a research portfolio is selected in my organization. Notably Dr. Daim - you willingly agreed to be my chairperson and made yourself available to answer my questions, provide advice, and make opportunities available for me. In addition, you agreed to be my mentor - I respect your input and look forward to your guidance as I move forward in the academic world. While the product is important, it is really the journey that you helped me appreciate.

Dr. Kocaoglu, at the time I didn't know how much I would value taking the ETM Decision Making class - it was a tough class and you challenged us. However, 
the way you presented the material, encouraged me to ask questions and to succeed, engaged me more than I realized such that I am using decision modeling as my research methodology. Thank you setting high expectations and accepting nothing less than excellence.

Dr. Lutzenhiser and Dr. Kim, I appreciate your input, especially as it pertained to energy related $R \& D$ - your expertise and thoughtful approach to energy topics and to research management was critical to the success of my research.

I am thankful for a collaborative work environment and for my manager, Terry Oliver, who encourages creativity and creates a space where there is NEVER a dumb question. I am excited to see how using this model will impact our portfolio. In addition, I am privileged to have access to some of the best practical thinkers on research management. My panels were made up of world-renowned experts who, without a doubt, had a significant impact on the quality of my research. Thank you to those who must remain anonymous.

Along the way, I met fabulous students who became friends - we share a common interest in higher learning and a desire to become well-rounded "T-type" people. Good luck on your journeys. I have every confidence that you will be successful. 


\section{TABLE OF CONTENTS}

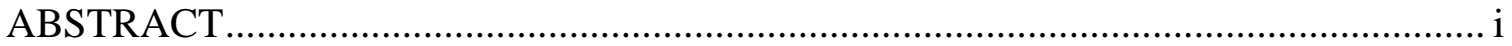

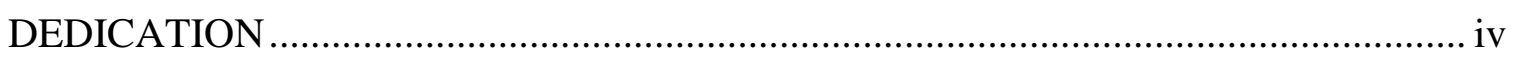

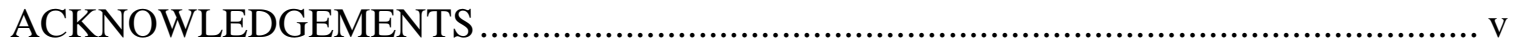

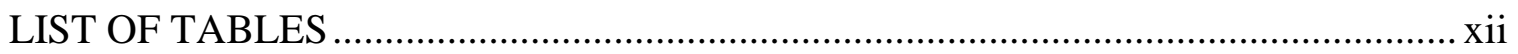

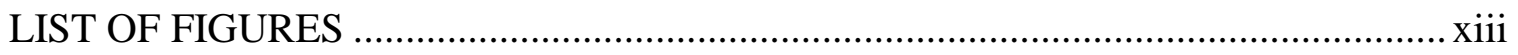

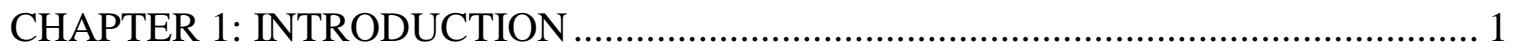

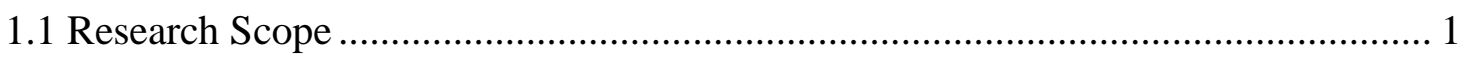

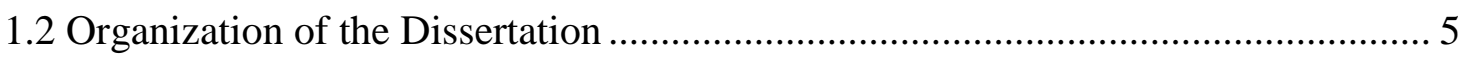

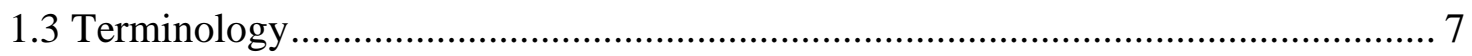

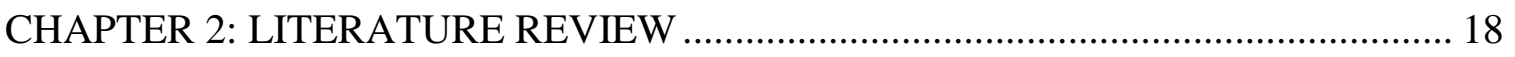

2.1 Citing TT in the Research Proposal Phase .......................................................... 18

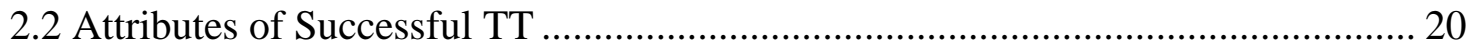

2.2.1 Organizational ........................................................................................ 21

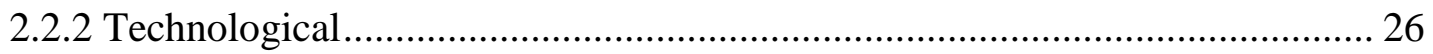

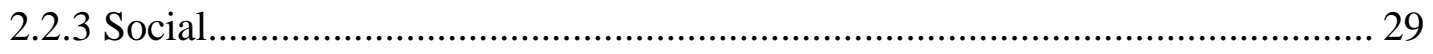

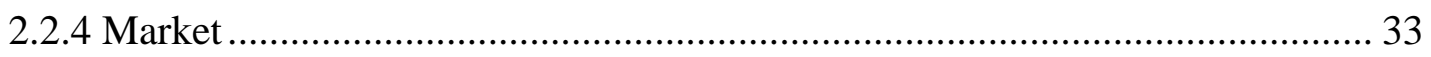

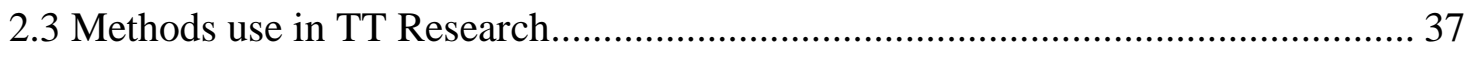

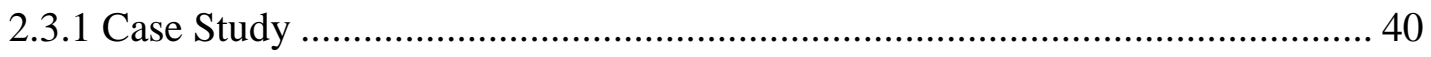

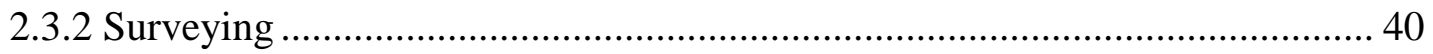

2.3.3 Literature Reports ..................................................................................... 41

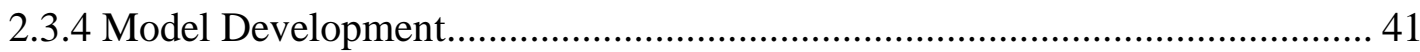

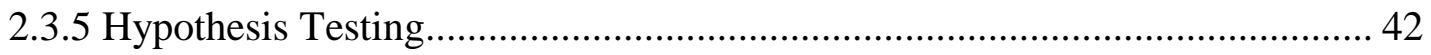

2.4 Evaluation of Research Proposals by Funding Agencies ......................................... 43

2.4.1 Department of Energy: EERE and ARPA-e .................................................. 44 
2.4.2 California Energy Commission..................................................................... 57

2.4.3 National Institutes of Health (NIH) ……………….................................... 59

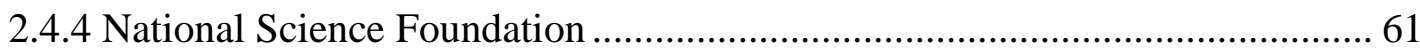

CHAPTER 3: RESEARCH OBJECTIVES, QUESTIONS, AND METHODOLOGY .. 70

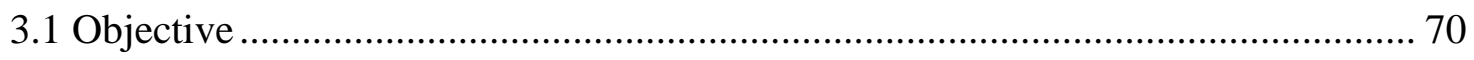

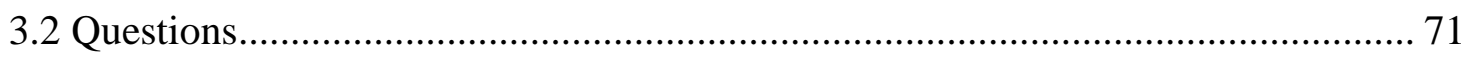

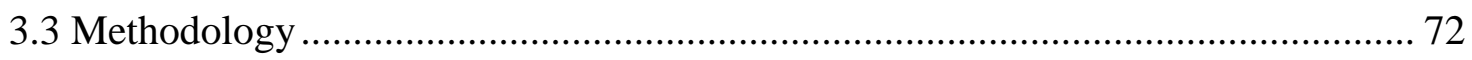

3.3.1 Introduction to Hierarchical Decision Modeling (HDM) ............................... 72

3.3.2 Inconsistency and Disagreement of Expert Judgments ................................... 76

3.3.3 Disagreement and Clustering .................................................................... 79

3.3.4 Calculating the Technology Transfer Score ………………............................. 82

3.3.5 Desirability Curves ……………………………......................................... 83

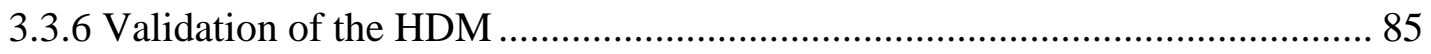

3.3.7 Expert Panel Development .......................................................................... 86

CHAPTER 4: DEVELOPMENT OF THE RESEARCH MODEL................................... 89

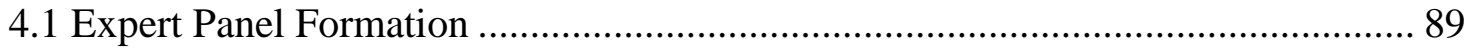

4.2 Conceptual HDM ................................................................................ 93

4.2.1 Mission Level............................................................................................... 96

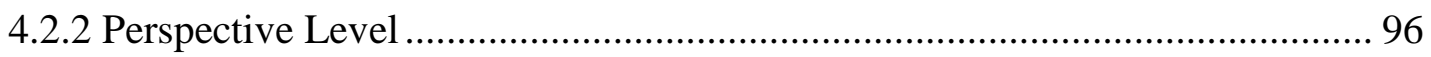

4.2.3 Success Attribute Level .................................................................................. 97

4.2.4 Alternative Level - Research Proposals ........................................................... 98

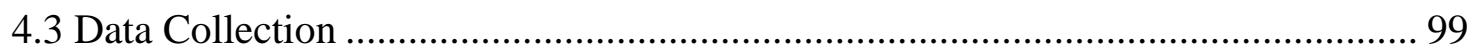

CHAPTER 5: RESULTS OF MODEL QUANTIFICATION........................................ 101

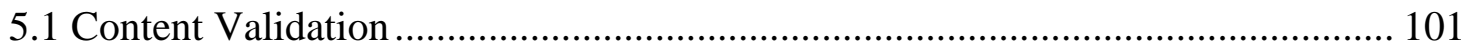

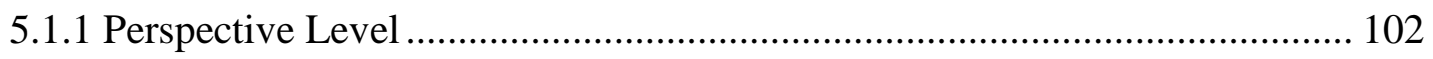

5.1.2 Organizational Success Attributes ……………………………………....... 103 
5.1.3 Technology Success Attributes.................................................................... 104

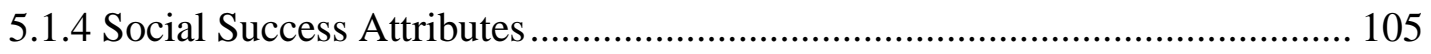

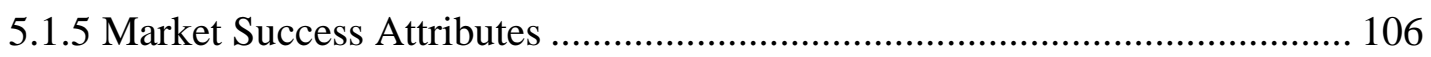

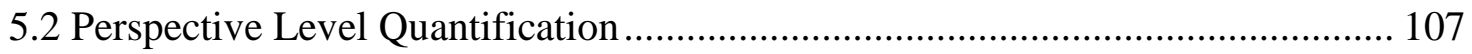

5.3 Success Attribute Quantification .................................................................. 109

5.3.1 Organizational Perspective ............................................................................ 109

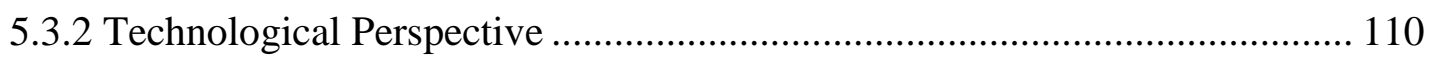

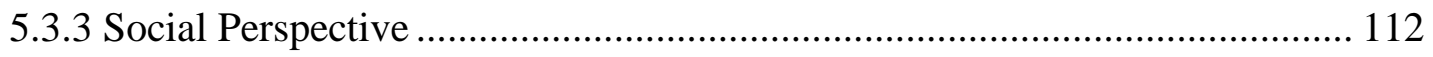

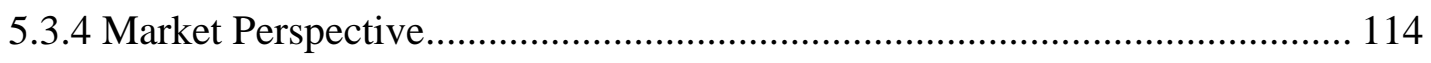

5.3.5 Final Model Weights.............................................................................. 115

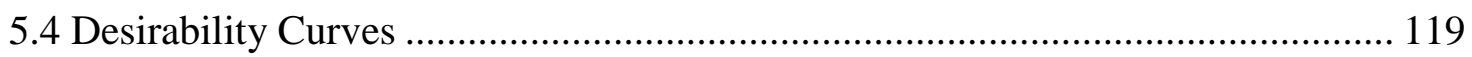

5.4.1 Organizational Success Attributes ................................................................. 119

5.4.2 Technological Success Attributes ............................................................ 125

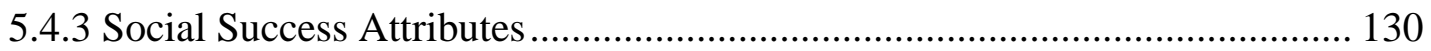

5.4.4 Market Success Attributes .............................................................................. 135

CHAPTER 6: ANALYSIS CASE DEVELOPMENT................................................... 141

6.1 DR in the Pacific Northwest - What is it and Why is it Important? ..................... 141

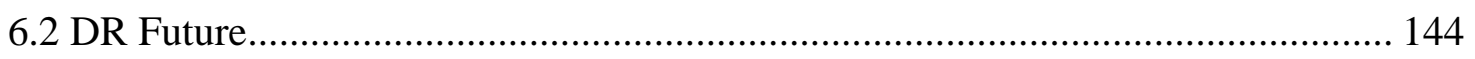

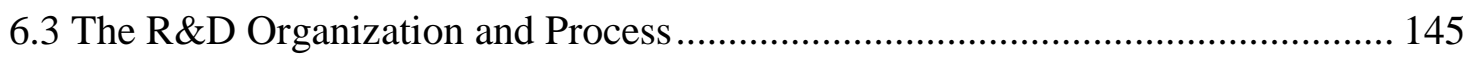

6.3.1 Research Proposals ............................................................................... 146

CHAPTER 7: ANALYSIS OF CASE AND SENSITIVITY ANALYSIS .................... 150

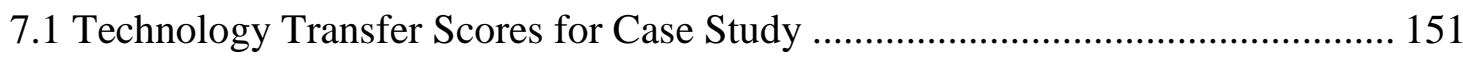

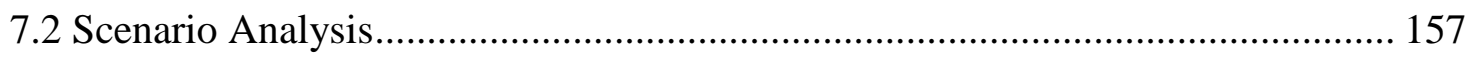

7.2.1 Future Based Scenario - Perspective Weights Change ................................ 158

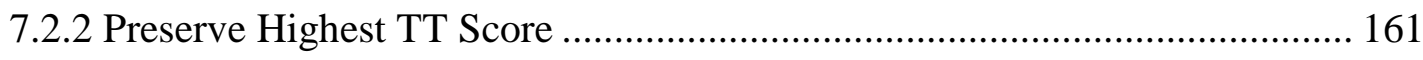

7.2.3 Can the Model be used for Other Technologies?............................................ 161 
7.2.4 What can the Researcher do to Improve Their TT Score (and increase the potential for successful TT)? ......................................................................... 164

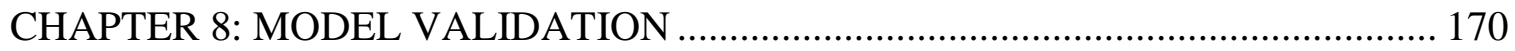

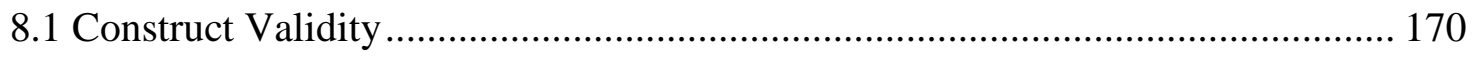

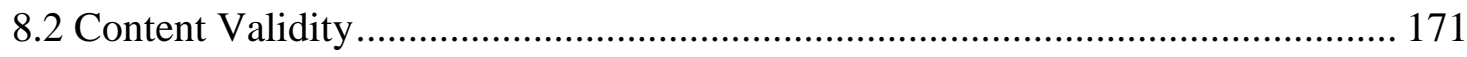

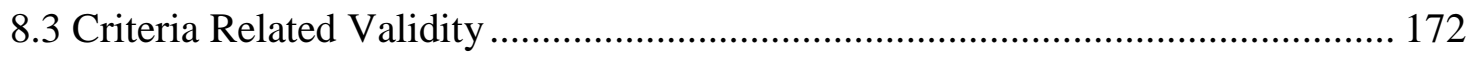

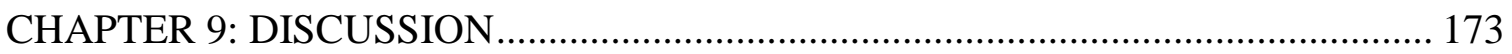

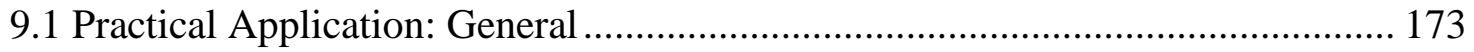

9.2 Practical Application: Organizational Perspective ........................................ 174

9.3 Practical Application: Technological Perspective ........................................ 175

9.4 Practical Application: Social Perspective ....................................................... 176

9.5 Practical Application: Market Perspective........................................................ 176

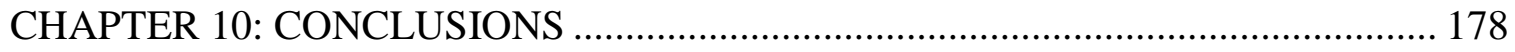

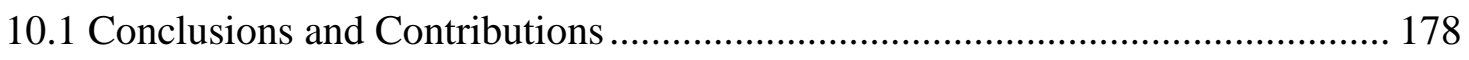

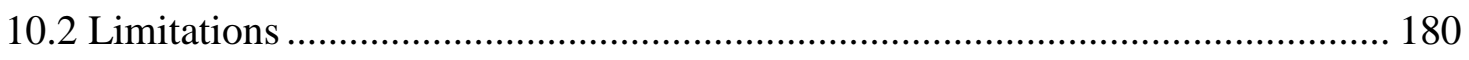

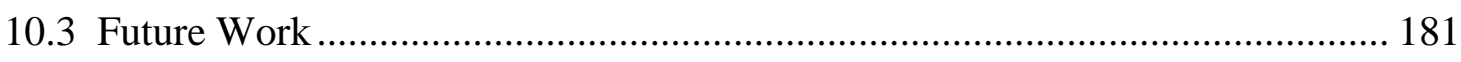

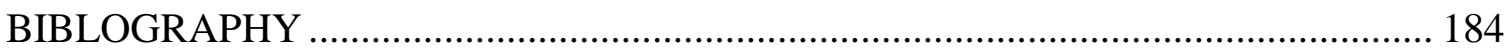

APPENDIX A: PROPOSAL EVALUATION CRITERIA ....................................... 197

Appendix A1: Proposal Evaluation Criteria: EERE ........................................... 197

Appendix A2: Proposal Evaluation Criteria: BPA .............................................. 198

Appendix A3: Proposal Evaluation Criteria: CEC ................................................ 199

Appendix A5: Proposal Evaluation Criteria: NSF ................................................ 206

APPENDIX B: DEFINITIONS OF REISMAN'S TAXONOMY .............................. 209

APPENDIX C: MODEL VALIDATION ASSESSMENT TOOL .............................. 215

APPENDIX D: MODEL QUANTIFICATION ASSESSMENT TOOLS .................. 222

Appendix D1: Quantification Tool for Perspective Level .................................... 222

Appendix D2: Quantification Tool for Organizational Success Attributes ............... 223

Appendix D3: Quantification Tool for Technological Success Attributes ................ 224

Appendix D4: Quantification Tool for Social Success Attributes ........................... 225 
Appendix D5: Quantification Tool for Market Success Attributes 226

APPENDIX E: MODEL VALIDATION RESULTS ……………………………..... 227

Appendix E1: Validation of Perspective Level .................................................... 227

Appendix E2: Validation of Organizational Perspective Success Attributes ............. 228

Appendix E3: Validation of Technological Perspective Success Attributes .............. 229

Appendix E4: Validation of Social Perspective Success Attributes ......................... 230

Appendix E5: Validation of Market Perspective Success Attributes ………………... 231

APPENDIX F: PAIRWISE COMPARISON RESULTS ............................................ 232

Appendix F1: Perspective Level Pairwise Comparisons ........................................... 232

Appendix F2: Organizational Pairwise Comparisons .............................................. 233

Appendix F3: Technological Pairwise Comparisons................................................ 234

Appendix F4: Social Pairwise Comparisons......................................................... 235

Appendix F5: Market Pairwise Comparisons .................................................... 236

APPENDIX G: DESIRABILITY CURVES FOR CASE STUDY-ACTUAL VALUES

237

Appendix G1: Summary of Desirability Curves...................................................... 237

Appendix G2: Success Attributes for Case Studies ……………………………..... 238

Appendix G3: Corresponding Desirability Curve Values .......................................... 239 


\section{LIST OF TABLES}

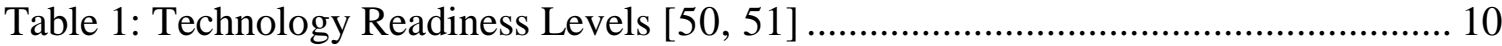

Table 2: Definitions of Technology Transfer .......................................................... 15

Table 3: Organizational Success Attributes ............................................................... 26

Table 4: Technological Success Attributes ................................................................. 29

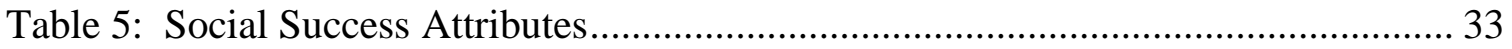

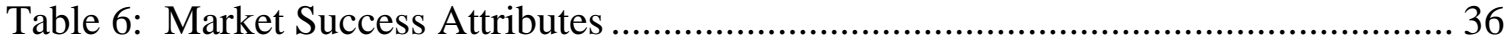

Table 7: Technology Transfer Analysis Methods........................................................ 39

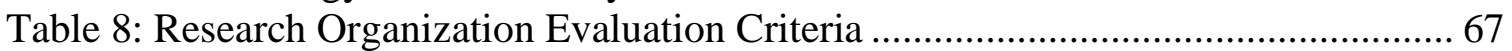

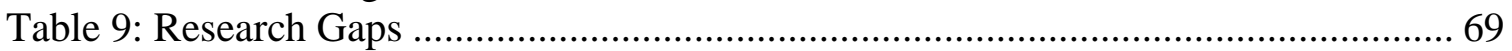

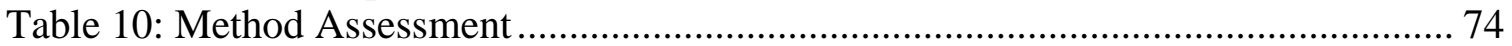

Table 11: Example of Inconsistency and Disagreement................................................ 82

Table 12: Summary of Expert Panels ………………….......................................... 92

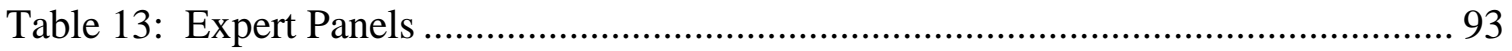

Table 14: Success Attribute Measurements ................................................................ 98

Table 15: Perspective Level Quantification................................................................ 108

Table 16: Organizational Success Attribute Quantification .......................................... 110

Table 17: Technological Success Attribute Quantification ......................................... 111

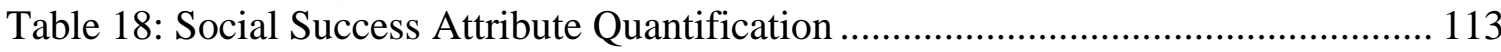

Table 19: Market Success Attribute Quantification...................................................... 115

Table 20: Final Model Weights ............................................................................... 117

Table 21: BPA Project Evaluation Criteria [19] ........................................................... 146

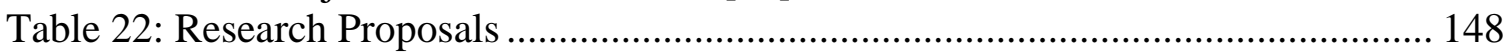

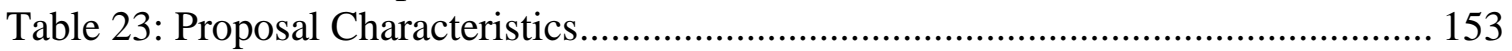

Table 24: Proposal \#1 Strengths and Weaknesses ........................................................ 153

Table 25: Proposal \#2 Strengths and Weaknesses ...................................................... 154

Table 26: Proposal \#3 Strengths and Weaknesses ....................................................... 155

Table 27: Baseline Technology Transfer Scores ………………............................. 155

Table 28: Organizational Emphasis - Impact on Proposal Rank ................................... 158

Table 29: Technological Emphasis - Impact on Proposal Rank .................................... 159

Table 30: Social Emphasis - Impact on Proposal Rank …….......................................... 160

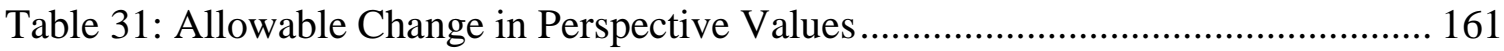

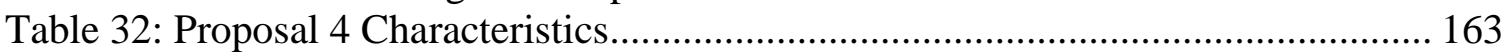

Table 33: TT Score Increases with Changes to Desirability Values ............................... 168

Table 34: Actions for the Organizational Perspective ................................................. 175

Table 35: Actions for the Technological Perspective ................................................... 175

Table 36: Actions for the Social Perspective .............................................................. 176

Table 37: Actions for the Market Perspective …………............................................. 177

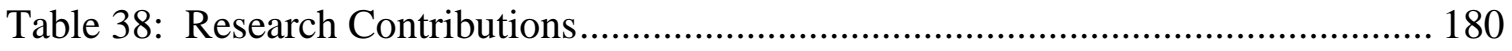




\section{LIST OF FIGURES}

Figure 1: Federal R\&D funding 2014-2015.......................................................... 2

Figure 2: How Technology Transfer is Understood for this Research ............................ 17

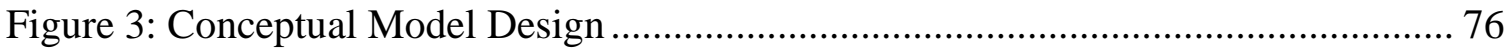

Figure 4: Template for Developing Desirability Curve ……….................................... 84

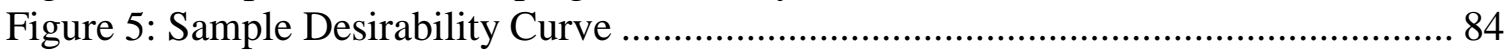

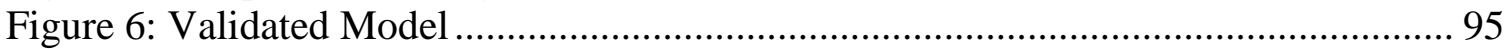

Figure 7: Perspective Validation Results ............................................................... 102

Figure 8: Organizational Strategies Success Attributes Validation ............................... 103

Figure 9: Technological Success Attributes Validation............................................... 104

Figure 10: Social Success Attributes Validation ........................................................ 105

Figure 11: Market Success Attributes Validation.......................................................... 106

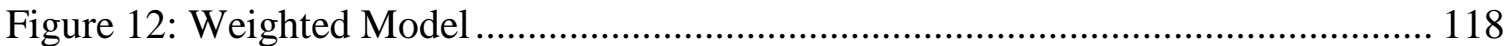

Figure 13: Budget Cost Share Desirability Curve ………………………………..... 120

Figure 14: Geographic Proximity Desirability Curve.................................................... 121

Figure 15: Average Time to Contract Desirability Curve ……………........................ 122

Figure 16: Technical Complexities Desirability Curve ……………………………..... 123

Figure 17: Stakeholder Complexities Desirability Curve.............................................. 124

Figure 18: Combined Research Experience Desirability Curve …………………........ 125

Figure 19: Technology Publications Desirability Curve ............................................. 126

Figure 20: Personnel Assigned to TTO Desirability Curve ............................................ 127

Figure 21: Technology Benefits Desirability Curve ………………........................... 128

Figure 22: Budget Allocated to TT Activities Desirability Curve.................................. 129

Figure 23: Diversity Events Desirability Curve......................................................... 130

Figure 24: Personnel Dedicated to Support TT Desirability Curve................................ 131

Figure 25: Project Meetings Desirability Curve …………….................................... 132

Figure 26: Personnel Loaned to Recipient Desirability Curve ...................................... 133

Figure 27: Successful TT Experience Desirability Curve …………………………..... 134

Figure 28: Comprehensiveness of the Use Case Desirability Curve ............................. 135

Figure 29: Credibility of the Organizational Champion ................................................ 136

Figure 30: Level of Top Management Interest Desirability Curve................................. 137

Figure 31: Government Incentives Desirability Curve ................................................. 138

Figure 32: Common Technology Standards Desirability Curve...................................... 139

Figure 33: ROI Desirability Curve ……………………....................................... 140

Figure 34: BPA Balancing Authority Load for 05/05-12/2014 ..................................... 142 


\section{CHAPTER 1: INTRODUCTION}

The first chapter of the dissertation will lay the foundation for the research

effort. The scope of the research is defined and begins to describe why technology transfer is so important and why starting to think about technology application during the research phase is critical to overcoming technology transfer barriers. The focus of the research is on federal funding and moving this research into application, but the concept can easily be adapted to any research organization.

The introduction describes how the document is organized and ends with understanding the term "technology transfer" and how it will be interpreted for the purpose of this research.

\subsection{Research Scope}

In order to maintain a competitive edge, organizations must innovate. The National Science Board states that in order for an organization to remain competitive, investment in research is an imperative. Research and development investments by the National Labs are significant. The labs primarily invest in basic research and feed the innovation pipeline for companies to take the research into application. Figure 1 was derived from the individual organizations' websites and shows recent federal investments in research. 


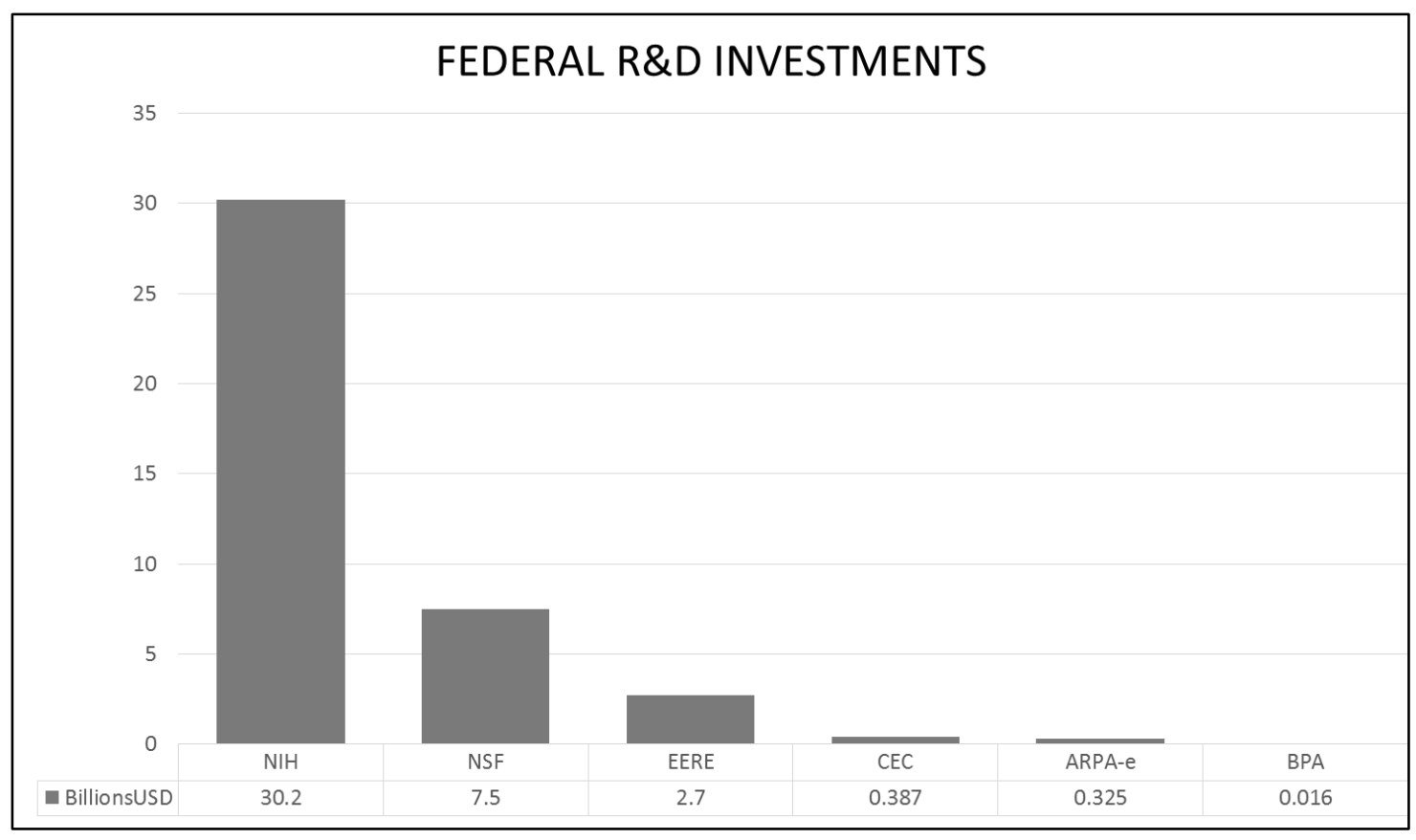

Figure 1: Federal R\&D funding 2014-2015

A company's growth hinges on successful R\&D [167]. However, investments in research alone do not guarantee success. Rather the application of research results is what propels an organization to remain competitive in a global economy.

Despite the significant investments, there are many examples of application failures. In fact, the reasons for some of these failures can be attributed to the technology transfer process. Solyndra was a manufacturer of solar panels. Their cylindrical design was unique and unlike other solar panel technology, Solyndra used copper indium gallium selenide thin film solar cells. This combination would allow the panels to be packaged more densely on commercial rooftops and absorb light from many directions because of it cylindrical design. As a result, Solyndra claimed this technology would produce more electricity than a contemporary solar panel. The company was one of the first recipients of the 2009 Recovery Act [39] - 
Solyndra received a $\$ 535 \mathrm{M}$ loan guarantee. The technology looked like a viable alternative to polysilicon, which, at the time, was in short supply. These shortages were temporary since new manufacturing plants were in process. The polysilicon market prices plummeted and Solyndra failed - spectacularly [168]. While the technology was a success, the reasons for their technology transfer failure were attributed to not putting a good business case together and a lack of understanding the end-user: their panel technology was not compatible with the residential sector or for large solar farms.

While there are voluminous amounts of information about technology transfer and attributes of successful technology transfer, there is a lack of information about how to assimilate these success attributes - in other words a framework for how successful technology transfer occurs.

The problem of successful technology transfer is critical for the energy sector, specifically power utilities; this is the basis for the research done by Jenkins and Mansur. Their research emphasizes “.... an urgent national imperative to modernize and diversify its energy system..." [161]. Against the backdrop of the United States' Energy Action Plan, which includes increased research investments in clean energy, the utility industry needs to respond to unprecedented technology challenges. These challenges include an aging infrastructure, a growing population, and aggressive energy efficiency targets. There is a large population of utility equipment (e.g. poles, power transformers) that has exceeded or is nearing its useful service life [36]. As the population grows, concerns about congestion management grow proportionately. Regarding energy efficiency 
targets, the President called for an energy strategy for the future, requiring out-of-the-box thinking about energy solutions. For example, the Pacific Northwest region has a target to meet $85 \%$ of the load growth with energy efficient devices and strategies [37]. To complicate matters, the changes to the grid, with the integration of "smart" technologies, demand response solutions, and renewable resource integration make a previously predictable system more unstable. The utility industry acknowledges these challenges and is investing in research to identify solutions. However, relative to other industries, utilities spend very little on research and development. A recent National Science Foundation report on R\&D spending (2012) shows that, on average, utilities spend $0.1 \%$ [38].

It is not enough to just develop a technology that solves an energy related problem. Utilities are also faced with a challenge of integrating the technology into an existing infrastructure and doing so, reliably and seamlessly $[70,71,72,36]$. In order for a solution to be effective and have an impact, the technology needs to be appliedwithout the technology transfer component, energy strategies cannot be realized. Therefore, there is a need to understand the difficulties associated with technology transfer. The better barriers are understood and the relevant success attributes are known, the more likely results can be applied, ensuring that these technologies are commercialized. However, success attributes need to be considered before the decision is made to develop these technologies as part of the proposal evaluation; literature is provided in Chapter 2.4 to support this supposition. Therefore, we need to look at the decision point when technology transfer or commercialization is considered. Specific to 
energy related topics, there is a need to understand how the Department of Energy (DOE) is evaluating technology proposals. While the preceding example emphasizes the need for successful technology transfer in the energy sector, other sectors face similar challenges with implementing research results.

The goals of this research are to:

1. Identify when technology transfer should be considered,

2. Identify what attributes should be the focus to facilitate successful technology transfer, and

3. Understand how federally funded organizations consider technology transfer as part of their research proposals.

Achieving these goals helped to meet the objective of this research. That is to develop a technology transfer score that can be used to inform the selection of research proposals that have the most potential for technology transfer.

Knowledge is power - by identifying those attributes, which contribute to successful technology transfers, an industry could take a proactive approach by ensuring that those elements are present during the research and development phase.

\subsection{Organization of the Dissertation}

The introduction includes a description of how technology transfer is considered for the purposes of this research. Technology transfer has different interpretations given the maturity of the technology, so it is important to understand the context. 
Chapter 2 provides an organized literature review, which considered: 1 . When an organization should start to consider technology transfer, 2: What are the attributes for successful technology transfer, 3: What mechanisms have been used to understand technology transfer, and 4: How and to what degree are research organizations considering technology transfer?

Chapter 3 and a discussion of the methodology follow the literature review. Included is justification for choosing a hierarchical decision model to research technology transfer as well as a discussion about the use of desirability curves to quantify subjective measures, selection of expert panels and how to measure inconsistency and disagreement with their responses.

Chapter 4 develops the model and talks about the expert panel and how the different panels will be used. Lastly, the research assessment tools that will collect their expert opinions to validate and quantify the model are discussed.

Chapter 5 presents the quantified model and chapter 6 develops the case study that will be used to test the model. The case study uses technologies and research proposals that are being considered for the Pacific Northwest. These technologies will help the utilities address grid stability issues resulting from renewable energy integration, meet aggressive energy efficiency targets, and provide alternatives to grid expansion or upgrades.

Case study and sensitivity analysis are conducted in Chapter 7, with the final model validation being discussed in Chapter 8 . 
Finally, Chapter 9 provides the research conclusions, contributions, assumptions, and discusses limitations. These limitations will identify opportunities for future work.

\subsection{Terminology}

It would be worthwhile to begin the research with an understanding of the term technology transfer. The definitions cover the spectrum from whimsical - PNNL has informally described the tech transfer process as a "contact sport" [165] to more formal definitions as describe by E.M. Rogers, et al: “...a technological innovation is fully transferred when it is commercialized into a product that is sold in the market place..."

[62]. In general, the technology transfer process involves the sharing of knowledge and facilities among:

- Federal laboratories

- Industry

- Universities

- Federal, state, and local governments

- Third party intermediaries [91]

Technology transfer is not a new concept. The considerable amount of literature agrees that defining technology transfer is difficult due to the complexity of the technology transfer process. The definitions vary depending on the organization, technology type, and technology maturity, among other factors.

The term technology transfer can be defined as the process of movement of technology from one entity to another. The transfer may be said to be successful if the 
receiving entity, the transferee, can effectively utilize the technology transferred and eventually assimilate it. The movement may involve physical assets, expertise, and technical knowledge. Technology transfer in some situations may be confined to relocating and exchanging of personnel or the movement of a specific set of capabilities. [106]

Technology transfer has also been used to refer to movements of technology from the laboratory to industry, developed to developing countries, or from one application to another domain [106].

The National Technology Transfer Center (NTTC) focuses on the players involved in federal technology transfer "... the purpose of a federal technology transfer program is to make federally generated scientific and technological developments accessible to private industry and state and local governments." The expectation is that the technology will be further developed once transferred and “...enhance our nation's industrial competitiveness or otherwise improve our quality of life." [110] A similar definition of federal research and technology transfer includes the reference to the serving public and private needs, “...technology transfer is the process by which existing knowledge, facilities or capabilities developed under federal research and development funding are utilized to fulfill public and private needs". [108] Further supporting the theme of providing efficiencies, the Transportation Research Board defines technology transfer as doing things better, “...technology transfer is the process by which research and other new technologies are transferred into useful process, products, and programs. Another way of saying the same thing is: technology transfer is the process by which a better way of doing something is put into use as quickly as possible.” [109] At a very basic level technology transfer has been 
defined as simply, “...technology transfer addresses the assessment, adoption and implementation of technology" [108]

The definitions of technology transfer are as disparate as the organizations that apply them. Technology transfer includes knowledge transfer, enabling people or countries to be ready to accept new technologies - preparations, and involves many stakeholders to include national labs, government agencies, private industries, technical and management level personnel, as well as developing countries. Because of the literature review it can be inferred that the definition of technology transfer is dependent on the context and the technology.

The type of technology transfer also depends on the maturity of the technology. For less mature technologies, it may be appropriate to transfer knowledge about the technology so it can be developed further. In contrast, more mature technologies are more likely to be applied. The idea of Technology Readiness Levels (TRLs) helps a researcher to communicate the maturity of a technology. Lower TRL values 1-5 would be considered more basic research, with one being the lowest, while TRLs 6-9 describe technologies that are more advanced. A complete description of the Department of Energy (DOE) TRLs with the NASA stages is presented in Table 1.

\begin{tabular}{|c|c|c|}
\hline STAGES & $\begin{array}{c}\text { TECHNOLOGY } \\
\text { READINESS } \\
\text { LEVEL }\end{array}$ & DESCRIPTION \\
\hline Discovery & 1 & $\begin{array}{l}\text { Scientific research begins translation to applied R\&D, } \\
\text { lowest level of technology readiness. Scientific research } \\
\text { begins to be translated into applied R\&D. Examples } \\
\text { might include paper studies of a technology's basic } \\
\text { principles. }\end{array}$ \\
\hline
\end{tabular}




\begin{tabular}{|c|c|c|}
\hline \multirow[t]{2}{*}{ STAGES } & $\begin{array}{c}\text { TECHNOLOGY } \\
\text { READINESS } \\
\text { LEVEL }\end{array}$ & DESCRIPTION \\
\hline & 2 & $\begin{array}{l}\text { Invention begins - Once basic principles are observed, } \\
\text { practical applications can be invented. Applications are } \\
\text { speculative and there may be no proof or detailed } \\
\text { analysis to support the assumptions. Examples are } \\
\text { limited to analytic studies. }\end{array}$ \\
\hline \multirow[t]{3}{*}{ Development } & 3 & $\begin{array}{l}\text { Active } R \& D \text { is initiated - This includes analytic studies } \\
\text { and laboratory studies to physically validate analytical } \\
\text { predictions of separate elements of the technology. } \\
\text { Examples include components that are not yet integrated } \\
\text { or representative. }\end{array}$ \\
\hline & 4 & $\begin{array}{l}\text { Basic technological components are integrated to } \\
\text { establish that the pieces will work together. }\end{array}$ \\
\hline & 5 & $\begin{array}{l}\text { Fidelity of breadboard technology improves } \\
\text { significantly. The basic technological components are } \\
\text { integrated with reasonably realistic supporting elements } \\
\text { so it can be tested in a simulated environment. } \\
\text { Examples include "high fidelity" laboratory integration } \\
\text { of components. }\end{array}$ \\
\hline \multirow[t]{2}{*}{ Demonstration } & 6 & $\begin{array}{l}\text { Model/prototype is tested in a relevant environment - } \\
\text { represents model or prototype system, which is tested } \\
\text { well beyond TRL 5, is tested in a relevant environment. } \\
\text { Represents a major step up in a technology's } \\
\text { demonstrated readiness. Examples include testing a } \\
\text { prototype in a high fidelity laboratory environment or in } \\
\text { a simulated operational environment. }\end{array}$ \\
\hline & 7 & $\begin{array}{l}\text { Prototype near or at planned operational system. } \\
\text { Represents a major step up from TRL } 6 \text {, requiring } \\
\text { demonstration of an actual system prototype in an } \\
\text { operational environment. }\end{array}$ \\
\hline \multirow[t]{2}{*}{ Commercialization } & 8 & $\begin{array}{l}\text { Technology is proven to work - actual technology } \\
\text { completed and qualified through test and demonstration. }\end{array}$ \\
\hline & 9 & $\begin{array}{l}\text { Actual application of technology is in the final form - } \\
\text { technology proven through successful operations. }\end{array}$ \\
\hline
\end{tabular}

Table 1: Technology Readiness Levels [50, 51]

Frank Geels describes the multi-criteria aspects of technology transfer process, relative to sustainability transitions. He emphasizes that, “...technological transitions not only involve the technology...but also changes in elements such as user practices, regulation, industrial networks, infrastructure....”. [42] and “...technical trajectories 
are not only influenced by engineers, but also by users, policy makers, societal groups, suppliers, ..." [43] In this context, Geels refers to the technology transfer process as a relationship and describes the interaction of different perspectives as the “...dynamics of structural change...". [42] Geels identifies the unique levels of interaction: landscape developments, socio-technical regimes, and technological niches. Technology transitions occur when there is an interaction among the different levels. The interaction results from a need in the landscape created by the sociotechnical regime in the form of understanding user preferences, policy drivers, culture, etc. In anticipation, the niche has technology developments ready to respond to the landscape need - a window of opportunity is opened and the technology is transitioned. In other words, transition occurs when all three levels are synchronized and reinforce each other. A definition of each level is provided:

- Socio-technical landscape: impacted by external inputs; change happens slowly, typically over a period of decades. Relative to this research, the technology recipient can be seen as the landscape.

- Socio-technical regime: Influences the landscape through identification of market/user preferences, culture, and policy implementation

- Niche - Innovations: research and development of new technologies occurs in this space.

A verbatim explanation from Frank Geels puts context around the relationship: [44] “...(a) niche-innovations build up internal momentum, through learning processes, price/performance improvements, and support from powerful groups, (b) changes at the 
landscape level create pressure on the regime and (c) destabilization of the regime creates a window of opportunity for niche-innovations. The alignment of these processes enables the breakthrough of these...technologies...". The different levels are similarly described in several of Geels' research [42, 43, 44, 45, 46].

Geels explains issues with sustainable technology transitions. These include not offering obvious benefits for the end-user, comfort level with incumbent technologies that requires a strategic over-haul of those who support existing technologies, existing infrastructures, and user practices that are aligned with the existing technology. [42] In this research, a utility is seen as the incumbent.

Sharma's dissertation [48] describes the technology transfer process through time and clearly shows building a relationship as a prominent theme to successful technology transfer.

The relationship theme is also prominent in the work of Franza, R.M., and K.P. Grant. "Improving Federal to Private Sector Technology Transfer," Research-Technology Management 49, no. 3 (2006): 36-40 [49]. The attributes they identify as necessary for technology transfer demonstrate that a relationship is important. Franza and Grant highlight the "difference makers" - those attributes that are essential for successful technology transfer.

For the purposes of this research, the relationship definition of technology transfer will be understood as transfer of a technology or application from a research partner (e.g. national lab, industry partner, university, or an internal researcher) to a utility. A description of the research partners considered for this research is provided. 
The research organizations include five likely partners: Universities, Collaborative Partnerships (EPRI, CEATI, etc.), National Labs (LBNL, PNNL, etc.), Industry Partners (Intel, IBM, etc.), and other utilities (So Cal Edison, Consolidated Edison, etc.).

Collaborative Partnerships: Utilities partner with national labs or purchase memberships through consortiums such as Electric Power Research Institute (EPRI), Centre for Energy Advancement through Technological Innovation (CEATI), or Power System Engineering Resource Center (PSERC). These consortiums conducted research on behalf of the utility industry. A query of utility partners has identified these organizations as collaborative partnerships.

Industry: The research is proposed by industry. Examples of industry partners include Intel, GE, and IBM. Existing technology may have been applied to other industries but an application to the utility industry has been identified.

University: Consists of research conducted by universities.

National Labs: The United States Department of Energy national laboratories and technology centers are a system of facilities and laboratories overseen by the United States Department of Energy (DOE) for the purpose of advancing science and technology to fulfill the DOE mission. Sixteen of the seventeen DOE national laboratories are federally funded research and development centers administered, managed, operated and staffed by private-sector organizations under management and operating (M\&O) contract with DOE. [85] There are 17 national labs operated by the US Department of Energy. 
Analogous to Geels research, the research partner can be seen as developing the niche innovations and the research drivers (renewable integration, meeting energy efficiency targets, etc.) and utilities are represented by the socio-technical landscape. The objective is for these technologies to help a utility address the challenges of an aging infrastructure, meeting energy efficiency targets, integrating renewable resources, or accommodating load growth.

As stated, there are many ways to think about technology transfer. It can be described, in early stages of research, as transferring knowledge that will help to move the technology into more mature stages of development. In contrast, for more mature technologies, technology transfer can mean the actual adoption and availability of a technology in the market place.

More subjective definitions of technology transfer include building a relationship between the researchers and the technology recipients. A strong relationship is a mechanism for successful technology transfer. Important to the relationship is the technology transfer "player" - who is conducting the research and who is receiving the technology. The literature review describing these definitions is summarized in Table 2.

\begin{tabular}{|c|c|c|}
\hline TT Topic & Description & Source \\
\hline $\begin{array}{l}\text { Knowledge } \\
\text { Transfer }\end{array}$ & $\begin{array}{l}\text { Tacit knowledge transfer which is seen } \\
\text { as having the potential for greater pay- } \\
\text { offs than tangible products } \\
\text { - Process of moving proof-of-concept, } \\
\text { prototypes into application }\end{array}$ & $\begin{array}{l}\text { Rogers, E.M. et al. [62] } \\
\text { Bozeman [54], } \\
\text { Gopalakrishnan, S, et al. } \\
\text { [101] }\end{array}$ \\
\hline Commercialization & $\begin{array}{l}\text { Technological innovation is fully } \\
\text { transferred when it is commercialized } \\
\text { into a product that is sold in the market } \\
\text { place }\end{array}$ & $\begin{array}{l}\text { Rogers, E.M. et al. [62], } \\
\text { Ramanathan, K., [106] }\end{array}$ \\
\hline
\end{tabular}




\begin{tabular}{|c|c|c|}
\hline TT Topic & Description & Source \\
\hline & $\begin{array}{l}\text { - Effectively utilize the technology } \\
\text { transferred and eventually assimilate it }\end{array}$ & \\
\hline $\begin{array}{l}\text { Relationship } \\
\text { Building }\end{array}$ & $\begin{array}{l}\text { - Involve the technology ...but also } \\
\text { changes in elements such as user } \\
\text { practices, regulation, industrial } \\
\text { networks, infrastructure } \\
\text { - Technical trajectories are not only } \\
\text { influenced by engineers, but also by } \\
\text { users, policy makers, societal groups, } \\
\text { suppliers } \\
\text { - Describes the interaction of different } \\
\text { perspectives as the “... dynamics of } \\
\text { structural change..." } \\
\text { Technology transfer is described as a } \\
\text { "contact sport”: requiring continuous } \\
\text { interaction between technology } \\
\text { sources, academia, the government, } \\
\text { industry, and end users } \\
\text { Process by which existing knowledge, } \\
\text { facilities or capabilities developed } \\
\text { under federal research and } \\
\text { development funding are utilized to } \\
\text { fulfill public and private needs; } \\
\text { Described as technology development } \\
\text { chains }\end{array}$ & $\begin{array}{l}\text { Sharma, [48], Geels, et al. } \\
\text { [44], www.pnnl.gov, [164] } \\
\text { Lecture ETM 533, [108], } \\
\text { Perry [56], Franza, RM, et } \\
\text { al. [49] }\end{array}$ \\
\hline TT Players & $\begin{array}{l}\text { Transfer process involves the sharing } \\
\text { of knowledge and facilities among: } \\
\text { Federal laboratories, Industry, } \\
\text { Universities, Federal, state, and local } \\
\text { governments, Third party } \\
\text { intermediaries } \\
\text { - Movements of technology from the } \\
\text { laboratory to industry, developed to } \\
\text { developing countries, or from one } \\
\text { application to another domain }\end{array}$ & $\begin{array}{l}\text { Okoli and Pawlowski, [91], } \\
\text { Ramanathan, K., [106], } \\
\text { Bozeman [54] }\end{array}$ \\
\hline
\end{tabular}

Table 2: Definitions of Technology Transfer

Figure 2 represents how technology transfer will be understood for the

purposes of this research. The players are the research organizations (national labs, universities, non-profit collaborators, and private industry) and the technology recipient. The model is generalizable such that the technology recipient could be any organization that sponsors research; several federally funded labs are evaluated in 
chapter 2. The case study emphasis will be on the Bonneville Power Administration. The technologies considered in the case study (Chapter 6) have higher TRLs, so the transfer is more about application of the technology. The technology transfer success attributes describe the continuous relationship building between the research and the technology recipient that is a necessary ingredient for success. 


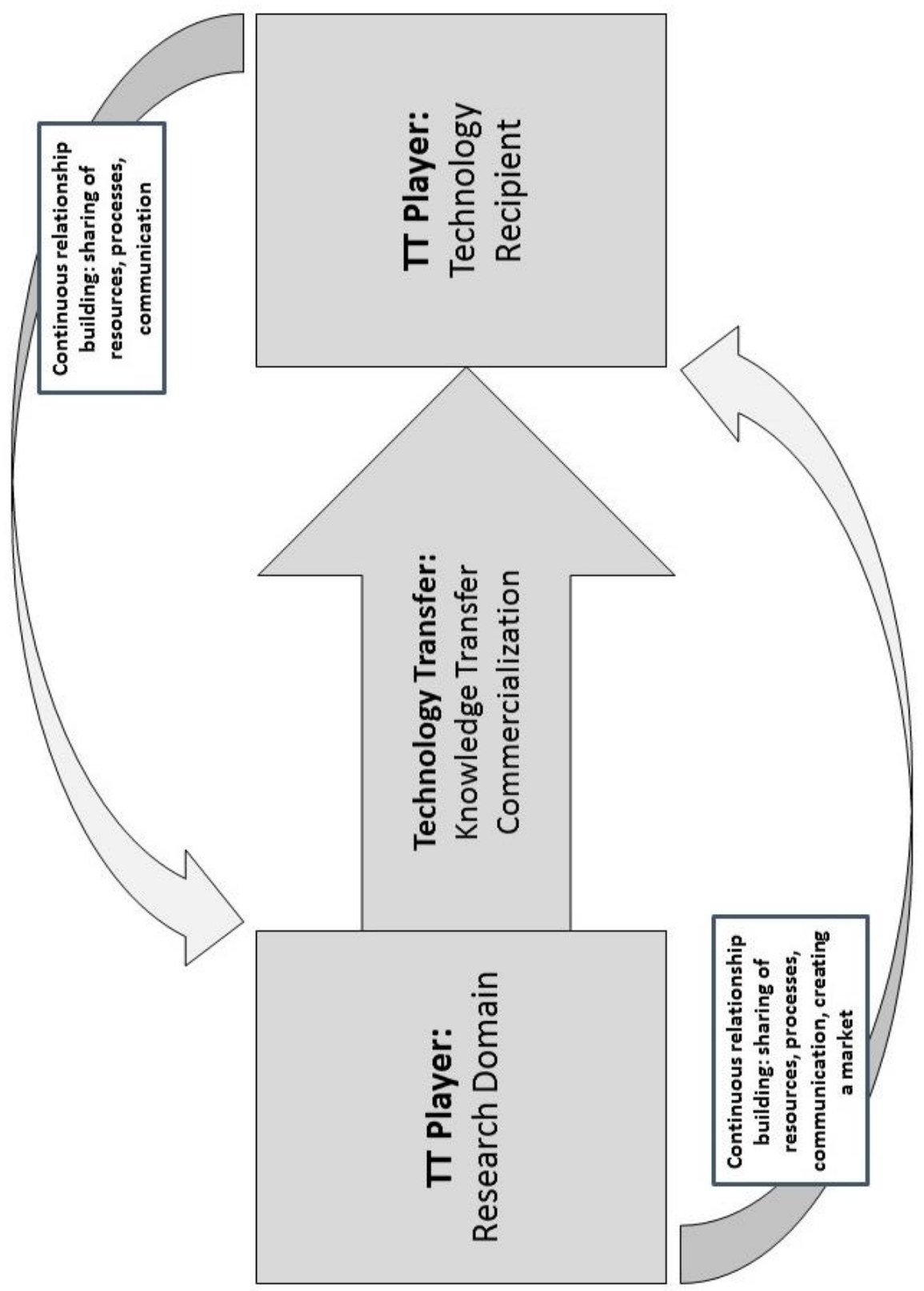

Figure 2: How Technology Transfer is Understood for this Research 


\section{CHAPTER 2: LITERATURE REVIEW}

The focus of this chapter is to understand how the various dimensions of technology transfer are described in literature. Four primary literature reviews were completed. The first review was on the timing of when an organization should start to consider technology transfer. Is it at the beginning of the research or should technology transfer start when the research is completed? Next, the literature review focused on those attributes that have been identified as necessary for technology transfer. In addition, taxonomies were used to understand logical grouping of the success attributes.

The next literature review considered how technology transfer was analyzed and which would be appropriate for understanding the groups of success attributes. The final review synthesized the information by looking at the evaluation criteria of several different federally funded research organizations. The objective was to understand if these organizations assess technology transfer success attributes as part of their evaluation criteria for research proposals.

Ultimately, the literature review identified gaps that are addressed by this research effort.

\subsection{Citing TT in the Research Proposal Phase}

One assumed outcome of research is that it will be applied to solve a problem. When should the technology transfer activities start? Literature suggests that technology transfer should not start once the research is finished. Rather, it is an integral part of the 
research and development process. The following literature review infers that TT should be considered as part of the research proposal evaluation process.

In Mead and Presley's research [111], they connect the need to innovate and stay competitive to research that addresses an organization's strategic objectives. As such, they developed a model to select a research portfolio. The evaluation criteria include elements that consider the end-state of the research, in other words, the technology transfer. For example, the probability of market success, market size, existence of a project champion, and availability and competence of resources were assessed [111]. While technology transfer was not explicitly mentioned, consideration is given to the potential of project success and application or technology transfer.

Hsu, et al [112], explicitly mention technology transfer as part of their research project selection model. Their selection criteria consider the "... success rate of commercialization...the probability of the success in technology transfer, product development, and commercialization...". The authors also state that their methodology will help to develop better projects and hence improve the likelihood of commercialization and technology transfer.

Similar evaluation criteria regarding assessment of commercialization are seen in the research done by Bordley [113] and Bard [114]. In both cases, the probability of successful commercialization is seen as a necessary evaluation consideration when selecting a research proposal.

Kumar's research of using an AHP based system for R\&D project evaluation has commercial sponsorship as one of the evaluation criteria [115]. When the importance of 
the evaluation criteria was determined, commercial sponsorship ranked the most important (when compared to other criteria).

This section of the literature review suggests that technology transfer should be an integral part of the research proposal evaluation phase. The implication is that the earlier researchers and recipients start to consider technology transfer the more likely the technology will survive the theoretical "valley of death" often experienced by research projects. The theories about including technology transfer topics as part of the research proposal phase are practically considered when the evaluation criteria for several research organizations are presented in section 2.4 of the literature review.

The next section examines those success attributes that are necessary for technology transfer and organizes them using a multi-perspective approach.

\subsection{Attributes of Successful TT}

A comprehensive literature review was conducted to understand what is necessary for successful technology transfer. Is there a special "recipe" that will guarantee a successful technology transfer? What should the research organization focus on to be successful? Should the technology recipient focus on similar attributes? Or do something different instead? How should the researcher and the technology recipient interact to emphasize the relationship element of technology transfer? The goal of this literature review section is to identify and define the success attributes. Initially the technology transfer literature was organized using Reisman's taxonomy. Organizing the literature this way was helpful to identify ways of conceptualizing the voluminous amount of technology transfer literature. Reisman's taxonomy categorizes technology 
transfer into four main factors: the actors, transaction types, motivations, and disciplines involved in the technology transfer [116]. The first factor describes the actors - who is involved in the transfer process? Sub groups include scientific discipline, geographic locations, etc. Next are the transaction types that are important to frame the transfer process - does the process include internal or external elements, joint venture opportunities, or intellectual property, etc. As implied, motivations describe the reasons for executing the technology transfer. The disciplines factor helps to understand if the technology transfer discussion is related to economics, management, etc. A complete definition of the framework is included in Appendix B. As previously stated, a taxonomy framework was helpful to identify likely themes for organizing technology transfer literature.

The taxonomy was an initial way to frame the success attributes and look for logical groupings. The final aggregation of success attributes is an assimilation of H.A. Linstone, Bozeman, and Greiner and Franza's work $[160,54,61]$. The final analysis structure looks at Organizational, Technological, Social, and Market Readiness; Bozeman and Franza, Greiner's emphasis is on creating a market ready to accept the technology. Using this framework, success attributes related to technology transfer are considered.

\subsubsection{Organizational}

Organizational elements emphasize actions or processes within an organization that are necessary for successful technology transfer. Resounding themes in literature are developed in subsequent paragraphs. Researchers agree that less bureaucracy, close proximity between the researcher and the technology recipient and the benefits of the two 
organizations to have a similar make-up in terms of size, mission objectives, overall having organizational homogeneity, are beneficial for technology transfer. Literature also discusses the need to have a flexible budget as beneficial for technology transfer. Understanding the technical and stakeholder organizational complexities is also important to consider for technology transfer success.

Agreements or contracts are necessary for research and subsequent technology transfer. However, the degree of process or bureaucracy related to these agreements has an impact on successful technology transfer. Big or small, all organizations have a certain amount of agreements or contracts that are a necessary part of technology transfer. Bureaucracy is associated with any organization. Franza and Greiner suggest that organizations that have long times to contract or are otherwise bureaucratic in their processes is not good for technology transfer [61]. The impact of too much process is also described by Bozeman when he discusses Cooperative Research and Development Agreements (CRADAs). A CRADA agreement provides a quick and unique access to extensive government-funded $R \& D$ resources that can be pooled with your own money to yield powerful research results, while providing intellectual property protection as you move swiftly to commercialization [100]. Franza, Rogers, and Bozeman agree that the length of time to execute agreements and extensive bureaucracy is not desirable for technology transfer.

Ham and Mowrey say that flexible budgets are necessary for successful technology transfer. Working with the government labs, flexible budgets allow for a gradual ramp-up of a project. However, too much time to negotiate the contracting 
mechanism can stall the research and potentially change the project goals. [52]. Bozeman states the inflexible budgets and managerial processes make the CRADA ineffective with requirements of technology development projects that must meet a tight schedule for success [100]. Another way of defining budget flexibility is with requiring cost share as part of the project funding. The Bonneville Power Administration, along with other Department of Energy research organizations, requires research partners to share in the financial responsibility of funding a project. There are varying degrees of cost share required but the purpose is to create a collaborative work environment between the researcher and technology recipient. This is done through a shared investment.

The proximity between the researcher and the technology recipient is an important characteristic for successful technology transfer. Mora-Valentin et. al. hypothesized that the closer the two entities are the better for technology transfer. Closer geographic locations facilitate face-to-face communications among team members and encourage relationship building. However, their research results were not conclusive [63]. In contrast, Franza, et al, identify geographic proximity as a "difference maker". As defined a difference maker is a set of attributes that were present in the successful transfers they researched and tend to be absent in the failed transfer attempts. [49]

Boulter and Bendell look at the contributions of firm size, high degree of institutionalization, similar experiences for success, the mission of the organization, similar agendas to successful technology transfers [64]. They describe these similarities as homophily or organizational homogeneity - they allow people to communicate better based on the degree of similarity. When there are disparities, especially with the 
expectations for success, there could be difficulties in successfully transferring the technology. One example of different expectations would be with national labs. Typically, the national lab culture is described as slow to change, with a basic research focus. This is in sharp contrast to private firms, which are characterized by speed, a quick decision making, and fast returns on investments [53], [138]. Establishing common goals is a foundation for building collaborative relationships, which are fundamental to successful technology transfer. Grant and Franza researched 19 technology transfer actions from the US Air Force lab. The 19 actions or projects included failed and successful technology transfer. Of these $92.9 \%$ of the successes had technology transfer between similar industries and 100\% had similar composition [49]. Research results from Ham and Mowrey, Balachandra, Bozeman, Wen-Hsiang, and Greiner and Franza supports the concept of similarities between the research organization and the technology recipient as contributing to successful technology transfer. The concept of organizational homogeneity can be extended to include risk propensity. Risk propensity is defined as the level of research risk he researcher and technology recipient are willing to manage. Perry states that national labs are risk averse - their target is to by $80-90 \%$ successful. Compare this risk inclination to a start-up where the expectation is an $80-90 \%$ failure rate; these mindsets are in stark contrast. The expectations for success are very different so the likelihood of successful technology transfer is diminished [56]. Greiner, Franza specify technical risk adversity as a barrier to technology transfer. In their research operators are comfortable with the status-quo, which creates an unwillingness to test or accept the new technology. [61] 
Finally, complexities related to technologies and stakeholders are considered relative to successful technology transfer. In order to ensure a sense of ownership is created with the research, stakeholders need to be considered during the R\&D phase. Their contributions during the R\&D phase will facilitate a successful technology transfer. A common theme related to organizational cultures is the need for stakeholder engagement. Balachandra states, “...a climate for stimulating innovation and facilitating meaningful technology diffusion is created by...stakeholders." [53] Painuly identifies critical elements necessary for a successful technology transfer to include mechanisms to realize and encourage stakeholder involvement. Stakeholders are also pivotal to the identification and navigating barriers to successful outcomes [69]. Related to technical complexities the more complex technology requires higher cooperation between transferor and transferee in order to make the best utility in the technology. Technologies that are more complex will incite more interest and interest in obtaining the technology from the researcher. [57]

Table 3 summarizes the organizational strategies that are necessary for successful technology transfer. 


\begin{tabular}{|l|l|l|}
\hline \multicolumn{1}{|c|}{$\begin{array}{c}\text { Attribute: Literature } \\
\text { Defined }\end{array}$} & \multicolumn{1}{|c|}{ Description } & \multicolumn{1}{c|}{ Source } \\
\hline Bureaucracy & $\begin{array}{l}\text { This attribute considers the level of } \\
\text { detail and duration of setting up } \\
\text { agreements/contracts between the } \\
\text { researchers and technology recipients. }\end{array}$ & $\begin{array}{l}\text { Bozeman [54], Franza, et al. [55] } \\
\text { Lutzenhiser, [58] }\end{array}$ \\
\hline Budget Flexibility & $\begin{array}{l}\text { The ability to have budget flexibility is } \\
\text { preferred for successful technology } \\
\text { transfer. In this context budget flexibility } \\
\text { is defined as allowing budget to move } \\
\text { between fiscal years, amount of } \\
\text { discretionary funding or cost share } \\
\text { required to fund a project, and the } \\
\text { personnel level that is authorized to } \\
\text { release funding. }\end{array}$ & $\begin{array}{l}\text { Franza, Grant [49], Ham, } \\
\text { Mowery [52], Balachandra, et }\end{array}$ \\
al. Bozeman [54] \\
\hline Geographic proximity & $\begin{array}{l}\text { Refers to the geographic proximity } \\
\text { between the researcher and technology } \\
\text { recipient. }\end{array}$ & $\begin{array}{l}\text { Franza, Grant [49], Bozeman } \\
\text { [54] Greiner, Franza, [61] Mora- } \\
\text { Valentin, et.al. [63], Boutler, } \\
\text { Bendell, [64] }\end{array}$ \\
\hline $\begin{array}{l}\text { Technical \& Stakeholder } \\
\text { Complexities }\end{array}$ & $\begin{array}{l}\text { This attribute refers to the number of } \\
\text { impacted stakeholders/project team and } \\
\text { the number of research areas (roadmap } \\
\text { topics) addressed by the proposal. }\end{array}$ & $\begin{array}{l}\text { Wen-Hsiang, Tsai, [57], } \\
\text { Mueller, Wallace, [60], Greiner, } \\
\text { Franza, [61] }\end{array}$ \\
\hline $\begin{array}{l}\text { Organizational } \\
\text { Homogeneity }\end{array}$ & $\begin{array}{l}\text { Similar strategic alignment, high degree } \\
\text { of institutionalization, similar industries } \\
\text { and composition of personnel, size of } \\
\text { firms, motivations for doing research, } \\
\text { and similar expectations for success }\end{array}$ & $\begin{array}{l}\text { Franza, Grant [49], Ham, } \\
\text { Mowery [52], Balachandra, et } \\
\text { al.[53], Bozeman [54], Wen- } \\
\text { Hsiang, Tsai, [57], Lutzenhiser, } \\
\text { [58], and Greiner, Franza, [61] }\end{array}$ \\
\hline
\end{tabular}

Table 3: Organizational Success Attributes

\subsubsection{Technological}

This perspective considers actions related to the technology as important for successful technology transfer. Actions include the researcher's previous cooperative experience and ability to demonstrate the technology, understanding of the recipient's technology needs, and the existence of and ability of the Technology Transfer Office to be effective at marketing the technology. The literature review summary that follows supports this perspective definition.

Some technology transfer barriers are related to the maturity of the technology. Technologies that are immature, or lower on the technology readiness level (TRL) scales, are associated with basic research, and not yet likely to be considered for application. 
However, technologies that have higher TRLs (levels 8-9) are ready for demonstration; the concept of technology readiness levels was introduced in Chapter 1. Mueller, M, et al, Shove, E, and Luiten, E. et al state that the interest in a technology is elevated when there have been successful demonstration projects [60]. Successful demonstrations minimize the risk of investing in an otherwise unknown technology communicate the benefits of using the technology, help to develop interoperability standards [122] and provide an opportunity for user feedback that could be included in future revisions. In fact, these demonstrations help to create a market, or demand, for the technology. These demonstrations set the stage for a "market-pull" environment, where technology transfer is more likely to occur. The researchers suggest that successful demonstration projects help to establish the market and this market is made up of individuals who will be technology recipients. Demonstration projects are helpful to minimize the public's perception of the "invisibility of energy measures" [61]. In other words, the public is less likely to adopt a technology if they cannot appreciate the net benefit. The technology must address the question, "What's in it for me?" Specific to energy efficiency innovations, communication is vital to increase user acceptance or encourage people to use the technology. One way of communicating is through demonstrations or technology publications.

It is important to understand the needs of the technology recipient. This knowledge helps to proactively address the question of "what's in it for me." The public's willingness to change has the potential of stifling technology transfer. They don't want to change their lifestyle (e.g. turning back their hot water heater or turning up 
their air conditions in demand response scenarios), they are skeptical of new innovations, and there is a feeling that the public opinion was not considered when designing products. In these cases, a market was not created. [69], [54].

The existence of a dedicated technology transfer office is identified as a “difference maker", when considering successful attributes. Franza, et al research [49] was to identify attributes most strongly associated with successful technology transfer. Franza identified "difference makers" as essential elements that were included in the majority of successful transfers. The existence of a dedicated TT Office was foremost. It is a necessary conduit moving from research into application. Given the existence of a TTO, it should be staffed with marketing experience and dedicate a portion of the budget to marketing and technology transfer activities is seen as essential to create a market that is willing to accept the technology [66]. Franza states that emphasis should be placed on advertising to the relevant industry [49]. In fact, Siegel suggests that the TT Office should be staffed with marketing personnel [66]. A market pull is more easily created if the needs of the adopters are understood.

Technology elements do not refer to the technology itself, in terms of its ability to meet technology specifications (e.g. durability, etc.). Rather the focus is on setting up an environment for technology transfer to occur. In addition, an emphasis is placed on activities that create a market that is ready to accept the technology. Therefore, Technological elements are defined as creating these opportunities. Table 4 summarizes the Technological success attributes. 


\begin{tabular}{|l|l|l|}
\hline $\begin{array}{c}\text { Attribute: Literature } \\
\text { Defined }\end{array}$ & \multicolumn{1}{|c|}{ Description } & \multicolumn{1}{c|}{ Source } \\
\hline Cooperative Experience & $\begin{array}{l}\text { How much experience does the researcher have } \\
\text { working with others? Are they new (no } \\
\text { cooperative experience) or are they very familiar } \\
\text { working with other organizations on R\&D. More } \\
\text { cooperative experience implies higher likelihood } \\
\text { of technology transfer because they are familiar } \\
\text { with potential barriers based on their previous } \\
\text { experience. }\end{array}$ & $\begin{array}{l}\text { Wen-Hsiang, Tsai, } \\
\text { [57], Mora-Valentin, } \\
\text { et.al. [63] }\end{array}$ \\
\hline $\begin{array}{l}\text { Understanding the } \\
\text { Recipient }\end{array}$ & $\begin{array}{l}\text { Understand perceptions of adopters; How familiar } \\
\text { is the research organization with the customer } \\
\text { requirements and/or market needs? }\end{array}$ & $\begin{array}{l}\text { Sharma, [48], } \\
\text { Balachandra, et al. } \\
\text { [53], Isaacs, et al. [67] }\end{array}$ \\
\hline $\begin{array}{l}\text { Educate/Demonstrate } \\
\text { Technology }\end{array}$ & $\begin{array}{l}\text { How many successful technology demonstrations } \\
\text { does the organization have (for the case study)? As } \\
\text { an example, assuming the case study is for demand } \\
\text { response technologies, how many demonstrations } \\
\text { of heat pump water heaters has the researcher been } \\
\text { involved with - more technology demonstrations } \\
\text { are better for successful technology transfer. } \\
\text { Demonstrations are one way to educate others } \\
\text { about the technology. }\end{array}$ & $\begin{array}{l}\text { Balachandra, et al. } \\
\text { [53], Wen-Hsiang, } \\
\text { Frainza, [61], Spann, et } \\
\text { al. [65] }\end{array}$ \\
\hline $\begin{array}{l}\text { Does the research organization have a dedicated } \\
\text { TTO that can coordinate activities between the } \\
\text { researcher and the technology recipient? }\end{array}$ & $\begin{array}{l}\text { Literature suggests that the TTO should be staffed } \\
\text { with personnel who have marketing experience. }\end{array}$ & Siegel, et al. [66] \\
\hline Dedicated TTO & $\begin{array}{l}\text { Franza, Grant, [49] } \\
\text { Experience }\end{array}$ &
\end{tabular}

Table 4: Technological Success Attributes

\subsubsection{Social}

The social perspective is the view of the situation from the eyes of the individual(s) and involve actions related to people. A common theme among the researchers is creating an atmosphere of trust - having transparent, effective communication is pivotal for success. This involves a heightened cultural awareness as necessitated by an ever-developing global economy. The policies around how many people are dedicated to the technology transfer effort and the willingness of the researcher to "loan" personnel is desirable for successful technology transfer. Finally, recognizing success with a reward system is cited as beneficial for technology transfer. These themes will be developed and substantiated with literature citations. 
An atmosphere of trust is created by effective and frequent communication throughout the $\mathrm{R} \& \mathrm{D}$ process. Communication within or to an organization is also significant as technology moves from research and development to the early stages of technology transfer. Consistent throughout the literature was the significant influence communication had on the technology transfer process, especially when discussing energy innovation. L.M. Murphy, et al states that "...reducing information gaps between public and private sectors..." and "...ensuring access to data knowledge..." is essential. [123]. Other authors discuss the higher the trust the more willing an organization is to share information - the trust is established via effective and active communication. [52] "Trust is crucial in aiding the process involved with the transfer of all types of knowledge" [101]. Lai and Tsai state that the technology transfer process faces many skills related to the interaction of the stakeholders [57]. Therefore, a clear, positive, and understandable message facilitates technology transfer. Mora-Valentin verified that there was a correlation between higher levels of trust and a positive influence on technology transfer. [63]

The idea of developing a relationship by creating an atmosphere of trust between the researcher and the recipient is complementary to the success attribute of cultural awareness. The global world economy provides opportunities to interface with other cultures. Being sensitive to communication styles, different heritages, and being cognizant of the diversity of technology recipients is necessary for successful technology transfer. Lai and Tsai state “...cultural awareness is seen by researchers as necessary for successful technology transfer. Cultural differences have a significant impact on the 
success or failure of TT. Also, it is obvious that the higher similarity of cultures for two parties, the greater facilitation to the TT's performance..." [57]. Boulter and Bendell agree by stating “....attitude towards outsiders...find a common ground to be able to communicate effectively about multiple interests to seek a shared sense of purpose, goals, and rewards..." [64] Regarding university technology transfer, Siegal says that work to eliminate cultural and informational barriers which are an impediment to technology transfer process. [66]

Personnel involved in the technology transfer process, whether they be dedicated to integrate the technology or whether the research organization has a favorable leave policy, is beneficial for technology transfer. Related to university technology transfer, Siegal suggests devoting extra resources to the process [66]. Franza et al., suggest that the technology recipient should dedicate personnel over the life of the transfer project. This is one of the seven "difference makers" Franza identifies for successful technology transfer [49]. The research done by Mora-Valentin et al., says that more commitment has a positive influence on technology transfer [63]. Finally, E.M. Rogers suggests that the favorable entrepreneurial leave policies of the federal labs encourage technology transfer. By allowing researchers to be loaned to the technology recipient they are being used as a technology transfer mechanism, in essence, the movement of technology through people. This is a common practice in Japan. E.M. Rogers, et al uses a case study to illustrate the effectiveness of 'shuko' - a Japanese term that describes the temporary transfer of personnel knowledgeable about the technology to work with the technology recipient. 
This process encourages tacit knowledge transfer which is seen as having the potential for greater pay-offs than tangible products [62].

Acknowledging successful transfers by having an established reward system encourages more innovative thinking as well as suggests the researchers have knowledge and experience with those attributes necessary for successful technology transfer. Siegal states that if universities want to foster an atmosphere of commercialization, one area of focus should be on developing a rewards system [66]. This practice is also in place at national labs and industry with the appointment of "Fellows". This is a way of recognizing technical excellence in support of the organization's mission statement. To encourage research not being done in their "spare time", the CHI panel discussion encourages a reward system. [166]

The balance between the public's disdain for new technology and realizing the benefits of the technology is precarious. The relationships between national labs and private firms are on similar footing. The consensus among the researchers is that sharing of information, personnel, and using opportunities for transparency are fundamental for successful technology transfer. Table 5 summarizes the social success attributes for technology transfer.

\begin{tabular}{|l|l|l|}
\hline \multicolumn{1}{|c|}{$\begin{array}{c}\text { Attribute: } \\
\text { Literature Defined }\end{array}$} & \multicolumn{1}{|c|}{ Description } \\
\hline $\begin{array}{l}\text { Atmosphere of } \\
\text { Trust }\end{array}$ & $\begin{array}{l}\text { Fundamental to successful technology } \\
\text { transfer is establishing a trusting } \\
\text { relationship between the research and } \\
\text { technology recipient. This can be } \\
\text { accomplished by frequent communication, } \\
\text { structured project management, } \\
\text { cooperative risk assessments, etc. }\end{array}$ & $\begin{array}{l}\text { Franza, Grant, [49], Wen- } \\
\text { Hsiang, Tsai, [57], Greiner, } \\
\text { Franza, [61], Rogers, et al. } \\
\text { [62], Mora-Valentin, et al. } \\
\text { [63], Boulter, Bendell, [64] }\end{array}$ \\
\hline Cultural Awareness & $\begin{array}{l}\text { Personnel that are more aware of and have } \\
\text { more experience interacting with different }\end{array}$ & $\begin{array}{l}\text { Wen-Hsiang, Tsai, [57], } \\
\text { Greiner, Franza, [61], Mora- }\end{array}$ \\
\hline
\end{tabular}




\begin{tabular}{|l|l|l|}
\hline \multicolumn{1}{|c|}{$\begin{array}{c}\text { Attribute: } \\
\text { Literature Defined }\end{array}$} & \multicolumn{1}{|c|}{ Description } & \multicolumn{1}{c|}{ Source } \\
\hline & $\begin{array}{l}\text { cultures are more successful at technology } \\
\text { transfer. }\end{array}$ & $\begin{array}{l}\text { Valentin, et al. [63], Boulter, } \\
\text { Bendell, [64] }\end{array}$ \\
\hline $\begin{array}{l}\text { Personnel } \\
\text { Involvement }\end{array}$ & $\begin{array}{l}\text { This attribute refers to the degree that } \\
\text { researchers are involved in the hand-off } \\
\text { process. When do the researchers start to } \\
\text { consider technology transfer and start to } \\
\text { involve end-users/technology recipients }\end{array}$ & $\begin{array}{l}\text { Ham, Mowrey, [52], Rogers, et } \\
\text { al. [68] }\end{array}$ \\
\hline $\begin{array}{l}\text { Manpower } \\
\text { Flexibility }\end{array}$ & $\begin{array}{l}\text { The willingness to "loan" researchers to } \\
\text { help with technology transfer was cited as } \\
\text { necessary for technology transfer; } \\
\text { favorable leave policies; }\end{array}$ & $\begin{array}{l}\text { Balachandra, et al. [53], Perry } \\
\text { [56] }\end{array}$ \\
\hline Rewards System & $\begin{array}{l}\text { Does the research or technology recipient } \\
\text { organization have systems in place to } \\
\text { recognize innovative thinking? Literature } \\
\text { suggests that having a reward system in } \\
\text { place facilitates technology transfer. }\end{array}$ & $\begin{array}{l}\text { Franza, Grant, [49], Wen- } \\
\text { Hsiang, Tsai, [57], Greiner, } \\
\text { Franza, [61], Rogers, et al. } \\
\text { [62], Mora-Valentin, et al. [63] }\end{array}$ \\
\hline
\end{tabular}

Table 5: Social Success Attributes

\subsubsection{Market}

The last perspective to consider when identifying technology transfer success attributes is Market. As the name implies, these success elements emphasize those attributes that are necessary to create a market that is willing and ready to accept the technology. These attributes include creating a business plan, having common standards and government incentives to encourage transfer, and establishing that the technology is financially feasible - think making a business case for solar panels. Related to people within the technology recipient organization, a supportive champion and the level of interest from top management can have an impact on technology transfer success. Each of these assertions is developed to include references from literature.

The adoption of solar panels is a good example of how financial feasibility, using government incentives, works to create a viable market for the technology. Initially 
solar was too expensive for widespread adoption by the consumer. However, as the technology matured and incentives were implemented the business case improves and adoption increases. Examples of government incentives include the 2009 Recovery Act, which invested billions into energy research. At the consumer level, the Ashland, OR "Bright Way to Heat Loan" encourages solar-based water heating. The latter incentive is targeted to residential customers in the form of rebates or access to interest free loans. In a market dominated by incumbent technologies, the researchers agree that in order to realize wide spread diffusion of a new technology, policies that encourage adoption are necessary. L.M.Murphy, et al, states “...government activities to promote sustainable energy technologies must include both a supply push and a demand pull...” [123] This environment is created by effective government policies. Fred Gordon, Energy Trust Oregon, suggested that in order to transform the market, the government agencies need to inject supply chain features when developing a technology as well as to provide training skills to help market adoption. Related to green buildings N.Kok, et al, provides evidence that the "...diffusion of energy efficient technologies is more responsive to energy prices..." [153]. Incentives to help create financial feasibility is also supported by Balachandra, “...government activities to support...adoption include both supply-push and demand-pull policies during the period spanning pre-commercialization..." [53]. Lai and Tsai state that, “...government policy is always a crucial factor in influencing technology transfer. The integrity of law... will stimulate or facilitate technology transfer activities." [57] Franza identifies having a business plan for commercialization as one of his "difference makers" and serves as the basis for determining financial feasibility [49]. 
Grant and Franza's research, which examined 19 technology transfer activities, shows that an adequately funded project was present in $71 \%$ of successful transfers and having a business plan in place was identified in $80 \%$ of successful transfers. [49]

Related to the need for support within the technology recipient organization, the CHI panel discussion stated, “...people, not papers, transfer technology. Technology transfer is a grass roots effort and requires buy-in and active participation. It requires support from the top." [166] Lai and Tsai state that the technology recipient's support is an important factor for successful technology transfer [57]. Carayannis, et al., examined five successful technology transfer cases and the presence of an internal champion and their commitment through the transfer process was vital; a strong champion was identified as a bridge between the research and technology application [103]. In Balachandra's research, top management support was a component in $100 \%$ of all successful technology transfers [53]. Bozeman supports the need for active support from management, “...Projects were more likely to transfer if they were initiated by either the R\&D managers or top managers in the company..." [54]

The Table 6 summarizes the market related success attributes.

\begin{tabular}{|l|l|l|}
\hline Attribute: Literature Defined & \multicolumn{1}{|c|}{ Description } & \multicolumn{1}{|c|}{ Source } \\
\hline Business Plan & $\begin{array}{l}\text { Clearly defined need is created; } \\
\text { technology recipient has a } \\
\text { business plan for } \\
\text { commercialization; Diffusion } \\
\text { process needs to be induced; } \\
\text { Does a comprehensive business } \\
\text { plan exist that supports the } \\
\text { technology in the recipient } \\
\text { organization? }\end{array}$ & \\
Balachandra, et al. [53] & \\
\hline
\end{tabular}




\begin{tabular}{|c|c|c|}
\hline Attribute: Literature Defined & Description & Source \\
\hline Government Incentives & $\begin{array}{l}\text { Incentives are seen as a way to } \\
\text { entice a market to invest in } \\
\text { technology. Examples include } \\
\text { rebates for purchasing LED } \\
\text { lightbulbs or tax credits for } \\
\text { wind farms. }\end{array}$ & Balachandra, et al. [53] \\
\hline Financial Feasibility & $\begin{array}{l}\text { Has financial feasibility been } \\
\text { determined? Examples include, } \\
\text { price point of solar panels for } \\
\text { the residential market have not } \\
\text { been completely realized and is } \\
\text { seen as one of the barriers to } \\
\text { their widespread adoption in } \\
\text { the US. }\end{array}$ & $\begin{array}{l}\text { Sharma, [48], Franza, Grant } \\
\text { [49] }\end{array}$ \\
\hline $\begin{array}{l}\text { Organizational Technology } \\
\text { Champion }\end{array}$ & $\begin{array}{l}\text { A dedicated champion in the } \\
\text { recipient organization is } \\
\text { fundamental to successful } \\
\text { technology transfer. The } \\
\text { champion can shepherd the } \\
\text { technology through } \\
\text { organizational barriers; a sense } \\
\text { of ownership is created. }\end{array}$ & $\begin{array}{l}\text { Balachandra, et al. [53], } \\
\text { Bozeman [54], and Painuly, } \\
{[69]}\end{array}$ \\
\hline $\begin{array}{l}\text { Level of Top Management } \\
\text { Interest }\end{array}$ & $\begin{array}{l}\text { Technology transfer initiated } \\
\text { and having top management } \\
\text { involvement is necessary for } \\
\text { technology transfer. } \\
\text { The top management in the } \\
\text { organization needs to see the } \\
\text { value of the technology. Their } \\
\text { support is required for } \\
\text { successful technology transfer. }\end{array}$ & Bozeman [54] \\
\hline Common Standards & $\begin{array}{l}\text { Common standards help to } \\
\text { facilitate the introduction of } \\
\text { multiple but similar } \\
\text { technologies into the market. } \\
\text { Common communication } \\
\text { protocols are examples of } \\
\text { standards that help to facilitate } \\
\text { demand response technologies. }\end{array}$ & $\begin{array}{l}\text { Neshati, [41], Balachandra, et } \\
\text { al. [53] }\end{array}$ \\
\hline
\end{tabular}

Table 6: Market Success Attributes 


\subsection{Methods use in TT Research}

The comprehensive review of technology transfer attributes identified a number of ways to understand and evaluate technology transfer. However, none assimilates multiple attributes into a practical tool for assessing the potential of technology transfer.

A taxonomy approach was successful to understand the relationships and success attributes related to technology transfer. Therefore, a similar approach was used to capture how other researchers have analyzed technology transfer. Table 7 was adapted from the taxonomy used by Tran and Kocaoglu [75]. The adaptation was to add the success attributes as a sub-category to the research topics completed in Tran, Kocaoglu's work. As an example, literature, patents, license, etc. were added as examples of transfer media. The articles were categorized based on their research method. A number of different methods were used to understand the success attributes and their contribution to technology transfer. However, none attempted to assess them in totality. Following the table, considerations for each research method are discussed. 


\begin{tabular}{|c|c|c|c|c|c|c|}
\hline \multirow[b]{2}{*}{ Modes } & \multicolumn{6}{|c|}{ Research Methods } \\
\hline & & $\begin{array}{c}\text { Case } \\
\text { Studies }\end{array}$ & Surveying & $\begin{array}{c}\text { Literature } \\
\text { Reports }\end{array}$ & $\begin{array}{c}\text { Model } \\
\text { Development }\end{array}$ & $\begin{array}{l}\text { Hypothesis } \\
\text { Testing }\end{array}$ \\
\hline \multirow{5}{*}{ 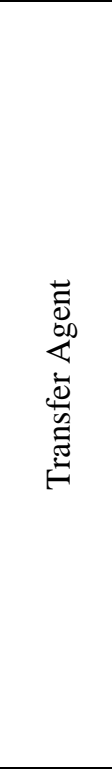 } & $\begin{array}{l}\text { Technology Niche } \\
\text { (renewable } \\
\text { energy, energy } \\
\text { storage, etc.) }\end{array}$ & $\begin{array}{l}\text { Greiner, } \\
\text { Franza [61] }\end{array}$ & & & $\begin{array}{l}\text { Wen-Hsiang, } \\
\text { Tsai [57], } \\
\text { Balachandra, } \\
\text { et al. [53] }\end{array}$ & \\
\hline & $\begin{array}{l}\text { Geographic } \\
\text { Location }\end{array}$ & $\begin{array}{l}\text { Greiner, } \\
\text { Franza [61] }\end{array}$ & & & & $\begin{array}{l}\text { Mora-Valentin, } \\
\text { et al. [63] }\end{array}$ \\
\hline & $\begin{array}{l}\text { Organizational } \\
\text { Design }\end{array}$ & $\begin{array}{l}\text { Perry [56], } \\
\text { Greiner, } \\
\text { Franza [61] }\end{array}$ & $\begin{array}{l}\text { Bozeman, } \\
\text { et al. } \\
\text { [100]; } \\
\text { Franza, } \\
\text { Grant } \\
\text { [49], } \\
\text { Siegal, et } \\
\text { al. [66] }\end{array}$ & $\begin{array}{l}\text { Boulter, } \\
\text { Bendell } \\
{[64]}\end{array}$ & $\begin{array}{l}\text { Wen-Hsiang, } \\
\text { Tsai [57], } \\
\text { Lee, et al. } \\
\text { [102] }\end{array}$ & $\begin{array}{l}\text { Mora-Valentin, } \\
\text { et al. [63] } \\
\text { Gopalakrishnan, } \\
\text { et al. [101], } \\
\text { Spann, et al. } \\
\text { [65] }\end{array}$ \\
\hline & $\begin{array}{l}\text { Prioritization of } \\
\text { TT factors }\end{array}$ & Perry [56] & $\begin{array}{l}\text { Bozeman, } \\
\text { et al. } \\
{[100]}\end{array}$ & & & \\
\hline & $\begin{array}{l}\text { Other (e.g. } \\
\text { resources) }\end{array}$ & $\begin{array}{l}\text { Ham, et al. } \\
\text { [52] }\end{array}$ & & & & \\
\hline \multirow{8}{*}{ 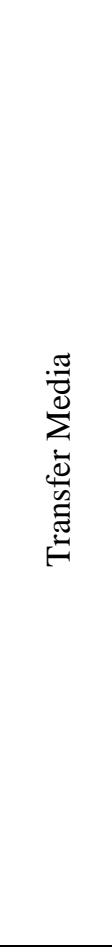 } & & & & & & \\
\hline & Literature & & & $\begin{array}{l}\text { Rogers, } \\
\text { et al. [62] }\end{array}$ & & \\
\hline & Patent & $\begin{array}{l}\text { Rogers, et } \\
\text { al. [68] }\end{array}$ & $\begin{array}{l}\text { Bozeman, } \\
\text { et al. } \\
{[100] \text {; }}\end{array}$ & & & \\
\hline & License & $\begin{array}{l}\text { Rogers, et } \\
\text { al. [68] }\end{array}$ & & & & \\
\hline & $\begin{array}{l}\text { Personnel } \\
\text { Exchange }\end{array}$ & $\begin{array}{l}\text { Carayannis, } \\
\text { et al. }\end{array}$ & $\begin{array}{l}\text { Siegal, et } \\
\text { al. [66] }\end{array}$ & $\begin{array}{l}\text { Rogers, } \\
\text { et al. [62] }\end{array}$ & & \\
\hline & $\begin{array}{l}\text { Communication } \\
\text { Styles }\end{array}$ & $\begin{array}{l}\text { Perry [56], } \\
\text { Greiner, } \\
\text { Franza [61] }\end{array}$ & $\begin{array}{l}\text { Franza, } \\
\text { Grant } \\
{[49]}\end{array}$ & $\begin{array}{l}\text { Isaacs, et } \\
\text { al. [67]; } \\
\text { Boulter, } \\
\text { Bendell } \\
\text { [64] }\end{array}$ & $\begin{array}{l}\text { Wen-Hsiang, } \\
\text { Tsai [57], } \\
\text { Balachandra, } \\
\text { et al. [53], } \\
\text { Walsh, } \\
\text { Kirchhoff } \\
\text { [104] }\end{array}$ & $\begin{array}{l}\text { Mora-Valentin, } \\
\text { et al. [63], } \\
\text { Spann, et al. } \\
\text { [65] }\end{array}$ \\
\hline & Spin-Off & & & $\begin{array}{l}\text { Rogers, } \\
\text { et al. [62] }\end{array}$ & $\begin{array}{l}\text { Walsh, } \\
\text { Kirchhoff } \\
\text { [104] }\end{array}$ & \\
\hline & $\begin{array}{l}\text { Other (e.g. } \\
\text { CRADA) }\end{array}$ & $\begin{array}{l}\text { Rogers, et } \\
\text { al. [68], } \\
\text { Ham, et al. } \\
\text { [52] }\end{array}$ & & $\begin{array}{l}\text { Rogers, } \\
\text { et al. [62] }\end{array}$ & & $\begin{array}{l}\text { Mora-Valentin, } \\
\text { et al. [63] } \\
\text { Franza, et al. } \\
\text { [55] }\end{array}$ \\
\hline \multirow{3}{*}{ 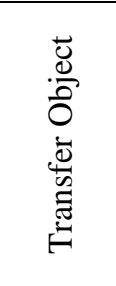 } & $\begin{array}{l}\text { Technology } \\
\text { Design }\end{array}$ & & & & $\begin{array}{l}\text { Balachandra, } \\
\text { et al. [53], } \\
\text { Lee, et al. } \\
\text { [102] }\end{array}$ & \\
\hline & Scientific Object & & & & & \\
\hline & Maturity of Object & & & & $\begin{array}{l}\text { Balachandra, } \\
\text { et al. [53], }\end{array}$ & \\
\hline
\end{tabular}




\begin{tabular}{|c|c|c|c|c|c|c|}
\hline \multirow{4}{*}{ Modes } & \multicolumn{6}{|c|}{ Research Methods } \\
\hline & \multicolumn{2}{|r|}{$\begin{array}{c}\text { Case } \\
\text { Studies }\end{array}$} & \multirow[t]{2}{*}{ Surveying } & \multirow[t]{2}{*}{$\begin{array}{c}\text { Literature } \\
\text { Reports }\end{array}$} & \multirow{2}{*}{\begin{tabular}{l}
\multicolumn{1}{c}{ Model } \\
Development \\
Lee, et al. \\
{$[102]$,} \\
Walsh, \\
Kirchhoff \\
{$[104]$}
\end{tabular}} & \multirow[t]{2}{*}{$\begin{array}{c}\text { Hypothesis } \\
\text { Testing }\end{array}$} \\
\hline & & & & & & \\
\hline & Other & & & & & \\
\hline \multirow{4}{*}{ 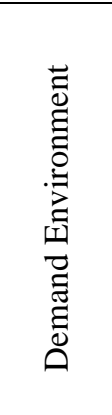 } & $\begin{array}{l}\text { Existing Demand- } \\
\text { Tech Pull }\end{array}$ & $\begin{array}{l}\text { Perry [56], } \\
\text { Greiner, } \\
\text { Franza [61] }\end{array}$ & & $\begin{array}{l}\text { Isaacs, et } \\
\text { al. [67] }\end{array}$ & $\begin{array}{l}\text { Balachandra, } \\
\text { et al. [53] }\end{array}$ & $\begin{array}{l}\text { Spann, et al. } \\
\text { [65] }\end{array}$ \\
\hline & $\begin{array}{l}\text { Created Demand - } \\
\text { Tech Push }\end{array}$ & $\begin{array}{l}\text { Perry [56], } \\
\text { Greiner, } \\
\text { Franza 61]. }\end{array}$ & & $\begin{array}{l}\text { Isaacs, et } \\
\text { al. [67] }\end{array}$ & $\begin{array}{l}\text { Balachandra, } \\
\text { et al. [53] }\end{array}$ & $\begin{array}{l}\text { Spann, et al. } \\
\text { [65] }\end{array}$ \\
\hline & $\begin{array}{l}\text { Economic } \\
\text { Character of the } \\
\text { Technology }\end{array}$ & & & & $\begin{array}{l}\text { Lee, et al. } \\
{[102]}\end{array}$ & \\
\hline & Other & & & & & \\
\hline \multirow{5}{*}{ 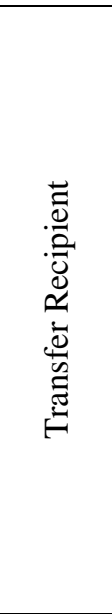 } & Resources & $\begin{array}{l}\text { Carayannis, } \\
\text { et al. [103] }\end{array}$ & $\begin{array}{l}\text { Franza, } \\
\text { Grant } \\
{[49]}\end{array}$ & & & \\
\hline & Size of Firm & $\begin{array}{l}\text { Ham, et al. } \\
\text { [52] }\end{array}$ & $\begin{array}{l}\text { Bozeman, } \\
\text { et al. } \\
\text { [100]; }\end{array}$ & & $\begin{array}{l}\text { Walsh, } \\
\text { Kirchhoff } \\
\text { [104] }\end{array}$ & \\
\hline & $\begin{array}{l}\text { Manufacturing } \\
\text { Expertise }\end{array}$ & & & & $\begin{array}{l}\text { Walsh, } \\
\text { Kirchhoff } \\
\text { [104] }\end{array}$ & \\
\hline & $\begin{array}{l}\text { Geographic } \\
\text { Location }\end{array}$ & $\begin{array}{l}\text { Greiner, } \\
\text { Franza [61] }\end{array}$ & & $\begin{array}{l}\text { Boulter, } \\
\text { Bendell } \\
\text { [64] }\end{array}$ & & \\
\hline & $\begin{array}{l}\text { Business } \\
\text { Strategies }\end{array}$ & $\begin{array}{l}\text { Carayannis, } \\
\text { et al. [103] }\end{array}$ & $\begin{array}{l}\text { Franza, } \\
\text { Grant } \\
{[49]}\end{array}$ & $\begin{array}{l}\text { Boulter, } \\
\text { Bendell } \\
\text { [64] }\end{array}$ & & \\
\hline
\end{tabular}

Table 7: Technology Transfer Analysis Methods

While Table 7 represents a cursory review of technology transfer literature, it does highlight a gap - there is no research for prioritization of technology transfer factors using a model development. The research methods are described further to understand an appropriate method for analyzing technology transfer success attributes. 


\subsubsection{Case Study}

As defined, a case study approach is a descriptive, exploratory or explanatory analysis of a person, group or event. An explanatory case study is used to explore causation in order to find underlying principles [76]. A case study provides a detailed contextual analysis of a limited number of events and describes their relationship. The method is often used by social scientists to understand the relationship between real-life and proposed models. In addition, the method is used for comparisons of organizations to illustrate their theoretical concept. [76]

Some of the drawbacks of a using a case study approach are that only a small number of environments are studied and the method does not offer reliability or repeatability as an analysis tool; as a tool they lack scientific rigor to draw definite conclusions. As a result, they are recommended for exploratory research only. In addition, the potential for bias is introduced when only one case is studied. [76]

\subsubsection{Surveying}

Surveying is defined as a non-experimental descriptive research method, used to assess thought, opinions or feelings [77]. The method is useful to collect data on phenomena that cannot be directly observed. Often, it is used to assess attributes and characteristics. Therefore, the sample population is critical to a successful survey. This last point is also an issue for using a survey as an analysis tool - designing an experiment can be challenging. The challenges include ensuring the sample is random and that the questions asked are to exact and accurate to obtain the desired information. Also, assumptions about the terminology can lead to incorrect outcomes or conclusions. [77] 


\subsubsection{Literature Reports}

This analysis tool is defined as text written by someone to consider the critical points of current knowledge including substantive findings, as well as theoretical and methodological contributions to a particular topic. Literature reviews are secondary sources, and as such, does not report any new or original experimental work [78]. This analysis tool is helpful to identify gaps in the literature as was done for this research.

This analysis tool should be used as a basis for starting research; it is effective to generate a hypothesis or as a background. However, the tool does not synthesize information and often the reader is left to draw his or her own conclusions. [78]

\subsubsection{Model Development}

Model development is an effective research method. It assists investigators and scientists in relating more accurately to reality; it also aids them to describe, predict, test or understand complex systems or events. Thus, models often provide a framework for the conduct of research and might consist of actual objects or abstract forms, such as sketches, mathematical formulas, or diagrams. A model is an abstraction, a mental framework for analysis of a system. [79]

There are several benefits to developing a model for analysis purposes. In general, a multi-criteria decision model is used to illustrate relationships. The information is presented in a way such that policy makers can understand alternatives and their relationship to the hierarchy or other intangible attributes [81]. A model also aggregates the opinions of experts - their input is captured and allows for ranking of alternative to inform a decision. 
Model development has limitations. The number of pairwise comparisons required to comprehensively describe the model could be significant and a deterrent to soliciting expert participation. Additionally, there is a potential for achieving linear quality on outcomes/decisions - the framework to solicit feedback could be considered restrictive (e.g. pairwise comparisons). As mentioned with surveying, the word choice needs to be explicit and decisive to minimize interpretation by the expert panels. Finally, the tendency is to use the outcome of a model as an absolute answer. Rather, the outcomes should be used to inform decisions.

\subsubsection{Hypothesis Testing}

The process of testing an assumption about a population parameter is referred to as hypothesis testing. The process defines the null hypothesis $\left(\mathrm{H}_{\mathrm{o}}\right)$ which is the sample observation results purely from chance and the alternate hypothesis $\left(\mathrm{H}_{\mathrm{a}}\right)$ which is he sample observation is influenced by some non-random cause. [80] The issues with hypothesis testing, relative to this research, include sample size, obtaining a representative population, and interpretation of results. The results only represent the probability that the null hypothesis should be rejected. The design of the experiment is critical. Overall, this would not be an appropriate tool for the purposes of this research.

There are many approaches to analyzing a research topic. For the research presented, a decision model is well suited to describe a multi-dimensional relationship as well as to quantify otherwise subjective attributes. Also, it provides clear connections to the mission objective and alternatives, allowing decision makers to make informed choices. 
The next section describes how the success attributes are considered as part of the research proposal phase. Recall from section 2.1, literature suggests that technology transfer should be reflected in the research proposals.

\subsection{Evaluation of Research Proposals by Funding Agencies}

The last section of the literature review is to understand how research organizations evaluate research proposals. Are the criteria identified as necessary for technology transfer used in their decision processes?

A subset of government organizations was reviewed to determine if and how technology transfer was considered in their proposal evaluation criteria. These organizations included the Department of Energy (DOE), National Science Foundation (NSF), National Institutes of Health (NIH), Bonneville Power Administration (BPA) and the California Energy Commission (CEC); the DOE is a large organization with many groups that sponsors research. Therefore, two DOE groups were reviewed: the Advanced Research Project Agency - Energy (ARPA-e) and Energy Efficiency and Renewable Energy (EERE) [1] - [35], [170], [171]. The investments made by these organizations are significant, ranging from $\$ 30.2 \mathrm{~B}$ in 2015 by the $\mathrm{NIH}$ to approximately $\$ 18 \mathrm{M}$ by BPA in 2016. Despite the disparity in the investments levels, there is still a need to ensure that the research dollars are spent purposefully in order to achieve their individual missions. Templates and evaluation criteria used by each organization are provided for reference in Appendix A. Are there similarities in how they select a portfolio? How do they differ in their evaluations? To what extent do they consider the technology transfer attributes identified in chapter 2.2? These topics are presented followed by a discussion of how this 
research topic, a technology transfer score, could contribute to a more comprehensive evaluation approach.

\subsubsection{Department of Energy: EERE and ARPA-e}

The United States Department of Energy (DOE) is a Cabinet-level department of the United States government concerned with the United States' policies regarding energy and safety in handling nuclear material. Its responsibilities include the nation's nuclear weapons program, nuclear reactor production for the United States Navy, energy conservation, energy-related research, radioactive waste disposal, and domestic energy production. The agency's current administrator is Energy Secretary Dr. Ernest Moniz.

The origin of the agency resides in nuclear energy. In 1942, during World War II, the United States started the Manhattan Project, a project to develop the atomic bomb, under the eye of the U.S. Army Corps of Engineers. After the war, the Atomic Energy Commission (AEC) was created to control the future of the project. The AEC was reinstated and gave way to Nuclear Regulatory Commission, which was tasked with regulating the nuclear power industry, and the Energy Research and Development Administration, which was tasked to manage the nuclear weapon, naval reactor, and energy development programs.

The 1973 oil crisis called attention to the need to consolidate energy policy. On August 4, 1977, President Jimmy Carter signed into law The Department of Energy Organization Act of 1977 (Pub.L. 95-91, 91 Stat. 565, enacted August 4, 1977), which created the Department of Energy. The new agency, which began operations on October 1, 1977, consolidated the Federal Energy Administration, the Energy Research and 
Development Administration, the Federal Power Commission, and programs of various other agencies. [27]

EERE

The mission statement for the EERE includes its commitment to creating a clean energy economy. Also, the agency leads the DOE's “....efforts to develop and deliver market-driven solutions for energy-saving homes, buildings, and manufacturing; sustainable transportation; and renewable electricity generation."[33]. Similar to the other organizations discussed in this response, the EERE partners with industry, state/local governments, universities and other manufacturers to develop a portfolio that invests in clean energy technologies. The net effect of sponsoring these proposals will be to strengthen the economy, protect the environment and reduced dependency on foreign oil supplies [33]. The emphasis of EERE proposals are around improving energy efficiency practices and increasing their adoption.

The EERE has a process in place for managing the portfolio using a structured approach. The process begins with a solicitation, referred to as a Funding Opportunity Announcement (FOA), via a web portal (http://www1.eere.energy.gov/financing/) [36]. The link directs the applicant to relevant documents, templates, and evaluation criteria. EERE's uses a two-phased approach to evaluate proposals. Phase I is an initial review and serves as a screening process. An eligibility determination is made based on the information that is provided in the initial documents. This information should include clear objectives for a relevant topic. The assessment can be done by the financial officer and is facilitated by the checklist provided in Appendix A. This checklist can be tailored 
to include more specific criteria as appropriate for the solicitation. Assuming the requirements are met, the proposal is submitted to a more thorough Phase II review. However, if the applicant fails to provide the required information in Phase I (e.g. statement of clear objectives, project team, etc.) they would be removed from further consideration and notified of their ineligibility by the financial officer.

Phase II is a more comprehensive merit review. This phase includes an evaluation of the proposal by two review panels, an independent review and then a requirement to achieve consensus ratings. The purpose of this phase is to conduct a thorough, consistent and objective examination of applications based on the preestablished evaluation criteria set forth in the funding announcement. The evaluation criteria include the following elements:

Criterion 1: Scientific and Technological Merit - This criterion describes the degree to which the proposed technology and methodology meets the stated objectives of the funding announcement, identifies and/or makes progress with new or existing concepts, and the degree to which the work is based on sound scientific and engineering principles. The likelihood of developing the successful technology is also considered. The evaluators are asked to assess the anticipated benefits of the proposed work, relative to current commercial or emerging technologies.

Criterion 2: Technical Approach - This criterion takes into account the following elements:

- Adequacy and feasibility of approach to achieving the stated objectives, 
- Appropriateness, rationale, and completeness of the objectives - in other words the clarity of the proposal

- Extent of prior research experience

- Adequacy of the schedule, staffing plan, and travel, identified high risk challenges and presented reasonable mitigation strategies, and

- Sufficiency of the technology transfer plan

Criterion 3: Technical and Management Capabilities - Finally the evaluators assess the capability and experience of the applicant and associated organizations. The focus of this criterion is on the clarity, completeness and appropriateness of the project management plan, demonstrated capability and experience of the team (to include participating organizations), and the adequacy of the proposed personnel and other resources to perform the project tasks.

While the financial assistance officer can exclusively conduct the initial review, the reviews may include obtaining input and expertise from individuals within EERE, or other individuals from industry, academia, and national laboratories. This process ensures a comprehensive and well-vetted review.

\section{ARPA-e}

The Advanced Research Projects Agency Energy (ARPA-E), an organization within the Department of Energy is chartered by Congress in the America COMPETES Act of 2007 (P.L.110-69), as amended by the America COMPETES Reauthorization Act of 2010 (P.L. 111-358). The agency was established with the sole objective of 
supporting the creation of transformational energy technologies and systems through funding and managing Research and Development (R\&D) efforts. A more detailed history of the agency was obtained on the ARPA-e website [28]: In 2005, leaders from both parties in Congress asked the National Academies to "identify the most urgent challenges the U.S. faces in maintaining leadership in key areas of science and technology," as well as specific steps policymakers could take to help the U.S. compete, prosper, and stay secure in the 21st Century. In its report for Congress, Rising Above the Gathering Storm: Energizing and Employing America for a Brighter Economic Future, the National Academies called for decisive action, warning policymakers that U.S. advantages in science and technology--which made the country a world leader for decades--had already begun to erode. The report recommended that Congress establish an Advanced Research Projects Agency within the U.S. Department of Energy (DOE) modeled after the successful Defense Advanced Research Projects Agency (DARPA) the agency credited with such innovations as GPS, the stealth fighter, and computer networking.

In 2007, Congress passed and then President George W. Bush signed into law The America COMPETES Act, which officially authorized ARPA-E's creation. In 2009, Congress appropriated and President Barack Obama allocated \$400 million to the new Agency, which funded ARPA-E's first projects. Since this time, ARPA-E has funded over 350 potentially transformational energy technology projects. Many of these projects have already demonstrated early indicators of technical success and include: 
- Developed a 1 megawatt silicon carbide transistor the size of a fingernail

- Engineered microbes that use hydrogen and carbon dioxide to make liquid transportation fuel

- Pioneered a near-isothermal compressed air energy storage system ARPA-e funds applied research and development projects. As defined by the Office of Personnel Management, applied research is “...study designed to gain knowledge or understanding necessary to determine the means by which a recognized and specific need may be met." Ultimately, the ARPA-e proposals want to ensure that the United States maintains a technological lead in developing and deploying advanced energy technologies. Their website provides a very explicit and clear understanding of the types of proposals they fund and, by extension, those they do not fund: “...ARPAe exists to support transformational, rather than incremental research. ... While this incremental improvement of technology is important to the ultimate success of a technology in the marketplace, ARPA-E exists to fund transformational research - i.e., research that creates fundamentally new learning curves rather than moving existing technologies down their learning curves." [30]

How does ARPA-e differ from EERE? Without looking further, it would appear that they have similar mission statements and objectives. In reality, ARPA-e is a complement to other DOE R\&D organizations by supporting objectives that are "...transformational and translational...". The basic research would be funded out of the Office of Science, and proposals that are interested in the improvement of existing technology (incremental research) would be supported by the applied programs (e.g. 
EERE, Office of Nuclear Energy, or Office of Electricity Delivery and Energy Reliability).

Similar to EERE, ARPA-e has a comprehensive and rigorous portfolio process. The process begins with a solicitation, referred to as a Funding Opportunity Announcement (FOA), via a web portal. The portal directs the applicant to relevant documents, templates, and evaluation criteria.

Unique to ARPA-e, the proposal is required to devote a certain percentage of its funding to Technology Transfer and Outreach (TT\&O) activities. As stated, every project team must devote $5 \%$ of its federal funding award to TT\&O. These activities must be detailed in the proposal. The details of the plan are outlined in the Tech-ToMarket Plan described below:

During award negotiations, Prime Recipients are required to negotiate and submit an initial Technology-to-Market Plan to the ARPA-E Program Director, and obtain the ARPA-E Program Director's approval prior to the execution of the award. Prime Recipients must show how budgeted Technology Transfer and Outreach (TT\&O) costs relate to furthering elements of the Technology-to-Market Plan. During the project period, Prime Recipients are required to provide regular updates on the initial Technology-to-Market plan and report on implementation of Technology-to-Market activities. Prime Recipients may be required to perform other actions to further the commercialization of their respective technologies. [31]

Regarding the evaluation process, a reoccurring theme of using a multi-phased approach is evident. A description of each phase is provided. [32] 


\section{ARPA-e Phase 1 Criteria}

The emphasis of the first phase is on the impact of the proposal to state of the art and the overall scientific merit. Each is weighted $50 \%$ of the total evaluation. The impact of the proposal considers the extent to which the technology merits demonstrate the potential for transformation of an energy related field. It is important that the applicant demonstrate a comprehensive understanding of the current technology status and the ability to improve the status quo. This includes knowing other technologies that provide a solution and a clear statement regarding why this proposal is better (than other technology solutions). The emphasis of the other $50 \%$ is on the scientific and technical merit of the proposal. Evaluation factors include technical feasibility, a unique and innovative solution is provided, and the applicants ability to communicate, clearly, the outcomes, deliverables, and how the technology could be deployed.

\section{ARPA-e Phase 2 Criteria}

The first two criteria for phase 2 are the same as phase 1 - impact of technology and technical merit. However, each is only weighted as $30 \%$ of the total. The focus of the remaining $40 \%$ is on the project team and project plan. Of the forty percent, thirty is reserved for evaluating the qualifications, experience, and capabilities of the project team. The proposed team must clearly demonstrate that they have the necessary skill, expertise, and access to facilities as demonstrated by other R\&D work. While not insignificant, $10 \%$ of the overall phase 2 evaluation is reserved for evaluating the soundness of the management plan. Factors that are considered include the clarity of the plan to achieve 
deliverables/results, appropriate levels of effort are communicated, and whether the schedule is feasible to complete the work.

In addition to the Phase 1 and 2 criteria, other factors may be used at ARPA-e's discretion and include:

- Portfolio Balance: The goal is to strike a balance between factors like technology, organizational (e.g. industry, national labs), geographic regions, and commercialization risk.

- Contribution to ARPA-e's mission goals of reduction of dependence on foreign oil sources, emphasis on domestic manufacturing and competitiveness, reduction of emissions, and increases in energy efficiency.

- Minimize duplication of efforts between public and private projects, encourages collaboration with non-governmental entities, and to promote technology transfer.

- Funding sources: the extent that the applicant has identified cost sharing opportunities and demonstrates high potential project impact, relative to the overall project cost.

The ARPA-e website suggests a yearly solicitation with subsequent year portfolio projects announced in June and contracts executed to start work at the beginning of the next fiscal year. Similar to EERE, APRA-e relies on outside reviewers for Phase 2 proposals. These individuals are selected based on their knowledge and expertise in a relevant field.

\section{Bonneville Power Administration}


BPA is under the Department of Energy and operates as a non-profit organization in the Pacific Northwest. The agency provides transmission and markets wholesale electrical power to five states in the Pacific Northwest. The source of electrical power comes from 31 federal hydro projects in the Columbia River Basin, one non-federal nuclear plant, and several other small non-federal power plants. In total, one-third of the electric power used in the Northwest is provided by BPA. Related to transmission, BPA operates and maintains approximately three-fourths of the high voltage transmission lines in the region, approximately 15,300 circuit miles. BPA's service territory includes Idaho, Oregon, Washington, and parts of Montana, California, Nevada, Utah and Wyoming. Overall, the area serviced by BPA covers approximately 300,000 square miles. The BPA pamphlet provides specifics on their mission, vision, and values. [24]

The Bonneville Power Administration's mission as a public service organization is to create and deliver the best value for our customers and constituents as we act in concert with others to assure the Pacific Northwest:

- An adequate, efficient, economical and reliable power supply;

- A transmission system that is adequate to the task of integrating and transmitting power from federal and non-federal generating units, providing service to BPA's customers, providing interregional interconnections, and maintaining electrical reliability and stability; and

- Mitigation of the Federal Columbia River Power System's impacts on fish and wildlife. 
BPA is committed to cost-based rates, and public and regional preference in its marketing of power. BPA will set its rates as low as possible consistent with sound business principles and the full recovery of all of its costs, including timely repayment of the federal investment in the system.

As part of their responsibility, BPA promotes energy efficiency, renewable resources and new technologies. New technologies and energy efficient solutions are identified through the utilization of a roadmapping process. Roadmapping is widely used across the agency to ensure that research proposals are consistent with BPA's Vision [24].

The Technology Innovation office is responsible for selecting and managing BPA's R\&D portfolio of projects. The process involves a rigorous portfolio selection which is completed March through July of every year. Subsequently, a review cycle is conducted from January through March, implementing project management best practices, and once the research projects are complete transferring the projects to application. The primary function of this department is therefore portfolio, project management, and technology transfer.

Roadmaps serve as the basis for selecting research proposals. The input from the roadmaps is used to drive focus area decisions that are used as the basis for the annual R\&D solicitation. The roadmaps represent a cross-functional effort, involving many stakeholders, subject-matter-experts (SME's) within the agency, as well as soliciting input from external organizations. 
The Agency solicits research proposals for the next fiscal year (FY) in March and final decisions are made by July. The proposals are subjected to a two-phase review approach. [25]

Phase I Criteria [9]

The Phase 1 application will be evaluated individually based on the response to BPA's requirements and the evaluation criteria. Phase 1 submittals will not be evaluated against each other. BPA reserves the right to utilize third party consultants in the review of Phase 1. BPA is solely responsible for any decisions made pursuant to this phase, including the determination of the applicant's capability to bring the proposed idea to a successful conclusion and the relative technical and schedule risks for the project. Applicants will be notified of the decision by BPA of whether they can proceed to Phase 2. Phase 1 submittals will be evaluated using the following criteria, listed in descending order of importance:

a. Relevance of the proposed project to the identified Technology Roadmap

b. Principal investigator and project team qualifications including technical expertise, capabilities, related experience, and previous project successes, as well as the resources, facilities, techniques and/or unique combinations of these which are integral factors for achieving the application objectives;

c. Probability of achieving the 50 percent cost-share requirement; and

d. Clarity, quality, and organization of the Phase 1 application.

Phase II Criteria [9] 
Applications will be reviewed by the Financial Assistance Officer to determine responsiveness to the application requirements provided in the announcement. These requirements include submission of all required documents and meeting the $50 \%$ minimum cost share. Responsive applications will proceed to the next level of evaluation. Non-responsive applications will not be given any further consideration for award.

Responsive applications will then be reviewed and evaluated by an evaluation panel composed of BPA staff and third party subject matter experts. Qualified subject matter experts are used at BPA's sole discretion and are required to sign non-disclosure agreements and certify that they do not have a conflict of interest in participating in the evaluation of each application along with internal evaluators.

The application will be evaluated across several criteria. BPA applies a portfolio model to manage its technology innovation projects. Under this portfolio model, BPA's goal is to have a balance of projects in its Technology Innovation Portfolio across various technologies, time horizons, risk/reward profiles, cost concerns, and other needs. Highly ranked applications will be considered for inclusion in the BPA Technology Innovation Portfolio. Portfolio decisions are more complex than a technical review of a project taken in isolation. The decision to include a project in the Technology Innovation Portfolio includes consideration of the project risk/benefit profiles, the need to address the Roadmap, a balance of projects, ability to commit resources, a balance of time horizons and other factors.

Applicants are advised that an application for a project on a subject matter that is not currently included in BPA's TI portfolio may stand a better chance of selection for 
award compared to another application on a subject matter that is already well represented in the portfolio. Portfolio funding decisions are based in part on the information provided in the application. BPA reserves the right to consider other information from any source, including past performance information, for all project participants. BPA may request an oral project presentation after Phase 2. Applicants will be contacted if this is required.

\subsubsection{California Energy Commission}

As defined on the California Energy Commission website, the CEC is the state's primary energy policy and planning agency. The Commission was by the Legislature in 1974 and located in Sacramento, six basic responsibilities guide the Energy Commission as it sets state energy policy:

- Forecasting future energy needs;

- Promoting energy efficiency and conservation by setting the state's appliance and building efficiency standards;

- Supporting public interest energy research that advances energy science and technology through research, development and demonstration programs;

- Developing renewable energy resources and alternative renewable energy technologies for buildings, industry and transportation;

- Licensing thermal power plants 50 megawatts or larger; Planning for and directing state response to energy emergencies 
Similar to the other organizations, the agency's mission and vision statements support collaboration with others to improve energy systems and promote a stronger economy and environment.

The Energy Commission administers several research programs. The primary emphasis is to drive innovation and advance science in the following areas: energy efficiency, renewable energy, clean generation, transmission, and transportation. One program is the newly created electric Program Investment Charge (EPIC). EPIC was created in November 2013 by the California Public Utilities Commission (CPUC) and replaces the Public Goods Charge R\&D program. CEC is one of the four administrators of the EPIC program [13]. Others include Southern California Edison (SCE), Pacific Gas \& Electric (PG\&E), and San Diego Gas and Electric (SDG\&E). The objectives of the program are to fund research that will promote more reliability, lower costs, increased safety, and environmental sustainability for the ratepayers in the service territories designated as administrators of the program. Ultimately the goal of the program is to move "...energy technologies and products from the lab to life..." and give ratepayers choices in their electricity consumption [13].

There are other research programs that address specific topics. Examples are provided and selected based on their relevance to the PNW research interests. There is a big emphasis on end-use energy efficiency to meet load growth in the PNW so the work that the CEC is funding related to buildings end-use energy efficiency is of interest. As described on the CEC website, this research focuses on effective building and appliance technologies that put California on the path to zero net energy residential buildings by 
2020 and zero net energy commercial buildings by 2030 [19]. This research explores new and emerging energy efficiency technologies suitable for retrofitting existing buildings, as well as energy efficiency techniques for building maintenance and commissioning to optimize all cost-effective energy efficiency measures. The focus of this program is on short- to medium-term applied research in new and existing buildings.

Related to their evaluation criteria, the CEC also uses a multi-phased approach. The template or checklist for Phase 1 is included in Appendix A. The checklist does not evaluate the technical aspects of the proposal, only if the required documentation has been provided. Although the checklist does require that the proposal addresses a topic area.

\subsubsection{National Institutes of Health (NIH)}

The NIH invests billions of dollars annually to prevent diseases and improve health. The mission of the organization is to "... seek fundamental knowledge about the nature and behavior of living systems and the application of that knowledge to enhance health, lengthen life, and reduce illness and disability." [171]. The agency started as the Laboratory of Hygiene in 1887 and has grown in to many Institutes (National Cancer Institute, National Eye Institute, etc.) and Centers (Center for Scientific Review, NIH Clinical Center, etc.). The federal agency is under the Department of Health and Human Services and is the focal point for health related research in the US.

The NIH seeks research proposals to support their mission and goals of protecting and improving health, preventing disease, and expanding their knowledge 
base. Their research portfolio spans basic research to clinical translational research that "...transforms discoveries into medical practice..." [171]. Similar to the other research organizations reviewed for this research, the NIH uses a rating scale and two phased approach to evaluation the proposals.

The proposals are reviewed by a Scientific Review Group (SRG) against several criteria. The reviewers for each proposal are selected by the SRG based on their area of expertise. Reviews may be done in peer review meetings and are rated on the following criteria:

- Significance of the proposal

- Are the investigators well suited to conduct the research?

- Is the idea innovative? In other words, does it challenge or seek a shift in the status quo.

- Approach - this includes a review of strategic alignment, and are the methodologies and analysis well-reasoned, and

- Environmental considerations: Does the scientific environment contribute to the probability of success?

The evaluation criteria are reviewed on a scale of $1-9$. These reviews are provided to the SRG who makes a recommendation to the Institute and Center National Advisory Councils. The decisions about portfolio projects are made by the Advisory Council based on strategic needs and really involve more of a prioritization effort of the recommendations provided by the SRG. 


\subsubsection{National Science Foundation}

The NSF was created in 1950 by Congress to "...promote the progress of science; to advance the national health, prosperity, and welfare; to secure the national defense...". [170] Their annual budget is in excess of \$7B USD and is used to issue limited term grants. There are in excess of 12,000 new awards per year with a typical project duration of three years. Most of the 12,000 awards go to individuals or small group investors.

The NSF's “organic" legislation allows the agency flexibility to engage in a variety of different initiatives. The NSF web site describes their areas of participation: (www.nsf.gov)

- Initiate and support, through grants and contracts, scientific and engineering research and programs to strengthen scientific and engineering research potential, and education programs at all levels, and appraise the impact of research upon industrial development and the general welfare.

- Award graduate fellowships in the sciences and in engineering.

- Foster the interchange of scientific information among scientists and engineers in the United States and foreign countries.

- Foster and support the development and use of computers and other scientific methods and technologies, primarily for research and education in the sciences. 
- Evaluate the status and needs of the various sciences and engineering and take into consideration the results of this evaluation in correlating our research and educational programs with other federal and non-federal programs.

- Provide a central clearinghouse for the collection, interpretation and analysis of data on scientific and technical resources in the United States, and provide a source of information for policy formulation by other federal agencies.

- Determine the total amount of federal money received by universities and appropriate organizations for the conduct of scientific and engineering research, including both basic and applied, and construction of facilities where such research is conducted, but excluding development, and report annually thereon to the President and the Congress.

- Initiate and support specific scientific and engineering activities in connection with matters relating to international cooperation, national security and the effects of scientific and technological applications upon society.

- Initiate and support scientific and engineering research, including applied research, at academic and other nonprofit institutions and, at the direction of the President, support applied research at other organizations.

- Recommend and encourage the pursuit of national policies for the promotion of basic research and education in the sciences and engineering. Strengthen research and education innovation in the sciences and engineering, including independent research by individuals, throughout the United States. 
- Support activities designed to increase the participation of women and minorities and others underrepresented in science and technology. [170]

The NSF is the funding source for approximately $24 \%$ of all federally funded basic research. Their approach to identifying research is "bottom-up" - their organizations keep in touch with research communities in the US and around the world to have an awareness of the latest technology developments in their areas of interest. Their goal is to support basic research and to find those technologies that “...may seem like science fiction today...”. [170]

Similar to the other research organizations, the NSF uses a two-phased approach to evaluating research proposals. However, unique to NSF is that they encourage the proposers to engage with the NSF program personnel prior to the preparation and submission of a proposal.

Phase I includes a review by at least three external reviewers based on their area of expertise. The reviews may be conducted ad-hoc and/or by a panel review and could even include some site visits as part of the evaluation process. The reviewers are asked to review the proposals against two criteria: Intellectual Merit and Broader Impacts. The purpose of Intellectual Merit is to consider if the research has the potential to advance knowledge. The Broader Impacts criteria look at the potential benefits to society under the following conditions:

1. What is the potential for the proposed activity to:

a. Advance knowledge and understanding within its own field or across different fields (Intellectual Merit); and 
b. Benefit society or advance desired societal outcomes (Broader Impacts)?

2. To what extent do the proposed activities suggest and explore creative, original, or potentially transformative concepts?

3. Is the plan for carrying out the proposed activities well-reasoned, well-organized, and based on a sound rationale? Does the plan incorporate a mechanism to assess success?

4. How well qualified is the individual, team, or organization to conduct the proposed activities?

5. Are there adequate resources available to the PI (either at the home organization or through collaborations) to carry out the proposed activities? [170]

Phase II of the proposal review process starts with providing the evaluation criteria to the NSF Program Office. The Program Office makes a recommendation to the Division Director who makes a final decision about which projects are selected, based on strategic and agency needs. The budget contracting and budget officers do a final review.

The use of a multi-attribute perspective, as suggested in this research, helps to identify more than just the technical aspects of an issue. In this case, the issue that is addressed is the need to apply research results. While the importance of technology cannot be underscored, there are many other attributes that contribute to successful application of research - a multi-perspective approach identifies and emphasizes these other characteristics. The attributes that were identified in the literature review as necessary for successful technology transfer that were considered for this comparison are: 
- Dedicated TTO

- Cooperative experience

- Bureaucracy

- Technology and Stakeholder complexity

- Cultural awareness

- Manpower flexibility

- Demonstrations

- Geographic proximity

- Organizational homogeneity

- Budget flexibility
- Rewards system in place

- Business plan exists

- Government incentives exist

- Financial feasibility is assessed

- Organizational champion is identified

- TT initiated by top management

- Common standards and codes

- TTO staffed with marketing experience

- Create an atmosphere of trust

- Personnel involved in TT

- Understanding the recipient

Some general observations can be made about how all of the organizations considered in this research evaluated proposals. Each organization uses a two-phased approach to solicit and evaluate proposals. This approach minimizes the work for both the applicant and the sponsoring organization - if not all the Phase 1 criteria is met, the application is terminated. In all cases, the applicant is notified about their status and why they are unable to continue in the solicitation process. Also, the Phase 2 criterion is similar - all ask about the technical feasibility, the project team, and potential application.

Regarding potential application, all evaluation processes fall short of quantifying the potential for technology transfer success. While some organizations ask evaluators to consider some of the attributes identified in literature, none develops a comprehensive evaluation that considers many perspectives of technology transfer. The CEC program is 
the closest when the application is evaluated on whether or not the project team has previous research experience as well as successful demonstrations. However, even for this case, the amount of experience is not quantified (e.g. five years of experience is better than one year of experience, etc.). As an example, assigning a relative value to this would provide a more tangible quantification about the amount of research experience, as opposed to having it (research experience) or not.

Despite being identified as necessary for successful technology transfer in literature, none of the organizations consider geographic proximity, time to contract, manpower flexibility, organizational homogeneity, marketing experience of the Technology Transfer Office, or most success attributes in the social perspective, as part of the evaluation criteria. This inference was drawn from the absence of these success attributes as part of the evaluation forms. Table 8 summarizes the evaluation criteria for each of the federal organizations reviewed for this research. The emphasis for the evaluation criteria are on the technical aspects and largely does not address the other success attributes identified in research. The use of a technology transfer score, as proposed by this body of work, would provide a more comprehensive, multi-criteria approach to evaluating research proposals, with the focus of improving the potential of moving from research into application. 


\begin{tabular}{|c|c|c|c|c|}
\hline \multirow{2}{*}{$\begin{array}{c}\text { Research } \\
\text { Organization }\end{array}$} & \multicolumn{4}{|c|}{ TT Success Attributes Considered for Evaluating Research Proposals } \\
\hline & Organizational & Technological & Social & Market \\
\hline BPA & $\begin{array}{l}\text { - Time to } \\
\text { Contract } \\
\text { - Geographic } \\
\text { Proximity }\end{array}$ & $\begin{array}{l}\text { - Cooperative } \\
\text { Experience } \\
\text { - Technical } \\
\text { Complexity } \\
\text { - Understanding } \\
\text { the Recipient }\end{array}$ & $\begin{array}{l}\text { - Communication } \\
\text { Plan }\end{array}$ & $\begin{array}{l}\text { - Use } \\
\text { Case }\end{array}$ \\
\hline CEC & N/A & $\begin{array}{l}\text { Cooperative } \\
\text { Experience; } \\
\text { technology } \\
\text { demonstrations } \\
\text { - Technical } \\
\text { Complexity }\end{array}$ & N/A & N/A \\
\hline ARAP-e & N/A & $\begin{array}{l}\text { - Cooperative } \\
\text { Experience } \\
\text { - Technical } \\
\text { Complexity } \\
\text { - Percentage of } \\
\text { budget } \\
\text { dedicated to TT }\end{array}$ & N/A & N/A \\
\hline EERE & N/A & $\begin{array}{l}\text { Cooperative } \\
\text { Experience } \\
\text { - Technical } \\
\text { Complexity }\end{array}$ & N/A & N/A \\
\hline NSF & N/A & $\begin{array}{l}\text { - Cooperative } \\
\text { Experience } \\
\text { - Technical } \\
\text { Complexity }\end{array}$ & N/A & N/A \\
\hline NIH & N/A & $\begin{array}{l}\text { - Cooperative } \\
\text { Experience } \\
\text { - Technical } \\
\text { Complexity }\end{array}$ & N/A & N/A \\
\hline
\end{tabular}

Table 8: Research Organization Evaluation Criteria 
Overall, while there is a common theme of applying research or technology transfer as an organization's goal, there are no evaluation criteria to assess its probability. Adopting a TT score and including it as part of the proposal evaluation process will help an organization close the gap between technologies just being available to their actual adoption and delivery of expected results.

A comprehensive literature review to include a review of journal articles, text citations, web searches, and meetings with utility research leaders has been completed in the following areas:

- When technology transfer should be considered,

- Technology transfer definitions and success attributes,

- The research methods used to analyze technology transfer, and

- What criteria an organization uses to evaluate a research proposal

Because of the literature reviews, interviews and preliminary content validation, several research gaps have been identified. Table 9 describes the gap and relevant citations. 


\begin{tabular}{|c|c|c|}
\hline Literature Review & Research Gap & Description of Gap \\
\hline $\begin{array}{l}\text { 2.1: Technology Transfer } \\
\text { in the Research Proposal } \\
2.4 \\
\text { How An Organization } \\
\text { Evaluates a Research } \\
\text { Proposal }\end{array}$ & $\begin{array}{l}\text { G1: Research } \\
\text { Proposals Do Not } \\
\text { Comprehensively } \\
\text { Address TT } \\
\text { Potential During } \\
\text { the Proposal Stage }\end{array}$ & $\begin{array}{l}\text { Research proposals are evaluated with some } \\
\text { qualitative consideration to technology transfer. } \\
\text { Specific to the utility industry, despite a clear } \\
\text { need to apply research results, a review of how } \\
\text { research proposals are evaluated confirms that } \\
\text { technology transfer is only peripherally } \\
\text { addressed. }\end{array}$ \\
\hline $\begin{array}{l}\text { 2.2: Definitions of TT and } \\
\text { TT Success Attributes }\end{array}$ & $\begin{array}{l}\text { G2: No TT } \\
\text { Success } \\
\text { Characteristic } \\
\text { Framework Exists }\end{array}$ & $\begin{array}{l}\text { Technology transfer research has clearly and } \\
\text { consistently defined the requirements that } \\
\text { facilitate the technology transfer process. } \\
\text { However, no framework has been established to } \\
\text { aggregate these characteristics or understand the } \\
\text { relationship between them. }\end{array}$ \\
\hline $\begin{array}{l}\text { 2.3: Methods That are } \\
\text { Used to Understand } \\
\text { Technology Transfer }\end{array}$ & $\begin{array}{l}\text { G3: No } \\
\text { Quantitative } \\
\text { Method of } \\
\text { assessing TT } \\
\text { Potential }\end{array}$ & $\begin{array}{l}\text { Success attributes have been well identified but } \\
\text { there is no mechanism to quantitatively assess } \\
\text { the technology transfer potential of a research } \\
\text { proposal. }\end{array}$ \\
\hline
\end{tabular}

Table 9: Research Gaps 


\section{CHAPTER 3: RESEARCH OBJECTIVES, QUESTIONS, AND METHODOLOGY}

The framework for how the research gaps are analyzed is presented in this chapter. The appropriateness of a multi-criteria hierarchical decision model and the use of associated data collection analysis tools are discussed. These tools include the general model framework to determine the technology transfer score, inconsistency and disagreement analysis, the use of desirability curves to characterize the "usefulness" of the success attributes, and the validation and quantification of the model. The validation and quantification of the model and desirability curves rely on expert judgment so this chapter also includes considerations for selecting expert panels.

\subsection{Objective}

The preceding chapter identified research gaps in literature regarding technology transfer. That, despite the need for addressing technology transfer at the start of research and development, specifically as part of the research proposal, a review of the evaluation criteria from several organizations determined that technology transfer is not comprehensively or quantitatively assessed. In addition, there is consistent information among the research community about what is necessary for successful technology transfer. However, there is not a way of aggregating this information into a framework for assessing and measuring technology transfer potential as part of the research and development phase.

Assuming the ultimate goal of research is to apply results, it is important to understand how the transfer occurs most effectively. The objective of this research is 
to develop a technology transfer score that can be used for assessing the technology transfer potential of a research proposal. It will be used during the proposal evaluation stage to identify those research proposals that have the most potential for technology transfer because the organizations involved in the technology transfer

exhibit characteristics that have been identified as necessary for technology transfer.

\subsection{Questions}

Once the framework for assessing and quantifying technology transfer has been developed, an organization can use the tool to inform the selection of a research portfolio. The premise is that in addition to technical feasibility and strategic alignment, the potential for successful application should be considered.

The case study and recommendations will be used to ask some key questions. These include:

1. Is the proposed framework and method for assessing transfer potential an appropriate assimilation of literature findings?

2. Are some attributes more important than others for the case study industry?

3. What level of effort is required to gather the data in order to compute the technology transfer score? and

4. Is the assessment framework appropriate for assessing multiple technologies in any industry? In other words, is the model generalizable? 


\subsection{Methodology}

\subsubsection{Introduction to Hierarchical Decision Modeling (HDM)}

Much the same way Geels and Sharma describe an interaction between levels to capture the technology transfer relationship, the proposed conceptual model describes a similar relationship. However, this research goes a step further to specify the success attributes associated with technology transfer, using a multi-perspective view. In total, the literature review identified 22 success attributes, across the four perspectives, which contribute to successful technology transfer.

A multi-criteria decision model was the selected tool to analyze technology transfer success attributes and develop a technology transfer score. Alternative approaches to analyze and assimilate technology transfer success attributes into a tool that can be used to evaluate research proposals have been considered. Statements regarding the strengths and weakness of each method are provided in Table 10.

Following the table is further justification to substantiate the selected research method.

\begin{tabular}{|c|c|c|}
\hline ANALYSIS METHOD & $\begin{array}{l}\text { STRENGTHS OF THE } \\
\text { ANALYSIS METHOD }\end{array}$ & $\begin{array}{l}\text { WEAKNESSES OF THE } \\
\text { ANALYSIS METHOD }\end{array}$ \\
\hline $\begin{array}{l}\text { Case Studies are used to } \\
\text { explore causation and find } \\
\text { the underlying principle. } \\
\text { The approach is defined } \\
\text { as a descriptive, } \\
\text { exploratory or } \\
\text { explanatory analysis of a } \\
\text { person, group or event. } \\
\text { [76] }\end{array}$ & $\begin{array}{l}\text { - Emphasizes a detailed contextual } \\
\text { analysis of a limited number of } \\
\text { events and their relationship } \\
\text { - Often used by social scientists to } \\
\text { understand the relationship } \\
\text { between real-life and proposed } \\
\text { methods } \\
\text { - Used for comparisons of } \\
\text { organizations to illustrate a } \\
\text { theoretical concept. }\end{array}$ & $\begin{array}{l}\text { - Only studies a small number of } \\
\text { environments and do not offer } \\
\text { reliability } \\
\text { - Intense study in one case } \\
\text { introduces the potential for bias } \\
\text { - Case studies should only be used } \\
\text { as an exploratory tool } \\
\text { - Typically lacks scientific rigor to } \\
\text { draw definite correlations }\end{array}$ \\
\hline $\begin{array}{l}\text { Surveying is used to } \\
\text { assess thoughts, opinions } \\
\text { or feelings. [77] }\end{array}$ & $\begin{array}{l}\text { - Collects data on phenomena that } \\
\text { cannot be directly observed } \\
\text { - Used to assess attributes and } \\
\text { characteristics - sample }\end{array}$ & $\begin{array}{l}\text { - Design of the survey is critical to } \\
\text { success } \\
\text { - Needs to ensure the sample being } \\
\text { surveyed is random }\end{array}$ \\
\hline
\end{tabular}




\begin{tabular}{|c|c|c|}
\hline ANALYSIS METHOD & $\begin{array}{l}\text { STRENGTHS OF THE } \\
\text { ANALYSIS METHOD }\end{array}$ & $\begin{array}{c}\text { WEAKNESSES OF THE } \\
\text { ANALYSIS METHOD }\end{array}$ \\
\hline & $\begin{array}{l}\text { population is key to a successful } \\
\text { survey }\end{array}$ & $\begin{array}{l}\text { - Questions are asked explicitly to } \\
\text { extract correct information; don't } \\
\text { assume terms are familiar to } \\
\text { sample population. }\end{array}$ \\
\hline $\begin{array}{l}\text { Literature Reviews are } \\
\text { defined as text written by } \\
\text { someone to consider the } \\
\text { critical points of current } \\
\text { knowledge including } \\
\text { substantive findings, as } \\
\text { well as theoretical and } \\
\text { methodological } \\
\text { contributions to a } \\
\text { particular topic. Literature } \\
\text { reviews are secondary } \\
\text { sources, and as such, do } \\
\text { not report any new or } \\
\text { original experimental } \\
\text { work [78] }\end{array}$ & $\begin{array}{l}\text { - Combines a summary of a } \\
\text { particular topic(s). } \\
\text { - How the literature review is } \\
\text { presented could give new } \\
\text { interpretation to old material; } \\
\text { similar to a taxonomy to identify } \\
\text { research gaps }\end{array}$ & $\begin{array}{l}\text { - Information is reported - not } \\
\text { synthesized. The researcher is } \\
\text { left to draw inferences or } \\
\text { assimilate to form new ideas. } \\
\text { - Used to generate a hypothesis- } \\
\text { provides background } \\
\text { information to form ideas. }\end{array}$ \\
\hline $\begin{array}{l}\text { Decision Model } \\
\text { Development is defined } \\
\text { as an effective research } \\
\text { method. It assists } \\
\text { investigators and } \\
\text { scientists in relating more } \\
\text { accurately to reality; it } \\
\text { also aids them to describe, } \\
\text { predict, test or understand } \\
\text { complex systems or } \\
\text { events. Thus, models } \\
\text { often provide a } \\
\text { framework for the } \\
\text { conduct of research and } \\
\text { might consist of actual } \\
\text { objects or abstract forms, } \\
\text { such as sketches, } \\
\text { mathematical formulas, or } \\
\text { diagrams. A model is an } \\
\text { abstraction, a mental } \\
\text { framework for analysis of } \\
\text { a system. [79] }\end{array}$ & $\begin{array}{l}\text { - Aggregates the opinions of } \\
\text { experts - captures a rank of } \\
\text { candidates to inform a decision } \\
\text { - Provides better problem } \\
\text { abstraction } \\
\text { - Good predictive outcome tool } \\
\text { - Multi-criteria decision models are } \\
\text { used to illustrate multi-level } \\
\text { relationships } \\
\text { - Helpful for policy makers to } \\
\text { understand alternatives [81] } \\
\text { - Structures tangible and intangible } \\
\text { attributes } \\
\text { - Multi-Attribute Utility Theory } \\
\text { (MAUT) includes the use of } \\
\text { utility functions to describe the } \\
\text { preference of the decision maker. } \\
\text { [173] }\end{array}$ & $\begin{array}{l}\text { - The number of pairwise } \\
\text { comparisons required to } \\
\text { comprehensively describe the } \\
\text { model could be significant and a } \\
\text { deterrent to soliciting expert } \\
\text { participation } \\
\text { - A model is an abstract } \\
\text { representation of reality. } \\
\text { - When models have not been } \\
\text { properly validated, their use as a } \\
\text { knowledge source might be } \\
\text { unwarranted. In addition, unless } \\
\text { care is taken, models often invite } \\
\text { overgeneralizations. } \\
\text { - It is critical to be explicit and } \\
\text { unambiguous with terms. } \\
\text { There may be a tendency to use } \\
\text { model output as a decision } \\
\text { (versus being used as a tool to } \\
\text { inform decisions) }\end{array}$ \\
\hline $\begin{array}{l}\text { Hypothesis Testing is } \\
\text { defined as the process of } \\
\text { testing an assumption } \\
\text { about a population } \\
\text { parameter. The process } \\
\text { defines the null } \\
\text { hypothesis }\left(\mathrm{H}_{\mathrm{o}}\right) \text { which is } \\
\text { the sample observation } \\
\text { results purely from }\end{array}$ & - Doesn't rely on subjective input & $\begin{array}{l}\text { - The test statistic is influenced by } \\
\text { the effect size, the explained } \\
\text { variation and sample size } \\
\text { - Sample needs to be } \\
\text { representative of the population } \\
\text { - } 95 \% \text { confidence interval is } \\
\text { arbitrary } \\
\text { - Results are misinterpreted as } \\
\text { absolute when they are really }\end{array}$ \\
\hline
\end{tabular}




\begin{tabular}{|l|l|l|}
\hline \multicolumn{1}{|c|}{ ANALYSIS METHOD } & \multicolumn{1}{|c|}{$\begin{array}{c}\text { STRENGTHS OF THE } \\
\text { ANALYSIS METHOD }\end{array}$} & \multicolumn{1}{c|}{$\begin{array}{c}\text { WEAKNESSES OF THE } \\
\text { ANALYSIS METHOD }\end{array}$} \\
\hline $\begin{array}{l}\text { chance and the alternate } \\
\text { hypothesis }\left(\mathrm{H}_{\mathrm{a}} \text { ) which is }\right. \\
\text { the sample observation is } \\
\text { influenced by some non- } \\
\text { random cause. [80] }\end{array}$ & & $\begin{array}{l}\text { only providing a probability for } \\
\text { the null hypothesis should be } \\
\text { rejected. } \\
\text { Design of the experiment is } \\
\text { critical }\end{array}$ \\
\hline
\end{tabular}

Table 10: Method Assessment

Model development is an appropriate methodology to understand the relationship between the success attributes and the research environment $[81,82,84]$ and ultimately to develop a tool that can be used to inform the selection of research proposals. There is a significant amount of literate to support the use of a decision model to analyze the research that is being proposed. A recent and relevant example is Phan's research to calculate an innovation index [82]. In this research, he used an HDM and subjective attributes to develop an innovation score. He notes that the use of a decision model should recognize the subjectivity of inputs. While experts are invaluable to assigning values to decision attributes, their input is subjective, resulting in disagreement among the experts. This impact can be offset by selecting the right expert panel for each level of the decision model and using tools to measure and minimize any potential disagreement. Other research has used cluster analysis to understand disagreements [83] - is there a particular group of experts that disagree? If so, then sensitivity analysis can be used to determine the impact of their disagreement. In addition, sensitivity analysis is used to assess the impact of a change in the expert panel. When different experts are used this could change the model assessments, influencing criteria weights. It is important to consider the model's sensitivity to changes in expert opinion resulting in different criteria weights. Phan states that HDM is used frequently to capture complex and multi-criteria 
problems. The HDM provides a mechanism for clearly describing the relationships between the decision model factors. Technology transfer, especially when it is understood in terms of building a relationship, is an ideal issue to be framed by a HDM.

Other literature supports the use of a decision model to understand relationship between multiple levels. Geels' research identifies a model to describe the relationship that facilitates technology transfer [43]. Decision models have been used to decompose problems related to health care, technology selections... and strategic planning [84]. A hierarchical decision model is used to illustrate multi-level relationships and is commonly used to help outline alternatives using a systematic and quantitative approach [81]. It is a tool that incorporates qualitative and quantitative feedback from subject matter experts via the use of pairwise comparisons. These comparisons allow the subject matter experts to provide their feedback about the relative importance of success criteria. Phan states that “...this process makes the experts more comfortable because their decisions are based on the relative preference of one criterion over another rather than an absolute preference" [82].

The comprehensive literature review discussed in chapter 2.2 identified that successful technology transfer is dependent more on qualitative characteristics rather than quantitative and involves interaction among many different domains. As described, this type of problem is particularly suited for the Hierarchical Decision Model approach. Figure 3 presents a conceptual HDM. 


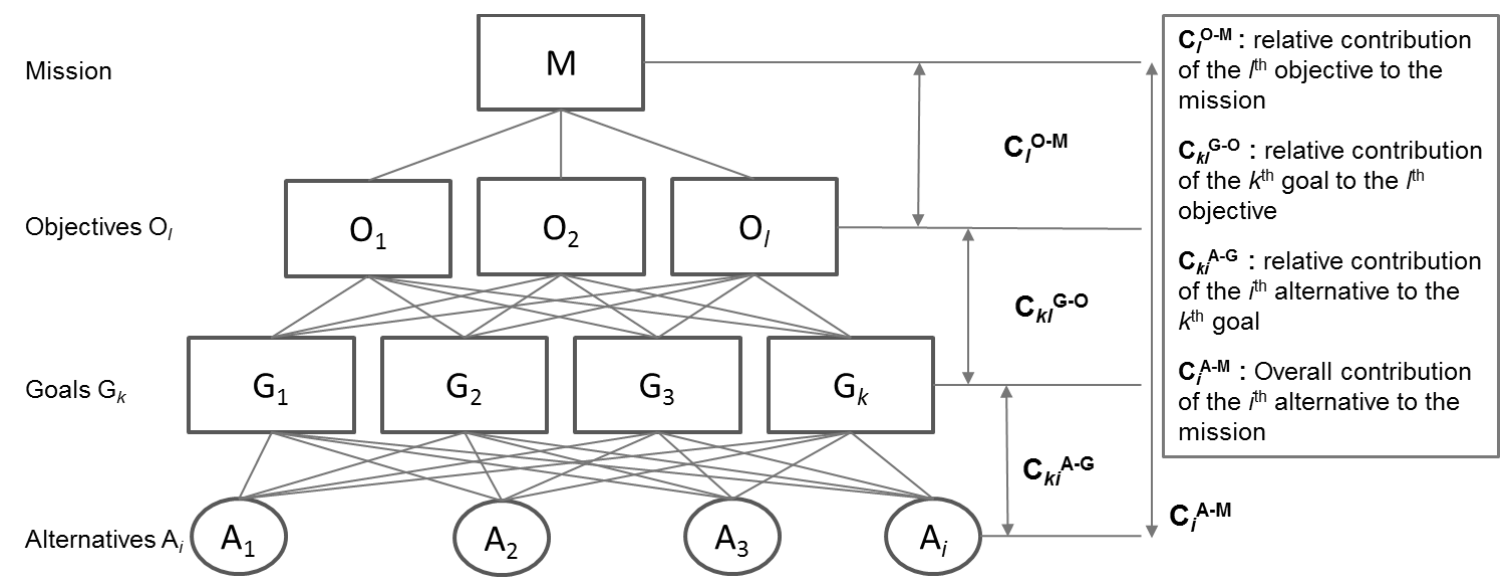

Figure 3: Conceptual Model Design

\subsubsection{Inconsistency and Disagreement of Expert Judgments}

Generally, inconsistency can be defined as disagreement within an individual's evaluation. The concept can be illustrated with the following example. Suppose an expert is asked to compare three types of music, classical (a), jazz (b), or modern (c). The expert likes classical more than jazz $(a>b)$, and jazz more than modern $(b>c)$. An inconsistent response would be that the respondent liked modern more than classical, or $c>a$. In other words, if $a>b$, and $b>c$, then $c>a$. This example demonstrates measuring ordinal inconsistency. Ordinal consistency does not take into account the strength of a decision maker's comparison. [93] Another measure is cardinal inconsistency which does take into account the decision makers preference of one option over another. In the example cited, suppose that the expert likes classical music twice as much as jazz, and jazz three times as much as modern music. Cardinal consistency would require the decision maker to like classical six times as much as modern. Otherwise, cardinal consistency is violated. 
Kocaoglu's research provides a comprehensive definition of inconsistency and discusses the analysis and measurement of the term. The methodology is widely referenced in recent dissertations by Chan, Phan, and Sheik [82, 84, 92, 93]. It is provided here for reference:

For $\mathrm{n}$ elements, the constant sum calculations result in a vector of relative values $r_{1}, r_{2}, \ldots, r_{n}$ for each of the $n$ ! orientations of the elements. For example, if three elements are evaluated, $\mathrm{n}$ is 3 , and $\mathrm{n}$ ! is 6 . The six orientations would be $\mathrm{ABC}, \mathrm{ACB}, \mathrm{BAC}, \mathrm{BCA}$, $\mathrm{CAB}$, and $\mathrm{CBA}$. If an expert is consistent in providing pairwise comparisons, the relative values are consistent for each orientation. However, if an expert is inconsistent in providing pairwise comparisons, the relative values are different for each unique orientation. The inconsistency in this methodology is measured by the variance among the relative values of the elements calculated in the $\mathrm{n}$ ! orientations.

Let

$\mathrm{r}_{\mathrm{ij}}=$ relative value of the $\mathrm{i}^{\text {th }}$ element in the $\mathrm{j}^{\text {th }}$ orientation for an expert

$\bar{r}_{\mathrm{i}}=$ mean relative value of the ith element for that expert

$\frac{1}{n !} \sum_{j=1}^{n !} r_{\mathrm{ij}}$

Equation 1

The population standard deviation is shown in Equation 2:

$$
\sqrt{\left(\frac{1}{n !}\right) \sum_{j=1}^{n !}\left(\overline{r_{i}}-r_{i j}\right)^{2}}
$$

Equation 2

For $\mathrm{i}=1,2, \ldots, \mathrm{n}$ 
Inconsistency is defined as the mean standard deviation of $\mathrm{n}$ elements and is described in Equation 3:

$$
\frac{1}{n} \sum_{i=1}^{n} \sqrt{\left(\frac{1}{n !}\right) \sum_{j=1}^{n !}\left(\bar{r}_{i}-r_{i j}\right)^{2}} \quad \text { Equation } 3
$$

Kocaoglu recommends 0.10 as the limiting value for the inconsistency for any value of $n$.

Recent research conducted by Dr. Mustafa Abbas refines the inconsistency measure using the Root Sum of the Variance (RSV) method [169], versus the mean of the standard deviations to measure inconsistency. Dr. Abbas' research objectives were to “...establish consistency threshold that are tied to the number of variables and linked to corresponding $\propto$ levels." [169].

The next measure to consider is the disagreement among the group of experts. Before defining disagreement and methods used to analyze and measure it is important to mention that disagreement among experts should not be unexpected [92]. What is important is to understand why there would be disagreement. Often times, when there is disagreement, follow-up by the researcher is necessary. Did the expert interpret something incorrectly? In which case their evaluation may change, resulting in no disagreement. On the other hand, did the expert make the pairwise comparisons correctly? In this case, the disagreement would remain along with an explanation for a discrepancy. 
Dissertations by Chan, Phan, and Iskin, who also used decision modeling for their research interests, included a discussion about disagreement. Their work is referenced here along with literature reviews on how to analyze and measure disagreement.

As mentioned, it is not uncommon for experts to disagree. This is potentially due to a number of factors such as their experiences, both personal and professional, having an impact on how they would respond to a question. Also, the clarity of the questions has an influence on how they are interpreted - less ambiguous questions infer a more consistent interpretation by the expert panel. Therefore, it is important to be clear and encourage the experts to ask questions about the survey.

\subsubsection{Disagreement and Clustering}

The extent to which an expert panel is in agreement with their judgment quantification is represented by a disagreement value. There is group disagreement if the disagreement exceeds a value of 0.10 and a value of 0 would imply complete agreement among the experts [172]. The disagreement index is presented in Kocaoglu's work [93] and determined by the following equations:

Let $m$ be the number of experts and $n$ be the number of decision variables

$r_{i k}$ be mean relative value of the $i^{\text {th }}$ decision variable for $k^{\text {th }}$ expert

Group relative value of the $i^{\text {th }}$ decision variable for $m$ experts is

$$
R_{i}=\sum_{k=1}^{m} r_{i k} \cdot \frac{1}{m} \text { for } i=1,2, \ldots, n \quad \text { Equation } 4
$$


The standard deviation of the relative value of the $i^{\text {th }}$ decision variable is:

$S T D_{i}=\sqrt{\frac{1}{m} \sum_{k=1}^{m}\left(R_{i}-r_{i k}\right)^{2}} \quad$ Equation 5

Disagreement for $m$ experts is calculated as the mean standard deviation of the group $n$ relative values of variables

$\mathrm{D}=\frac{1}{n} \sum_{i=1}^{n} S T D_{i} \quad$ Equation 6

The disagreement can also be represented by an intra-class correlation coefficient, $r_{i c}$. The intra-class correlation compares the means among the judgments of the experts to show whether a pairwise comparison result might have a high or low disagreement. The intra-class correlation coefficient takes a value from $-1 /(\mathrm{k}-1) \leq \mathrm{r}_{\mathrm{ic}} \leq 1$. A coefficient of 1 means an absolute agreement among the experts, and a value of 0 or less indicates a significant disagreement. [174].

In order to make a more confident decision about the value of $r_{i c}$, and whether there is significant disagreement among the expert panel, a hypothesis testing procedure is used with the F-test [175]. The Null Hypothesis $\left(\mathrm{H}_{0}\right)$ for the F-test is that there is a significant disagreement among the expert panel judgment quantification, or $\mathrm{H}_{0}: \mathrm{ric}_{\mathrm{ic}}=0$. The F-value of a pairwise comparison procedure is calculated and compared against the F-critical value of the procedure to determine whether the Null Hypothesis can be rejected or not. If $\mathrm{H}_{0}$ is rejected, we can conclude that there is not a significant 
disagreement in the experts' judgments. The F-values and F-critical values of the pairwise comparisons are provided readily by the OHDM software.

Iskin used a combination of pairwise comparison group disagreement and hierarchical clustering to understand disagreements between experts in his research of developing an assessment model for Energy Efficiency Program Planning [83]. The group disagreement was used to identify group disagreements and the clustering identified those experts who disagreed with the others. Acceptable disagreement is a value of 0.1 or less.

What if there are disagreements among the experts? The Hierarchical Clustering Method is used to identify those data points in a group that are similar, or agree. The objective is for clustering to discover natural groupings. For instance, when assessing the Level limportance, is the disagreement among experts in the utility industry, when compared to other experts at universities, for example? This method was used in Iskin's research of Energy Efficiency Program Planning. Hierarchical clustering was defined as, “.... obtains homogeneous clusters of cases based on measured characteristics. The process starts where each case is considered as a separate cluster; and for each iteration, a new cluster is determined by combining one case with a cluster identified earlier in a fashion that the arithmetic distance between new and old clusters remain the shortest among all possible alternatives. The process continues until one cluster is left.” [83]

In summary, if disagreement among the experts exists, one of the three methods described in this chapter can be used to understand the source and 
severity/importance of the disagreement. Table 11 provides an example of inconsistency and disagreement scores. As shown, the inconsistency and disagreement scores are within acceptable limits so no further analysis would be necessary.

\begin{tabular}{|c|c|c|c|c|c|c|}
\hline \multirow{15}{*}{ 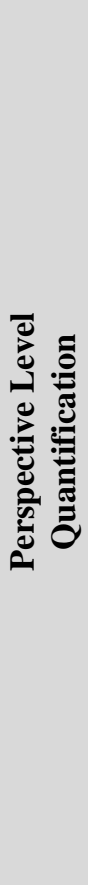 } & Expert & Organizational & Social & Technological & Market & Inconsistency \\
\hline & $\begin{array}{l}\text { Expert } \\
10\end{array}$ & 0.15 & 0.23 & 0.25 & 0.38 & 0.01 \\
\hline & $\begin{array}{l}\text { Expert } \\
11\end{array}$ & 0.12 & 0.23 & 0.29 & 0.36 & 0.06 \\
\hline & Expert 1 & 0.1 & 0.09 & 0.49 & 0.33 & 0.01 \\
\hline & Expert 2 & 0.31 & 0.05 & 0.37 & 0.28 & 0.02 \\
\hline & Expert 3 & 0.28 & 0.14 & 0.15 & 0.43 & 0.02 \\
\hline & Expert 4 & 0.16 & 0.34 & 0.09 & 0.41 & 0 \\
\hline & Expert 5 & 0.2 & 0.23 & 0.14 & 0.43 & 0.01 \\
\hline & Expert 6 & 0.1 & 0.23 & 0.23 & 0.44 & 0.02 \\
\hline & Expert 7 & 0.27 & 0.27 & 0.16 & 0.3 & 0.01 \\
\hline & Expert 8 & 0.17 & 0.18 & 0.21 & 0.44 & 0.06 \\
\hline & Expert 9 & 0.15 & 0.19 & 0.2 & 0.47 & 0.09 \\
\hline & Mean & 0.18 & 0.2 & 0.23 & 0.39 & \\
\hline & Std Dev & 0.07 & 0.08 & 0.11 & 0.06 & \\
\hline & & & & Disagreement & & 0.072 \\
\hline
\end{tabular}

Table 11: Example of Inconsistency and Disagreement

\subsubsection{Calculating the Technology Transfer Score}

The score is determined by the sum product of the success attributes and perspective weights. The weights are determined by judgment quantifications from the experts and are used as an input to calculating the overall score. The mathematical expression for calculating the score is represented by the following equation: 


$$
\begin{aligned}
& S_{n, j n}^{T T}=\sum_{n=1}^{N} \sum_{j n=1}^{J n}\left(O_{n}^{T T}\right)\left(S_{n, j n}^{O}\right) \quad \text { Equation 7 } \\
& S^{T T}{ }_{n, j n}=\text { Relative value of the } \mathrm{j}^{\text {th }} \text { success attribute under the } \mathrm{n}^{\text {th }} \text { perspective with respect to the Technology Transfer score (TT) } \\
& O_{n}{ }^{T T}=\text { Relative priority of the } \mathrm{n}^{\text {th }} \text { perspective with respect to the } \\
& \text { Technology Transfer Score (TT), } \mathrm{n}=1,2,3, . ., \mathrm{N} \\
& S^{O}{ }_{n j \text { jn }}=\text { Relative contribution of the } \mathrm{jn}^{\text {th }} \text { success attribute under } \\
& \text { the nth perspective, } \mathrm{jn}=1,2,3, \ldots, \mathrm{Jn} \text {, and } \mathrm{n}=1,2,3, \ldots \text {, } \\
& \mathrm{N}
\end{aligned}
$$

\subsubsection{Desirability Curves}

Several recent dissertations have used desirability curves as part of their research. In particular, Phan's research uses a similar approach as proposed here - development of an index using desirability curves [82]. The purpose of these curves is to identify how "desirable" or "valuable" a metric is for a decision maker. There are several ways to determine the value of a metric. These include standard gamble, constant-sum method, and graphically representing the relative value of the metric. As was done in Phan's dissertation, desirability curves for this research were developed using an expert panel, with consideration to inconsistency and disagreement.

As part of the content validation phase, subject matter experts provided their insight into the appropriateness of how each attribute is measured by a desirability curve. The measurements were determined based on one- on-one interviews with the expert panels. A sample of the quantification tool and subsequent desirability curve is provided. 


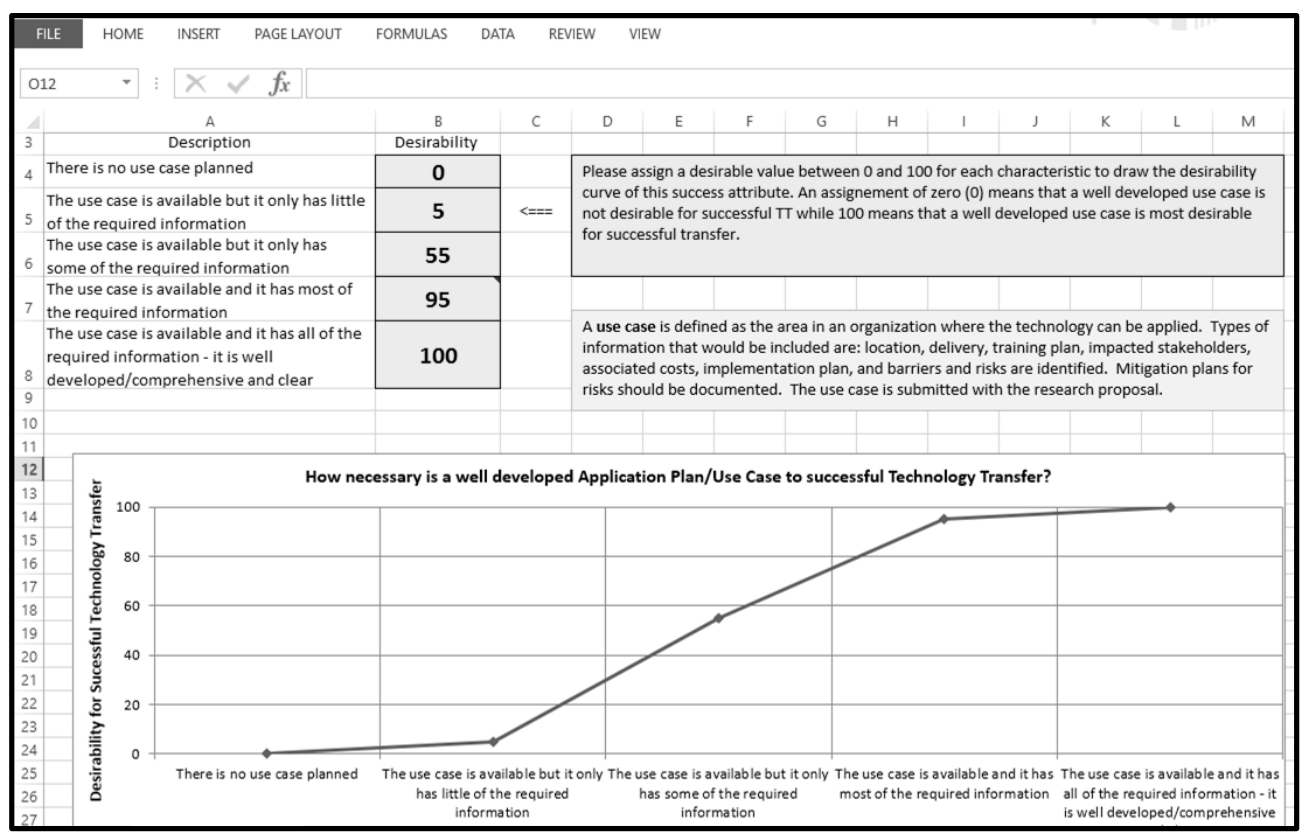

Figure 4: Template for Developing Desirability Curve

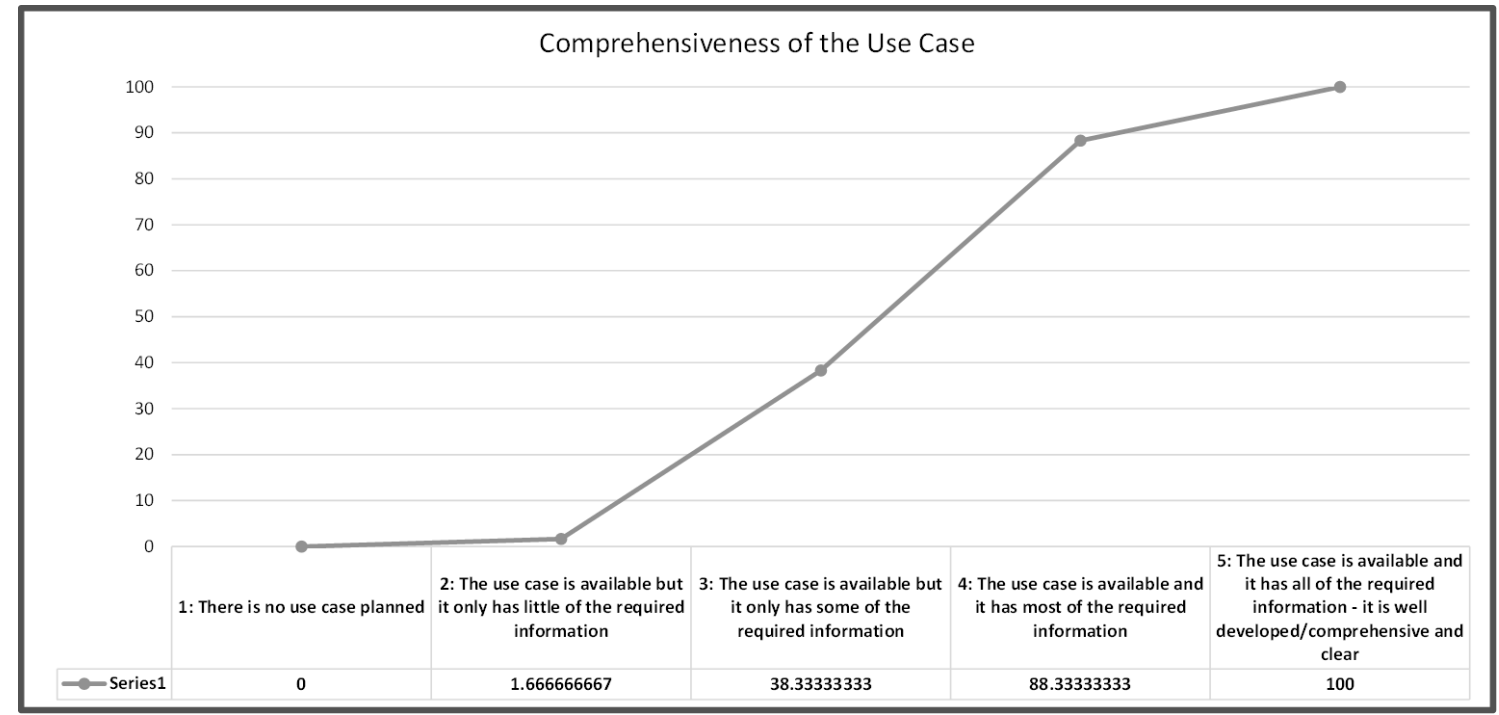

Figure 5: Sample Desirability Curve

Incorporating the influence of the desirability curves, the technology transfer score can be computed using the following mathematical representation: 


$$
\text { TT Score }=\sum_{n=1}^{N} \sum_{j n=1}^{J n}\left(S T T n,{ }_{j n}\right)\left(D n,{ }_{j n}\right) \quad \text { Equation } 8
$$

$S^{T T}{ }_{n, j n}=$ Relative value of the $\mathrm{jn}^{\text {th }}$ success attribute under the $\mathrm{n}^{\text {th }}$

$D_{n, j n}=$ Desirability value of the performance measure corresponding to

the $\mathrm{j} \mathrm{n}^{\text {th }}$ success attribute under the $\mathrm{n}^{\text {th }}$ perspective

\subsubsection{Validation of the HDM}

\section{Content Validity}

In a technical setting, content validity refers to "...test items need to reflect the knowledge actually required for a given topic area (e.g., history) or job skill (e.g., accounting)..." [87]. In other words, does the model capture the necessary elements needed to define the test subject. Specific to this research, have the appropriate perspectives and success attributes been captured to sufficiently define technology transfer?

Given these results, how can it be determined if a perspective or attribute is valid? A widely accepted method for detecting disagreement among experts is given by Lawshe [87]. Ultimately, if more than half the panelists indicate that an item is essential, then there is some validity. Higher levels of validity are achieved as more expert panel members agree. An equation for determining content validity is given by:

$$
C V R=\left(n_{e}-N / 2\right) /(N / 2) \quad \text { Equation } 9
$$

Where

$C V R=$ Content validity ratio,

$$
n_{e}=\text { Number of SME panelists indicating "essential", }
$$


$N=$ Total number of SME panelists. This formula yields values that range from +1

to -1 ; positive values indicate that at least half the SMEs rated the item as essential. Construct Validity

The proposed model needs to be reviewed for accuracy - how well does the framework fit with established theories? Is it appropriate to be used for the intended purpose - in this case as a tool to measure technology transfer potential? Subject matter experts who are familiar with decision models were asked to provide their feedback using a nominal group technique.

Criterion Related Validity

The quantified model, tested against a case study, was validated by experts to determine if the results were acceptable. The experts were asked to verify if the model could be generalized to other than the case study application. Finally, the experts were asked how the model could be implemented in their organizations and to comment on any issues or barriers to adoption.

\subsubsection{Expert Panel Development}

It would be worthwhile to start with how an expert panel is defined. A. Fink, et al, defines expert panels as “....representative of their profession, have power to implement the findings...they are not likely to be challenged as experts in the field..." [88]. Proceedings from a peer exchange on developing land use forecasts define an expert panel as " ... a group of individuals with access to current, high quality information to a related topic..." [89]. Also, this research prescribes a specific approach to forming expert panels to include: 
- The researcher has to know and communicate the big picture - being able to describe the purpose for the study ensures that the desired information is extracted.

- Design the process - what questions will each participant be asked to answer and understand how the information will be obtained. Will the results be provided anonymously, formal panel? Will there be interaction or exchange among the participants?

- The researcher should determine the size of the panel that is needed to have credible information

- The remaining steps include finalizing the panel, managing the process, and documenting the results. [89]

Critical Issues and Benefits of an Expert Panel

The land use peer proceeding discusses the benefits of an expert panel. Most importantly, the expert panel provides credibility with stakeholders [89]. Stakeholders tend to believe the outcome of research if it is substantiated by expert opinion versus relying solely on a model output or abstract analysis. The research focus of the journal articles was on forming expert panels for land use projects and the importance of an expert panel to mediate sensitive situations related to public opinion and human interface, so not technical issues. However, inferences can be drawn between land use research and developing a technology transfer score. In each case the issues are not technical ones, rather they are more concerned with qualitative measures. 
The Federal Transportation article [89] addresses a number of potential issues with using expert panels. The relationship of the expert panel to other organizations/authorities needs to be closely considered. In fact, the article states that it is almost a paradox - by definition expert panels are often and likely made of subject matter experts, intimately familiar with a topic, but their participation could give the perception of bias. The bias could be introduced if the panel was allowed to discuss responses. By doing so, the article suggests that some panel responses could be influenced by other panel participant's opinions. In addition, the amount of flexibility placed on the panel to provide additional feedback, or elaborate on a response is seen as a potential drawback. Without some flexibility, the response could be too limiting. [89] Other issues could include the availability of experts and their willingness to participate.

Okoli and Pawlowski, in their research on e-commerce in sub-Saharan Africa, outline a systematic process for selecting experts. Specifically, their process includes identifying relevant disciplines or skills by looking at their connections to organizations or practitioners. In addition, Okoli and Pawlowski recommend between 10 and 18 experts to participate in the panel. [91]

Despite the rigor that is applied to selecting a panel, inconsistency and disagreements in the responses is inevitable. The expert panels were asked to assess the relative contribution for different levels of the model using pairwise comparisons. Templates for obtaining their judgment quantification are included in Appendix D. 


\section{CHAPTER 4: DEVELOPMENT OF THE RESEARCH MODEL}

The concept of technology transfer, the attributes that are necessary for successful technology transfer and an appropriate framework to describe the relationship of these factors have been presented in the previous chapters. The objective of this chapter is to describe the expert selection criteria and how these experts were included in appropriate panels to validate and quantify the decision model.

This chapter also shows the conceptual model that was validated by the expert panels. The assessment tools that were used to capture the expert judgment are described with the actual assessment tools given in Appendix C.

\subsection{Expert Panel Formation}

This research relies heavily on expert opinion of perspectives, success attributes and methodologies related to technology transfer. Model weights are determined and desirability curves are developed by quantified expert judgments.

The previous chapter identified the issues with identifying an appropriate expert panel. These issues were considered when forming the seven panels, comprised of 53 experts; some experts served on multiple panels. One of the most critical elements was their ability and willingness to participate.

The Federal Merit Review Guide identifies eight key characteristics of expert reviewers. These include consideration of the following:

- The individual's scientific or technical education 
- The extent to which the individual has engaged in relevant work or research, the capacities in which the individual has done so, and the quality of the research work

- Relevant publications and patents, including having a significant number of peer reviewed publications

- Other evidence of a recognized expert in the field

- An advanced degree in the relevant field

- Relevant awards

- Key Society Memberships

- And the need for the review panel to include experts from various specialty areas within relevant scientific research [90]

Using these criteria as the basis for selection, the panels were developed with key experts to evaluate the decision model.

Expert panel $\mathrm{P}_{0}$ was used for the validation of the literature based hierarchical decision model. The experts were selected based on their expertise in the areas of research management and subsequent technology transfer. The panel represented practitioners from the utility industry, collaborative partners, research labs and universities.

Expert panel $\mathrm{P}_{1}$ was formed to quantify the perspective level of the decision model. Members of this panel were selected based on their senior level positions in a research management organization. 
Expert panels $\mathrm{P}_{2}$ and $\mathrm{P}_{4}$ were the same. They quantified the organizational and social perspectives of the model. The success attributes related to these perspectives have to do more with the project management and relationship-building aspects of technology transfer. The expert panel represented project managers from industry, consulting organizations, and utilities.

Expert panel $\mathrm{P}_{5}$ was asked to quantify the market perspective. The success attributes associated with this perspective are strategic in nature. Therefore, policy strategists from collaborative research partners and utility organizations were asked to participate.

Each panel participant was contacted via email or personally to determine his or her ability and willingness to participate. The face-to-face or voice communications were helpful to describe the objective of the research and to discuss the level of the model they were asked to assess. The inconsistency and disagreements in the model results suggest that this was an effective means to clarify expectations.

Those who agreed to participate returned the necessary signed consent forms. Once these were received, the researcher sent a link to a Survey Monkey assessment tool to obtain their quantified judgment. Table 13 shows how the breakdown of each panel, their job titles, and the organizations they represent.

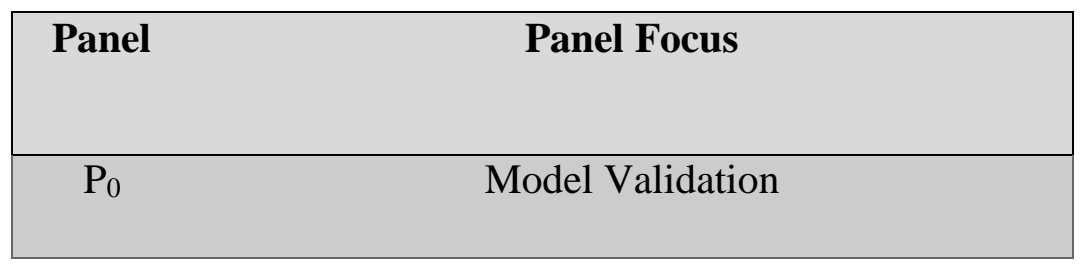




\begin{tabular}{|cc|}
\hline $\mathrm{P}_{1}$ & Perspective Level Quantification \\
\hline $\mathrm{P}_{2}$ & Organizational Strategies Quantification \\
\hline $\mathrm{P}_{3}$ & Technology Elements Quantification \\
\hline $\mathrm{P}_{4}$ & Social Strategies Quantification \\
\hline $\mathrm{P}_{5}$ & Market Readiness Quantification \\
\hline $\mathrm{P}_{6}$ & Desirability Curve Validation and Quantification \\
\hline
\end{tabular}

Table 12: Summary of Expert Panels

\begin{tabular}{|c|c|c|c|c|c|c|c|c|}
\hline Expert & Background & $\mathbf{P}_{0}$ & $\mathbf{P}_{1}$ & $\mathbf{P}_{2}$ & $\mathbf{P}_{3}$ & $\mathbf{P}_{4}$ & $\mathbf{P}_{5}$ & $\mathbf{P}_{6}$ \\
\hline E1 & Program Director, DOE & $\mathrm{x}$ & $\mathrm{x}$ & & & & & \\
\hline E2 & R\&D Chief Officer, Utility & $\mathrm{x}$ & $\mathrm{x}$ & & & & $\mathrm{x}$ & \\
\hline E3 & $\begin{array}{l}\text { Vice President, Utility R\&D } \\
\text { Cooperative }\end{array}$ & $\mathrm{x}$ & $\mathrm{x}$ & & & & & \\
\hline E4 & $\begin{array}{l}\text { Vice President, Utility R\&D } \\
\text { Cooperative }\end{array}$ & & $\mathrm{x}$ & & & & & \\
\hline E5 & Sr. Vice President, Utility & & $\mathrm{x}$ & & & & & \\
\hline E6 & Executive VP, Utility & & $\mathrm{x}$ & & & & & \\
\hline E7 & Sr. Research Scientist, National Lab & $\mathrm{x}$ & $\mathrm{x}$ & & & & & \\
\hline E8 & R\&D Executive, CAISO & & $\mathrm{x}$ & & & & & \\
\hline E9 & $\begin{array}{l}\text { Sr. Technology Transfer Manager, } \\
\text { National Lab }\end{array}$ & & $\mathrm{x}$ & & & & & \\
\hline E10 & Technology to Market Advisor, DOE & $\mathrm{x}$ & $\mathrm{x}$ & & & & & \\
\hline E11 & $\begin{array}{l}\text { Vice President Technology } \\
\text { Management, Utility R\&D } \\
\text { Cooperative }\end{array}$ & $\mathrm{x}$ & $\mathrm{x}$ & & & & & \\
\hline E12 & Sr. Analyst, NW Power Council & & & & & & $\mathrm{x}$ & \\
\hline E13 & Sr. Analyst, Utility & & & & & & $\mathrm{x}$ & \\
\hline E14 & Executive VP, Utility & & & & & & $\mathrm{x}$ & $\mathrm{x}$ \\
\hline E15 & Policy Strategist, Utility & & & & & & $\mathrm{x}$ & $\mathrm{x}$ \\
\hline E17 & Manager, Power Resources, Utility & & & & & & $\mathrm{x}$ & \\
\hline E18 & Public Utilities Specialist, Utility & & & & & & $\mathrm{x}$ & \\
\hline E19 & Director of Retail Programs, Utility & & & & & & $\mathrm{x}$ & \\
\hline E20 & Sr. Public Utilities Specialist, Utility & & & & & & $\mathrm{x}$ & $\mathrm{x}$ \\
\hline E21 & Project Manager, Industry & & & $\mathrm{x}$ & & $\mathrm{x}$ & & \\
\hline E22 & Project Manager, Utility & & & $\mathrm{x}$ & & $\mathrm{x}$ & & \\
\hline E23 & Project Manager, Consulting Services & & & $\mathrm{x}$ & & $\mathrm{x}$ & & $\mathrm{X}, \mathrm{X}$ \\
\hline E24 & Project Manager, Industry & & & $\mathrm{x}$ & & $\mathrm{x}$ & & \\
\hline E25 & Professor, University & & & $\mathrm{x}$ & & $\mathrm{x}$ & & \\
\hline E26 & Sr. Instructor, University & & & $\mathrm{x}$ & & $\mathrm{x}$ & & \\
\hline E27 & Project Manager, Industry & & & $\mathrm{x}$ & & $\mathrm{x}$ & & \\
\hline E28 & Project Manager, Industry & & & $\mathrm{x}$ & & $\mathrm{x}$ & & \\
\hline E29 & Project Manager, Industry & & & $\mathrm{x}$ & & $\mathrm{x}$ & & $\mathrm{X}, \mathrm{X}$ \\
\hline
\end{tabular}




\begin{tabular}{|c|c|c|c|c|c|c|c|c|}
\hline Expert & Background & $\mathbf{P}_{0}$ & $\mathbf{P}_{1}$ & $\mathbf{P}_{2}$ & $\mathbf{P}_{3}$ & $\mathbf{P}_{4}$ & $\mathbf{P}_{5}$ & $\mathbf{P}_{6}$ \\
\hline E30 & Project Manager, Utility & & & $\mathrm{x}$ & & $\mathrm{x}$ & & \\
\hline E31 & Project Manager, Consulting Services & & & $\mathrm{x}$ & & $\mathrm{x}$ & & \\
\hline E32 & Project Manager, Industry & & & $\mathrm{x}$ & & $\mathrm{x}$ & & \\
\hline E33 & Project Manager, Utility & $\mathrm{x}$ & & $\mathrm{x}$ & & $\mathrm{x}$ & & $\mathrm{x}, \mathrm{x}$ \\
\hline E34 & $\begin{array}{l}\text { Demand Response Program Manager, } \\
\text { Utility }\end{array}$ & & & & $\mathrm{x}$ & & & \\
\hline E35 & Principal Investigator, Utility & & & & $\mathrm{x}$ & & & \\
\hline E36 & $\begin{array}{l}\text { Technical Executive, Utility R\&D } \\
\text { Cooperative }\end{array}$ & & & & $\mathrm{x}$ & & & $\mathrm{x}$ \\
\hline E37 & Assistant Prof, University & & & & $\mathrm{x}$ & & & \\
\hline E38 & Principal Investigator, Utility & & & & $\mathrm{x}$ & & & \\
\hline E39 & Assistant Prof, University & & & & $\mathrm{x}$ & & & $\mathrm{x}$ \\
\hline E40 & Principal Investigator, Utility & & & & $\mathrm{x}$ & & & \\
\hline E41 & Principal Investigator, Utility & & & & $\mathrm{x}$ & & & $\mathrm{x}$ \\
\hline E42 & Principal Investigator, National Lab & & & & $\mathrm{x}$ & & & \\
\hline E43 & $\begin{array}{l}\text { Principal Investigator, Utility R\&D } \\
\text { Cooperative }\end{array}$ & & & & $\mathrm{x}$ & & & \\
\hline E44 & R\&D Manager, Utility & $\mathrm{x}$ & & & & & & \\
\hline E45 & $\begin{array}{l}\text { Technology Transfer Manager, Utility } \\
\text { R\&D Cooperative }\end{array}$ & $\mathrm{x}$ & & & & & & \\
\hline E46 & R\&D Executive Consultant & $\mathrm{x}$ & & & & & & \\
\hline E47 & $\begin{array}{l}\text { Sr. R\&D Technical Advisor, Utility } \\
\text { R\&D Cooperative }\end{array}$ & $\mathrm{x}$ & & & & & & \\
\hline E48 & Professor, University & $\mathrm{x}$ & & & & & & \\
\hline E49 & R\&D Manager, Utility & $\mathrm{x}$ & & & & & & \\
\hline E50 & R\&D Manager, Utility & $\mathrm{x}$ & & & & & & \\
\hline E51 & R\&D Manager, Utility & $\mathrm{x}$ & & & & & & \\
\hline E52 & R\&D Manager, Utility & $\mathrm{x}$ & & & & & & \\
\hline E53 & R\&D Manager, Utility & $\mathrm{x}$ & & & & & & \\
\hline E54 & $\begin{array}{l}\text { Sr. R\&D Technical Advisor, Utility } \\
\text { R\&D Cooperative }\end{array}$ & $\mathrm{x}$ & & & $\mathrm{x}$ & & & \\
\hline \multicolumn{2}{|r|}{$\begin{array}{ll}\text { TOTAL } \\
\end{array}$} & 18 & 11 & 13 & 11 & 13 & 9 & 9 \\
\hline
\end{tabular}

Table 13: Expert Panels

\subsection{Conceptual HDM}

The decision model was based on the comprehensive literature review that was described in Chapter 2. The perspective level was based on the assembly of several taxonomies to identify logical groupings of technology transfer success attributes.

Secondly, the corresponding success attributes were grouped under the appropriate perspective. The alternative level is represented as the proposals that are being 
considered for a research portfolio. Using this model, each proposal will have an associated technology transfer score.

During the model development process, subject matter experts from panel $\mathrm{P}_{0}$ provided input on the overall organization and nomenclature of the model. The terminology used for the literature-based model was polished, with consideration to the essence of the definitions presented to the expert panel. There were several iterations of the model before the final one was determined. Using a Survey Monkey tool, the experts were asked if the framework was appropriate for assessing technology transfer potential of a research proposal. They responded with "Yes" or "No" for each perspective and associated success attribute. In addition, the expert panel had the opportunity to provide comments to further explain their response. Verbatim responses for the content validation phase are presented in Chapter 5. Recent dissertations that used decision modeling and expert quantification identified an acceptance level of $2 / 3$ to determine if attributes were appropriate for their decision models. Using this criterion, a final, validated model was developed. The finalized model is shown in Figure 6. This model served as the basis for soliciting quantified judgments to determine relative contributions of success factors to the perspectives, and the perspective's contributions to the mission of developing a technology transfer score. 


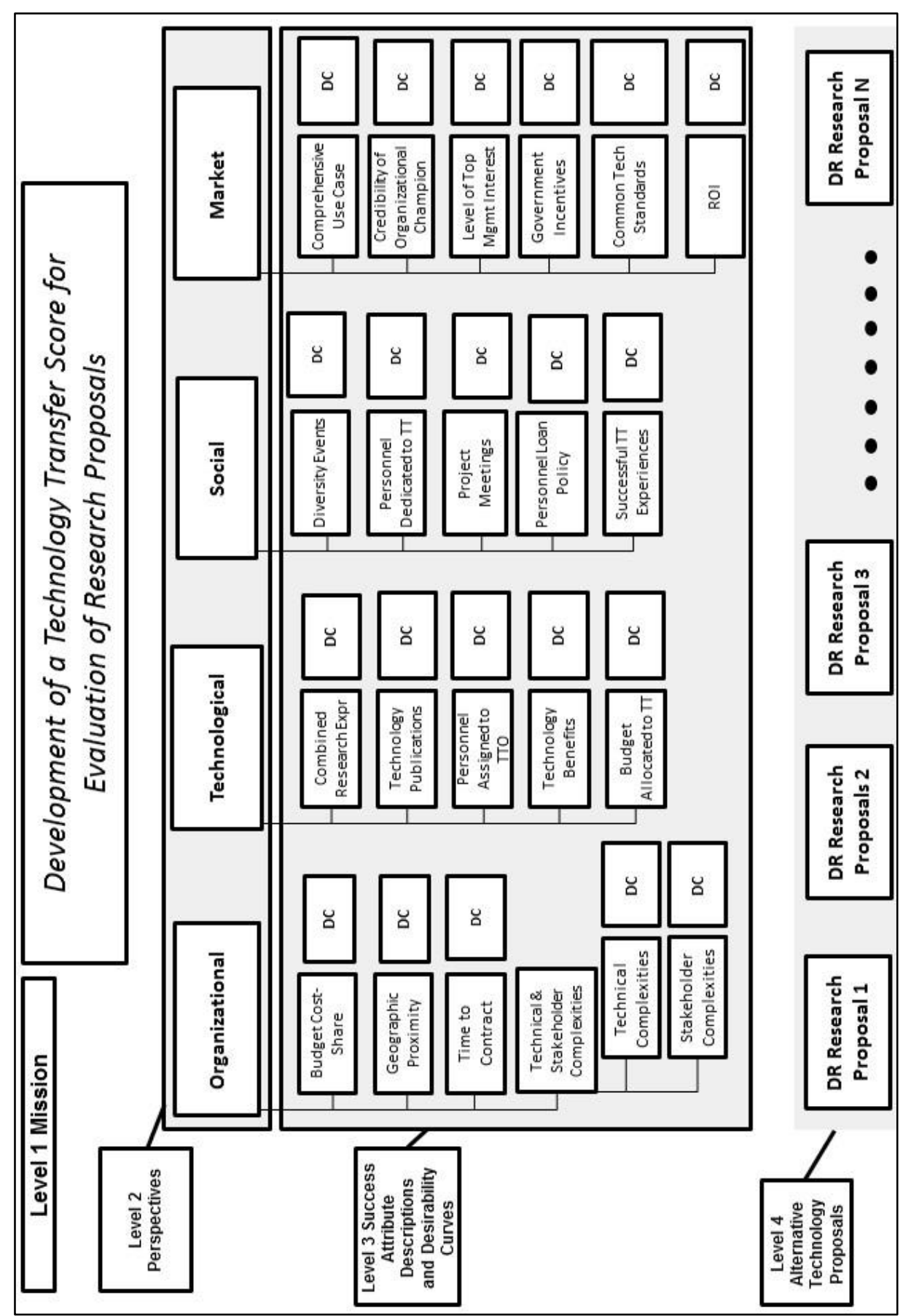

Figure 6: Validated Model 


\subsubsection{Mission Level}

The mission level states the objective of this research. That is to develop a technology transfer score, using a decision model, that can be used to evaluate research proposals. For the purposes of this research, the model will be validated with a case study from the utility industry. The case study will involve mature (high TRL) demand response research proposals for application in the Pacific Northwest. While the case study is specific to the utility industry, the model can be adapted for use by other research organizations, similar to those described in the introduction chapter, and for any technology readiness level.

\subsubsection{Perspective Level}

The perspective level was based on logical groupings of the literature review on success attributes. The perspectives are a combination of Linstone, Bozeman, and Greiner, Franza's methodologies.

1. The organizational perspective refers to the actions between the research organization and the technology recipient. For the purposes of this research the organizations include five likely research partners: Universities, Collaborative Partnerships (Electric Power Research Institute (EPRI), etc.), National Labs (Lawrence Berkley, Pacific Northwest National, etc.), Industry Partners (Intel, IBM, etc.), and other utilities (So Cal Edison, Consolidated Edison, etc.). 
2. The technology perspective considers actions related to the technology as important for successful technology transfer. It is not about the technical characteristics, rather it is about how the technology is communicated (e.g. through demonstrations, marketing through the Technology Transfer Office, etc.)

3. The emphasis on the social perspective is how to develop and maintain a relationship between the researchers and recipients such that technology transfer is more likely to occur.

4. The Market perspective assesses the market's readiness to accept the new technology - has a market-pull be sufficiently created such that it (the market) has a need established and assessed for the technology?

\subsubsection{Success Attribute Level}

The success attributes extend the perspectives into unique factors that are necessary for technology transfer. The measurements for each success attribute are characterized in Table 14.

\begin{tabular}{|c|c|c|}
\hline \multirow{5}{*}{ 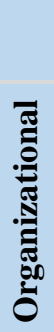 } & Success Attributes & Units of Measurement \\
\hline & Budget Cost-Share & $\%$ cost share required to fund research \\
\hline & Geographic Proximity & relative proximity between research and recipient \\
\hline & Time to Contract & time to execute a contract \\
\hline & $\begin{array}{l}\text { Technical \& Stakeholder } \\
\text { Complexity }\end{array}$ & $\begin{array}{l}\text { \# of technical characteristics identified in proposal } \\
\text { and \# of impacted stakeholders }\end{array}$ \\
\hline \multirow{2}{*}{ 䒿 } & Diversity Events & \# of diversity events to create cultural awareness \\
\hline & Personnel Integral to TT & \# of people dedicated to support TT \\
\hline
\end{tabular}




\begin{tabular}{|c|c|c|}
\hline & Success Attributes & Units of Measurement \\
\hline & Project Meetings & \# of comms described in the comm project plan \\
\hline & $\begin{array}{l}\text { Personnel Loaned to } \\
\text { Recipient }\end{array}$ & time that researchers are loaned to help with TT \\
\hline & Successful TT Awards & \# of previous successful TT \\
\hline \multirow{5}{*}{ 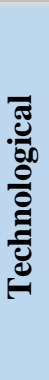 } & $\begin{array}{l}\text { Combined Research } \\
\text { Experience }\end{array}$ & \# years of cooperative experience of principles \\
\hline & Technology Publications & \# publications about technology \\
\hline & $\begin{array}{l}\text { Personnel Assigned to } \\
\text { TTO }\end{array}$ & personnel assigned to TTO \\
\hline & Technology Benefits & $\begin{array}{l}\text { \# technology benefits identified in the research } \\
\text { proposal }\end{array}$ \\
\hline & Budget Allocated to TT & $\%$ R\&D budget dedicated to TTO activities \\
\hline \multirow{6}{*}{ 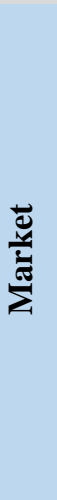 } & Comprehensive Use Case & How well is the use Case Defined \\
\hline & $\begin{array}{l}\text { Credibility of } \\
\text { Organizational Champion }\end{array}$ & Credibility of the Organizational Champion \\
\hline & $\begin{array}{l}\text { Level of Top Management } \\
\text { Interest }\end{array}$ & Level of Organizational Support for TT \\
\hline & Government Incentives & \# of government incentives \\
\hline & $\begin{array}{l}\text { Common Technology } \\
\text { Standards }\end{array}$ & How are common standards supported \\
\hline & ROI & ROI \\
\hline
\end{tabular}

Table 14: Success Attribute Measurements

\subsubsection{Alternative Level - Research Proposals}

The research proposals that were used to validate the model are discussed in detail in Chapter 6. Referring to Table 14 the source column indicates where the data are obtained to evaluate the contributions of each success attribute. The term "research proposal" in the SOURCE column of Table 14 means that the information is available in the proposals that were used for the model validation. If the source of the data is shown as Research Organization or Recipient, this means that the respective 
organization had to be contacted to obtain the data. Also, some success attribute measurements were publicly available.

\subsection{Data Collection}

Section 4.2 described the acceptance criteria for model validation. Eighteen experts responded to validate the model. Because of the expert's suggestions, one success attribute was omitted from the model. The attribute was organizational homogeneity. The researcher moved forward with data collection after that attribute was removed.

For all subsequent data collection efforts, Survey Monkey® was used. Each assessment tool included an introduction, a description of the elements to assess or compare, and an example of how to do a pairwise comparison. Equation 10 gives the number of comparisons each expert would make for "n" elements:

$$
\frac{n(n-1)}{2} \quad \text { Equation } 10
$$

The first assessment tool asked Expert Panel $\mathrm{P}_{1}$ to provide quantified judgments for relative contribution of each perspective to the mission. The experts considered how much each perspective contributes to technology transfer, in comparison to other perspectives. There was a total of six comparisons for four perspectives.

Assessment tools for weighting the importance of each success attribute within the corresponding perspective contained similar instructions except that the success attribute definitions changed depending on which panel was assessing which perspective. 
Expert panels $\mathrm{P}_{2}$ and $\mathrm{P} 4$ were asked to assess the contribution of organizational and social perspectives. For the organizational perspective, there were a total of six comparisons for four success attributes and the social perspective had 10 comparisons for five success attributes. For the organizational and social perspectives, the expert panel was asked to compare the relative importance of each success attribute. The experts considered which success attribute contributed more to enhancing the organizational effectiveness and therefore contributing to successful technology transfer. Similar comparisons were made for the social perspective success attributes.

Expert panel $\mathrm{P}_{3}$ was asked to assess the contribution of the success attributes of the Technology perspective. There were 10 comparisons for five success attributes.

Expert panel P5 was asked to assess the contribution of the success attributes of the Market perspective. There were 15 comparisons for six success attributes.

Each assessment tool is provided in Appendix D. 


\section{CHAPTER 5: RESULTS OF MODEL QUANTIFICATION}

This chapter provides the outcomes of model validation, the pairwise comparisons of the expert panels for all levels of the model quantification, and desirability curves. The output is a quantified model with the associated weights for perspectives and success attributes. The model is presented at the end of the chapter. Inconsistency and disagreements are discussed as appropriate.

\subsection{Content Validation}

Panel $\mathrm{P}_{0}$ consisted of 18 participants who had a broad overview of the technology transfer process. They are senior level personnel who have extensive research management experience, starting with the $R \& D$ project through technology transfer. The panel was asked to comment on the model structure and content. The assessment tool was intended to capture their judgment of the suitability of the proposed perspectives and success attributes, and identify those that might have gone undetected during the literature review. They were asked if the proposed perspectives and success attributes were appropriate for developing a technology transfer score, and if not, why. They were also given an opportunity to comment on other attributes that were not presented. The following graphs show their assessments. A $2 / 3$ majority was necessary to keep the attribute. 


\subsubsection{Perspective Level}

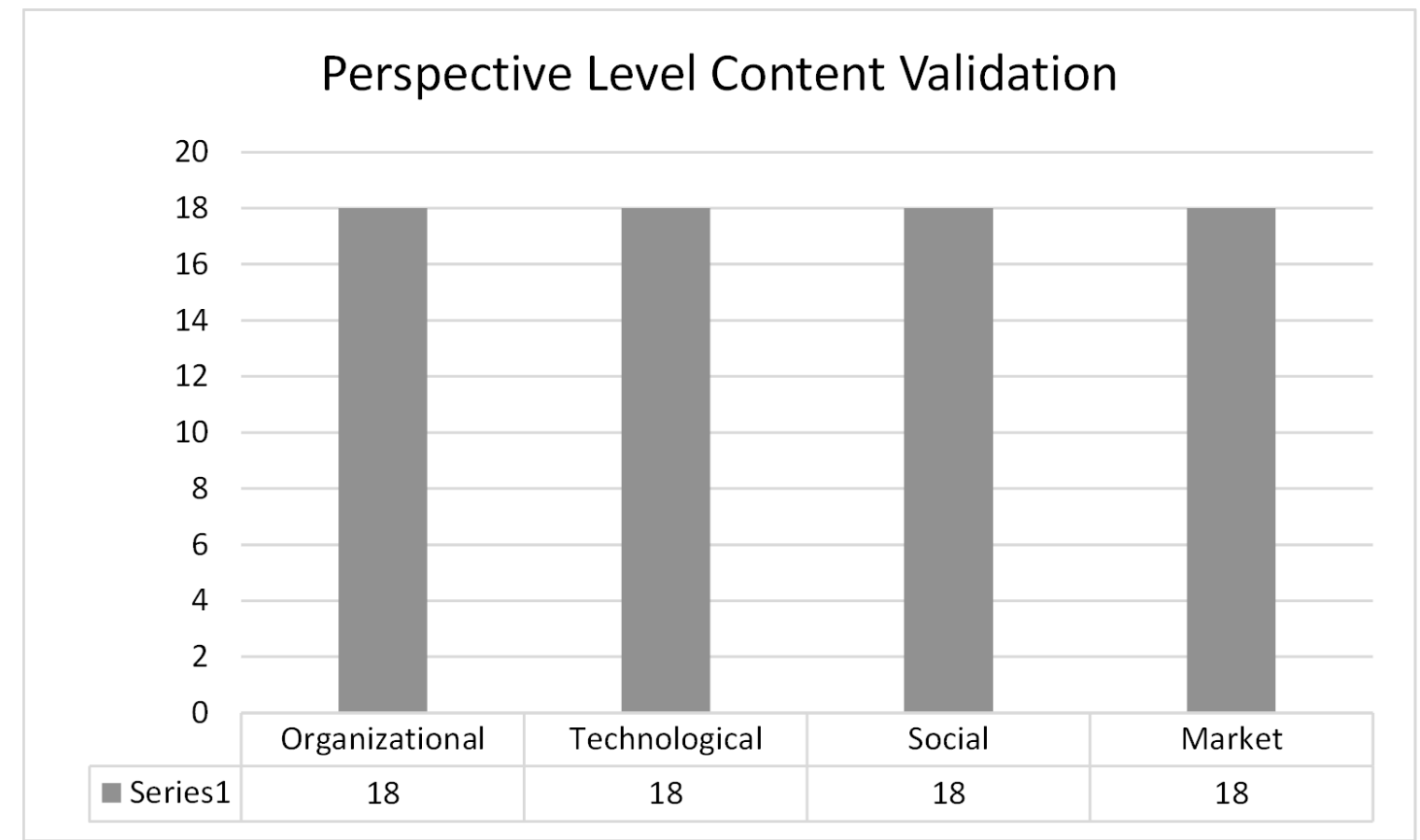

Figure 7: Perspective Validation Results

All experts agreed that the perspectives were appropriate for assessing technology

transfer. There were some general comments about needing to consider cost vs. benefit, the maturity of the technology, and to engage stakeholders early in the R\&D process. There were also many comments, about the importance of the market for technology transfer. These responses were captured as success attributes under the Market perspective. Also, the technology maturity is addressed in the case studies - more mature technologies were selected to test the model. 


\subsubsection{Organizational Success Attributes}

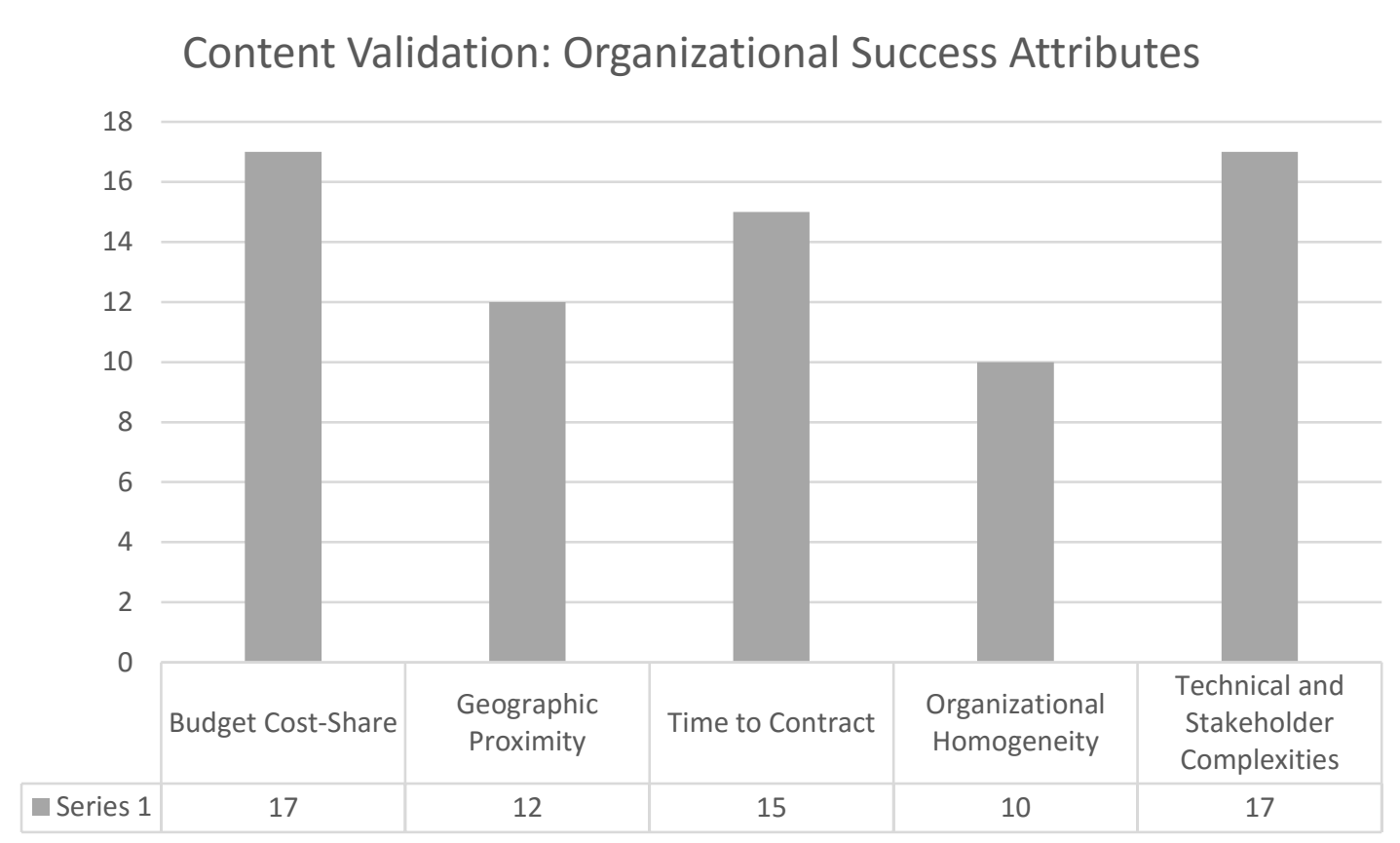

Figure 8: Organizational Strategies Success Attributes Validation

The success attributes for the Organizational perspective are related to the relationship between the researcher and technology recipient organizations. In general, the expert panel agreed with the success attributes associated with the Organizational perspective, except for organizational homogeneity. The expert panel thought that too much similarity between the research organization and the technology recipient could actually be an impediment, “...The organization taking technology to market should be very different than the $\mathrm{R} \& \mathrm{D}$ organization. They have a much different purpose and may be much smaller...” [Expert 7]. Another expert stated “...sometimes I have observed that large organizations have trouble working with each other. The organizations can have established processes, cultures, etc. that are not easily changed..." [Expert 1]. 
Therefore, organizational homogeneity was removed from the model since it did not meet the $67 \%$ criterion.

\subsubsection{Technology Success Attributes}

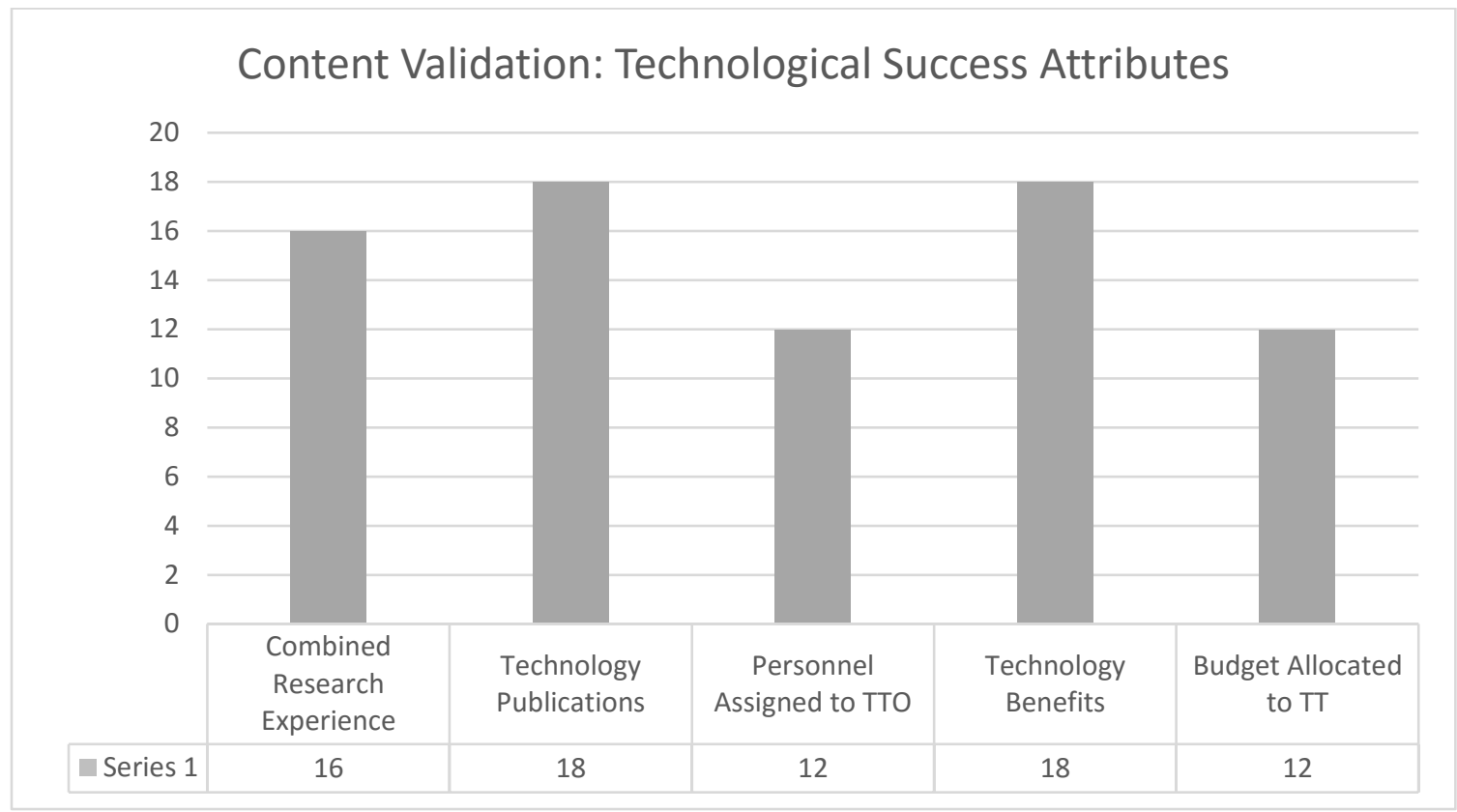

Figure 9: Technological Success Attributes Validation

The success attributes for the Technological perspective describe qualitative attributes about the technology and support a technology-push environment. The expert panel agreed with the success attributes assigned to the Technology perspective. For the two that were low, Personnel Assigned to TTO and Budget Allocated to TT, the expert comments included “...In this highly technical field, marketing and TTO are much less important than development of technologies that are known to meet emerging needs and that can be communicated on a technical level to the actual practitioners that will utilize the new technology. In some cases, those practitioners are averse to overt marketing and sales if it is not underpinned with obvious technical competence...." [Expert 54]. The 
term "much more important..." will be captured when expert panels will be asked to quantify, or rank, the success attributes, relative to others in the same perspective.

\subsubsection{Social Success Attributes}

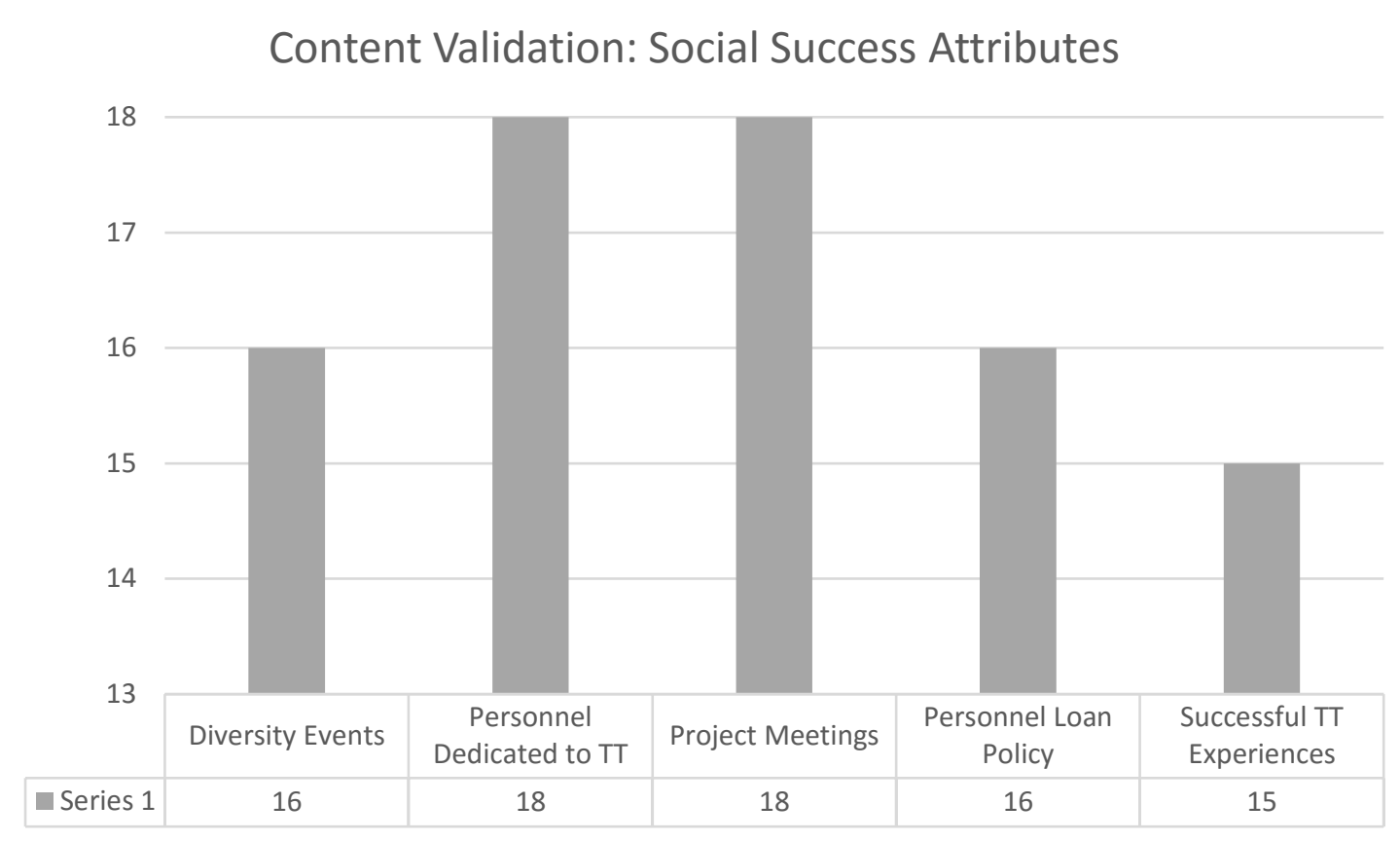

Figure 10: Social Success Attributes Validation

The success attributes for the Social perspective are related to the personnel involved with technology transfer. The experts agreed that the success attributes assigned to the Social perspective are appropriate for assessing technology transfer. Regarding diversity events as it relates to cultural awareness, one expert commented that, “...Although cultural awareness is important ..., I don't think it is at the same level of importance as the other categories. Something that measures an atmosphere of innovation would be interesting..." [Expert 3] 
Three experts did not think that successful technology transfer experiences were necessary for success. Expert 49 commented, “...the organization's culture should nurture innovative thinking. Rewarding seems like an afterthought.”

\subsubsection{Market Success Attributes}

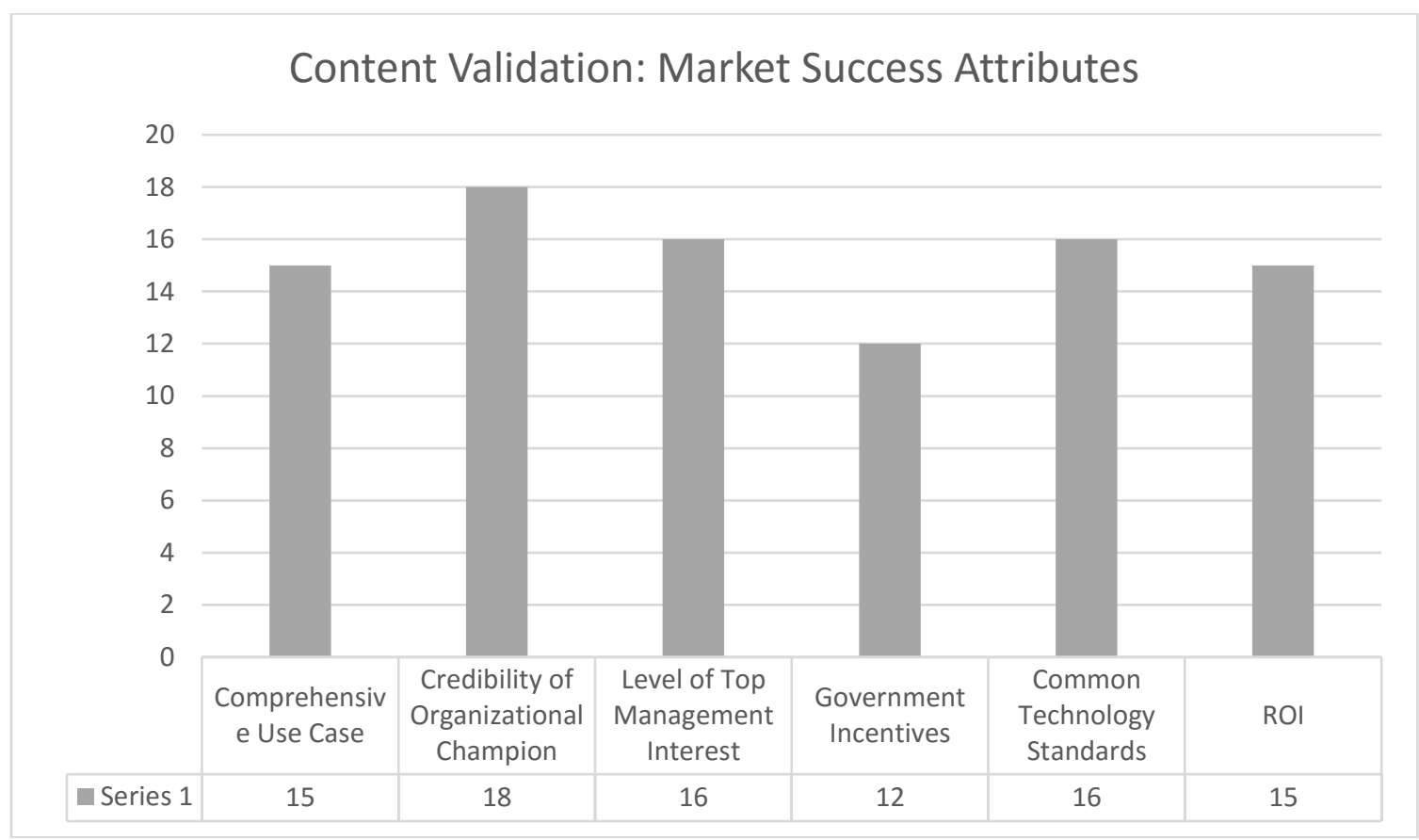

Figure 11: Market Success Attributes Validation

The success attributes for the Market perspective are related to creating a market for the technology. Again, we see general agreement among the expert panel regarding Market perspective success attributes. Government incentives is the attribute where there was the least agreement. Expert 44 commented that, “...For the Government Subsidy, I disagreed because that is really around making it more economical. A broader "Regulatory Support" might be better as in California with batteries pushing emerging markets. The subsidy itself would be the same as a 
breakthrough in technology reducing the cost." Expert 51 felt that government incentives were a subset of determining financial feasibility.

The next section presents the pairwise comparisons to determine the weights of the decision model. The expert panels identified in Chapter 4 were sent invitation letters to participate in the model quantification phase. Once their confirmation was received, they were sent a link to a Survey Monkey® assessment tool where they were asked to conduct a series of pairwise comparisons. The assessment tool included an example of how to complete an assessment as well as definitions of the elements that were being evaluated. The panels were asked distribute 100 points between two perspectives or success attributes, depending on the panel. This data was transcribed to the Hierarchical Decision Model Software $($ C to determine the weights for each assessment, the inconsistency, and disagreement. F-Test data is also provided.

\subsection{Perspective Level Quantification}

Panel $\mathrm{P}_{1}$ consisted of 11 participants. They were asked to compare the contribution of the four perspectives to the overall objective of defining a score to assess technology transfer potential. The experts completed six comparisons to determine the output shown in Table 15. 


\begin{tabular}{|c|c|c|c|c|c|c|}
\hline \multirow{15}{*}{ 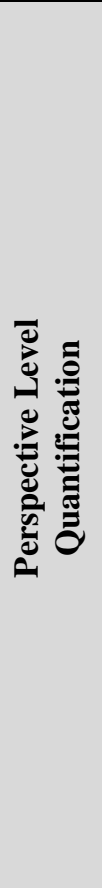 } & Expert & Organizational & Social & Technological & Market & Inconsistency \\
\hline & $\begin{array}{l}\text { Expert } \\
10\end{array}$ & 0.15 & 0.23 & 0.25 & 0.38 & 0.01 \\
\hline & $\begin{array}{l}\text { Expert } \\
11\end{array}$ & 0.12 & 0.23 & 0.29 & 0.36 & 0.06 \\
\hline & Expert 1 & 0.1 & 0.09 & 0.49 & 0.33 & 0.01 \\
\hline & Expert 2 & 0.31 & 0.05 & 0.37 & 0.28 & 0.02 \\
\hline & Expert 3 & 0.28 & 0.14 & 0.15 & 0.43 & 0.02 \\
\hline & Expert 4 & 0.16 & 0.34 & 0.09 & 0.41 & 0 \\
\hline & Expert 5 & 0.2 & 0.23 & 0.14 & 0.43 & 0.01 \\
\hline & Expert 6 & 0.1 & 0.23 & 0.23 & 0.44 & 0.02 \\
\hline & Expert 7 & 0.27 & 0.27 & 0.16 & 0.3 & 0.01 \\
\hline & Expert 8 & 0.17 & 0.18 & 0.21 & 0.44 & 0.06 \\
\hline & Expert 9 & 0.15 & 0.19 & 0.2 & 0.47 & 0.09 \\
\hline & Mean & 0.18 & 0.2 & 0.23 & 0.39 & \\
\hline & Std Dev & 0.07 & 0.08 & 0.11 & 0.06 & \\
\hline & & & & Disagreement & & 0.072 \\
\hline \multicolumn{2}{|c|}{ Source of Variation } & Sum of Squar & \multicolumn{2}{|c|}{$\begin{array}{l}\text { Degrees of } \\
\text { Freedom }\end{array}$} & Mean Square & $\begin{array}{l}\text { F-Test } \\
\text { Value }\end{array}$ \\
\hline \multicolumn{2}{|c|}{ Between Subjects } & 0.29 & \multicolumn{2}{|l|}{3} & 0.97 & 10.02 \\
\hline \multicolumn{2}{|c|}{ Between Conditions } & 0.00 & \multicolumn{2}{|l|}{10} & 0.000 & \\
\hline \multicolumn{2}{|c|}{ Residual } & 0.29 & \multicolumn{2}{|l|}{30} & 0.010 & \\
\hline \multicolumn{2}{|l|}{ Total } & 0.58 & \multicolumn{2}{|l|}{43} & & \\
\hline \multicolumn{6}{|c|}{ Critical F value with degrees of freedom $3 \& 30$ at 0.01 level: } & 4.51 \\
\hline \multicolumn{6}{|c|}{ Critical F value with degrees of freedom $3 \& 30$ at 0.025 level: } & 3.59 \\
\hline \multicolumn{6}{|c|}{ Critical $F$ value with degrees of freedom $3 \& 30$ at 0.05 level: } & 2.92 \\
\hline \multicolumn{6}{|c|}{ Critical F value with degrees of freedom $3 \& 30$ at 0.1 level: } & 2.28 \\
\hline
\end{tabular}

Table 15: Perspective Level Quantification

The inconsistency within each expert is acceptable (all $<0.10)$. Using F-Test data, the null hypothesis $\left(\mathrm{H}_{\mathrm{o}}=\right.$ there are disagreements among the experts $)$ can be rejected at the 0.01 level. The between subjects F-Test value is 10, while the critical F value at the 0.01 level is 4.51 . This expert panel assessed the Market perspective as most important (0.39) 


\subsection{Success Attribute Quantification}

\subsubsection{Organizational Perspective}

Panel $\mathrm{P}_{2}$ consisted of 13 participants. They were asked to assess the relative contribution of the four success attributes to the Organizational perspective. The experts completed six comparisons to determine the output shown in Table 16.

\begin{tabular}{|c|c|c|c|c|c|c|}
\hline \multirow{17}{*}{ 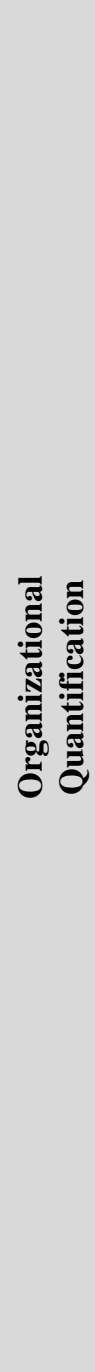 } & Expert & $\begin{array}{c}\text { Budget } \\
\text { Cost- } \\
\text { Share }\end{array}$ & $\begin{array}{l}\text { Geographic } \\
\text { Proximity }\end{array}$ & $\begin{array}{l}\text { Time to } \\
\text { Contract }\end{array}$ & $\begin{array}{c}\text { Technical/Stakeholder } \\
\text { Complexities }\end{array}$ & Inconsistency \\
\hline & $\begin{array}{l}\text { Expert } \\
29\end{array}$ & 0.2 & 0.29 & 0.22 & 0.29 & 0.06 \\
\hline & $\begin{array}{l}\text { Expert } \\
30\end{array}$ & 0.22 & 0.08 & 0.33 & 0.37 & 0.01 \\
\hline & $\begin{array}{l}\text { Expert } \\
31\end{array}$ & 0.34 & 0.22 & 0.13 & 0.31 & 0.09 \\
\hline & $\begin{array}{l}\text { Expert } \\
32\end{array}$ & 0.29 & 0.2 & 0.06 & 0.45 & 0.1 \\
\hline & $\begin{array}{l}\text { Expert } \\
33\end{array}$ & 0.25 & 0.15 & 0.31 & 0.28 & 0 \\
\hline & $\begin{array}{l}\text { Expert } \\
21\end{array}$ & 0.14 & 0.22 & 0.48 & 0.16 & 0.01 \\
\hline & $\begin{array}{l}\text { Expert } \\
22\end{array}$ & 0.22 & 0.1 & 0.26 & 0.42 & 0.02 \\
\hline & $\begin{array}{l}\text { Expert } \\
23\end{array}$ & 0.2 & 0.17 & 0.17 & 0.46 & 0.03 \\
\hline & $\begin{array}{l}\text { Expert } \\
24\end{array}$ & 0.42 & 0.14 & 0.23 & 0.22 & 0.01 \\
\hline & $\begin{array}{l}\text { Expert } \\
25\end{array}$ & 0.09 & 0.15 & 0.11 & 0.66 & 0.02 \\
\hline & $\begin{array}{l}\text { Expert } \\
26\end{array}$ & 0.29 & 0.08 & 0.29 & 0.34 & 0.01 \\
\hline & $\begin{array}{l}\text { Expert } \\
27\end{array}$ & 0.19 & 0.39 & 0.24 & 0.18 & 0.13 \\
\hline & $\begin{array}{l}\text { Expert } \\
28\end{array}$ & 0.26 & 0.29 & 0.12 & 0.32 & 0.01 \\
\hline & Mean & 0.24 & 0.19 & 0.23 & 0.34 & \\
\hline & Std Dev & 0.08 & 0.09 & 0.11 & 0.13 & \\
\hline & & & & & Disagreement & 0.095 \\
\hline \multicolumn{2}{|c|}{$\begin{array}{l}\text { Source of } \\
\text { Variation }\end{array}$} & \multicolumn{2}{|c|}{$\begin{array}{l}\text { Sum of } \\
\text { Square }\end{array}$} & $\begin{array}{l}\text { Degrees of } \\
\text { Freedom }\end{array}$ & Mean Square & F-Test Value \\
\hline
\end{tabular}




\begin{tabular}{|l|l|l|l|l|}
\hline $\begin{array}{l}\text { Between } \\
\text { Subjects }\end{array}$ & 0.21 & 3 & 0.071 & 4.88 \\
\hline $\begin{array}{l}\text { Between } \\
\text { Conditions }\end{array}$ & 0.00 & 11 & 0.000 & \\
\hline Residual & 0.48 & 33 & 0.015 & \\
\hline Total & 0.69 & 47 & & \\
\hline Critical F value with degrees of freedom 3 \& 33 at 0.01 level: & 4.44 \\
\hline Critical F value with degrees of freedom 3 \& 33 at 0.025 level: & 3.54 \\
\hline Critical F value with degrees of freedom 3 \& 33 at 0.05 level: & 2.89 \\
\hline Critical F value with degrees of freedom 3 \& 33 at 0.1 level: & 2.26 \\
\hline
\end{tabular}

Table 16: Organizational Success Attribute Quantification

The inconsistency within each expert is acceptable $($ all < 0.10$)$ for all experts except Expert 27 (0.13); there was slight inconsistency. The impact of Expert 27's inconsistency was determined not to have an impact on the overall rank of the success attributes - the assessment was removed and the rank of the success attributes remained the same. Using F-Test data, the null hypothesis $\left(\mathrm{H}_{\mathrm{o}}=\right.$ there are disagreements among the experts) can be rejected at the 0.01 level. The between subjects F-Test value is 4.88 , while the critical $\mathrm{F}$ value at the 0.01 level is 4.44 . This expert panel assessed the Technical and Stakeholder Complexities as contributing the most to the Organizational perspective (0.34).

\subsubsection{Technological Perspective}

Panel $\mathrm{P}_{3}$ consisted of 11 participants. They were asked to assess the relative contribution of the five success attributes to the Technological perspective. The experts completed 10 comparisons to determine the output shown in Table 17. 


\begin{tabular}{|c|c|c|c|c|c|c|c|}
\hline \multirow{15}{*}{ 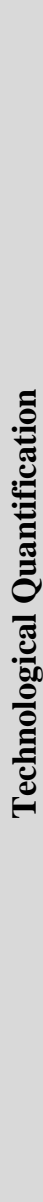 } & Expert & $\begin{array}{l}\text { Combined } \\
\text { Research } \\
\text { Experience }\end{array}$ & $\begin{array}{l}\text { Tech } \\
\text { Pubs }\end{array}$ & $\begin{array}{l}\text { Personnel } \\
\text { Assigned to } \\
\text { TTO }\end{array}$ & $\begin{array}{c}\text { Tech } \\
\text { Benefits }\end{array}$ & $\begin{array}{c}\text { Budgeted } \\
\text { Allocated to } \\
\text { TT }\end{array}$ & Inconsistency \\
\hline & $\begin{array}{l}\text { Expert } \\
43\end{array}$ & 0.23 & 0.15 & 0.15 & 0.36 & 0.1 & 0 \\
\hline & $\begin{array}{l}\text { Expert } \\
54\end{array}$ & 0.1 & 0.33 & 0.07 & 0.4 & 0.11 & 0.01 \\
\hline & $\begin{array}{l}\text { Expert } \\
34\end{array}$ & 0.11 & 0.26 & 0.14 & 0.4 & 0.08 & 0.03 \\
\hline & $\begin{array}{l}\text { Expert } \\
35\end{array}$ & 0.19 & 0.31 & 0.14 & 0.21 & 0.15 & 0.01 \\
\hline & $\begin{array}{l}\text { Expert } \\
36\end{array}$ & 0.2 & 0.2 & 0.06 & 0.44 & 0.1 & 0.02 \\
\hline & $\begin{array}{l}\text { Expert } \\
37\end{array}$ & 0.35 & 0.14 & 0.19 & 0.17 & 0.15 & 0.1 \\
\hline & $\begin{array}{l}\text { Expert } \\
38\end{array}$ & 0.09 & 0.18 & 0.4 & 0.27 & 0.06 & 0.06 \\
\hline & $\begin{array}{l}\text { Expert } \\
39\end{array}$ & 0.36 & 0.1 & 0.08 & 0.36 & 0.09 & 0 \\
\hline & $\begin{array}{l}\text { Expert } \\
40\end{array}$ & 0.14 & 0.27 & 0.36 & 0.14 & 0.08 & 0.02 \\
\hline & $\begin{array}{l}\text { Expert } \\
41\end{array}$ & 0.1 & 0.2 & 0.19 & 0.45 & 0.06 & 0.04 \\
\hline & $\begin{array}{l}\text { Expert } \\
42\end{array}$ & 0.11 & 0.3 & 0.11 & 0.34 & 0.13 & 0.01 \\
\hline & Mean & 0.18 & 0.22 & 0.17 & 0.32 & 0.1 & \\
\hline & Std Dev & 0.09 & 0.07 & 0.11 & 0.1 & 0.03 & \\
\hline & & & & & \multicolumn{2}{|r|}{ Disagreement } & 0.082 \\
\hline \multicolumn{2}{|c|}{$\begin{array}{l}\text { Source of } \\
\text { Variation }\end{array}$} & \multicolumn{2}{|c|}{$\begin{array}{l}\text { Sum of } \\
\text { Square }\end{array}$} & \multicolumn{2}{|c|}{$\begin{array}{l}\text { Degrees of } \\
\text { Freedom }\end{array}$} & Mean Square & F-Test Value \\
\hline \multicolumn{2}{|c|}{$\begin{array}{l}\text { Between } \\
\text { Subjects }\end{array}$} & \multicolumn{2}{|l|}{0.29} & 4 & \multicolumn{2}{|c|}{0.72} & 7.1 \\
\hline \multicolumn{2}{|c|}{$\begin{array}{l}\text { Between } \\
\text { Conditions }\end{array}$} & \multicolumn{2}{|l|}{0.00} & 10 & \multicolumn{2}{|c|}{0.000} & \\
\hline \multicolumn{2}{|c|}{ Residual } & \multicolumn{2}{|l|}{0.41} & 40 & \multicolumn{2}{|c|}{0.010} & \\
\hline \multicolumn{4}{|c|}{ Total } & & & & \\
\hline $\mathrm{Cr}$ & tical F v & ue with de & es of & eedom 4 \& & 0 at 0.01 & level: & 3.83 \\
\hline $\mathrm{Cr}$ & tical F v & ue with de & es of & eedom 4 \& & 0 at 0.02 & level: & 3.13 \\
\hline $\mathrm{Cr}$ & tical F v & ue with de & es of & eedom 4 \& & 0 at 0.05 & level: & 2.61 \\
\hline $\mathrm{Cr}$ & tical F v & ue with de & es of & eedom 4 \& & 0 at 0.1 & vel: & 2.09 \\
\hline
\end{tabular}

Table 17: Technological Success Attribute Quantification 
The inconsistency within each expert is acceptable (all < 0.10). Using F-Test data, the null hypothesis $\left(\mathrm{H}_{\mathrm{o}}=\right.$ there are disagreements among the experts $)$ can be rejected at the 0.01 level. The between subjects F-Test value is 7.1, while the critical F value at the 0.01 level is 3.83 . This expert panel assessed the technology benefits as most important (0.32)

\subsubsection{Social Perspective}

Panel $\mathrm{P}_{4}$ consisted of 13 participants. They were asked to assess the relative contribution of the five success attributes to the Social perspective. The experts completed 10 comparisons to determine the output shown in Table 18. 


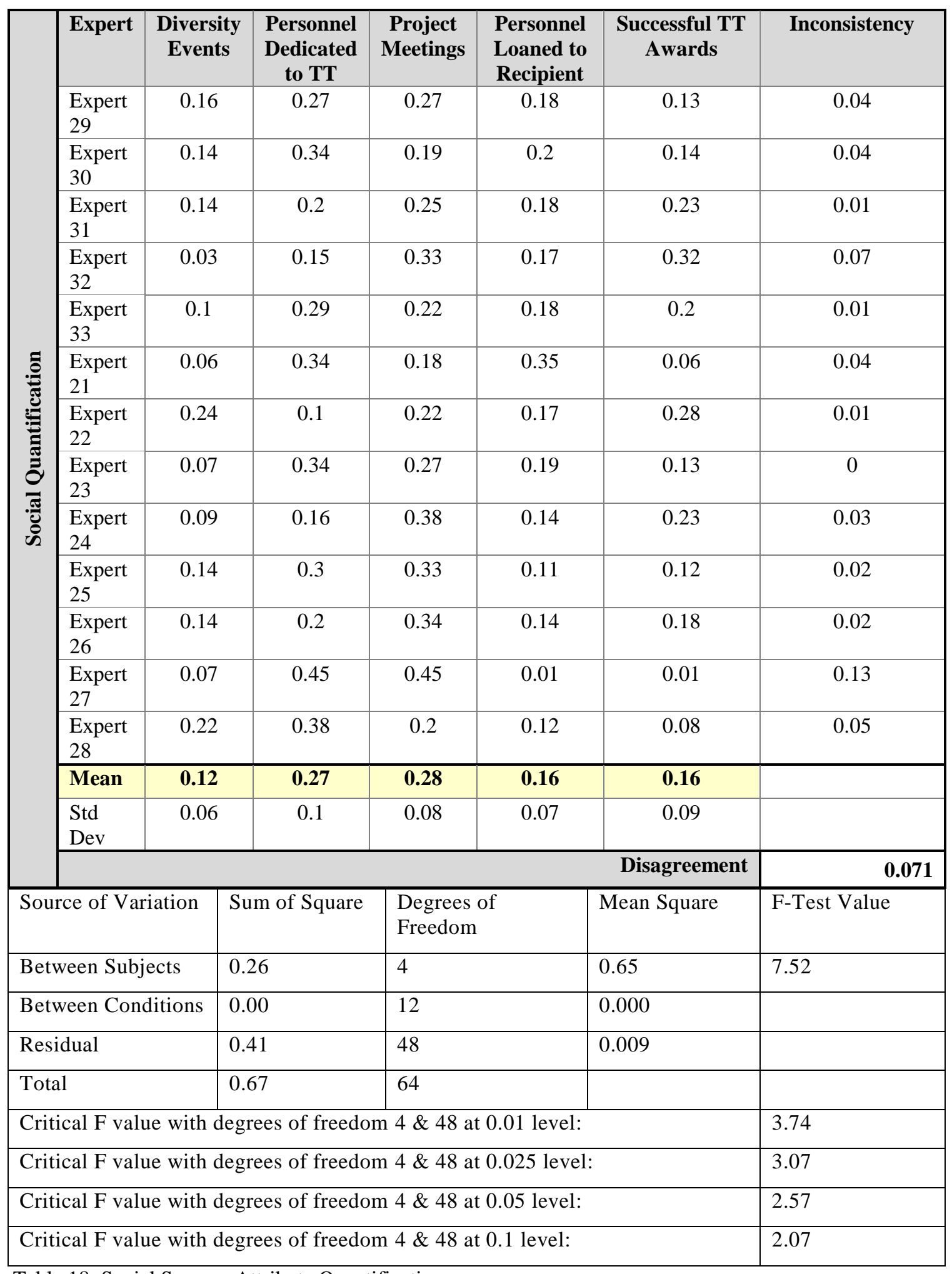

Table 18: Social Success Attribute Quantification 
The inconsistency within each expert is acceptable $($ all $<0.10)$ for all experts except Expert 27 (0.13); there was some inconsistency. Similar to Organizational success attribute assessments, the impact of Expert 27's inconsistency was determined not to have an impact on the overall rank of the success attributes - the assessment was removed and the rank of the success attributes remained the same. Using F-Test data, the null hypothesis $\left(\mathrm{H}_{\mathrm{o}}=\right.$ there are disagreements among the experts $)$ can be rejected at the 0.01 level. The between subjects F-Test value is 7.52 , while the critical F value at the 0.01 level is 3.74. This expert panel assessed Project Meetings as contributing the most to the Social perspective (0.28). However, this is only slightly higher than personnel dedicated to the technology transfer activities (0.27).

\subsubsection{Market Perspective}

Panel $\mathrm{P}_{5}$ consisted of nine participants. They were asked to assess the relative contribution of the six success attributes to the Market perspective. The experts completed 15 comparisons to determine the output shown in Table 19.

\begin{tabular}{|c|c|c|c|c|c|c|c|c|}
\hline \multirow{8}{*}{ 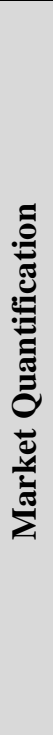 } & Expert & $\begin{array}{l}\text { Comp } \\
\text { Use } \\
\text { Case }\end{array}$ & $\begin{array}{l}\text { Credibility } \\
\text { of Org } \\
\text { Champion }\end{array}$ & $\begin{array}{c}\text { Level of } \\
\text { Top Mgmt } \\
\text { Interest }\end{array}$ & $\begin{array}{l}\text { Government } \\
\text { Incentives }\end{array}$ & $\begin{array}{l}\text { Common } \\
\text { Tech } \\
\text { Standards }\end{array}$ & ROI & Inconsistency \\
\hline & $\begin{array}{l}\text { Expert } \\
12\end{array}$ & 0.17 & 0.17 & 0.17 & 0.04 & 0.05 & 0.4 & 0 \\
\hline & $\begin{array}{l}\text { Expert } \\
13\end{array}$ & 0.14 & 0.1 & 0.19 & 0.11 & 0.25 & 0.18 & 0.02 \\
\hline & $\begin{array}{l}\text { Expert } \\
14\end{array}$ & 0.31 & 0.11 & 0.18 & 0.02 & 0.09 & 0.28 & 0.01 \\
\hline & $\begin{array}{l}\text { Expert } \\
15\end{array}$ & 0.12 & 0.12 & 0.29 & 0.07 & 0.26 & 0.13 & 0.04 \\
\hline & $\begin{array}{l}\text { Expert } \\
17\end{array}$ & 0.01 & 0.08 & 0.05 & 0.35 & 0.33 & 0.16 & 0.08 \\
\hline & $\begin{array}{l}\text { Expert } \\
18\end{array}$ & 0.1 & 0.19 & 0.18 & 0.07 & 0.15 & 0.31 & 0.01 \\
\hline & $\begin{array}{l}\text { Expert } \\
19\end{array}$ & 0.14 & 0.23 & 0.36 & 0.04 & 0.06 & 0.16 & 0.02 \\
\hline
\end{tabular}




\begin{tabular}{|c|c|c|c|c|c|c|c|}
\hline $\begin{array}{l}\text { Expert } \\
20\end{array}$ & 0.11 & 0.05 & 0.37 & 0.11 & 0.14 & 0.21 & 0.07 \\
\hline $\begin{array}{l}\text { Expert } \\
2\end{array}$ & 0.25 & 0.22 & 0.19 & 0.05 & 0.04 & 0.24 & 0.05 \\
\hline Mean & 0.15 & 0.14 & 0.22 & 0.1 & 0.16 & 0.23 & \\
\hline $\begin{array}{l}\text { Std } \\
\text { Dev }\end{array}$ & 0.08 & 0.06 & 0.09 & 0.09 & 0.1 & 0.08 & \\
\hline & & & & & \multicolumn{2}{|c|}{ Disagreement } & 0.082 \\
\hline \multicolumn{2}{|c|}{ Source of Variation } & Sum of Square & \multicolumn{2}{|c|}{$\begin{array}{l}\text { Degrees of } \\
\text { Freedom }\end{array}$} & \multicolumn{2}{|c|}{\begin{tabular}{l|} 
Mean Square \\
\end{tabular}} & F-Test Value \\
\hline \multicolumn{2}{|c|}{ Between Subjects } & 0.12 & \multicolumn{2}{|l|}{5} & \multicolumn{2}{|l|}{0.024} & 2.3 \\
\hline \multicolumn{2}{|c|}{ Between Conditions } & 0.00 & \multicolumn{2}{|l|}{8} & \multicolumn{2}{|l|}{0.000} & \\
\hline \multicolumn{2}{|l|}{ Residual } & 0.41 & \multicolumn{2}{|l|}{40} & \multicolumn{2}{|l|}{0.010} & \\
\hline \multicolumn{2}{|l|}{ Total } & 0.53 & \multicolumn{2}{|l|}{53} & & & \\
\hline \multicolumn{7}{|c|}{ Critical F value with degrees of freedom $3 \& 30$ at 0.01 level: } & 3.51 \\
\hline \multicolumn{7}{|c|}{ Critical F value with degrees of freedom $3 \& 30$ at 0.025 level: } & 2.9 \\
\hline \multicolumn{7}{|c|}{ Critical F value with degrees of freedom $3 \& 30$ at 0.05 level: } & 2.45 \\
\hline \multicolumn{7}{|c|}{ Critical F value with degrees of freedom $3 \& 30$ at 0.1 level: } & 2 \\
\hline
\end{tabular}

Table 19: Market Success Attribute Quantification

The inconsistency within each expert is acceptable (all <0.10). Using F-Test data, the null hypothesis $\left(\mathrm{H}_{\mathrm{o}}=\right.$ there are disagreements among the experts $)$ can be rejected at the 0.1 level. The between subjects F-Test value is 2.3 , while the critical $\mathrm{F}$ value at the 0.1 level is 2 . This expert panel assessed the ROI as most important (0.23). However, this is only slightly higher than the Level of Top Management Interest (0.22).

\subsubsection{Final Model Weights}

Table 20 summarizes the output of expert judgment quantification. The most important perspective is market with a value of 0.39 and the corresponding most important success attribute is determining financial feasibility by assessing the ROI (0.23). This is followed closely by level of top management interest (0.22). In order 
of contribution to developing a technology transfer score, technological, social, and organizational are next important. Within each perspective, the associated success attribute with the highest score supports the concept described in literature as important, that is building a relationship is necessary for successful technology transfer. For example, in organizational perspective, technical and stakeholder complexities are most important. In the technological perspective, describing the technology benefits ranked highest. Finally, in the social perspective, project team meetings to facilitate communication and develop trust is the most important success attribute. 


\begin{tabular}{|c|c|c|c|c|c|c|}
\hline \multirow[b]{2}{*}{ Perspectives } & \multirow[b]{2}{*}{ Value } & \multicolumn{4}{|c|}{ Success Attributes } & \multirow{2}{*}{$\begin{array}{c}\text { Success } \\
\text { Attribute } \\
\text { Global Value - } \\
\text { Contribution to } \\
\text { TT Score } \\
\end{array}$} \\
\hline & & Attribute & \multicolumn{3}{|c|}{ Local Value } & \\
\hline \multirow{5}{*}{ Organizational } & \multirow{5}{*}{0.18} & Budget Cost-Share & 0.24 & & & 0.043 \\
\hline & & $\begin{array}{l}\text { Geographic } \\
\text { Proximity }\end{array}$ & 0.19 & & & 0.034 \\
\hline & & Time to Contract & 0.23 & & & 0.041 \\
\hline & & \multirow{2}{*}{$\begin{array}{l}\text { Technical \& } \\
\text { Stakeholder } \\
\text { Complexities }\end{array}$} & \multirow{2}{*}{0.34} & $\begin{array}{c}\text { Technical } \\
\text { Complexities }\end{array}$ & 0.50 & 0.031 \\
\hline & & & & $\begin{array}{c}\text { Stakeholder } \\
\text { Complexities }\end{array}$ & 0.50 & 0.031 \\
\hline \multirow{5}{*}{ Technological } & \multirow{5}{*}{0.23} & $\begin{array}{l}\text { Combined Research } \\
\text { Experience }\end{array}$ & 0.22 & & & 0.041 \\
\hline & & $\begin{array}{l}\text { Technology } \\
\text { Publications }\end{array}$ & 0.22 & & & 0.051 \\
\hline & & $\begin{array}{c}\text { Personnel Assigned } \\
\text { to TTO }\end{array}$ & 0.17 & & & 0.039 \\
\hline & & Technology Benefits & 0.32 & & & 0.074 \\
\hline & & $\begin{array}{c}\text { Budget Allocated to } \\
\text { TT }\end{array}$ & 0.10 & & & 0.023 \\
\hline \multirow{5}{*}{ Social } & \multirow{5}{*}{0.20} & Diversity Events & 0.12 & & & 0.024 \\
\hline & & $\begin{array}{c}\text { Personnel Dedicated } \\
\text { to TT }\end{array}$ & 0.27 & & & 0.054 \\
\hline & & Project Meetings & 0.28 & & & 0.056 \\
\hline & & $\begin{array}{l}\text { Personnel Loan } \\
\text { Policy }\end{array}$ & 0.16 & & & 0.032 \\
\hline & & $\begin{array}{l}\text { Successful TT } \\
\text { Experiences }\end{array}$ & 0.16 & & & 0.032 \\
\hline \multirow{6}{*}{ Market } & \multirow{6}{*}{0.39} & Use Case & 0.15 & & & 0.058 \\
\hline & & $\begin{array}{c}\text { Organizational } \\
\text { Champion }\end{array}$ & 0.14 & & & 0.055 \\
\hline & & $\begin{array}{l}\text { Level of Top Mgmt } \\
\text { Interest }\end{array}$ & 0.22 & & & 0.086 \\
\hline & & $\begin{array}{c}\text { Government } \\
\text { Incentives }\end{array}$ & 0.1 & & & 0.039 \\
\hline & & $\begin{array}{l}\text { Common } \\
\text { Technology } \\
\text { Standards }\end{array}$ & 0.16 & & & 0.062 \\
\hline & & ROI & 0.23 & & & 0.089 \\
\hline Total & 1.0 & & & & & 1.0 \\
\hline
\end{tabular}

Table 20: Final Model Weights 


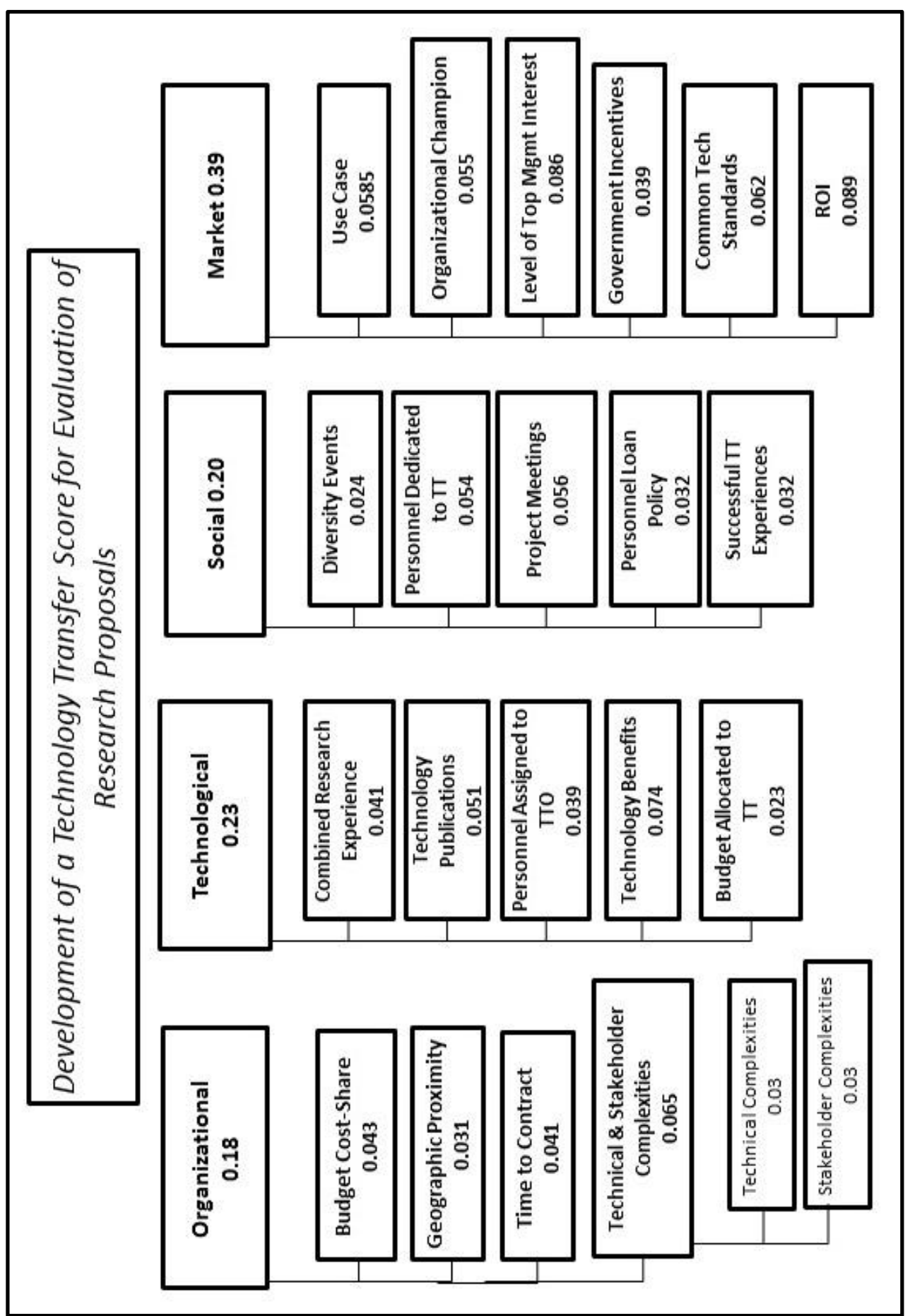

Figure 12: Weighted Model 


\subsection{Desirability Curves}

There were nine experts on panel $\mathrm{P}_{6}$ who validated and quantified the desirability curves. These experts were subsets of panels $\mathrm{P}_{2}-\mathrm{P}_{5}$. A significant amount of care was taken when working with the experts to explain the purpose of desirability curves and how they are developed. The researcher completed the desirability curves through a faceto-face meeting with the expert or via a phone conversation.

The graphical method was used to develop the curves. Participants were asked the desirability of a success attribute on a score of $0-100$. The arithmetic mean of their responses, for each success attribute, determined the overall desirability. Figures $13-33$ show the results of the desirability curves for each of the 20 success attributes.

\subsubsection{Organizational Success Attributes}

\section{Budget Cost Share Desirability Curve}

The measurement for budget cost share is the percentage of cost share that is required by the researcher to fund the project. The expert panel was asked to determine the intermediate desirability values between "no cost share required" with a desirability of 100 and " $100 \%$ of the funding comes from the cost-share by the researcher" with a desirability of zero. 


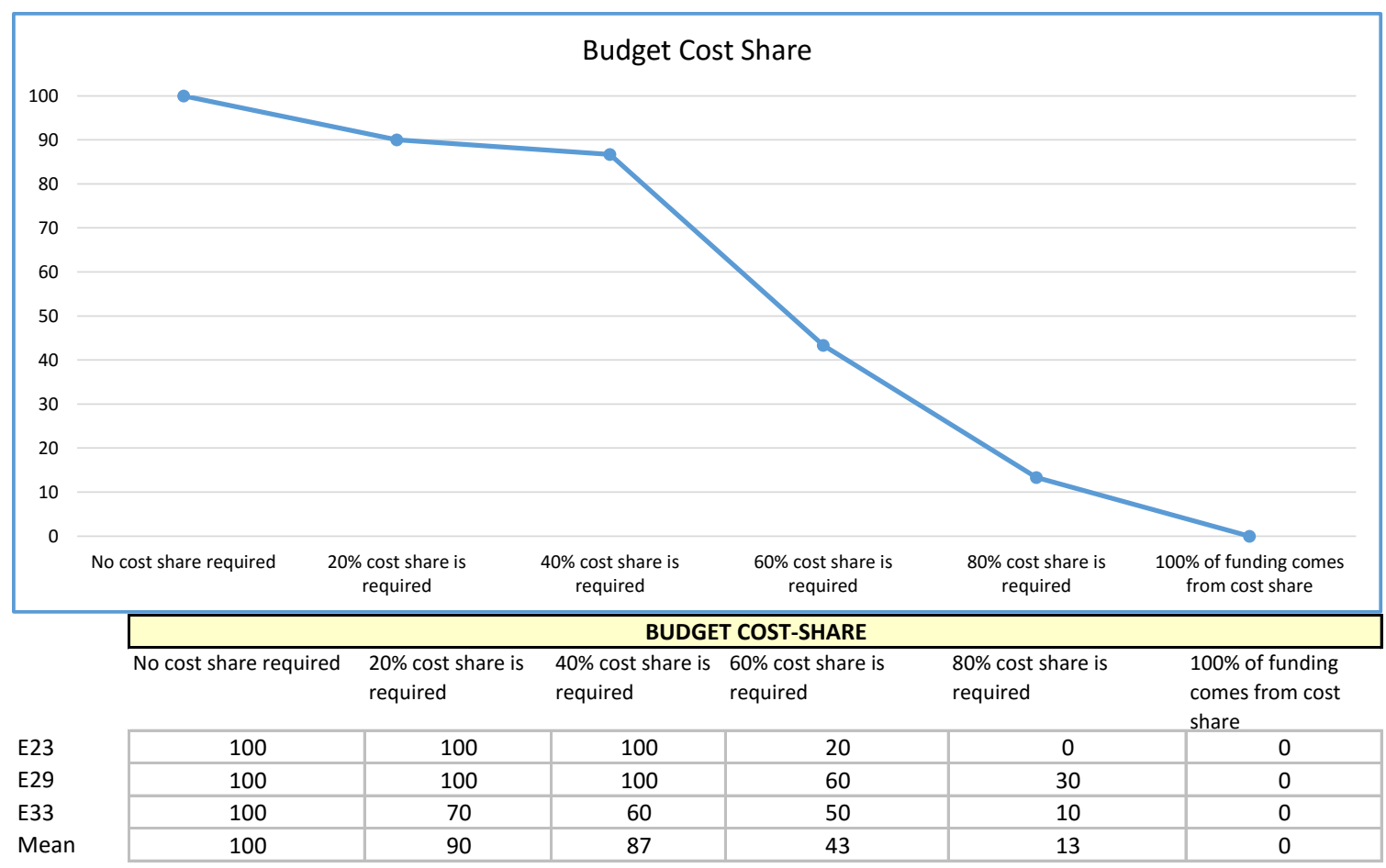

Figure 13: Budget Cost Share Desirability Curve 


\section{Geographic Proximity}

The measurement for geographic proximity is the distance between the researcher and the technology recipient. The expert panel was asked to develop the desirability curve for ranges of 0-10 miles to greater than 3000 miles. $0-10$ miles is the most desirable while greater than 3000 miles is the least desirable measure.

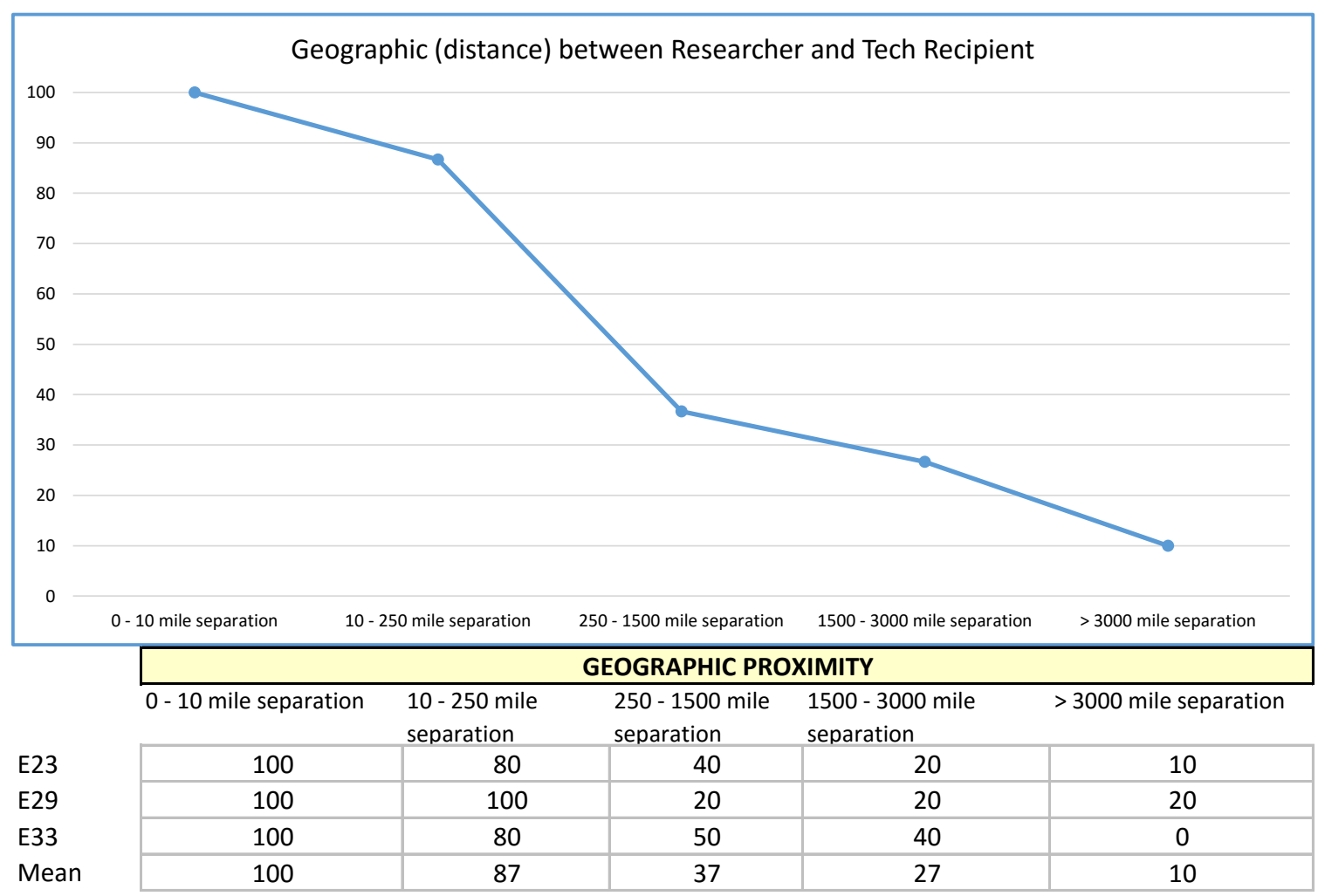

Figure 14: Geographic Proximity Desirability Curve 


\section{Average Time to Contract}

The measurement for average time to contract is the average time for the technology recipient to execute a contract with a researcher. If there is no prior experience with the researcher, it would be an estimate of the average time similar contracts took to execute; similar is defined as the same type of organization (e.g. university, utility, industry, national lab, collaborative research partner). The expert panel was asked to determine the desirability curve between 0.5 month and a contract execution time of greater than one year.

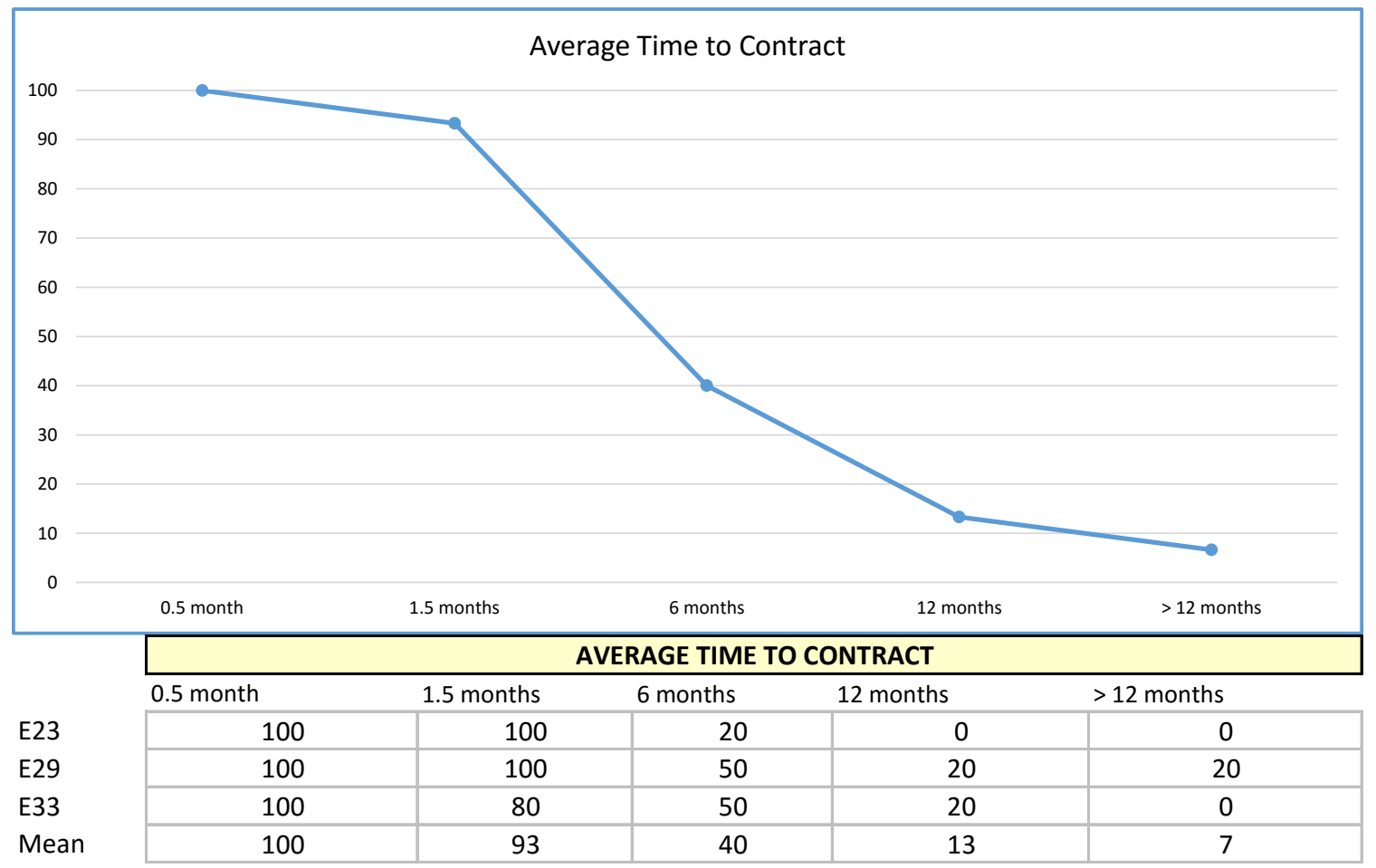

Figure 15: Average Time to Contract Desirability Curve 


\section{Technical Complexity}

The measurement for technical complexity is the number of technology characteristics the proposal addresses. For the case study, the technology characteristics are identified in the technology roadmaps of the recipient organization. The expert panel was asked to determine the desirability curve between the proposal addressing one technology characteristic to the proposal addressing more than five characteristics.

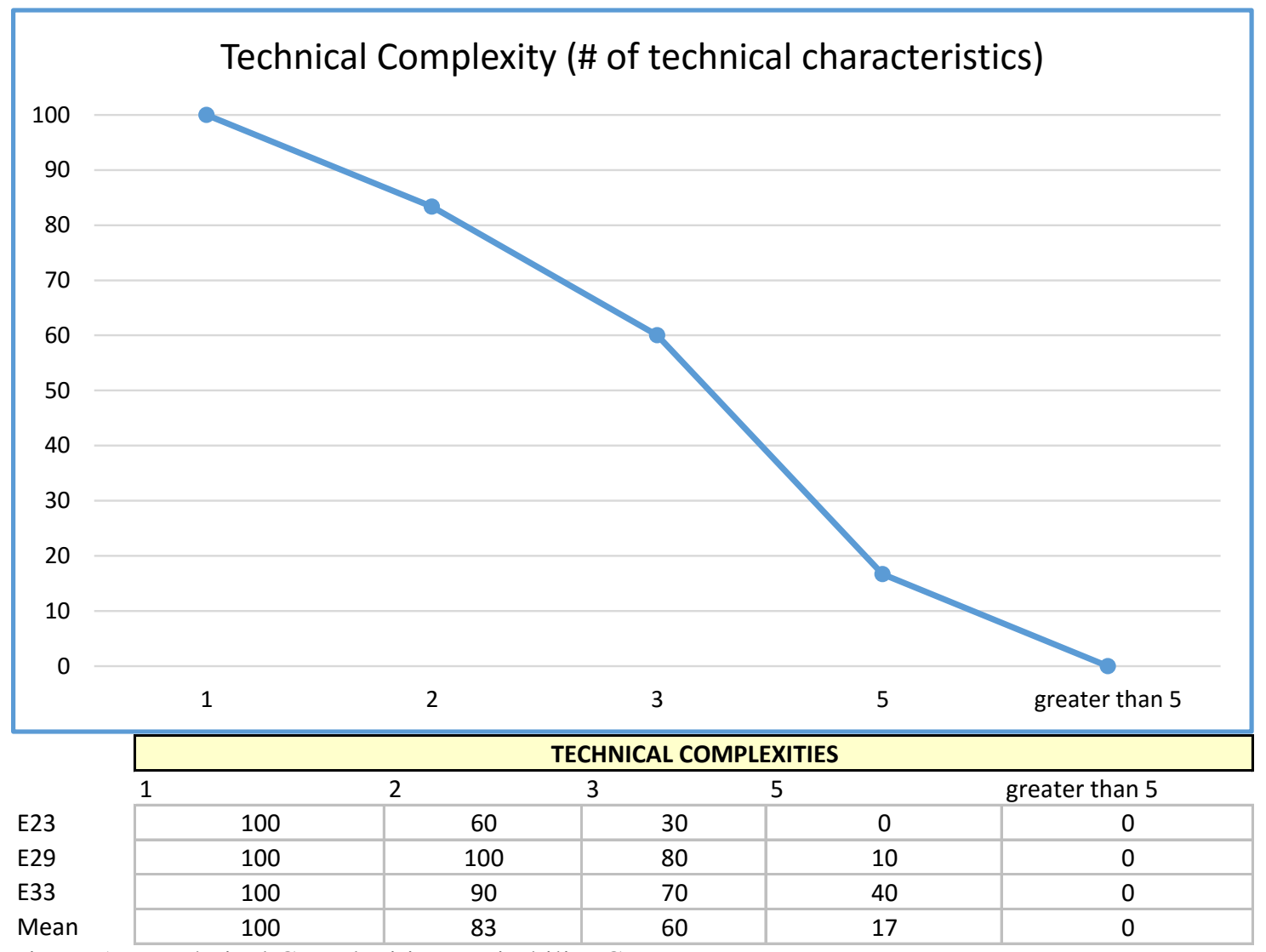

Figure 16: Technical Complexities Desirability Curve 
Stakeholder Complexity

The measurement for stakeholder complexity is the number of stakeholders involved in the research project. The expert panel was asked to determine the desirability curve for the proposal involving only one stakeholder and for the proposal involving more than five stakeholders.

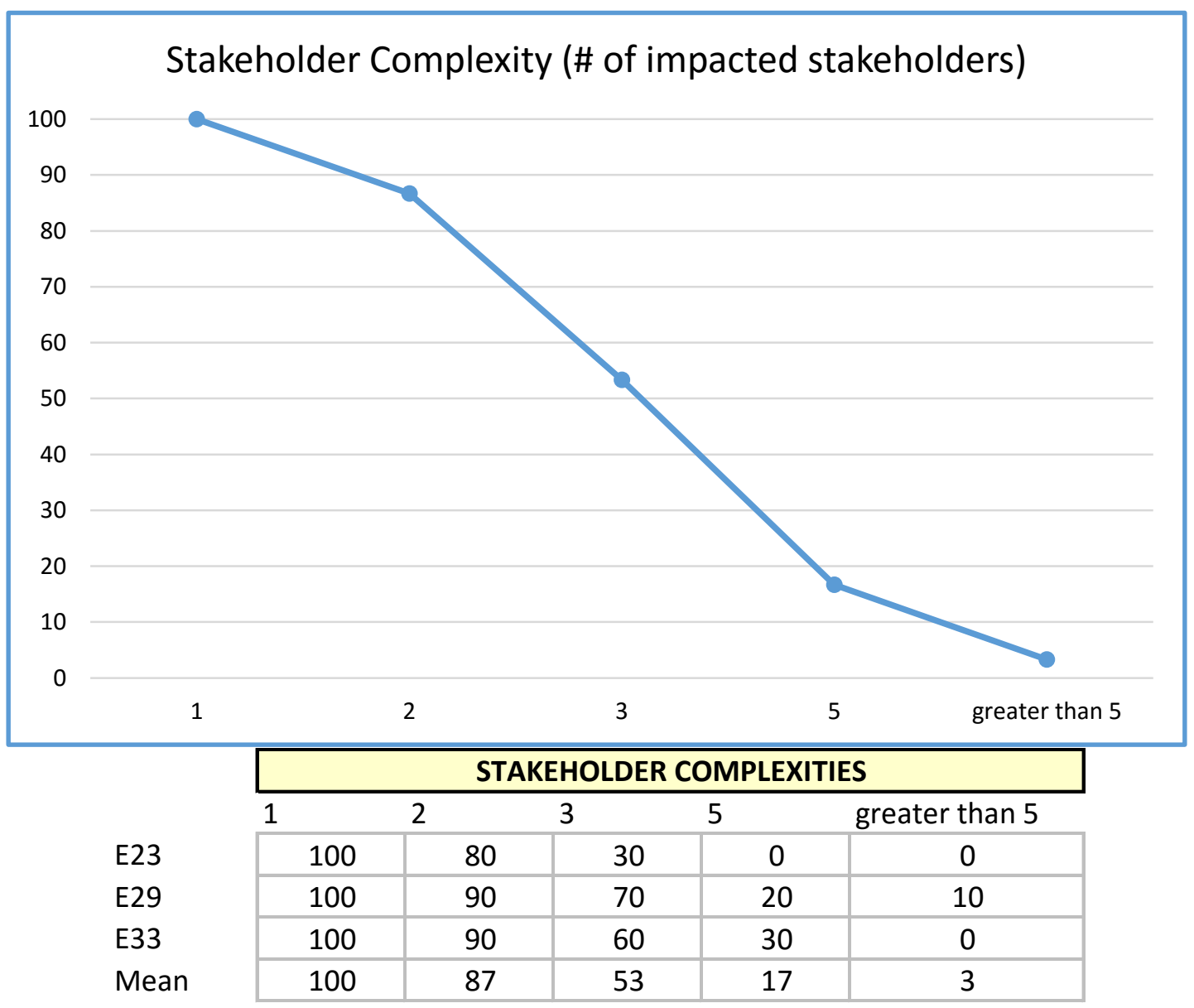

Figure 17: Stakeholder Complexities Desirability Curve 


\subsubsection{Technological Success Attributes}

\section{Combined Research Experience}

The measurement for combined research experience is the number of years of experience for the principal investigators. The scale ranges from zero years, which is least desirable, up to more than 75 years.

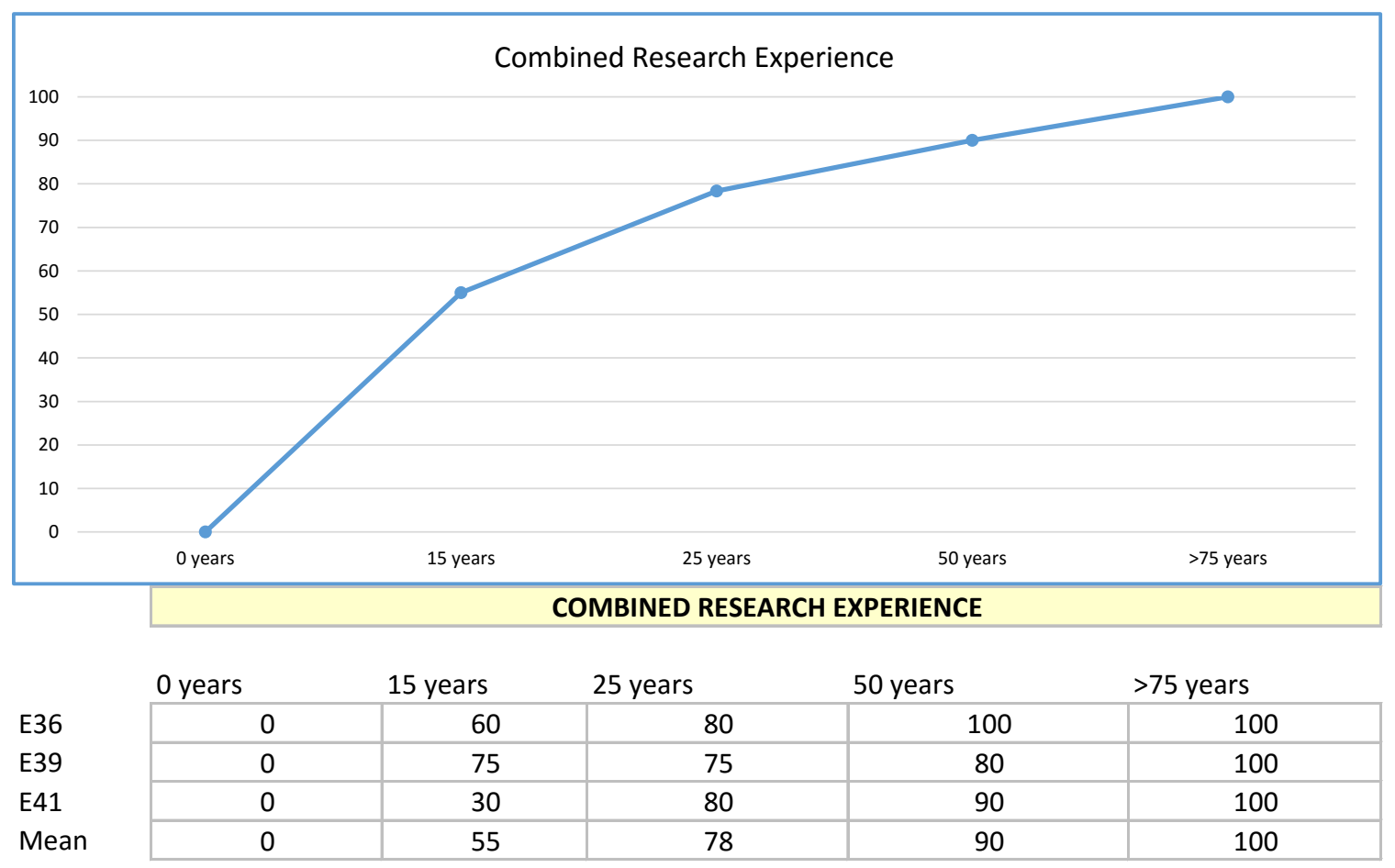

Figure 18: Combined Research Experience Desirability Curve 


\section{Technology Publications}

The measurement for technology publications is the number of publications, by the research team, related to the subject technology. The scale ranges from zero publications, which is least desirable, up to more than 80 publications.

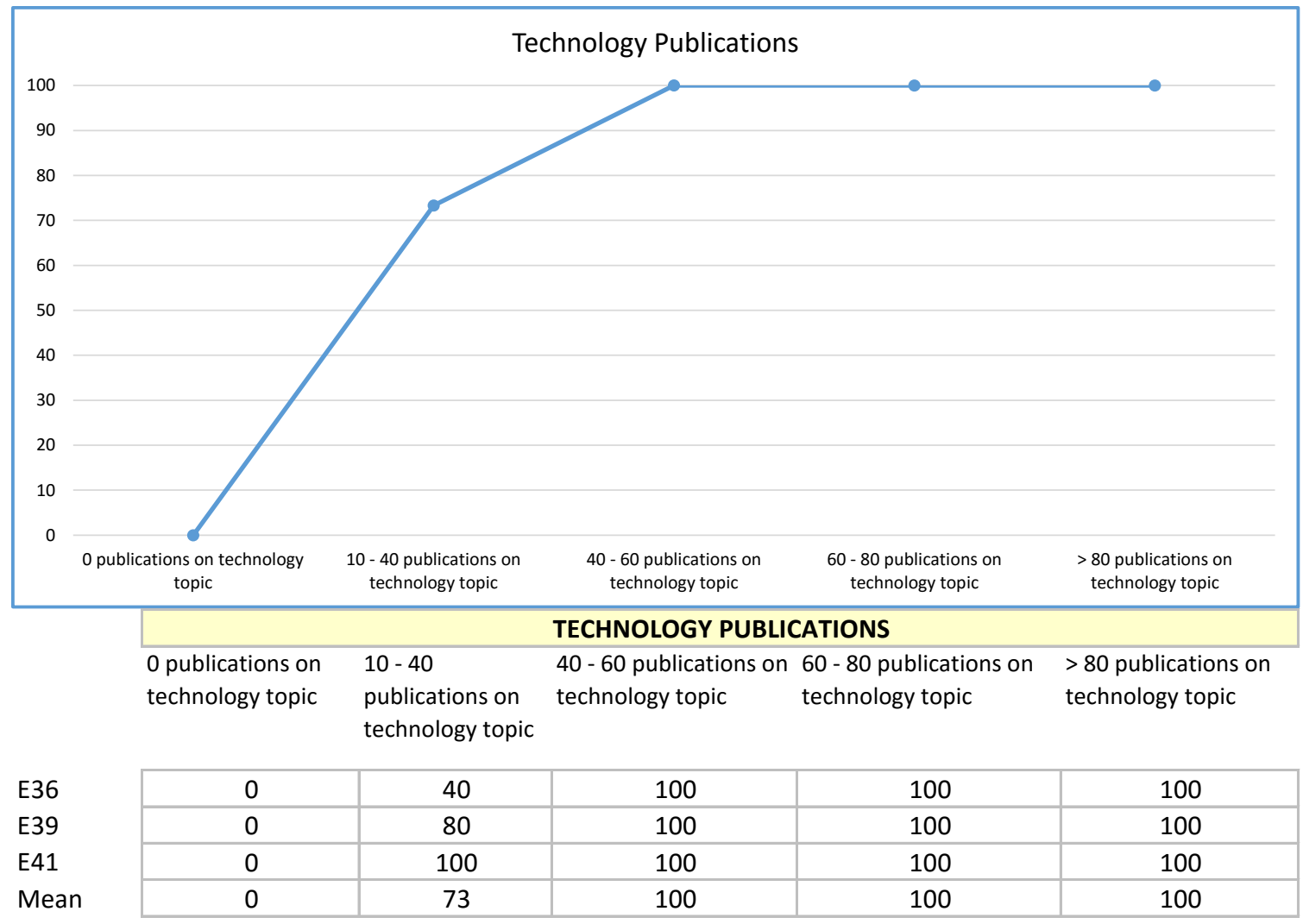

Figure 19: Technology Publications Desirability Curve 


\section{Personnel Assigned to TTO}

The measurement for personnel assigned to the technology transfer office

(TTO) is a count of the people assigned. The scale ranges from zero people assigned

to three full-time, dedicated staff.

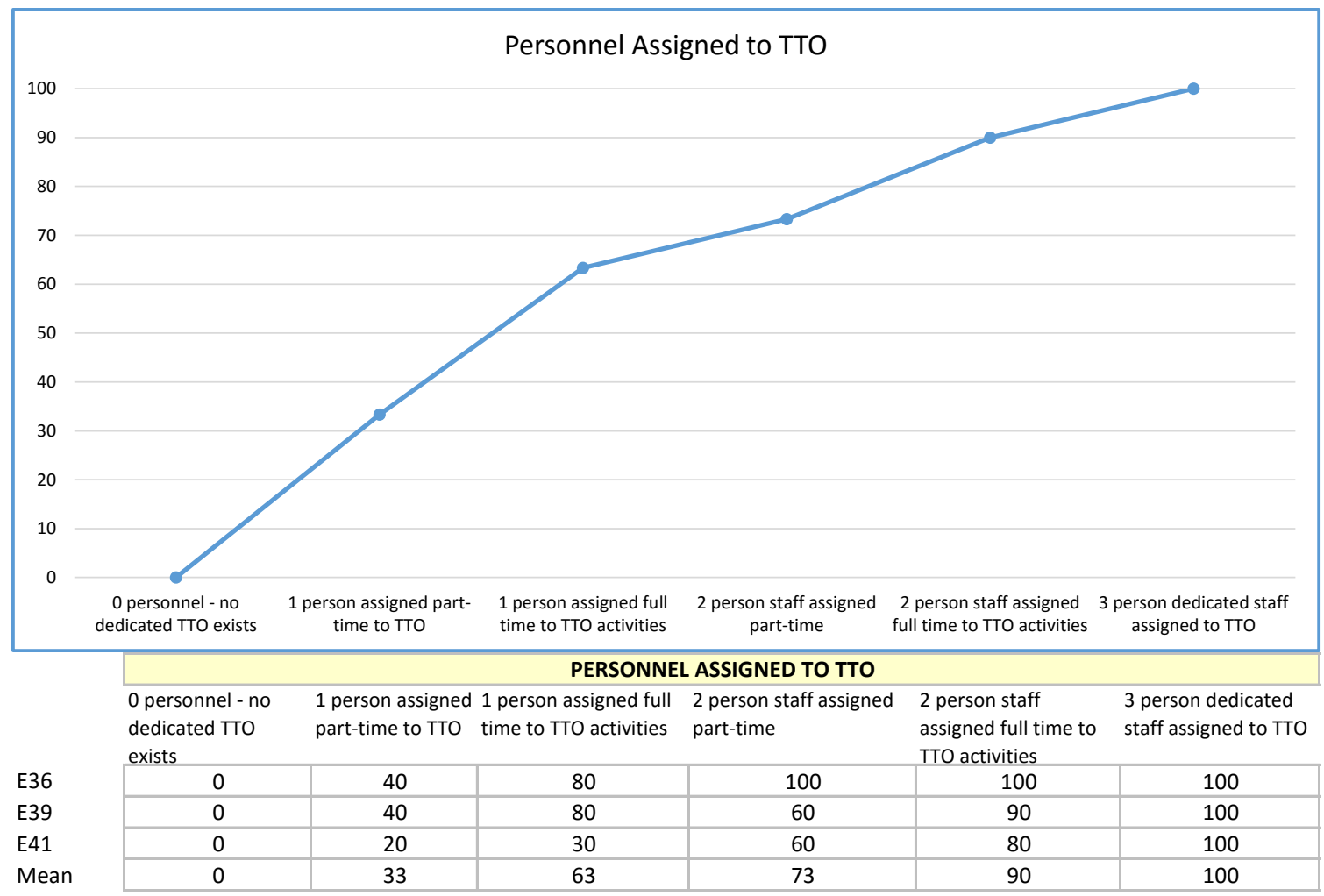

Figure 20: Personnel Assigned to TTO Desirability Curve 


\section{Technology Benefits}

The measurement for technology benefits is the number of benefits that are described in the research proposal. The scale ranges from no benefits identified to more than 10 benefits are defined.

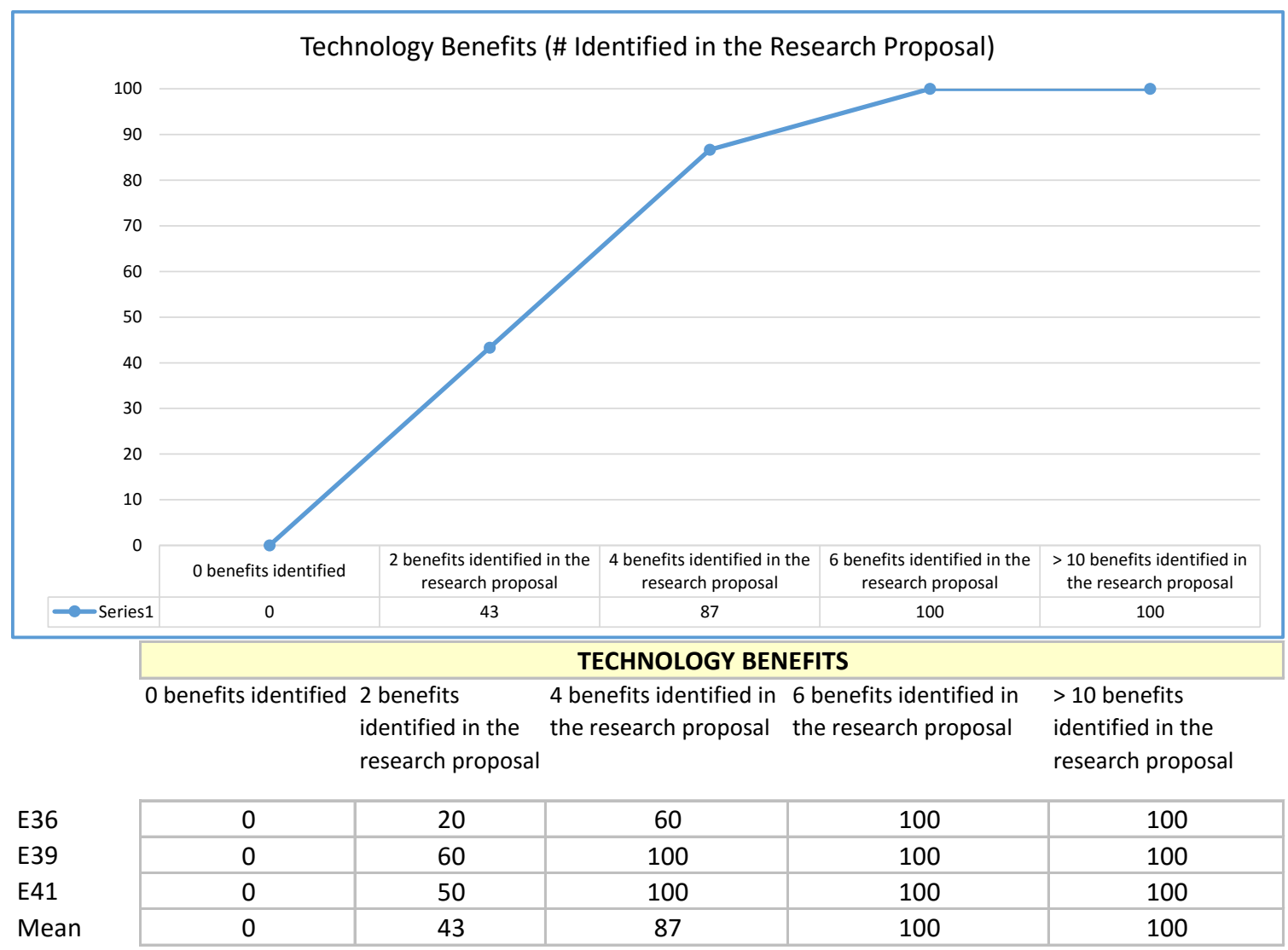

Figure 21: Technology Benefits Desirability Curve 


\section{Budget Allocated to TT}

The measurement for budget allocated to technology transfer is the percentage

of the R\&D budget that is allocated to technology transfer activities. The scale ranges

from no budget allocated to more than $10 \%$ of the budget is allocated.

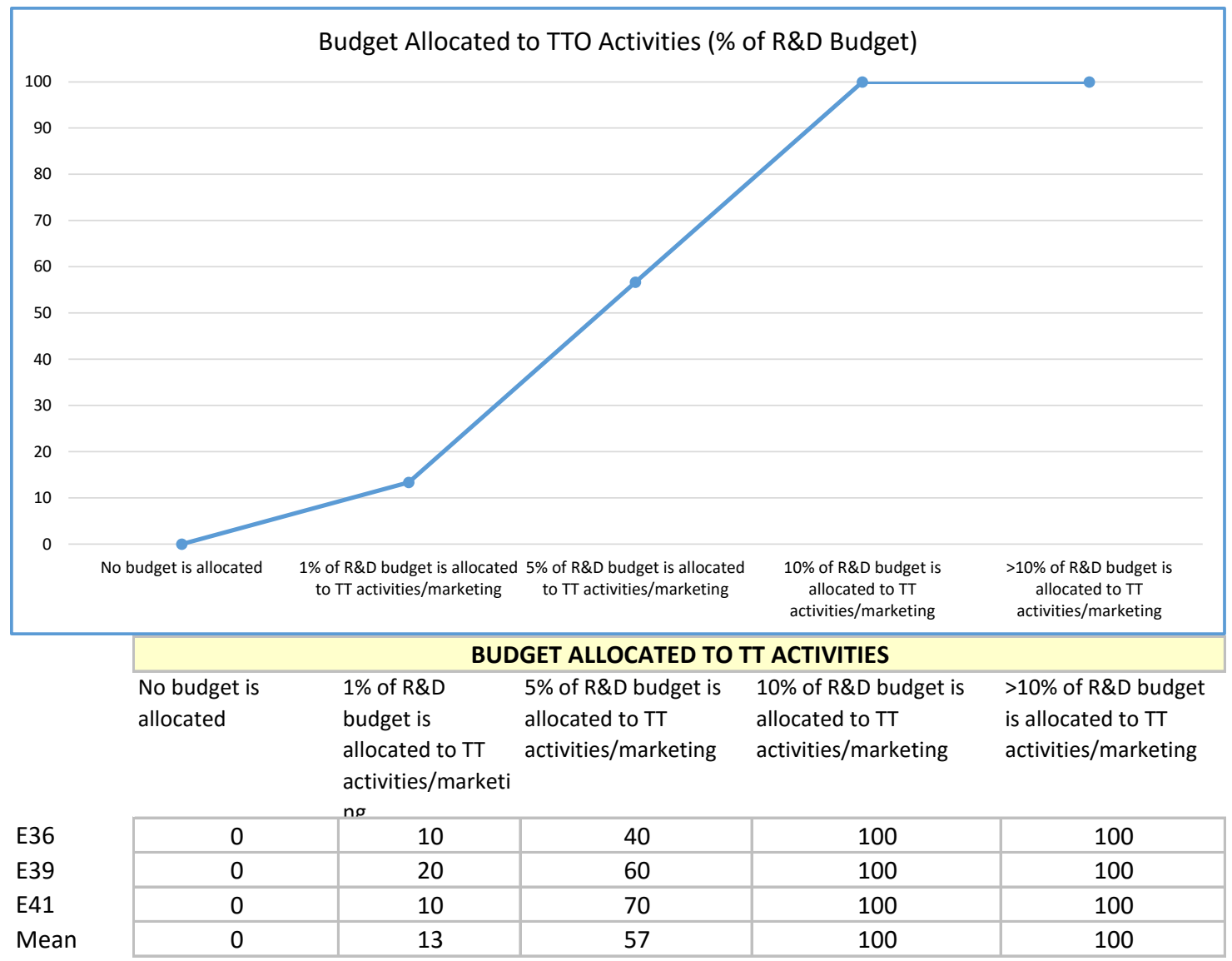

Figure 22: Budget Allocated to TT Activities Desirability Curve 


\subsubsection{Social Success Attributes}

\section{Diversity Events}

The measurement for diversity events is the number of events an organization requires to train their personnel on working with or being sensitive to other cultures. The scale differentiates between recommended and required events. The scale ranges from zero events are required to at least two events are required.

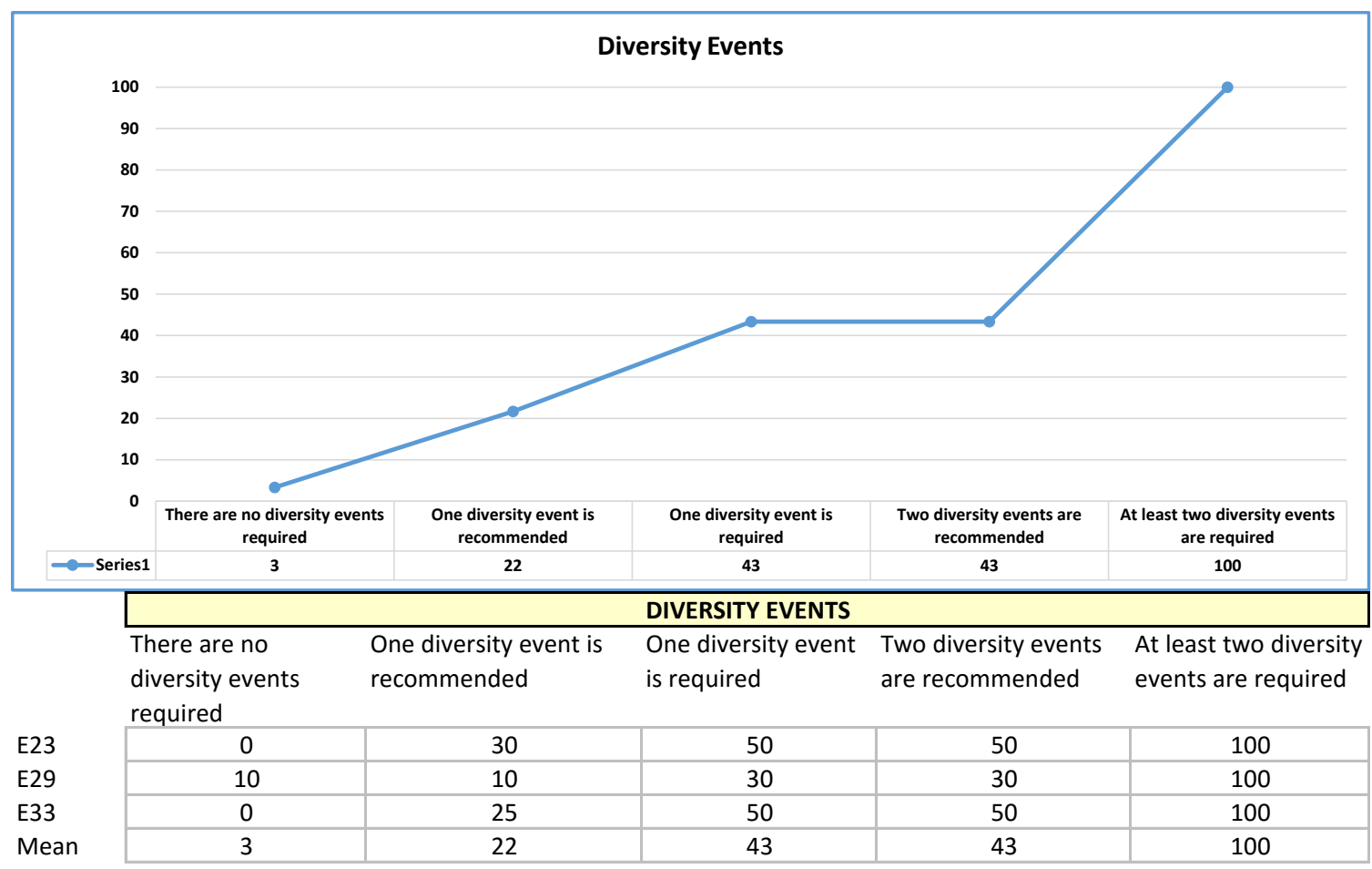

Figure 23: Diversity Events Desirability Curve 


\section{Personnel Dedicated to TT}

The measurement for personnel dedicated to technology transfer is the number of personnel, independent of the technology transfer office, that are dedicated to technology transfer. These people would include principal investigators, subject matter experts, or others from the research project team. The scale ranges from no one is dedicated to technology transfer activities to more than 10 personnel are assigned.

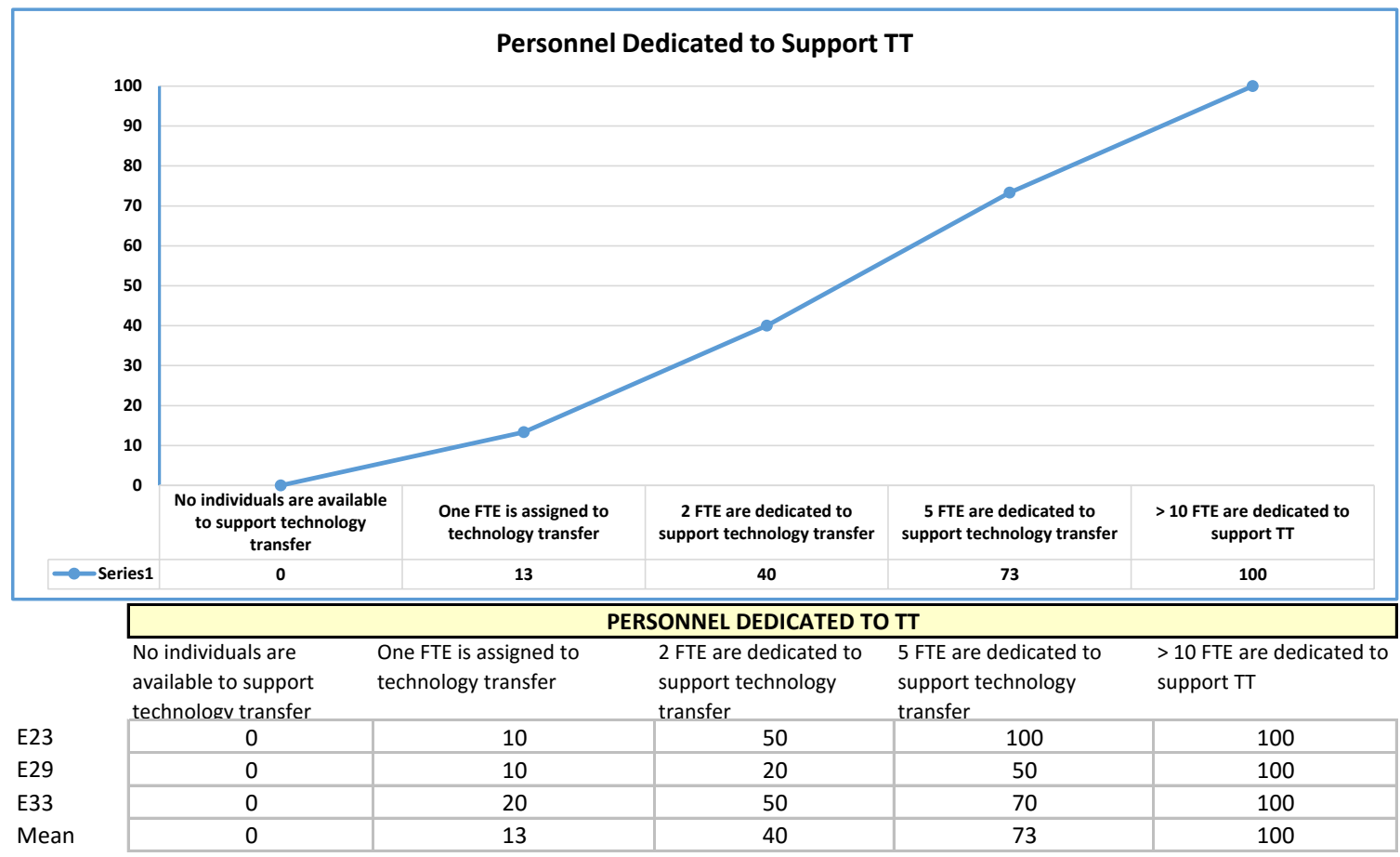

Figure 24: Personnel Dedicated to Support TT Desirability Curve 


\section{Project Meetings}

The measurement for project meetings is the frequency of project meetings.

The scale ranges from no planned meetings to frequent communications and site visits.

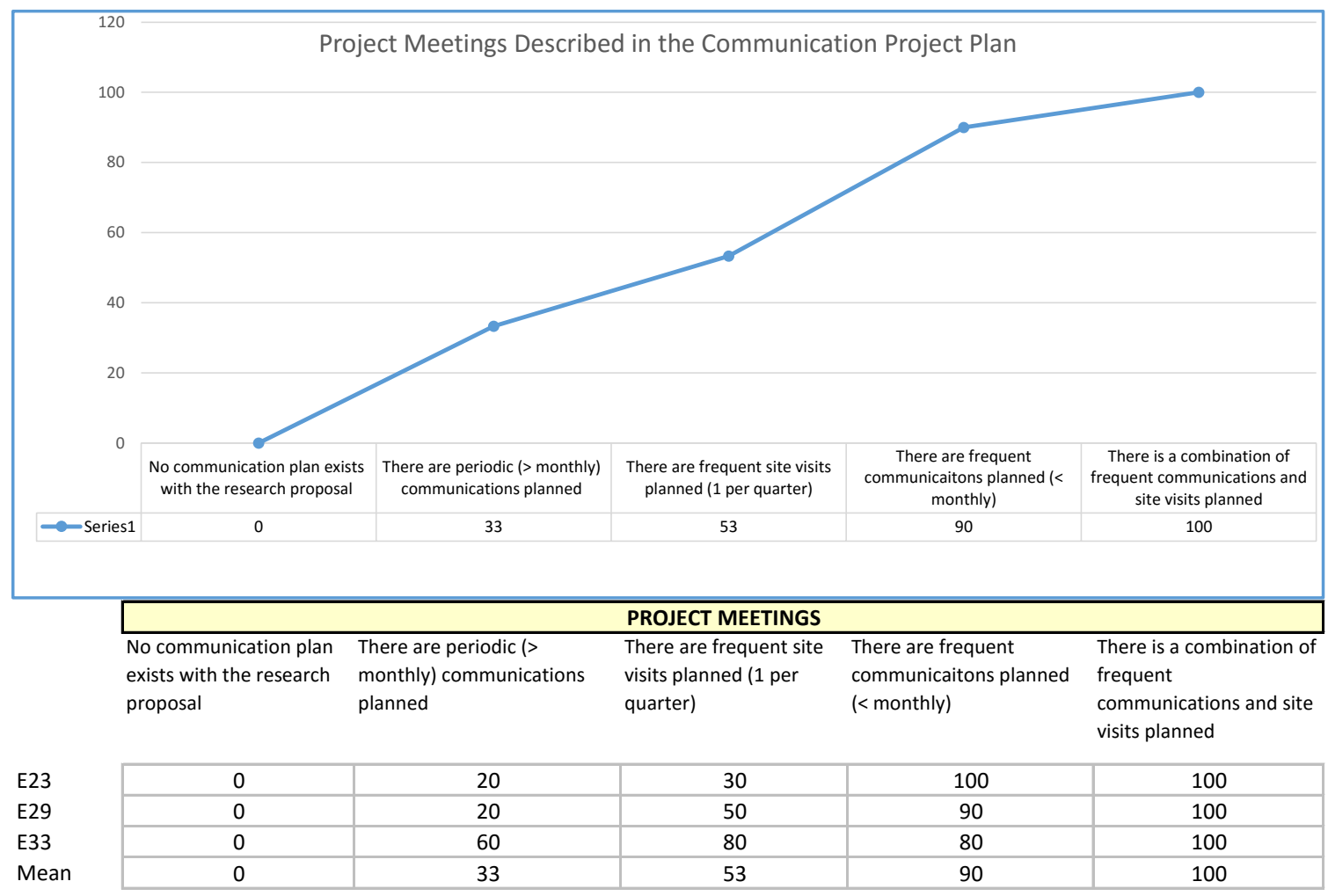

Figure 25: Project Meetings Desirability Curve 


\section{Personnel Loaned to Recipient}

The measurement for personnel loaned to the technology recipient is how many months the researcher is loaned to the recipient. The scale ranges from researchers are not loaned to researchers are loaned for more than 12 months.

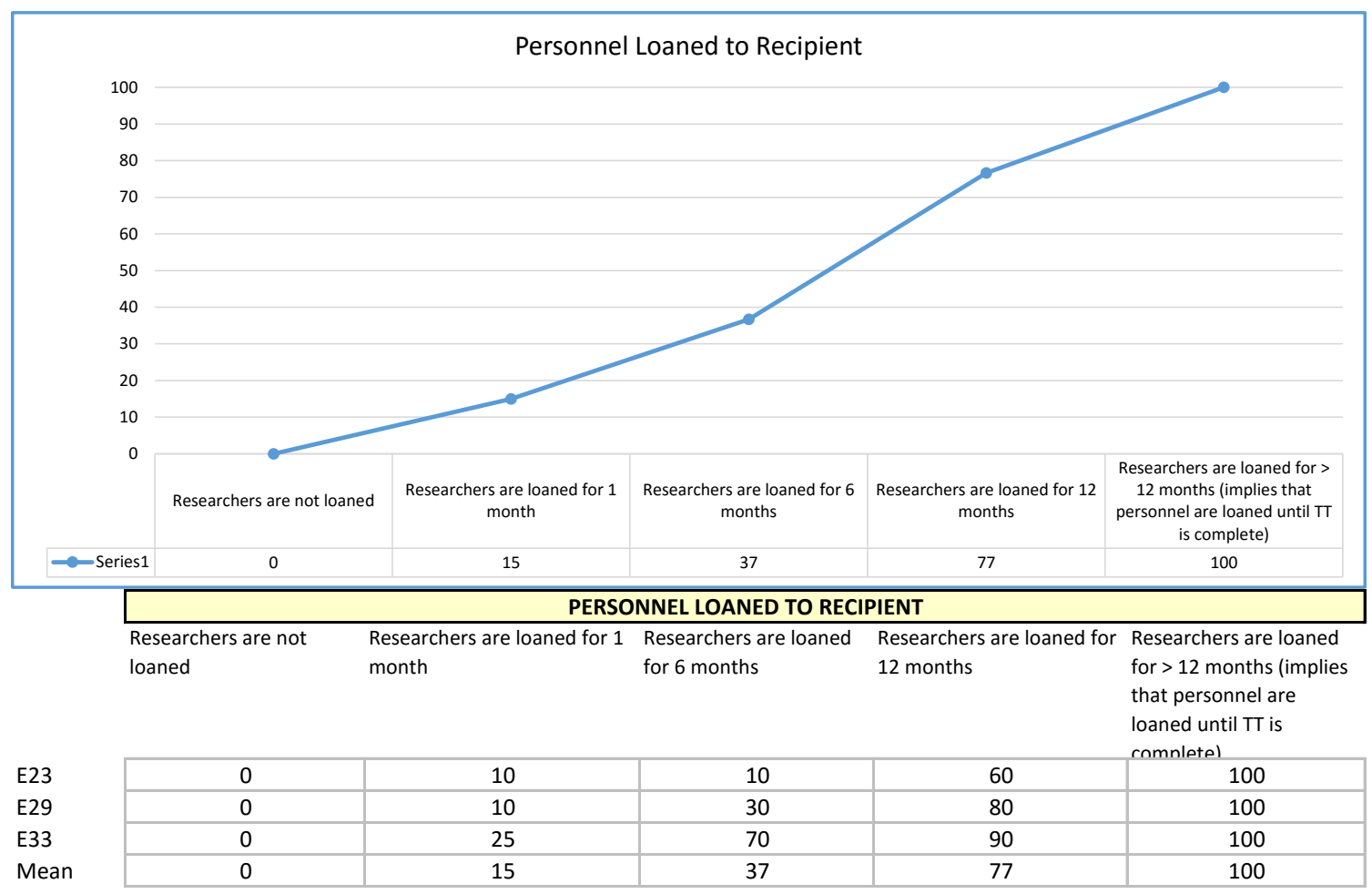

Figure 26: Personnel Loaned to Recipient Desirability Curve 


\section{Successful TT Experiences}

The measurement for successful technology transfer experiences is the number of previous project successes. The inference is that the more successful transfers, the more familiar the researcher is with how to be successful. The scale ranges from no previous successes to more than 10 successful transfers.

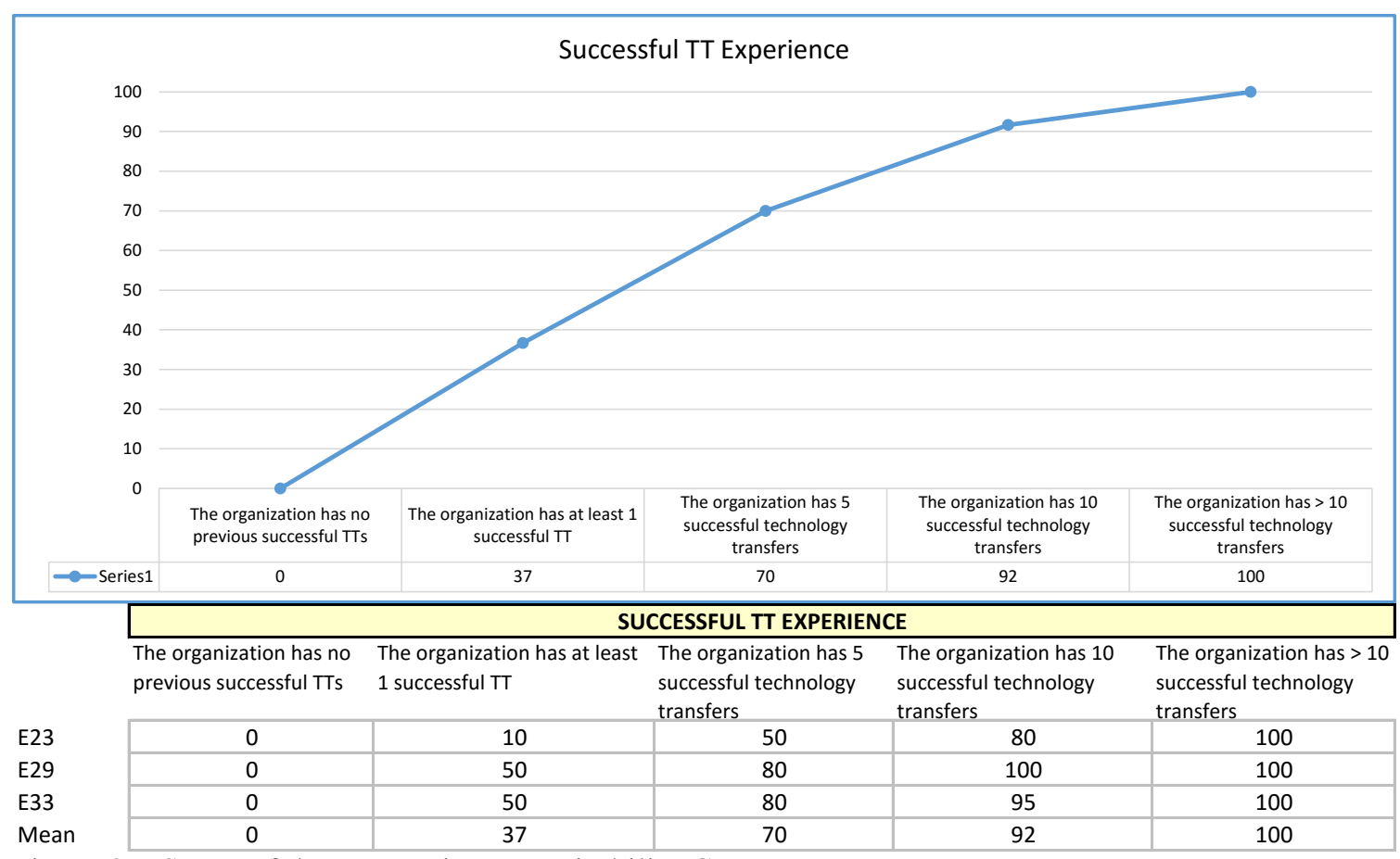

Figure 27: Successful TT Experience Desirability Curve 


\subsubsection{Market Success Attributes}

\section{Comprehensiveness of Use Case}

The measurement for a comprehensive use case is the level of detail in the use case. A use case is defined as the area in an organization where the technology can be applied. Types of information that would be included are: location, delivery, training plan, impacted stakeholders, associated costs, implementation plan, and barriers and risks are identified. Mitigation plans for risks should be documented. The scale ranges from no use case is planned to the use case has all of the necessary information.

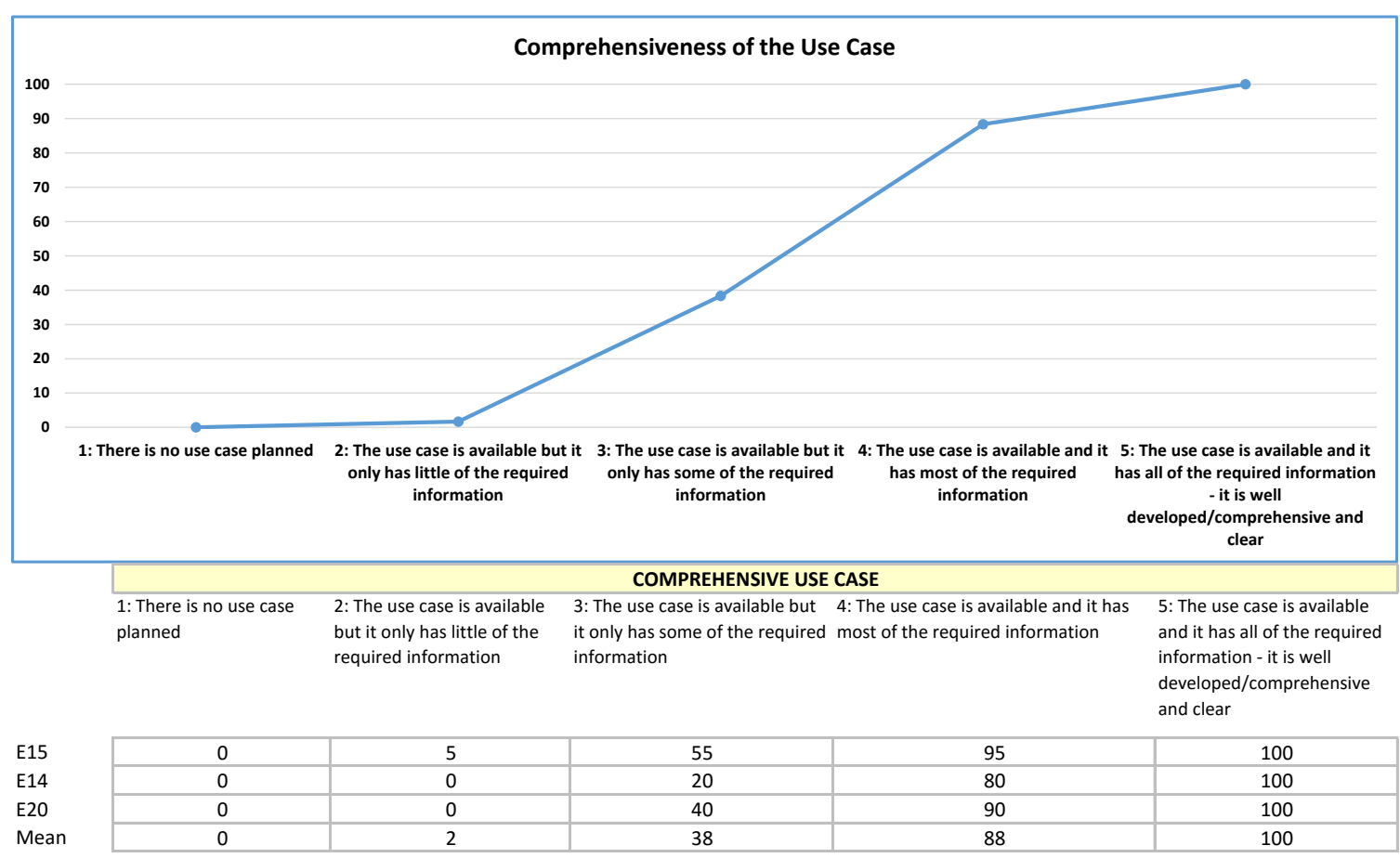

Figure 28: Comprehensiveness of the Use Case Desirability Curve 


\section{Credibility of the Organizational Champion}

The measurement for the organizational champion is intended to capture the experience or credibility of the champion. The organizational champion is seen as the advocate within the organization for the technology adoption. The level of experience of the organizational champion has an impact on the technology transfer potential. The scale ranges from no champion exists to the champion is internationally recognized as the leading technology expert.

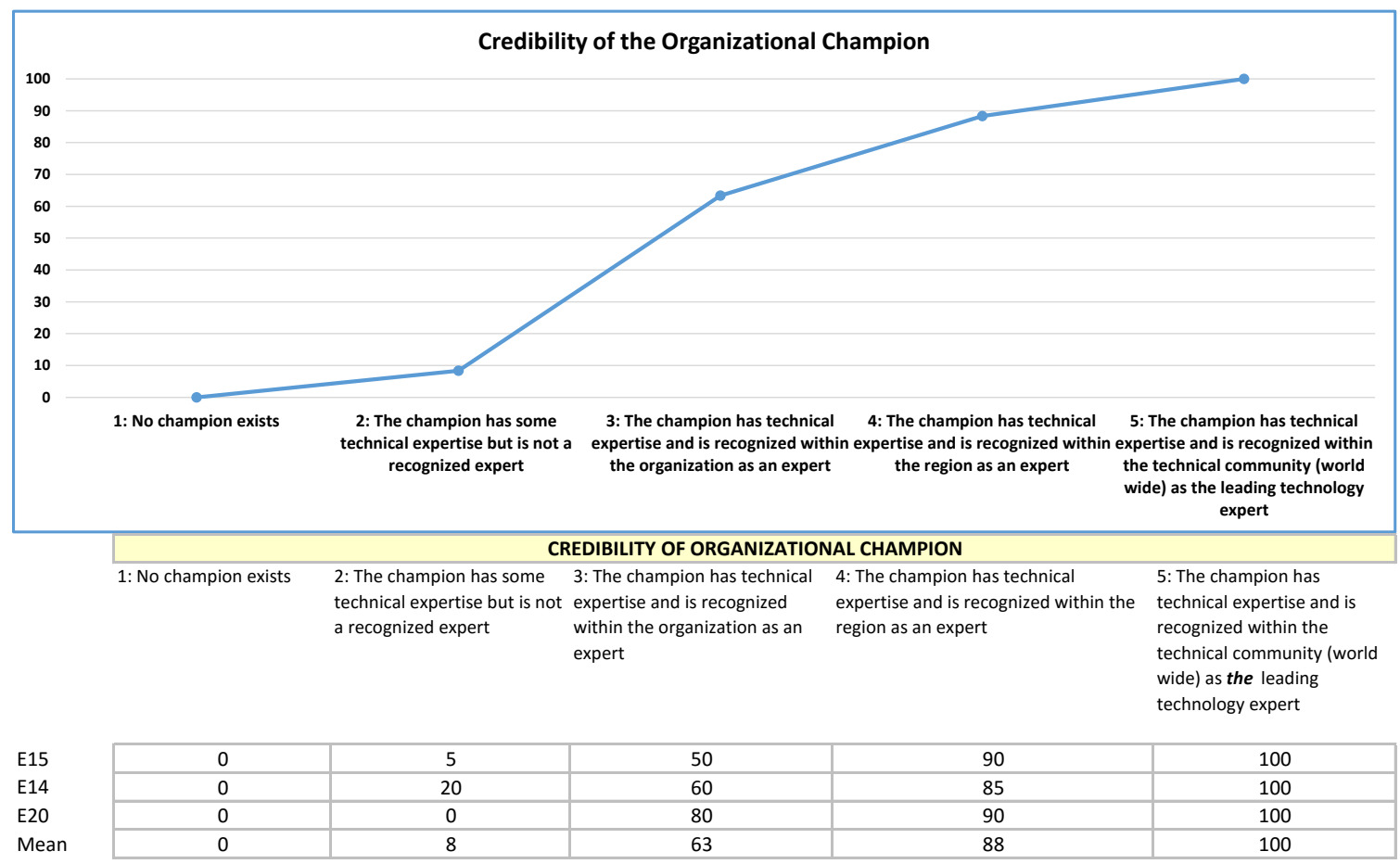

Figure 29: Credibility of the Organizational Champion 
Level of Top Management Interest

The measurement for level of top management interest is the degree and level that management that supports the technology. The need for managerial support in an organization is key to successful technology transfer. This success attribute identifies where in the organization there is support for the technology. The inference is that the higher up the support, the more likely there is for successful application. For this attribute, engagement and support would be defined as helping the champion and project team to overcome barriers, publicly advocates for the technology transfer, and has a practical understanding of how the technology will benefit the organization. The measurement scale goes from top management is not involved to there is evidence of consistent engagement at all levels in the organization.

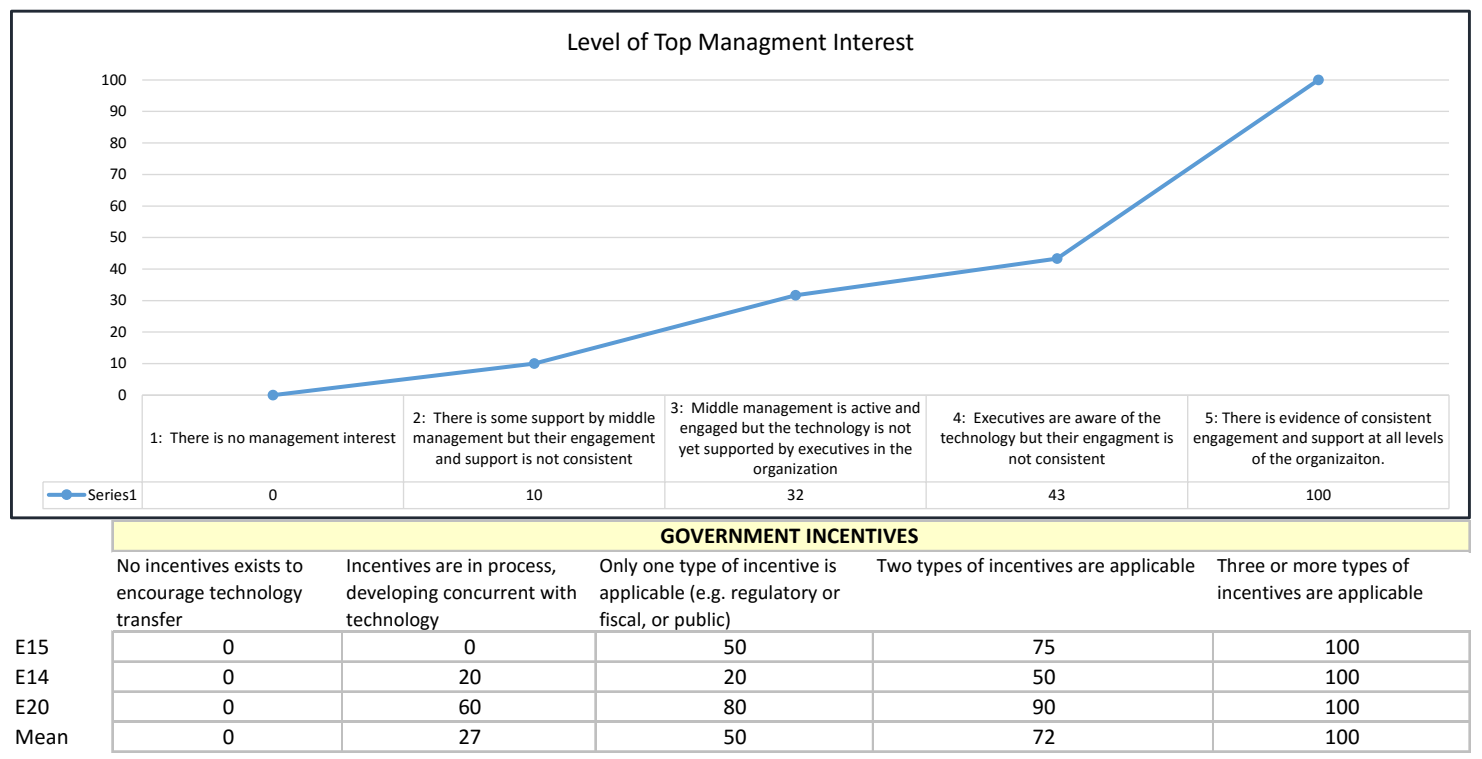

Figure 30: Level of Top Management Interest Desirability Curve 


\section{Government Incentives}

The measurement for government incentives is the number of incentives that are available to support the technology. The scale ranges from no incentives exist to there are three or more applicable incentives.

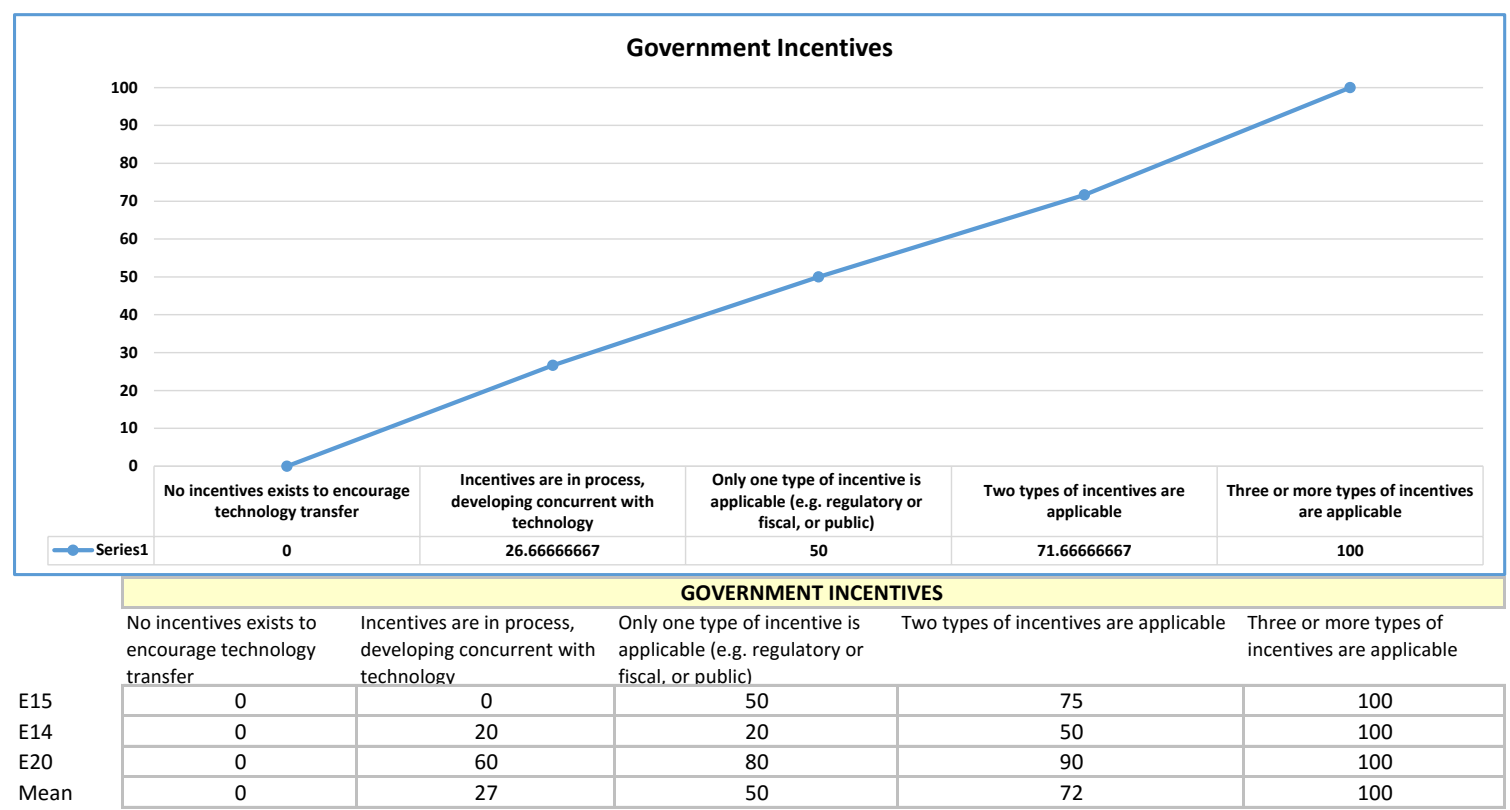

Figure 31: Government Incentives Desirability Curve 


\section{Common Technology Standards}

The measurement for common technology standards is understanding how the standard is supported. Standards that are encouraged by an organization with little support in the technical community are seen as not as influential as those required by the government (e.g . communication protocols, etc.); standards can be defined as a specification for how technology operates or interfaces with other technologies. The scale ranges from there are no common standards to the standard is mandated by the government.

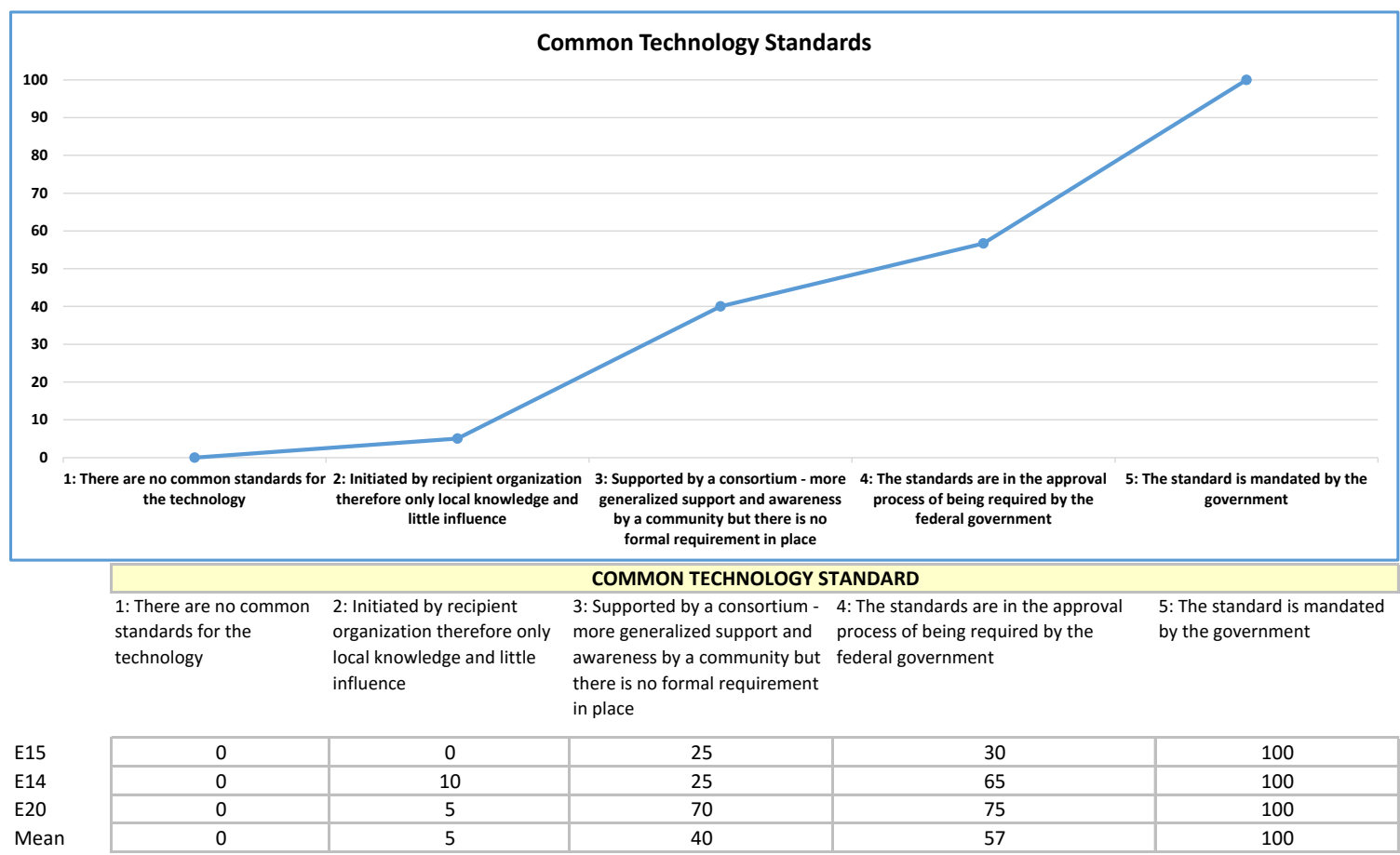

Figure 32: Common Technology Standards Desirability Curve 


\section{Return on Investment (ROI)}

The measurement for return on investment is, as the name implies, what is the financial return on the $\mathrm{R} \& \mathrm{D}$ investment. The scale ranges from $0-5 \% \mathrm{ROI}$ to greater than $75 \%$.

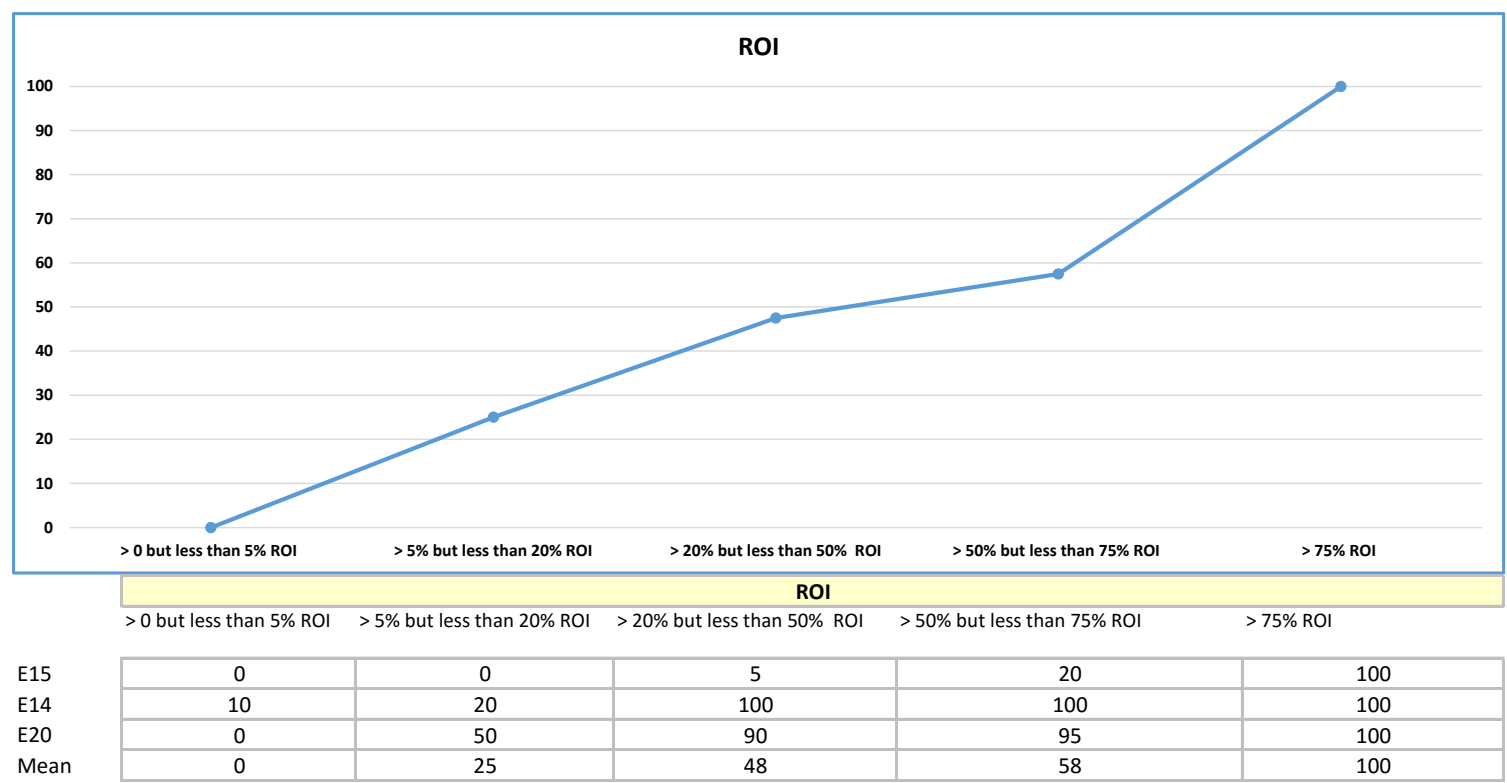

Figure 33: ROI Desirability Curve

The next chapter develops the case study that will be used to demonstrate the quantified model and associated desirability curves. 


\section{CHAPTER 6: ANALYSIS CASE DEVELOPMENT}

As previously described, this research focuses on moving (research) from a demonstration stage (TRLs 6-7) to the commercialization stage (TRLs 8-9). The model is validated using a case study of Demand Response technologies. The research portfolio at BPA has many projects that fall within the specified TRL range and will be used for this case study. A background of the BPA research program and the selected projects, abstracts, research organizations, and associated TRLs that will be used for the case study are provided.

\subsection{DR in the Pacific Northwest - What is it and Why is it Important?}

The case study will be based on the regional interest and application of DR in the Pacific North West. As such, the BPA has defined DR as “...changes in electric use by demand side resources from their normal consumption patterns in response to changes in the price of Electricity, or to incentive payments designed to induce changes in consumption and/or when system reliability is jeopardized." [70] Demand side resources would include technologies like heat pump water heaters, industrial loads (HVAC, lighting, or refrigeration). DR can be described as these types of technologies/systems are able to adjust their load requirements when a need arises.

The term DR is not new to the utility industry. Historically, DR has been used for emergency response and peak load management. In the past, system operators have been able to predict demand with $95 \%$ accuracy. The original version, DR v1.0, is characterized by manual, one-way communication to manage peak loads [40]. One example of when v1.0 would be used is in the summer to handle typical load increases due to air conditioning. But, the grid is changing. Renewable integration, specifically 
wind resources, ancillary services, and peak load management are requiring a more dynamic and flexible grid. Unlike its manual predecessor, DR v2.0 is more ready to respond to a dynamic system. DR v2.0 is described as an automated system intended to address several concepts which are described below.

DR helps with peak load management by balancing the supply of electricity on the system. This is done by adjusting or controlling the demand (versus adjusting power generation output). Typically, the system experiences peaks during the morning hours and late afternoon/early evening. Figure 34 shows a typical load on the BPA grid.

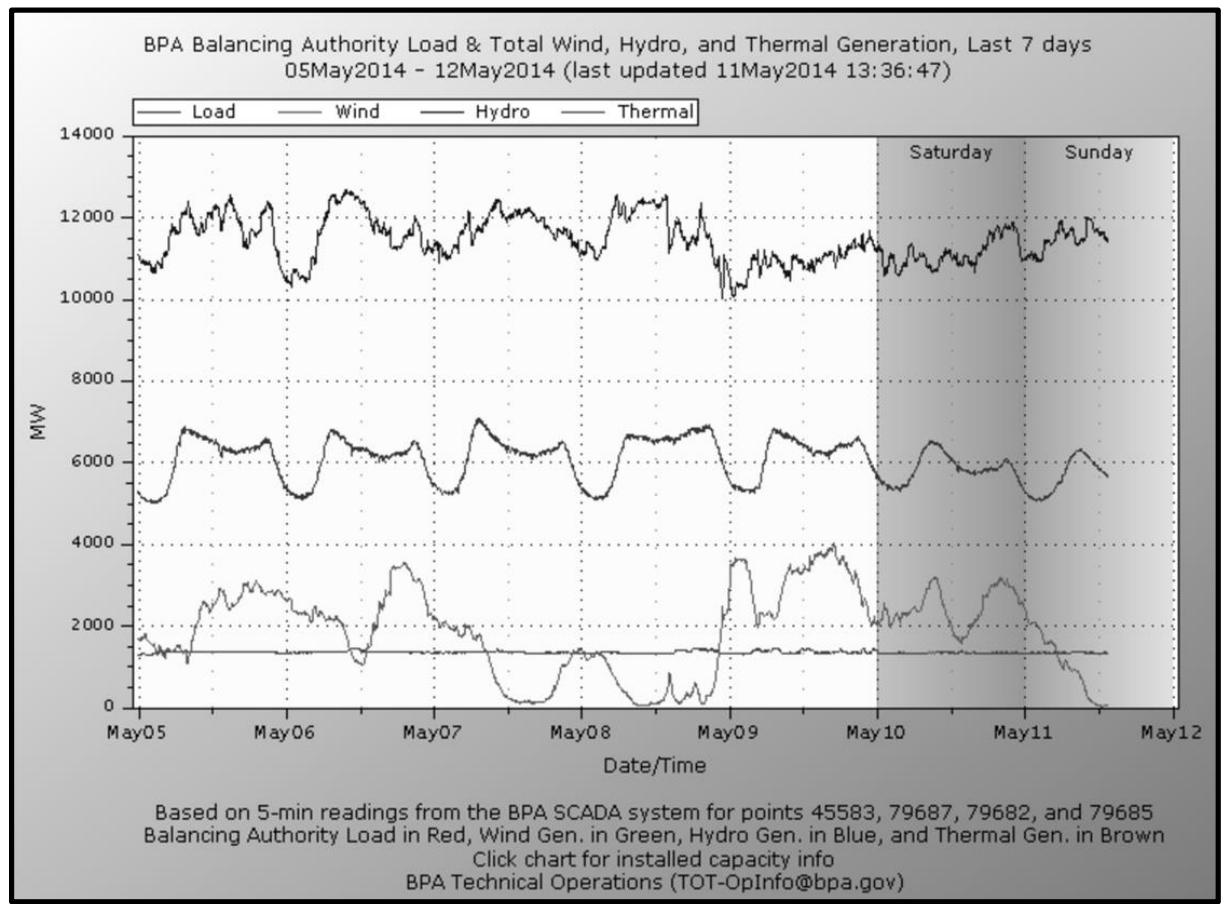

Figure 34: BPA Balancing Authority Load for 05/05-12/2014

Source: http://transmission.bpa.gov/business/operations/wind/baltwg.aspx

DR can act as a within hour balancing reserve. The North American Electric Reliability Corporation (NERC) and the Western Electricity Coordinating Council (WECC) have established reliability standards that require BPA to maintain a sufficient 
amount of balancing reserve capacity to ensure a reliable balancing authority (BA) area. In order to meet the standard, BPA must set aside or acquire an amount of capacity necessary to support the balancing reserve needs of the BPA transmission users. DR could be used as a source of acquired capacity.

Instead of building more transmission lines, DR can provide a "non-wire" solution. This term addresses the need to increase capacity of the transmission system without capital investment in new transmission lines. The solutions identify viable nontransmission alternatives to transmission expansion. BPA considers “...DR, distributed generation ... and conservation measures that individually, or in combination, delay or eliminate the need for upgrades to the transmission system”. [71]

However, with such relatively low cost of power in the PNW, what is the incentive for customers (commercial and residential) to implement DR? EnerNOC identifies four reasons why DR is an attractive alternative to PNW commercial and residential customers:

- A business can earn cash while supporting the electric grid - customers can use electricity when the price of electricity is low (in response to a market or target price signal, using DR v2.0), or the customer can receive paybacks from the utility when they responded to a DR event/request.

- Related to the payback, a customer could start an energy efficiency program. The funds raised by responding to a DR event can offset the cost of purchasing energy efficient equipment. 
- Participating in DR projects demonstrates the customer's commitment to sustainability. In turn, this would incentivize their customers, who also want to show their sustainability.

- Secure LEED credits - LEED certification is sponsored by the US Green Building Council (USGB). Statistically, buildings that have this certification command a higher rent premium ( $\$ 11.33 / \mathrm{ft}^{2}$ over non-certified buildings) and have a $4.1 \%$ higher occupancy rate. [74]

A number of past and current projects have demonstrated the potential for demand response technologies to provide reliable options for addressing the future needs of the grid.

\subsection{DR Future}

The BPA Demand Response team has outlined a plan to conduct more advanced DR projects to demonstrate larger scale capacity and reinforce the potential as a reliable and available resource, ultimately being able to use the resources for operational needs. This effort involves investigating the potential of aggregators. The commercial aggregators take many smaller, DR loads and "aggregate" them into a larger composite load. The aggregator concept is part of BPA's effort to develop a Demand Response Management System that is capable of managing and dispatching an evolving portfolio of DR projects. There are a number of other alternatives to adoption of DR in PNW to include policy incentives, regional outreach communication, and rate incentives. However, the emphasis of this response is on the technology solutions. 
To manage the demand response program more effectively, 2014-2015 work included the development of technology roadmaps based on prioritized research topics. These technology areas served as the basis for developing technology roadmaps that will be used to guide future research investments.

\subsection{The R\&D Organization and Process}

As part of their vision statement, BPA promotes energy efficiency, renewable resources and new technologies. The new technologies, energy efficient solutions, and integration of renewable resources are identified through the utilization of a roadmapping process. Roadmapping is widely used across the agency to ensure that product requirements that are consistent with BPA's Vision and are initiated through the Office of Technology Innovation (TI); the group manages all of the research and development for the agency. [24]

The Technology Innovation office is responsible for selecting and managing BPA's R\&D portfolio of projects. The process involves a rigorous portfolio selection, a yearly portfolio review, implementing project management best practices, and once the research projects are complete, transferring the projects to application. The primary functions of this department are therefore portfolio and project management and technology transfer.

The basis for the research portfolio is defined by the technology roadmaps. The roadmaps representation a cross-functional effort, involving many stakeholders, subjectmatter-experts (SME's) within the agency, as well as soliciting input from external organizations. The yearly solicitation opens in March and final decisions are made by 
July. The proposals are subjected to a two-phase review approach. [25] The proposal review process is described in detail in Chapter 2. The Phase II Evaluation criteria and corresponding Agency objective is shown in Table 21.

\begin{tabular}{|l|l|}
\hline \multicolumn{1}{|c|}{ Criteria } & \multicolumn{1}{|c|}{ BPA Objective } \\
\hline $\begin{array}{l}\text { The degree to which the project strengthens BPA's } \\
\text { existing portfolio of projects }\end{array}$ & The right portfolio \\
\hline $\begin{array}{l}\text { The degree to which project scope addresses the } \\
\text { R\&D Program(s) identified in the Technology } \\
\text { Roadmap(s) }\end{array}$ & The right research \\
\hline $\begin{array}{l}\text { The quantitative or qualitative expected benefits as } \\
\text { applied system-wide, assuming this project is a } \\
\text { technical success }\end{array}$ & $\begin{array}{l}\text { Magnitude of benefits to } \\
\text { BPA and Pacific } \\
\text { Northwest commensurate } \\
\text { with risks }\end{array}$ \\
\hline $\begin{array}{l}\text { Team members have sufficient experience and are } \\
\text { qualified to carry out the project }\end{array}$ & The right mix of talent \\
\hline $\begin{array}{l}\text { The probability of the project being a technical } \\
\text { success }\end{array}$ & $\begin{array}{l}\text { Achieving successful } \\
\text { project results }\end{array}$ \\
\hline $\begin{array}{l}\text { The probability of near or long term successful } \\
\text { application to BPA }\end{array}$ & $\begin{array}{l}\text { Successful application to } \\
\text { BPA business challenges }\end{array}$ \\
\hline $\begin{array}{l}\text { The degree to which proposed Stage Gates } \\
\text { (go/stop decision points) reflect real } \\
\text { options/choices for project decisions, and relate to } \\
\text { real discovery/science/achievement thresholds }\end{array}$ & The right decision points \\
\hline $\begin{array}{l}\text { Cost share which exceeds the minimum } \\
\text { requirement, e.g. greater than 50\% }\end{array}$ & The right leverage \\
\hline $\begin{array}{l}\text { The percentage of cost share which is a cash } \\
\text { contribution }\end{array}$ & The right leverage \\
\hline
\end{tabular}

Table 21: BPA Project Evaluation Criteria [19]

\subsubsection{Research Proposals}

The BPA sends out a yearly solicitation for research proposals to address topics identified in their technology roadmaps. Access to these research proposals is a unique opportunity to use them as a case study and test the concept of the technology transfer score. These proposals are part of the current R\&D portfolio, so performance data is available to measure against. 
Demand response technologies were selected for the case study because they provide solutions for Pacific Northwest Utility needs, which are renewable energy integration, load growth, and alternatives for an aging infrastructure. In addition, they are typically more mature technologies. This criterion (mature technologies) was also mentioned as increasing the technology transfer potential. Specific information about the research organization (e.g. name, technology characteristics) will remain anonymous.

Table 22 lists the general technology that is being tested, participating organizations, and the potential energy impact. The TRLs for these projects are 7-9 (e.g. ready for application). A more thorough discussion of each technology, and how it can be used as a resource for demand response, follows the summary table.

\begin{tabular}{|l|l|l|l|}
\hline & Proposal 1 & Proposal 2 & Proposal 3 \\
\hline DR Technology & $\begin{array}{l}\text { Utility scale } \\
\text { battery storage }\end{array}$ & $\begin{array}{l}\text { Consumer heat } \\
\text { pump water heaters } \\
\text { (HPWH) }\end{array}$ & $\begin{array}{l}\text { Retail Supermarket } \\
\text { refrigeration }\end{array}$ \\
\hline $\begin{array}{l}\text { Participating } \\
\text { Organizations }\end{array}$ & $\begin{array}{l}\text { Industry } \\
\text { Utility Partner }\end{array}$ & $\begin{array}{l}\text { University } \\
\text { Collaborative } \\
\text { Partner } \\
\text { National Lab }\end{array}$ & $\begin{array}{l}\text { National Lab } \\
\text { Industry }\end{array}$ \\
\hline $\begin{array}{l}\text { Potential Energy } \\
\text { Impact }\end{array}$ & 1 MWh storage & $\begin{array}{l}\text { Not stated - will be } \\
\text { measured as part of } \\
\text { research }\end{array}$ & $\begin{array}{l}\text { Not stated - will } \\
\text { be measured as } \\
\text { part of research }\end{array}$ \\
\hline Objectives & $\begin{array}{l}\text { Develop control } \\
\text { strategies to } \\
\text { maximize } \\
\text { storage potential } \\
\text { and } \\
\text { demonstration of } \\
\text { a 500-kW, 1- } \\
\text { MWh storage }\end{array}$ & $\begin{array}{l}\text { Develop protocols } \\
\text { for DR testing of } \\
\text { HPWH and fully } \\
\text { characterize the } \\
\text { energy storage } \\
\text { potential }\end{array}$ & $\begin{array}{l}\text { Develop control } \\
\text { strategies and } \\
\text { evaluate the } \\
\text { strategies in } \\
\text { supermarket field } \\
\text { tests. }\end{array}$ \\
\hline
\end{tabular}




\begin{tabular}{|l|l|l|l|}
\hline & Proposal 1 & Proposal 2 & Proposal 3 \\
\hline & $\begin{array}{l}\text { system at the } \\
\text { utility scale }\end{array}$ & & \\
\hline
\end{tabular}

Table 22: Research Proposals

Proposal 1: This proposal is testing large battery storage that can be used by a utility. The utility can use the battery system to store energy when the production of renewable energy exceeds energy consumption by the consumer. The battery can store renewable energy when it is produced; typically, wind energy production is highest at night, a time when energy demand is low. It acts as a DR technology because it can be used by the participating utility to reduce peak load demand by dispatching the stored energy during the peak demand.

The research proposal has identified a utility in the Pacific Northwest that is willing to partner to test the storage and demand response potential of the battery system.

Proposal 2: The inherent characteristics of heat pump water heaters (HPWH) make them an ideal candidate for DR. They contribute significantly to peak demand because people use hot water for showers in the morning, a peak demand time and because HPWHs have the ability to store and release heat energy over time.

This proposal aims to increase or decrease water heater electric loads in response to a communication signal via the homeowner's WiFi. The HPWH will be allowed to heat to $160^{\circ} \mathrm{F}$ but there are mechanisms in place to deliver the water no hotter than $130^{\circ} \mathrm{F}$. The HPWH will be allowed to charge when the demand is low 
(typically overnight) in anticipation of usage in the morning. The benefit is that it will reduce peak load in the morning, since it will already be charged during the night.

The proposal will work with end-use customers to understand the ability of HPWHs to respond to DR signals as well as get feedback from the customers regarding how they perceive the technology. For instance, was there any interruption to the quality of your hot water? Or, were there any interface issues with the DR signal equipment?

Proposal 3: The objective of this proposal is to use supermarket refrigeration for DR. Typically, supermarket refrigeration systems are "energy hogs" and represent a substantial load for a utility. As well, energy costs cut into the already slim profit margins for a supermarket. If the system can be used for DR and to control the load, there is a benefit for the utility as well as the operator.

There are many components in a refrigeration system. These include compressors, condensers, lighting, fans, and defrost equipment. If one or many of these can respond to a DR event, then there is the potential to balance system loads for a utility and for the supermarket, it allows them to operate the system more predictably and at potentially higher temperatures; one test was to ensure food integrity and safety. In this case, a DR event is defined as cooling the refrigeration system or turning off cooling capacity.

The next chapter applies the model to these use cases and conducts four scenario analyses to understand the model's sensitivity to perturbations. Project 
performance and reasons for including the projects in the portfolio will be considered in combination with the technology transfer score. During the model validation phase experts would be asked to verify: 1 . if a technology transfer score was used, would these proposals have been selected? And 2. Based on the project performance, would technology transfer scores provide an insight into what is actually happening in the project now? As an example, if a weak communication plan was identified as part of assessing the technology transfer score, how is the actual project communication occurring?

\section{CHAPTER 7: ANALYSIS OF CASE AND SENSITIVITY ANALYSIS}

This chapter uses the research proposals identified in the previous chapter to demonstrate the model. The desirability values and resulting technology transfer score will be calculated. The model is used to test several analysis scenarios. These include:

- Look at future based scenarios to determine the impact on the proposal rank if one of the other perspectives is evaluated as the most important,

- Determine how sensitive the model is to changes in expert opinion such that the highest TT Score is preserved,

- Assess whether the model is effective for other technology-type proposals, and

- What can an organization do to improve the overall technology transfer potential? 


\subsection{Technology Transfer Scores for Case Study}

The three Demand Response proposals presented in Chapter 6 are compared relative to the technology transfer success attributes used for this model. The results are shown in Table 23.

\begin{tabular}{|c|c|c|c|c|c|}
\hline \multirow{5}{*}{ } & Success Attributes & $\begin{array}{l}\text { Units of } \\
\text { Measurement }\end{array}$ & Proposal 1 & Proposal 2 & Proposal 3 \\
\hline & Budget Cost-Share & $\begin{array}{l}\% \text { cost share } \\
\text { required to } \\
\text { fund research }\end{array}$ & $62 \%$ & $50 \%$ & $50 \%$ \\
\hline & Geographic Proximity & $\begin{array}{l}\text { proximity } \\
\text { between } \\
\text { research and } \\
\text { recipient }\end{array}$ & $\begin{array}{l}250-1500 \\
\text { miles } \\
\text { separation }\end{array}$ & $\begin{array}{l}250-1500 \\
\text { miles } \\
\text { separation }\end{array}$ & $\begin{array}{l}250-1500 \\
\text { miles } \\
\text { separation }\end{array}$ \\
\hline & Average Time to Contract & $\begin{array}{l}\text { average time } \\
\text { to execute a } \\
\text { contract }\end{array}$ & 4 months & 1.5 months & 1.5 months \\
\hline & $\begin{array}{l}\text { Technical \& Stakeholder } \\
\text { Complexity }\end{array}$ & $\begin{array}{l}\text { \# of technical } \\
\text { characteristics } \\
\text { identified in } \\
\text { proposal and \# } \\
\text { of impacted } \\
\text { stakeholders }\end{array}$ & $\begin{array}{l}2 \text { technology } \\
\text { characteristics } \\
\text { and } \\
3 \\
\text { stakeholders }\end{array}$ & $\begin{array}{l}1 \text { technology } \\
\text { characteristic } \\
\text { and } 3 \\
\text { stakeholders }\end{array}$ & $\begin{array}{l}2 \text { technology } \\
\text { characteristics } \\
\text { and } \\
7 \text { stakeholders }\end{array}$ \\
\hline \multirow{5}{*}{ 晃 } & Diversity Events & $\begin{array}{l}\text { \# of diversity } \\
\text { events to } \\
\text { create cultural } \\
\text { awareness }\end{array}$ & 0 & 0 & recommended \\
\hline & $\begin{array}{l}\text { Personnel Dedicated to } \\
\text { Support TT }\end{array}$ & $\begin{array}{l}\text { \# of people } \\
\text { dedicated to } \\
\text { support TT }\end{array}$ & 0.5 & 0.5 & 0 \\
\hline & Project Meetings & $\begin{array}{l}\text { \# of comms } \\
\text { described in } \\
\text { the comm } \\
\text { project plan }\end{array}$ & $\begin{array}{l}\text { monthly } \\
\text { meetings }\end{array}$ & $\begin{array}{l}\text { weekly and site } \\
\text { visits }\end{array}$ & weekly \\
\hline & $\begin{array}{l}\text { Personnel Loaned to } \\
\text { Recipient }\end{array}$ & $\begin{array}{l}\text { time that } \\
\text { researchers are } \\
\text { loaned to help } \\
\text { with TT }\end{array}$ & 0 & 0 & 1 year \\
\hline & $\begin{array}{l}\text { Successful TT } \\
\text { Experiences }\end{array}$ & $\begin{array}{l}\text { \# of previous } \\
\text { successful TT } \\
\text { experiences }\end{array}$ & 0 & 0 & 0 \\
\hline
\end{tabular}




\begin{tabular}{|c|c|c|c|c|c|}
\hline \multirow{6}{*}{ 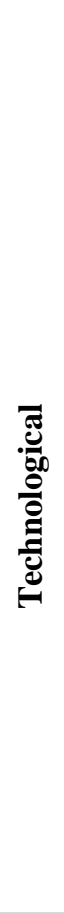 } & Success Attributes & $\begin{array}{l}\text { Units of } \\
\text { Measurement }\end{array}$ & Proposal 1 & Proposal 2 & Proposal 3 \\
\hline & $\begin{array}{l}\text { Combined Research } \\
\text { Experience }\end{array}$ & $\begin{array}{l}\text { \# years of } \\
\text { combined } \\
\text { research } \\
\text { experience of } \\
\text { principles }\end{array}$ & 47 years & 38 years & 46 years \\
\hline & Technology Publications & $\begin{array}{l}\text { \# publications } \\
\text { about } \\
\text { technology }\end{array}$ & $\begin{array}{l}45 \\
\text { publications }\end{array}$ & 23 publications & 16 publications \\
\hline & $\begin{array}{l}\text { Personnel Assigned to } \\
\text { TTO }\end{array}$ & $\begin{array}{l}\text { \# of personnel } \\
\text { assigned to } \\
\text { TTO }\end{array}$ & 0 & 3 & 3 \\
\hline & Technology Benefits & $\begin{array}{l}\text { \# technology } \\
\text { benefits } \\
\text { identified in } \\
\text { the research } \\
\text { proposal }\end{array}$ & 10 & 7 & 4 \\
\hline & Budget Allocated to TT & $\begin{array}{l}\% \text { R\&D } \\
\text { budget } \\
\text { dedicated to } \\
\text { TTO activities }\end{array}$ & 0 & 5 & 0 \\
\hline \multirow{4}{*}{ 离 } & $\begin{array}{l}\text { Comprehensiveness of } \\
\text { the Use Case }\end{array}$ & $\begin{array}{l}\text { How well is } \\
\text { the use Case } \\
\text { Defined }\end{array}$ & none & none & none \\
\hline & $\begin{array}{l}\text { Credibility of } \\
\text { Organizational Champion }\end{array}$ & $\begin{array}{l}\text { Credibility of } \\
\text { the } \\
\text { Organizational } \\
\text { Champion }\end{array}$ & $\begin{array}{l}\text { The } \\
\text { champion has } \\
\text { technical } \\
\text { expertise and } \\
\text { is recognized } \\
\text { within the } \\
\text { region as an } \\
\text { expert }\end{array}$ & $\begin{array}{l}\text { The champion } \\
\text { has technical } \\
\text { expertise and is } \\
\text { recognized } \\
\text { within the } \\
\text { region as an } \\
\text { expert }\end{array}$ & $\begin{array}{l}\text { The champion } \\
\text { has technical } \\
\text { expertise and is } \\
\text { recognized } \\
\text { within the } \\
\text { region as an } \\
\text { expert }\end{array}$ \\
\hline & $\begin{array}{l}\text { Level of Top } \\
\text { Management Interest }\end{array}$ & $\begin{array}{l}\text { Level of } \\
\text { Organizational } \\
\text { Support for TT }\end{array}$ & $\begin{array}{l}\text { There is some } \\
\text { support by } \\
\text { middle } \\
\text { management } \\
\text { but their } \\
\text { engagement } \\
\text { and support is } \\
\text { not consistent }\end{array}$ & $\begin{array}{l}\text { Executives are } \\
\text { aware of the } \\
\text { technology but } \\
\text { their } \\
\text { engagement is } \\
\text { not consistent }\end{array}$ & $\begin{array}{l}\text { Executives are } \\
\text { aware of the } \\
\text { technology but } \\
\text { their } \\
\text { engagement is } \\
\text { not consistent }\end{array}$ \\
\hline & Government Incentives & $\begin{array}{l}\text { \# and type of } \\
\text { government } \\
\text { incentives }\end{array}$ & $\begin{array}{l}\text { No incentives } \\
\text { for energy } \\
\text { pods used at } \\
\text { utility scale }\end{array}$ & $\begin{array}{l}\text { No incentives } \\
\text { exists to } \\
\text { encourage } \\
\text { technology } \\
\text { transfer }\end{array}$ & $\begin{array}{l}\text { No incentives } \\
\text { exists to } \\
\text { encourage } \\
\text { technology } \\
\text { transfer }\end{array}$ \\
\hline
\end{tabular}




\begin{tabular}{|c|c|c|c|c|}
\hline Success Attributes & $\begin{array}{l}\text { Units of } \\
\text { Measurement }\end{array}$ & Proposal 1 & Proposal 2 & Proposal 3 \\
\hline $\begin{array}{l}\text { Common Technology } \\
\text { Standards }\end{array}$ & $\begin{array}{l}\text { How are } \\
\text { common } \\
\text { standards } \\
\text { supported }\end{array}$ & $\begin{array}{l}\text { There are no } \\
\text { common } \\
\text { standards or } \\
\text { codes for the } \\
\text { technology }\end{array}$ & $\begin{array}{l}\text { Communication } \\
\text { standards (CEA } \\
2045, \mathrm{WiFi}, \\
\text { radio, etc.) - } \\
\text { Supported by a } \\
\text { consortium }\end{array}$ & $\begin{array}{l}\text { Communication } \\
\text { standards (CEA } \\
2045, \mathrm{WiFi}, \\
\text { radio, etc.) - } \\
\text { Supported by a } \\
\text { consortium }\end{array}$ \\
\hline ROI & ROI & 0 & 0 & 0 \\
\hline
\end{tabular}

Table 23: Proposal Characteristics

Relative to the other proposals, the strengths of proposal 1 (utility scale energy storage) is that they have the most years of combined research experience, most technology publications, and best awareness of recipient needs - their proposal includes 10 technology benefits. The weaknesses of their proposal are they require more cost-share and there is some support from middle management but it is not consistent. The strengths and weaknesses of proposal 1 and the corresponding desirability curve values are provided:

\begin{tabular}{|c|c|c|c|}
\hline Proposal 1 & Success Attribute & Success Attribute Score & Desirability Value \\
\hline \multirow[t]{3}{*}{ Strengths } & $\begin{array}{l}\text { Combined Research } \\
\text { Experience }\end{array}$ & $\begin{array}{l}47 \text { years of combined } \\
\text { experience }\end{array}$ & 85 \\
\hline & Technology Publications & 45 publications & 100 \\
\hline & Technology Benefits & 10 technology benefits & 100 \\
\hline \multirow[t]{2}{*}{ Weaknesses } & Cost-Share & $62 \%$ & 40 \\
\hline & $\begin{array}{l}\text { Level of Management } \\
\text { Interest }\end{array}$ & $\begin{array}{c}\text { Some support by middle Mgmt } \\
\text { but it is not consistent }\end{array}$ & 32 \\
\hline
\end{tabular}

Table 24: Proposal \#1 Strengths and Weaknesses 
Proposal 2's (heat pump water heaters for demand response) strengths include have the least technical complexity, therefore, the researchers are able to have very directed focus and not worry about the interface of many technology characteristics. The proposal has the best description of project team meetings - weekly meetings and site visits are planned. There is support, but not consistent, from executives within the organization. It also is the only proposal that dedicates a portion of the project budget to technology transfer activities. Its weakest area is in their personnel loan policy - one does not exist. The strengths and weaknesses of proposal 2 and the corresponding desirability curve values are provided:

\begin{tabular}{|l|l|c|c|}
\hline Proposal 2 & \multicolumn{1}{|c|}{ Success Attribute } & Success Attribute Score & Desirability Value \\
\hline Strengths & Technical Complexity & 1 technology characteristic & 100 \\
\cline { 2 - 4 } & Project Meetings & Weekly meetings and site visits & 100 \\
\cline { 2 - 4 } & $\begin{array}{l}\text { Level of Management } \\
\text { Interest }\end{array}$ & $\begin{array}{c}\text { Execs are aware but their } \\
\text { engagement is not consistent }\end{array}$ & 43 \\
\cline { 2 - 4 } & $\begin{array}{l}\text { Budget Allocated to TT } \\
\text { 5\% of R\&D budget is allocated } \\
\text { to TT }\end{array}$ & 57 \\
\hline Weaknesses & $\begin{array}{c}\text { Personnel Loan to Recipient } \\
\text { Researchers are not loaned to } \\
\text { TT recipient }\end{array}$ & 0 \\
\hline
\end{tabular}

Table 25: Proposal \#2 Strengths and Weaknesses

Proposal 3 (Supermarket Refrigeration) characteristics are similar to proposal 2 except that proposal 3 has a personnel loan policy and recommend diversity events - each of these supports successful technology transfer. However, this proposal has the most amount of stakeholder complexity, which could be a barrier to successful technology transfer. This weakness could be offset by the number of project team meetings they have proposed. The strengths and weaknesses of proposal 3 and the corresponding desirability curve values are provided: 


\begin{tabular}{|l|l|c|c|}
\hline Proposal 3 & \multicolumn{1}{|c|}{ Success Attribute } & Success Attribute Score & Desirability Value \\
\hline Strengths & Technical Complexity & 2 technology characteristics & 83 \\
\cline { 2 - 4 } & Project Meetings & Weekly meetings & 90 \\
\cline { 2 - 4 } & $\begin{array}{l}\text { Level of Management } \\
\text { Interest }\end{array}$ & $\begin{array}{c}\text { Execs are aware but their } \\
\text { engagement is not consistent }\end{array}$ & 43 \\
\cline { 2 - 4 } & Personnel Loan to Recipient & $\begin{array}{r}\text { Researchers are loaned up to 1 } \\
\text { year }\end{array}$ & 77 \\
\cline { 2 - 4 } & Diversity Events & Recommended & 22 \\
\hline Weakness & Stakeholder Complexity & 7 stakeholders & 3 \\
\hline
\end{tabular}

Table 26: Proposal \#3 Strengths and Weaknesses

For all proposals in the case study, an ROI was not available. It's not that one cannot be calculated; rather, it is about one not being determined for each proposal. Therefore, the score of ROI is zero for all three proposals and the corresponding desirability value is also zero.

The desirability values for each of the success attributes were captured for each proposal. These values were multiplied by the relative weights and the perspective weight to determine the technology transfer score. The corresponding success attributes are captured in Appendix G. Table 27 shows the technology transfer score for each proposal.

\begin{tabular}{|l|l|l|l|}
\hline Baseline Analysis & Proposal 1 & Proposal 2 & Proposal 3 \\
\hline Technology Transfer Score & 37.6 & 47.7 & 45.7 \\
\hline Rank & 3 & 1 & 2 \\
\hline
\end{tabular}

Table 27: Baseline Technology Transfer Scores

The highest possible score for each proposal, based on the perspective priorities and corresponding weights for the success attributes, is 100.00 . None of the 
proposals had a high technology transfer score. One of the analysis scenarios will discuss how a proposal can improve the technology transfer potential.

Proposal 2 had the highest technology transfer score. Looking at the desirability curve values, along with the success attribute and perspective prioritization to understand the resulting technology transfer score, proposal 2 had executive engagement in the Market perspective; Market perspective was the most important perspective as determined by the expert panel (.39). The executive engagement was not consistent, however. Nonetheless, this set the proposal apart for proposal 1 were there was only middle management support. The next most important perspective was technological (0.23). Within the technological perspective, the most important success attribute was technology benefits (0.32). Proposal 2 had a high number technology benefits identified. Proposal 2 also had personnel assigned to the TTO. The social perspective is where the biggest differences are for proposal 2. Relative to the other two proposals, proposal 2 has the best project meetings value. Their proposal identified weekly team meetings and site visits. These attributes are important to facilitate communication and subsequently trust among the project team.

Proposal 1 scored the lowest of all three (proposals). One difference was the level of top management support. This success attribute is associated with the highest ranked perspective (Market, 0.39) and it corresponds to the second highest ranked success attribute (level of top management interest, 0.22 ) - so if a proposal scores low in this area it is bound to have an impact on its overall technology transfer score. In 
fact, it does. Of the three proposals, this one only had middle management support and it was inconsistent.

In this section, we have established the baseline technology transfer scores. The remainder of this chapter will look several scenarios to understand the robustness of the model.

\subsection{Scenario Analysis}

In these scenarios, the model looks at the impact to the proposal rank if the emphasis or importance of the perspective level changes. Currently, the emphasis is on Market, suggesting that a "market-pull" is most important for successful technology transfer. In other words, creating an environment, through financial and managerial support systems, that creates a market that is ready to accept the technology. Each perspective will be changed to a value of 0.97 , keeping the other perspectives at 0.01 to maintain the overall contribution to the technology transfer score at 1.0. The result will be three scenarios where each perspective is changed, independently. The impact on the proposal rank will be discussed.

The next analysis will be to understand how sensitive the perspective level is to potential changes in the expert judgment quantification. If new experts were to quantify the perspective level, how sensitive is the model in order to preserve the rank of the proposals? The acceptable range of perturbations will be discussed.

The focus of the case study was on demand response technologies. However, can the model be used to evaluate other technology types? This scenario will test 
how generalizable the model is. A non-demand response technology will be used to determine if the success attributes are appropriate to be used with other technologies.

Finally, as we saw in the baseline analysis, the scores for the three proposals were not extraordinary - there is room for improvement. The last analysis scenario will address what a research organization can do to improve their technology transfer potential.

\subsubsection{Future Based Scenario - Perspective Weights Change}

The expert panels determined that the market perspective is the most important to facilitate technology transfer. However, what if another perspective was evaluated as more important?

If the organizational perspective were ranked highest, this suggests that organizational activities are more important to focus on to improve technology transfer potential. Setting the organizational perspective to 0.97 and the other values are kept at 0.01 . Doing this results in the following proposal rank:

\begin{tabular}{|l|l|l|l|}
\hline Baseline Analysis & Proposal 1 & $\begin{array}{l}\text { Proposal } \\
2\end{array}$ & $\begin{array}{l}\text { Proposal } \\
3\end{array}$ \\
\hline Technology Transfer Score & 37.6 & 47.7 & 45.7 \\
\hline Rank (baseline) & 3 & 1 & 2 \\
\hline $\begin{array}{l}\text { Organizational Emphasis } \\
\text { Technology Transfer Score }\end{array}$ & 48.78 & 62.09 & 51.06 \\
\hline Rank (organizational) & 3 & 1 & 2 \\
\hline
\end{tabular}

Table 28: Organizational Emphasis - Impact on Proposal Rank

Changing the emphasis to an organizational slant does not impact the rank of the proposals. The overall scores increase, especially for proposal 2. This is because the 
highest weighted success attribute is technical complexities - proposal 2 has the least technical complexity project, and therefore has a higher desirable value.

Changing the emphasis to a technological one would suggest a technology push is more important for developing a technology transfer score; in the baseline scenario, technological is the second most important perspective. For this scenario, technological weight was changed to 0.97 , while the other three were kept at 0.01 . The impact to the rank of the proposals is shown in Table 29.

\begin{tabular}{|l|l|l|l|}
\hline Baseline Analysis & Proposal 1 & $\begin{array}{l}\text { Proposal } \\
2\end{array}$ & $\begin{array}{l}\text { Proposal } \\
3\end{array}$ \\
\hline Technology Transfer Score & 37.6 & 47.7 & 45.7 \\
\hline Rank (baseline) & 3 & 1 & 2 \\
\hline $\begin{array}{l}\text { Technological Emphasis: } \\
\text { Technology Transfer Score }\end{array}$ & 71.58 & 87.23 & 78.52 \\
\hline Rank (organizational) & 3 & 1 & 2 \\
\hline
\end{tabular}

Table 29: Technological Emphasis - Impact on Proposal Rank

While the rank does not change, the gap between the scores is less, with a significant improvement by proposal 1 . This can be understood when looking at the highest success attribute within the technological perspective. The highest weighted success attribute is technology benefits $(0.32)$ and then technology publications (0.22). Both proposal 1 and 2 have the highest desirability scores for these attributes.

Finally, what happens to the rank if the social perspective is weighted the highest? This scenario would represent more emphasis on project management skills to improve the technology transfer score. 
Similar to the other scenarios, the social perspective is set to 0.97 and the other three perspectives have a value of 0.01 . The impact to the proposal rank is shown in Table 30.

\begin{tabular}{|l|l|l|l|}
\hline Baseline Analysis & Proposal 1 & $\begin{array}{l}\text { Proposal } \\
2\end{array}$ & $\begin{array}{l}\text { Proposal } \\
3\end{array}$ \\
\hline Technology Transfer Score & 37.6 & 47.7 & 45.7 \\
\hline Rank (baseline) & 3 & 1 & 2 \\
\hline $\begin{array}{l}\text { Social Emphasis: Technology } \\
\text { Transfer Score }\end{array}$ & 27.27 & 30.37 & 40.65 \\
\hline Rank (organizational) & 3 & 2 & 1 \\
\hline
\end{tabular}

Table 30: Social Emphasis - Impact on Proposal Rank

Changing the importance of the perspectives to a social emphasis does have an impact on the rank of the proposals. Proposal 1 remains in third place, but proposal 2 and 1 swap. Looking at the success attributes to understand the change, proposal 3 is the only one that recommends diversity events and has a personnel loan policy. These success attributes are included under the social perspective and therefore the swap of proposals 2 and 3 is appropriate.

Each of these represents an extreme, and unlikely, change in perspective weight. The unlikeliness is due to the probability that an expert panel would all answer similarly when doing pairwise comparisons, such that any perspective would result in such a high score.

The next scenario will examine the sensitivity of the model to perturbations in the expert responses at the perspective level. 


\subsubsection{Preserve Highest TT Score}

This scenario looks at what happens to the rank if there are changes in the expert judgment quantification. What are the allowable changes in their input in order to preserve the rank of the proposals? Using the sensitivity analysis presented by Chen [98], Table 31 shows the allowable changes in each perspective weight, in order to preserve the rank of Proposal 2, Proposal 3, and Proposal 1.

\begin{tabular}{|l|l|l|}
\hline Perspective & Base Value & Tolerance [min, max] \\
\hline Organizational & 0.18 & {$[0.008,1]$} \\
\hline Technological & 0.23 & {$[0.012,1]$} \\
\hline Social & 0.20 & {$[0,0.381]$} \\
\hline Market & 0.39 & {$[0.008,1]$} \\
\hline
\end{tabular}

Table 31: Allowable Change in Perspective Values

The model is sensitive to changes in the social perspective. Both proposal 2 and 3 have similar desirability values for the top weighted success attributes in the social perspective. However, when the personnel loan policy is considered (0.16), proposal 2 does not have a policy while proposal 3 has a favorable leave policy.

\subsubsection{Can the Model be used for Other Technologies?}

The emphasis of the case study is on demand response technologies because of their ability to address the system stability issues facing the utility industry. However, there are other technologies that can be used as potential solutions for stability that are not related to demand response. 
Another proposal was considered from the 2016 BPA R\&D portfolio. Again, specifics about the technology and research partnerships will remain anonymous. This technology looks at algorithms to push the operating envelope of the electric grid. By allowing the system operating limits to increase this would help with congestion management and subsequent system stabilities. Similar to the demand response proposals the technology is mature (TRL 7-9). This scenario also uses an actual value for ROI that was provided with the research proposal.

The corresponding proposal attributes are shown in Table 32 .

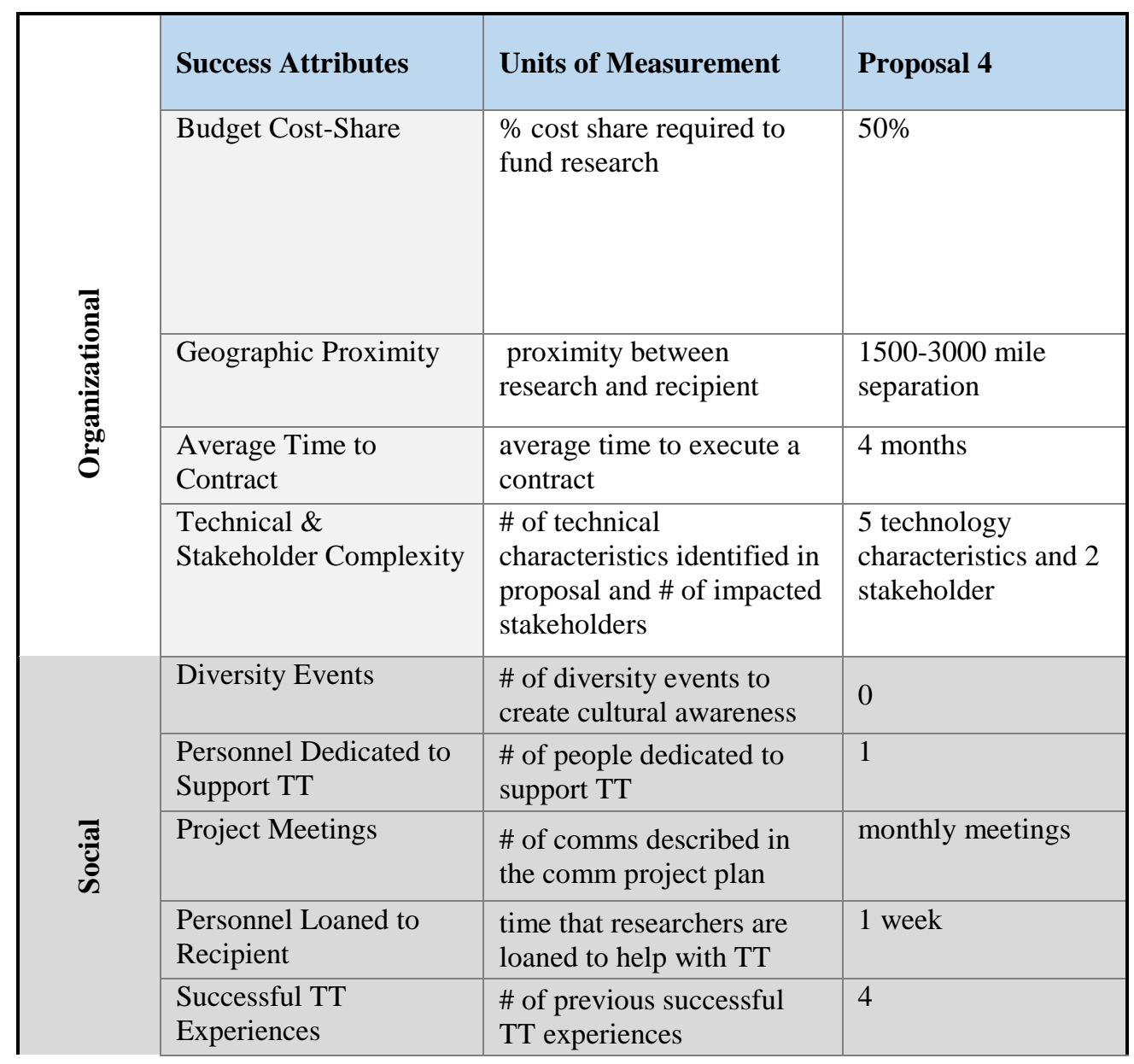




\begin{tabular}{|c|c|c|c|}
\hline \multirow{6}{*}{ "⿹ } & Success Attributes & Units of Measurement & Proposal 4 \\
\hline & $\begin{array}{l}\text { Combined Research } \\
\text { Experience }\end{array}$ & $\begin{array}{l}\text { \# years of combined } \\
\text { research experience of } \\
\text { principles }\end{array}$ & 44 years \\
\hline & $\begin{array}{l}\text { Technology } \\
\text { Publications }\end{array}$ & $\begin{array}{l}\text { \# publications about } \\
\text { technology }\end{array}$ & 16 publications \\
\hline & $\begin{array}{l}\text { Personnel Assigned to } \\
\text { TTO }\end{array}$ & $\begin{array}{l}\text { \# of personnel assigned to } \\
\text { TTO }\end{array}$ & 0 \\
\hline & Technology Benefits & $\begin{array}{l}\text { \# technology benefits } \\
\text { identified in the research } \\
\text { proposal }\end{array}$ & 7 \\
\hline & Budget Allocated to TT & $\begin{array}{l}\text { \% R\&D budget dedicated } \\
\text { to TTO activities }\end{array}$ & 0 \\
\hline \multirow{6}{*}{ 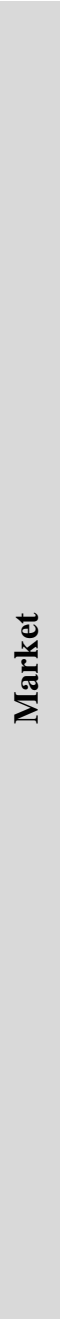 } & $\begin{array}{l}\text { Comprehensiveness of } \\
\text { Use Case }\end{array}$ & $\begin{array}{l}\text { How well is the use Case } \\
\text { Defined }\end{array}$ & none \\
\hline & $\begin{array}{l}\text { Credibility of } \\
\text { Organizational } \\
\text { Champion }\end{array}$ & $\begin{array}{l}\text { Credibility of the } \\
\text { Organizational Champion }\end{array}$ & $\begin{array}{l}\text { The champion has } \\
\text { technical expertise } \\
\text { and is recognized } \\
\text { within the } \\
\text { organization as an } \\
\text { expert }\end{array}$ \\
\hline & $\begin{array}{l}\text { Level of Top } \\
\text { Management Interest }\end{array}$ & $\begin{array}{l}\text { Level of Organizational } \\
\text { Support for TT }\end{array}$ & $\begin{array}{l}\text { There is some } \\
\text { support by middle } \\
\text { management but } \\
\text { their engagement } \\
\text { and support is not } \\
\text { consistent }\end{array}$ \\
\hline & Government Incentives & $\begin{array}{l}\text { \# and type of government } \\
\text { incentives }\end{array}$ & $\begin{array}{l}\text { transient stability } \\
\text { modeling important - } \\
1 \text { regulatory } \\
\text { incentive }\end{array}$ \\
\hline & $\begin{array}{l}\text { Common Technology } \\
\text { Standards }\end{array}$ & $\begin{array}{l}\text { How are common } \\
\text { standards supported }\end{array}$ & $\begin{array}{l}\text { IEEE Standards for } \\
\text { PMU data used with } \\
\text { modeling - } \\
\text { Supported by a } \\
\text { consortium - more } \\
\text { generalized support } \\
\text { and awareness by a } \\
\text { community but there } \\
\text { is no formal } \\
\text { requirement in place }\end{array}$ \\
\hline & ROI & ROI & $\begin{array}{l}>20 \% \text { but less than } \\
50 \% \text { ROI }\end{array}$ \\
\hline
\end{tabular}

Table 32: Proposal 4 Characteristics 
The technology transfer score is evaluated as 39.54

Looking at the success attributes and perspectives, none of them is specific to a technology. Therefore, the model is generalizable and technology agnostic - it can be used to evaluate research proposals for all types of technologies, not just those used for the case study.

\subsubsection{What can the Researcher do to Improve Their TT Score (and increase the potential for successful TT)?}

The value of this research is most readily seen when we consider the literature review in Chapter 2.4. This section looked at the evaluation criteria of several government R\&D organizations. While the objective for each organization is to apply promising research results - the evaluation criteria stops short of explicitly and comprehensively addressing the technology transfer success attributes as part of the evaluation criteria. This research would provide a supplemental assessment tool that would increase the likelihood of successful application. Recall that the top TT score possible is 100 . What could each proposal do to increase their technology transfer potential from the baseline values shown earlier is this chapter (Table 27)?

Proposal 1 (baseline score of 37.61)

To improve the baseline score the level of top management support needs to improve. It could improve by more dedicated meetings with the management team to understand their resistance to the technology and to clarify any misgivings or to emphasize the benefits of the technology. The next area of improvement would be to 
have dedicated people assigned to the TT office. However, because the company sponsoring the proposal is a small private organization, a dedicated TT Office might be a challenge from a resource or financial perspective. Assigning dual roles to the project team members could improve the TT potential but it may also be a distraction for the team trying to allocate time to many project activities.

For each of the individual extreme scenarios previously identified, Proposal 1 could emphasize other success attributes to improve their TT score. For the Technological focus, the proposal scored high in the number of technology benefits, but they would need to have some percentage of the R\&D budget dedicated to TT activities; currently there is no budget allocated.

If the extreme scenario is a Social focus, Proposal 1 could improve their score by having more frequent project team meetings; of the three proposals, this one had the fewest interactions. Regarding loaning researchers, this is a small company so loaning researchers might detract from other projects or work and would not be feasible. Likewise, if the extreme scenario is an Organizational focus, having a more focused proposal (e.g. fewer technology characteristics) and fewer stakeholders would improve their TT score. A similar analysis is done for Proposal 3.

Proposal 3 (baseline score: 45.73)

Proposal 3 had similar Market success attribute scores as Proposal 2 (the highest TT score). However, there is room for improvement in the other perspectives and success attributes. Having more consistent engagement from executives would be 
beneficial for the TT score; this is the highest weighted perspective (Market) and the highest rated success attribute (Level of Top Management Interest).

In a Technological focus extreme scenario increasing the number of technology publications and the number of technology benefits would improve the TT score; Proposal 3 had the lowest number of technology benefits identified of the three proposals.

For a Social focus Proposal 3 could increase the number of team meetings and the number of personnel dedicated to the TTO. Proposal 3 would benefit from decreasing the number of impacted stakeholders in an Organizational focus extreme scenario. Proposal 3 had the highest number of impacted stakeholders (7). The effort to maintain effective communication among so many stakeholders would be significant.

A summary of the changes is shown in Table 33. The table shows the baseline TT score as well as the impact of making incremental changes to improve desirability value. The incremental impacts are represented by the "better success attribute score" and the corresponding TT score and percent increase over the baseline TT score are shown. Also, the impact of increasing to the best success attribute score is provided. However, it may or may not be possible to increase the values this significantly (e.g. decreasing the number of impacted stakeholders or increasing the number of personnel dedicated to TT), but the outcome is shown for the best potential increase. Note that the changes in desirability values and subsequent TT scores are only 
considered for the highest success attributes. Increases in other success attributes would also incrementally improve the TT score. 


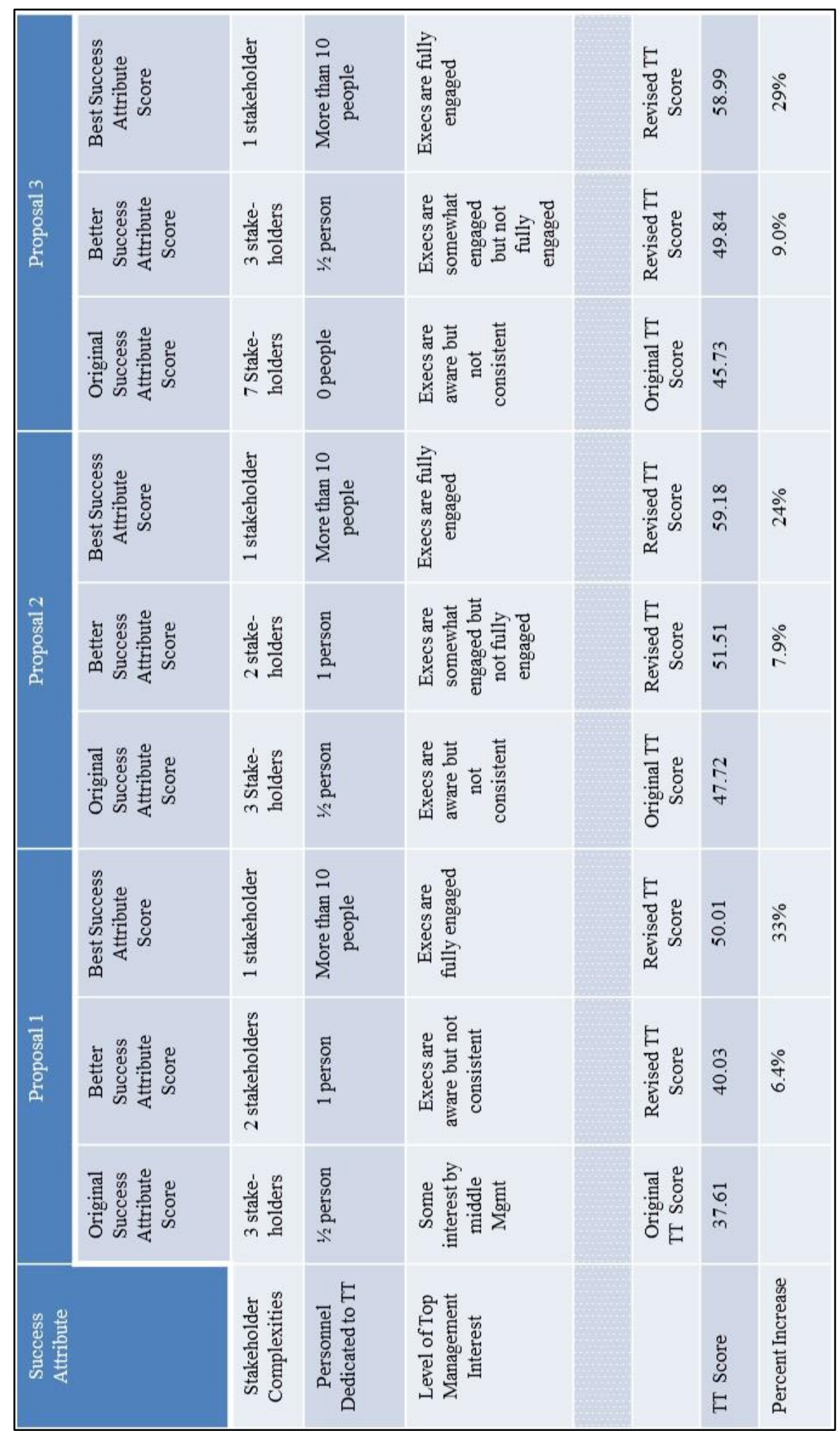

Table 33: TT Score Increases with Changes to Desirability Values 
The TT Scores can also be used to highlight potential areas where the researcher or technology recipient should focus during the R\&D phase. As an example, Proposal 1 does not have support in the organization from executives and there is no personnel loan policy. Despite the low TT score, the technology recipient may still want to include the proposal because it is technically interesting. Knowing the areas of weakness related to TT, the recipient organization can implement measures to address the weaknesses. For example, they may be able to fund personnel to encourage a loan policy and they can be proactive in engaging executives. The model provides enough detail that areas of proposal weakness, related to technology transfer potential, can be assessed. This information can be used to either 1. Not include the proposal in the portfolio or 2. Emphasize areas the technology recipient should focus on if the proposal is selected. This latter scenario assumes that the project is technically attractive but the technology transfer score suggests it should not be added to the portfolio.

In summary, the case study and analysis scenarios demonstrate the capabilities of this model. It is generalizable and technology agnostic and relatively robust to changes in the perspective weights.

The next chapter reviews the validation processes and comments on the model's ability to represent what happened: did the case study results accurately reflect portfolio decisions at BPA? 


\section{CHAPTER 8: MODEL VALIDATION}

The process for developing a model includes construct validation, content validation and criterion related validation. Each of these steps was performed with the model developed for this research. Each process is discussed to include the purpose for doing the validation, the method, and the outcomes.

\subsection{Construct Validity}

The purpose for doing construct validation is to determine if the preliminary model construct is suitable for measuring the desired outcome - this is the initial check with the people who are familiar with model development and solicit their feedback.

The model was developed based on a comprehensive literature review that included four parts - these are outlined in chapter 2. The outcome resulted in a multiperspective decision model that included more than 50 technology transfer success attributes. These 50-plus attributes were consolidated as appropriate, to the final number of 22 success attributes. As an example, organizational homogeneity was used to capture similar strategic alignment, similar industries and composition of personnel, size of firms, motivations for doing research, and similar expectations for success.

The next step was for faculty and students who are familiar with hierarchical decision modeling to comment on the clarity of the questions and definitions. Their feedback was incorporated into the model that is used for content validation. 


\subsection{Content Validity}

Experts from panel $\mathrm{P}_{0}$ were asked to validate the content of the HDM as a tool to measure the technology transfer potential of a research proposal. In other words, do these perspectives and success attributes look appropriate for successful technology transfer?

Panel $\mathrm{P}_{0}$ provided their input via a Survey Monkey assessment tool. They were asked if each perspective and success attribute was accurate for a successful technology transfer (yes or no) and if not, they were asked to comment why. Also, space was provided to add additional comments.

Based on their input and follow-up with my committee members, the following model adaptations were made:

- Organizational homogeneity was removed

- Technical and stakeholder complexities was further subdivided into Technical Complexities and Stakeholder Complexities

- The nomenclature was simplified to define exactly what was being measured. As an example, bureaucracy is a very broad term. The attribute was further refined to "Average Time to Contract" - the spirit of the attribute did not change, it was made more specific with what was being measured

The revised model was presented to other expert panels for quantification. 


\subsection{Criteria Related Validity}

The final validation was to test the model against a case study and ask experts to determine if the results of the model represent reality. The experts were also asked to verify if the model could be generalized to other than the case study application. Finally, the experts are asked how the model could be implemented in their organizations and to comment on any issues or barriers to adoption.

The model results were presented to BPA executives and they were asked if the model represented the performance of these projects in the portfolio. Both proposal two and three were performing well and said that the model correctly identified these two as high performers and having the most potential for technology transfer. Proposal one scored low based on the level of top management support. In fact, the proposal was cut from the BPA portfolio before it completed due to lack of support from upper management. In addition, BPA confirmed that the Technology Transfer score will be piloted as part of their fiscal year 2018 research solicitation.

The analysis scenarios were also appropriate and mirror activities at the agency. The BPA is reviewing their current portfolio and project management practices for capital projects - this activity is what is postulated in the analysis scenarios where the Social perspective could be the most important. While there was only one expert from BPA on the P1 panel, this is the panel that quantified the perspective level, the agency may consider re-evaluating the perspective level, representing a more BPA focus. This would be a recommended action if the technology transfer score were going to be implemented for the capital program. 


\section{CHAPTER 9: DISCUSSION}

So far the research and analysis results show that the technology transfer score is an agnostic tool that can help an organization in the selection of proposals that have the most potential for technology transfer. But how can a research organization, like those discussed in Chapter 2.4, practically apply the results?

\subsection{Practical Application: General}

Looking at the general structure of the decision model, the perspective level and success attributes can be applied to any research organization. Each perspective and corresponding success attribute has been validated by expert panels that have a broad understanding of technology transfer, across many sectors. The expert panels confirmed that the structure and model content were appropriate for measuring successful technology transfer. Similarly, the perspective level and success attribute weights were assessed by expert panels with a breadth of appropriate technology transfer expertise. Therefore, the model is generalizable and can be readily applied to any research organization, regardless of technology.

A specific response for how a research organization can practically use the tool is understood with a more thorough consideration of the case study results. For these proposals, the desirability scores were extracted, in most cases, from the information already included in the research proposal provided to the BPA. In a few cases (e.g. level of top management interest, etc.), interviews with BPA personnel was required. Knowing that other research organizations may not have the same proposal requirements, the proposal content may have to be adapted to obtain the 
information required to calculate the score. In fact, the BPA will be conducting a pilot of the technology transfer score as part of their fiscal year 2018 solicitation. The solicitation will include an appendix that specifically asks for the information needed to calculate a technology transfer score. The objectives of the pilot will be to assess the willingness of the researchers to provide information and any other potential issues with collecting the necessary data.

The remaining sections of this chapter review the prioritized success attributes within each perspective and make suggestions about actions an organization can take to ensure these are incorporated into their technology transfer process. Note that the emphasis of these recommendations is only on the highest ranked success attribute within each perspective - it will have the biggest impact on the technology transfer score. Of course actions can be taken for the other success at tributes.

\subsection{Practical Application: Organizational Perspective}

The success attributes within the organizational perspective that ranked highest are technology and stakeholder complexities. This attribute refers to the number of technology characteristics or research areas the proposal addresses as well as the number of impacted stakeholders. An organization should aim for projects with less technical and stakeholder complexity for successful technology transfer. The recommended actions are summarized in Table 34. 


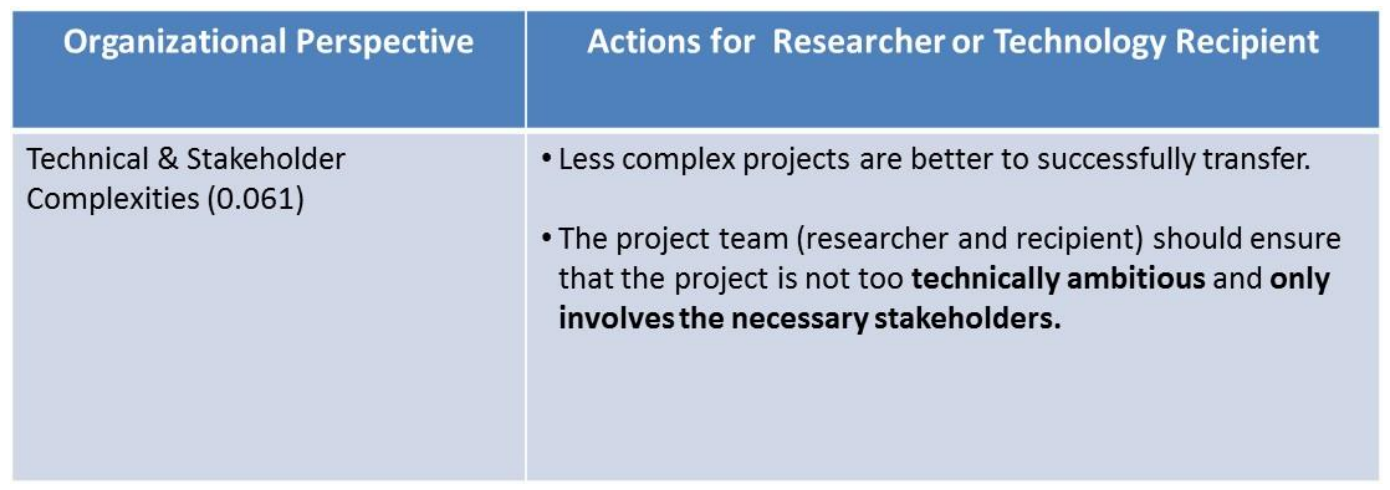

Table 34: Actions for the Organizational Perspective

\subsection{Practical Application: Technological Perspective}

The success attribute within the technological perspective that ranked the highest is technology benefits. As defined, this success attribute emphasizes the need to understand the perceptions of the technology adopter. Actions that an organization can take to improve the technology benefit value are identified in Table 35. The understanding of technology recipient needs was underscored by the expert panel during the model validation phase, “...ensure technology is developed with an understanding of ultimate transfer requirements..."

\begin{tabular}{|c|c|}
\hline Technological Perspective & Actions for Researcher or Technology Recipient \\
\hline Technology Benefits (0.074) & $\begin{array}{l}\text { - Being able to communicate about the technology's } \\
\text { benefits is complementary to the Market Perspective. } \\
\text { - The research organization should be able to identify the } \\
\text { technology benefits } \\
\text { - The technology recipient should validate the researcher's } \\
\text { claims about technology benefits and resolve } \\
\text { discrepancies. }\end{array}$ \\
\hline
\end{tabular}

Table 35: Actions for the Technological Perspective 


\subsection{Practical Application: Social Perspective}

The success attribute within the social perspective that ranked as most important is project meetings. This attribute refers to one method of establishing trust among the research team. The recommended action is to conduct frequent team meetings as a way of creating an open dialogue within the team. The open dialogue will be essential to identification of barriers to successful technology transfer. The importance of communication was described by the expert panel during model validation: “...major item that directly relates to success is communication. Users need to understand the value for their company. Communication is absolutely necessary...". The recommended actions are summarized in Table 36.

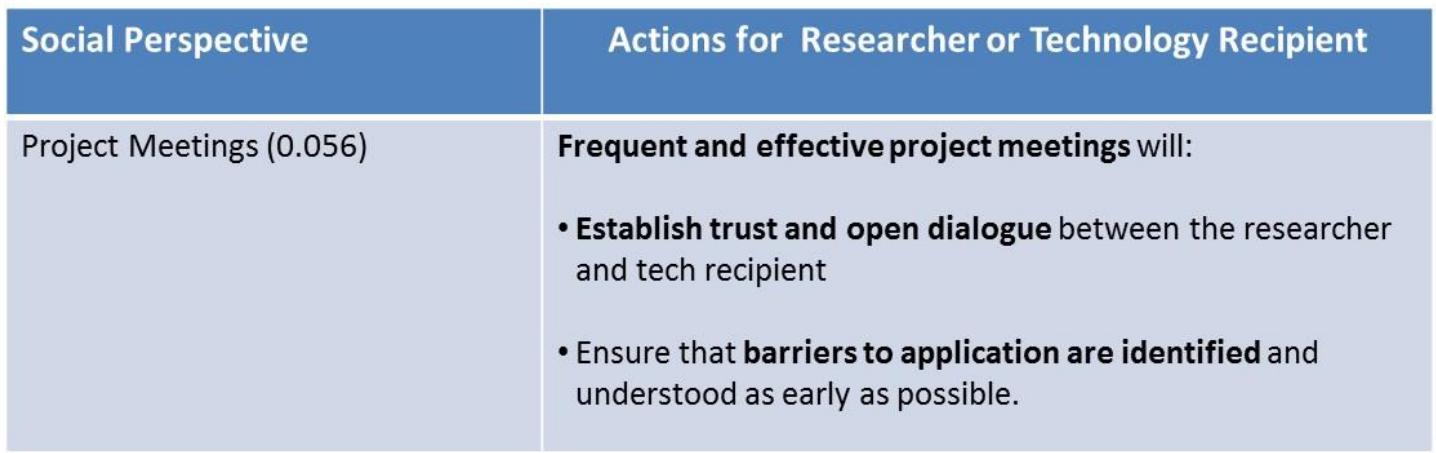

Table 36: Actions for the Social Perspective

\subsection{Practical Application: Market Perspective}

There were two success attributes within the market perspective that were rated the highest, ROI and the level of top management interest. These success attributes create a foundation for successful technology transfer to occur by creating a favorable ROI and ensuring that top management are actively engaged in the project. The importance of these success attributes were emphasized by several expert panel responses during the model validation phase, “...understand the need for market 
interest....does the result fix a specific problem or can it be broadly applied...", “...cost/benefit assessments for the technology and applications are necessary for technology transfer...”, and “...successful technology transfer requires 1. Early management of commercial entities/vendors and the end users within the R\&D organization developing the technology to ensure it is developed with an understanding of ultimate transfer requirements 2. Significant commitment from the R\&D organization..." The recommended actions are described in Table 37.

\begin{tabular}{|c|c|}
\hline Market Perspective & Actions for Researcher or Technology Recipient \\
\hline Market Perspective (0.39) & $\begin{array}{l}\text { - Expert opinion underscores resounding themes in literature that } \\
\text { creating a market-pull is more effective for technology transfer } \\
\text { - The two highest success attributes lay the foundation in the recipient } \\
\text { organization: the technology is a good financial investment and has } \\
\text { top management support. }\end{array}$ \\
\hline Level of Top Management Interest (0.085) & $\begin{array}{l}\text { - The technology recipient should ensure that the business case is } \\
\text { understood at the highest levels in the organization. Frequent } \\
\text { communication (via project meetings) with executives will ensure that } \\
\text { their concerns are identified early. In addition, executives can be used } \\
\text { to eliminate barriers to adoption - the higher up the more influential. }\end{array}$ \\
\hline
\end{tabular}

Table 37: Actions for the Market Perspective 


\section{CHAPTER 10: CONCLUSIONS}

This final chapter summarizes the research by documenting the conclusions, demonstrating how the gaps were addressed, and how this research contributes to increasing the potential of successful technology transfer. The analysis of the data identified potential limitations; assumptions were made that represent constraints or model limitations. Discussion is included to suggest how the limitations present opportunities for future research.

\subsection{Conclusions and Contributions}

This research focused on identifying what attributes should be the focus to facilitate successful technology transfer and development of a technology transfer score that can be used to inform the selection of the most promising research proposal. The model framework and literature defined success attributes were determined appropriate for assessing the technology transfer potential of a research proposal by an extensive expert panel. The qualitative results of the model are consistent with literature findings. That is, technology transfer is more about building and maintaining an effective relationship between the researcher and technology recipient.

The real benefit of this research is seen when Chapter 2.4 is considered. This segment of the literature review demonstrated that the success attributes necessary for technology transfer are only peripherally addressed as part of the proposal evaluation criteria. While some are addressed, they are not quantified. For instance, having 10 technology related publications is better than five publications versus whether the research organization just had relevant publications. While the objective for each organization is to apply promising research results - the evaluation criteria stops short of 
explicitly and comprehensively addressing the technology transfer success attributes as part of the evaluation criteria. This research would provide a supplemental assessment tool that would increase the likelihood of successful application.

The results of this research will provide valuable information to organizations that sponsor research. Knowledge is power - by identifying those attributes which contribute to successful technology transfers, an organization could take a proactive approach by ensuring that those elements are implemented and effective in their organizations. While the case study focus is on the utility industry, the model can easily be applied to any organization that solicits technology research proposals and the TT score can be incorporated appropriately in an assessment methodology.

The criterion related validation confirmed that this model would be useful as an additional input into the proposal evaluation process. If the model had been used, would proposal 3 have been selected? If so, it would have identified potential issues with management support that could have been addressed, instead of the project being removed from the portfolio.

The model addresses the gaps identified as part of the literature review. Table 38 summarizes the gaps and the contributions this research addresses.

\begin{tabular}{|l|l|}
\hline \multicolumn{1}{|c|}{ Research Gaps } & \multicolumn{1}{c|}{ Contributions } \\
\hline $\begin{array}{l}\text { Research proposals do not } \\
\text { comprehensively consider technology } \\
\text { transfer potential }\end{array}$ & $\begin{array}{l}\text { The model demonstrates that attributes } \\
\text { that are included with research proposal } \\
\text { can be used to develop a framework for } \\
\text { comprehensively considering technology } \\
\text { transfer during the research proposal } \\
\text { phase. }\end{array}$ \\
\hline $\begin{array}{l}\text { No comprehensive technology transfer } \\
\text { success attribute framework exists }\end{array}$ & $\begin{array}{l}\text { Using desirability curves along with the } \\
\text { hierarchical decision model provides a } \\
\text { technology transfer potential exits }\end{array}$ \\
\hline
\end{tabular}




\begin{tabular}{|l|l|}
\hline \multicolumn{1}{|c|}{ Research Gaps } & \multicolumn{1}{c|}{ Contributions } \\
\hline & $\begin{array}{l}\text { technology transfer potential of a research } \\
\text { proposal }\end{array}$ \\
\hline
\end{tabular}

Table 38: Research Contributions

\subsection{Limitations}

The proposed model develops a technology transfer score that can be used as a part of the proposal selection process at a research organization. For the purposes of this research, the case study is on utility industry R\&D. However, the research model can be extended to other types of organizations (e.g. National Institute for Heath, Department of Energy, etc.). This assertion is practically demonstrated with the non-demand response research proposal. This analysis scenario demonstrated that the proposed model is technology agnostic. However, what is unknown is the willingness or interest of other organizations to adopt the methodology.

Great care was taken to identify the best panels to provide their judgment quantification. However, if different expert panel were used, the outcomes, definitions could be different. The model reflects their bias and understanding of the model at the time. Changing markets, strategies and other factors would likely influence their

judgment. While the scenario analysis attempted to mitigate these biases, there still is the potential for some impact.

The proposed research has support from utility R\&D executives and subject matter experts; as mentioned the model will be used as part of BPA's next R\&D solicitation. During the criterion related validation, comments were provided that could be identified as limitations with the model framework. These include: 
- Quantifying data: most of the success attributes that were identified are qualitative (e.g. level of top management interest, personnel loan policies, etc.). Translating these to quantitative measurements via desirability curves requires explicit definition of terms. Nevertheless, the evaluations and development of utility curves is left to interpretation by subject matter experts and reliance on linguistic choices [99]. Therefore, it is extremely important that the success attribute terms be defined to minimize the interpretation by evaluators.

- Who would be responsible for gathering data to develop the technology transfer score? When considering the entire model, there were 21 grouped success attributes identified. The concern is that a lot of information is required to calculate the score and this effort could detract from the evaluation process. The practical implications of the technology transfer score are discussed in the next section, Future Work.

- The case study proposals were on more mature technologies. It would likely have to be adapted to evaluate more basic research proposals. In this case the model could be modified (e.g. some of the success attributes would not be applicable) to exclude those that are focused on more mature technologies. One example would be when calculating an ROI for basic research would be nothing more than an estimate. More accurate ROIs are expected as the technology continues to mature.

\subsection{Future Work}

The limitations described in the previous section offer opportunities to develop the model further. In particular, it is anticipated that the pilot with the BPA will 
inspire additional opportunities that were not considered as part of this research. However, specific to the limitations identified, the success attribute definitions that were used for this research could be assessed by a larger group of experts, and groupings around their responses considered to see if a particular group is inclined to one definition or another. Because the disagreements were all at an acceptable level, categorical groupings were not considered.

The case study was very specific, in that they involved demand response technologies, higher TRLs, and were moving from research into application at a utility. However, depending on how technology transfer is defined, could impact which success attributes are applicable. As was pointed out, some of the success attributes may not be appropriate to assess for early stage or basic research. Often, technology transfer for basic research is more about knowledge transfer than it is putting something into use - the technology just is not ready. The model could be better understood to identify which attributes are universal and which are intended for more mature technologies.

The pilot study will likely identify additional opportunities. How would the organizations considered in this research practically implement the model as part of their research proposal evaluation? The planned pilot will require modifications to the solicitation to minimize the need for outreach to the research organization. Recall that some of the success attributes relied on additional communication with the recipient or researching public information. Having all the information available, to easily populate the model, will be an improvement and address feedback during the 
validation phase of this research. Other questions, regarding the researcher's willingness to provide the information to populate the model will be assessed as part of the pilot. Additional questions to consider for the pilot include, are there any legal issues with providing the information? Is a score calculated for all research proposals in a portfolio or should a strategy be developed to use the score for an individual $R \& D$ program? Is the score reassessed throughout the $R \& D$ phase to measure improvements over the initial score? It is certain there will be other findings as a result of the pilot that can be captured and reported as part of a future study.

Additionally, there has been some discussion at BPA to use the model for improving the performance of capital projects. The attributes for successful change management are similar to those identified in this research. The model can be used to emphasize areas where the capital project is weak (e.g. project communication or credibility of the organizational champion) and the program office can address these before they become an issue. 


\section{BIBLOGRAPHY}

[1] Available: http://science.energy.gov/about/organization/

[2] Available: http://science.energy.gov/wdts/vfp/how-to-apply/submitting-a-proposalto-doe/

[3] Available: http://science.energy.gov/wdts/vfp/how-to-apply/developing-a-researchproposal/

[4] Available: http://www.energy.gov/

[5] Available:

http://www.grants.gov/web/grants/home.html;jsessionid=8QZyTQfRTnGQ3XnlRfG RQjQSW9TKyNJcfBwhlmQVgMkbNnJwqTLN

[6] Available: https://eere-exchange.energy.gov/\#FoaIdb3ab7cc1-f5b1-45f2-9f4d$\underline{0 \mathrm{~d} 5 \mathrm{a} 091 \mathrm{f} 8 \mathrm{ef5}}$

[7] Available: http://science.energy.gov/sbir/funding-opportunities/

[8] Available: http://www.energy.gov/leadership/organization-chart

[9] Available: http://en.wikipedia.org/wiki/United_States_Department_of_Energy

[10] Available: http://arpa-e.energy.gov/?q=arpa-e-site-page/arpa-e-history

[11] Available: http://arpa-e.energy.gov/?q=arpa-e-site-page/arpa-e-budget

[12] Available: http://arpa-e.energy.gov/?q=arpa-e-site-page/about

[13] Available: (http://arpae.

energy.gov/sites/default/files/documents/files/Applicants\%20Guide\%20to\%20ARPAE\% 20Award\%20Negotiations\%20Nov2012.pdf)

[14] Available: https://arpa-e-foa.energy.gov/

[15] Available: http://www.energy.gov/eere/about-us/mission

[16] Available: http://www4.eere.energy.gov/office_eere/current_budget.php

[17] Available: http://energy.gov/sites/prod/files/maprod/documents/meritrev.pdf: Appendix D

[18] Available: http://www1.eere.energy.gov/financing/

[19]: Available https://bpa-exchange.energy.gov/

[20] Walls, D., Kinross, A., Graham, S., Prasad,S, “R\&D Management Benchmarking Study", Navigant Energy, Chicago, IL, Contract \# Final Report, February 19, 2014 
[21] Callahan, J., interview/private conversation, May 2014

[22] Oliver, T., interview/private conversation, April 2014

[23] Vowles, M., interview/private conversation, May 2014

[24] Available: http://www.bpa.gov/news/pubs/GeneralPublications/gi-BPA-Facts.pdf

[25] Available: http://www.bpa.gov/news/pubs/FactSheets/fs-201310-TechnologyInnovation.pdf

[26] Available: http://www.energy.ca.gov/2012publications/CEC-500-2012-082/

[27] Available: http://www.energy.ca.gov/contracts/

[28] Available: http://www.energy.ca.gov/research/

[29] Available: http://www.energy.ca.gov/contracts/epic.html\#PON-13-301

[30] Available: Example FOA: http://www.energy.ca.gov/contracts/pier.html\#PON-

$\underline{13-301}$

[31] Available: http://www.energy.ca.gov/

[32] Available: http://www.energy.ca.gov/commission/orgchart.html

[33] Available: http://www.energy.ca.gov/commission/mission_statement.html

[34] Available: http://www.energy.ca.gov/research/buildings/index.html

[35] Available: http://www.energy.ca.gov/research/innovations/

[36] Available: http://www.resilience.org/stories/2008-05-07/u-s-electric-grid-will-it-beour-undoing

[37] Available: http://www.nwcouncil.org/energy/powerplan/6/plan/

[38] Available: http://www.nsf.gov/statistics/seind10/c4/c4s3.htm

[39] Available: http://energy.gov/recovery-act

[40] De Martini, Paul, “DR 2.0: A Future of Customer Response”, Newport Consulting, prepared for Association for Demand Response and Smart Grid, July 2013, Available:

http://www.demandresponsesmartgrid.org/Resources/Documents/FINAL_DR\%202. 0_13.07.08.pdf 
[41] Neshati, Ramin, "Participation in Technology Standards Development: A Decision Model for the Information and Communications Technology Industry" (2014). Dissertations and Theses. Paper 1850.

[42] Geels, Frank, "The Multi-Level Perspective on Sustainability Transitions: Responses to Seven Criticisms", Environmental Innovation and Societal Transitions, 1(2011) 2440

[43] Geels, Frank, "Technological Transitions as Evolutionary Reconfiguration Processes: A Multi-Level Perspective and a Case-Study”, Research Policy, 31 (2002) 1257-1274

[44] Geels, Frank and Schot, Johan, "Typology of Sociotechnical Transition Pathways", Research Policy, 36 (2007) 399-417

[45] Verbong, GPJ and Geels, Frank, "Exploring Sustainability Transitions in the Electricity Sector with Socio-Technical Pathways", Technological Forecasting and Social Change, 77 (2010) 1214-1221

[46] Verbong, GPJ and Geels, Frank, “The Ongoing Energy Transition: Lessons from a Socio-Technical, Multi-Level Analysis of the Dutch Electricity System (1960 2004)”, Energy Policy, 35 (2007) 1025 - 1037

[47] Meseri, O and Maital, S, "A Survey Analysis of University-Technology Transfer in Israel: Evolution of Projects and Determinants for Success", Journal of Technology Transfer, 26, (2001) 115-126

[48] Sharma, Kishandutt Jaydayal "A new inquiring system for technology transfer and its role in planning and policymaking", (1973). Dissertations and Theses. Paper 582.

[49] Franza, R.M., and K.P. Grant. "Improving Federal to Private Sector Technology Transfer," Research-Technology Management 49, no. 3 (2006): 36-40

[50] DOE TRL definitions Available: http://en.wikipedia.org/wiki/Technology_readiness_level

[51] NASA TRL Heat Map Available: http://www.nasa.gov/directorates/heo/scan/engineering/technology/txt_accordion1pr $\underline{\text { t.htm }}$ 
[52] Ham, R.M., and D.C. Mowery. "Improving Industry-government Cooperative R\&D" Issues in Science and Technology 11, no. 4 (1995): 67-73

[53] P. Balachandra, H. S. Kristle Nathan, and B. S. Reddy, "Commercialization of sustainable energy technologies," Renewable Energy, vol. 35, no. 8, pp. 1842-1851, 2010

[54] B. Bozeman, "Technology transfer and public policy: a review of research and theory," Research policy, vol. 29, no. 4-5, pp. 627-656, 2000

[55] Franza, R.M., K.P. Grant, and W.A. Spivey. "Technology Transfer Contracts Between R\&D Labs and Commercial Partners: Choose Your Words Wisely.” The Journal of Technology Transfer (n.d.): 1-11

[56] Perry IV, T.D. Ampulse Corporation: A Case Study on Technology Transfer in US Department of Energy Laboratories. National Renewable Energy Laboratory (NREL), Golden, CO., 2010

[57] WEN-HSIANG, LAI, and C.T.Z.U. TSAI. “Analyzing Influence Factors of Technology Transfer Using Fuzzy Set Theory” PICMET Proceedings, 2008

[58] L. Lutzenhiser, "Innovation and organizational networks Barriers to energy efficiency in the US housing industry," Energy Policy, vol. 22, no. 10, pp. 867-876, 1994

[60] M. Mueller and R. Wallace, "Enabling science and technology for marine renewable energy," Energy Policy, vol. 36, no. 12, pp. 4376-4382, 2008

[61] Greiner, M.A., and R.M. Franza. "Barriers and Bridges for Successful Environmental Technology Transfer" The Journal of Technology Transfer 28, no. 2 (2003): $167-177$

[62] Rogers, Everett M., Shiro Takegami, and Jing Yin. "Lessons Learned About Technology Transfer.” Technovation 21, no. 4 (April 2001): 253-261

[63] E. M. Mora-Valentin, A. Montoro-Sanchez, and L. A. Guerras-Martin, "Determining factors in the success of $R \& D$ cooperative agreements between firms and research organizations," Research Policy, vol. 33, no. 1, pp. 17-40, 2004 
[64] Boulter, L., and T. Bendell, "Managing the Technology Transfer Process" In Engineering Management Conference, 2002, IEMC'02. 2002 IEEE International, 2:643-648, 2002

[65] Spann, M.S., M. Adams, and W.E. Souder. "Measures of Technology Transfer Effectiveness: Key Dimensions and Differences in Their Use by Sponsors, Developers and Adopters." Engineering Management, IEEE Transactions vol 42, no. 1 (1995): 19-29

[66] Siegel, D.S., D.A. Waldman, L.E. Atwater, and A.N. Link. "Toward a Model of the Effective Transfer of Scientific Knowledge from Academicians to Practitioners: Qualitative Evidence from the Commercialization of University Technologies." Journal of Engineering and Technology Management 21, no. 1-2 (2004): 115-142

[67] Isaacs, E.A., J.C. Tang, J. Foley, J. Johnson, A. Kuchinsky, J. Scholtz, and J. Bennett. "Technology Transfer: So Much Research, so Few Good Products." In Conference Companion on Human Factors in Computing Systems: Common Ground, 155-156, 1996

[68] Rogers, E.M., E.G. Carayannis, K. Kurihara, and M.M. Allbritton. "Cooperative Research and Development Agreements (CRADAs) as Technology Transfer Mechanisms," R\&D Management 28, no. 2 (1998): 79-88

[69] J. P. Painuly, "Barriers to renewable energy penetration; a framework for analysis," Renewable Energy, vol. 24, no. 1, pp. 73-89, 2001

[70] Hall, L., Draft - BPA Business Plan for Demand Response, dated: 4/10/2014

[71] Hall, L., interview/private conversation, May 2014

[72] “Demand Response Aligning EPRI's Research Portfolio", Omar Siddiqui, EPRI presentation, PDU Sector Council - Energy Utilization Breakout, Huntington Beach, California, February 13, 2014

[74] EnerNOC EnergySmart Conference March 2014, Philadelphia PA http://energysmart.enernoc.com/4-ways-your-peers-use-demand-response-as-acompetitive-advantage 
[75] Tran, T.A., and D.F. Kocaoglu. "Literature Review on Technology Transfer from Government Laboratories to Industry", Management of Engineering \& Technology, 2009 PICMET 2009, Portland International Conference, 2771-2782, 2009

[76] Case Studies - Available: (a)

https://www.ischool.utexas.edu/ ssoy/usesusers/1391d1b.htm and (b) Rowley, Jennifer. "Using case studies in research," Management research news 25.1 (2002): $16-27$

[77] Surveying - Available: http://www.research.psu.edu/training/research-protectionsworkshops/orp-video-archive/documents/irb-101-best-practices-in-surveyresearch.pdf

[78] Literature Reviews - Available: http://writingcenter.unc.edu/handouts/literaturereviews/

[79] Model Development- Available: http://www.webpages.uidaho.edu/ mbolin/shafique-mahmood.htm

[80] Hypothesis Testing - Available: (a) http://en.wikipedia.org/wiki/Statistical_hypothesis_testing and (b) Carver, Ronald P. "The case against statistical significance testing." Harvard Educational Review 48.3 (1978): 378-399 and (c) Gliner, Jeffrey A., Nancy L. Leech, and George A. Morgan. "Problems with null hypothesis significance testing (NHST): what do the textbooks say?." The Journal of Experimental Education 71.1 (2002): 83-92.

[81] T. Saaty, The Analytical Hierarchy Process: Planning, Priority Setting, Resource Allocation, New York: McGraw-Hill, 1980

[82] Phan, Kenny, "Innovation Measurement: A Decision Framework to Determine Innovativeness of a Company" (2013), Dissertations and Theses, Paper 1017

[83] Iskin, Ibrahim, “An Assessment Model for Energy Efficiency Program Planning in Electric Utilities: Case of Northwest U.S.” Ph.D. dissertation, ETM, PSU, Portland, OR, 2014

[84] Chang, Leong, "Developing a Strategic Policy Choice Framework for Sustainable Technological Innovation", Ph.D. dissertation, ETM, PSU, Portland, OR, 2013 
[85] Wikipedia:

http://en.wikipedia.org/wiki/United_States_Department_of_Energy_National_Labor atories

[86] Francoise Bourdonnec, Intel, Guest lecture, ETM 533/633 Summer 2011, July 29, Tech Transfer Process

[87] Content validity defined - Available: http://en.wikipedia.org/wiki/Content_validity

[88] A. Fink, J. Kosecoff, M. Chassin, and R. H. Brook, "Consensus methods: characteristics and guidelines for use.," American journal of public health, vol. 74, no. 9, pp. 979-983, 1984.

[89] "Use of Expert Panels in Developing Land Use Forecasts", Proceedings of Peer Exchange, Federal Highway Administration, Oct 23-24, 2002 doc \# FHWA-EP-03018 Available:

http://www.fhwa.dot.gov/planning/tmip/publications/other_reports/expert_panels_lu forecasting/panels.pdf

[90] Available: http://energy.gov/management/downloads/merit-review-guide

[91] C. Okoli and S. D. Pawlowski, "The Delphi method as a research tool: an example, design considerations and applications," Information \& Management, vol. 42, no. 1, pp. 15-29, Dec. 2004.

[92] Sheikh, Nasir Jamil, "Assessment of Solar Photovoltaic Technologies Using Multiple Perspectives and Hierarchical Decision Modeling" (2013). Dissertations and Theses. Paper 978.

[93] D. F. Kocaoglu, "A participative approach to program evaluation," Engineering Management, IEEE Transactions on, no. 3, pp. 112-118, 1983.

[94] Abel, E, et. al, "Reducing Inconsistency in Pairwise Comparisons Using Multiobjective Evolutionary Computing", 2013 IEEE International Conference on Systems, Man, and Cybernetics, Oct. 2013, pp.80-85

[95] McKenna, Hugh P. "The Delphi technique: A worthwhile research approach for nursing?", Journal of advanced nursing 19.6 (1994): 1221-1225. 
[96] G. Rowe and G. Wright, “The Delphi technique: Past, present, and future prospects

- Introduction to the special issue," Technological Forecasting and Social Change, vol. 78, no. 9, pp. 1487-1490, Nov. 2011.

[97] C.-W. Chang, C.-R. Wu, C.-T. Lin, and H.-C. Chen, “An application of AHP and sensitivity analysis for selecting the best slicing machine," Computers \& Industrial Engineering, vol. 52, no. 2, pp. 296-307, Mar. 2007.

[98] Chen, Hongyi, "Sensitivity Analysis for Hierarchical Decision Models”, Ph.D dissertation, ETM, PSU, Portland, OR, 2007

[99] E. Triantaphyllou and S. H. Mann, "Using the analytic hierarchy process for decision making in engineering applications: some challenges," International Journal of Industrial Engineering: Applications and Practice, vol. 2, no. 1, pp. 3544, 1995

[100] Bozeman, B., and S. Pandey. "Cooperative R\&D in Government Laboratories: Comparing the US and Japan.” Technovation 14, no. 3 (1994): 145-159.

[101] Gopalakrishnan, S., and M.D. Santoro. "Distinguishing Between Knowledge Transfer and Technology Transfer Activities: The Role of Key Organizational Factors.” Engineering Management, IEEE Transactions On 51, no. 1 (2004): 5769.

[102] Lee, A.H.I., W.M. Wang, and T.Y. Lin. “An Evaluation Framework for Technology Transfer of New Equipment in High Technology Industry." Technological Forecasting and Social Change 77, no. 1 (2010): 135-150.

[103] Carayannis, Elias G, and Jeffrey Alexander. "Secrets of Success and Failure in Commercialising US Government R\&D Laboratory Technologies: a Structured Case Study Approach.” International Journal of Technology Management 18, no. 3 (January 1, 1999): 246-269.

[104] Walsh, S.T., and B.A. Kirchhoff. "Technology Transfer from Government Labs to Entrepreneurs.” Journal of Enterprising Culture 10, no. 2 (2002): 133-149.

[105] E. G. Carayannis, J. Alexander, and A. Ioannidis, "Leveraging knowledge, learning, and innovation in forming strategic government university- industry 
(GUI) R\&D partnerships in the US, Germany, and France," Technovation, vol. 20, no. 9, pp. 477-488, 2000.

[106] K. Ramanathan. "An Overview of Technology Transfer and Technology Transfer Models". Available Online:

http://www.businessasia.net/Pdf_Pages/Guidebook\%20on\%20Technology\%20Tra nsfer\%20Mechanisms/An\%20overview\%20of\%20TT\%20and\%20TT\%20Models.p $d f$

[107] “Technology Transfer Definitions". CACCI journal,Vol.2, 2005. Available Online:http://www.cacci.org.tw/Journal/2005\%20Vol\%202/Technology\%20Transf er\%20Definitions.pdf

[108] Lecture: Daim, T., "Technology Transfer (Research Phase)”, ETM 533, Summer 2011, Portland State University, Portland, OR

[109] "What is Technology Transfer?" Available Online: http://onlinepubs.trb.org/onlinepubs/millennium/00114.pdf

[110] National Technology Transfer Center (NTTC), USA http://www.nttc.edu/products/guide/seca01.html

[111] Meade, L. and Presley, A., "R\&D Project Selection Using the Analytic Network Process", IEEE Transactions on Engineering Management, Vol 49, No. 1, February 2002

[112] Hsu, Y., Gwo-Hshing,T., and Shyu, J., "Fuzzy Multiple Criteria Selection of Government-Sponsored Frontier Technology R\&D projects", R\&D Management, Vol 33, 5, 2003

[113] Bordley, R., "R\&D Project Selection Versus R\&D Project Generation", IEEE Transactions on Engineering Management, Vol 45, 4, Nov 1998

[114] Bard, J.F., "Using Multi-criteria Methods in the Early Stages of New Product Development", the Journal of the Operational Research Society, Vol. 41, No. 8 (Aug., 1990), pp. 755-766

[115] Kumar, Suresh, "AHP Based Formal System for R\&D Project Evaluation", Journal of Scientific and Industrial Research, Vol 63, Nov 2004, pp 888-896

[116] Reisman, Arnold, "Transfer of technologies: a cross-disciplinary taxonomy," Omega, vol. 33, no. 3, pp. 189-202, Jun. 2005.

[117] T. U. Daim and N. Intarode, "A framework for technology assessment: Case of a Thai building material manufacturer," Energy for Sustainable Development, vol. 13, no. 4, pp. 280-286, 2009.

[118] P. Ogden, J. Podesta, and J. Deutch, "A new strategy to spur energy innovation," Issues in Science and Technology, vol. 24, no. 2, pp. 35- 44, 2008.

[119] J. N. Erlich and A. Gutterman, "A practical view of strategies for improving Federal technology transfer," The Journal of TechnologyTransfer, vol. 28, no. 3, pp. 215-226, 2003.

[120] M. Weiss, M. Junginger, M. K. Patel, and K. Blok, "A review of experience curve analyses for energy demand technologies," Technological forecasting and social change, vol. 77, no. 3, pp. 411-428, 2010. 
[121] T. Okazaki and M. Yamaguchi, "Accelerating the transfer and diffusion of energy saving technologies steel sector experience-Lessons learned," Energy Policy, 2011.

[122] B. N. Lohani and A. M. Azimi, "Barriers to energy end-use efficiency," Energy policy, vol. 20, no. 6, pp. 533-545, 1992.

[123] L. M. Murphy, P. L. Edwards, N. R. E. L. (US), and A. G. LLC, Bridging the Valley of Death: Transitioning from Public to Private Sector Financing. National Renewable Energy Laboratory, 2003.

[124] S. Reddy and J. P. Painuly, "Diffusion of renewable energy technologies-barriers and stakeholders' perspectives," Renewable Energy, vol. 29, no. 9, pp. 1431-1447, 2004.

[125] P. D. Lund, "Effects of energy policies on industry expansion in renewable energy," Renewable Energy, vol. 34, no. 1, pp. 53-64, 2009.

[126] L. A Greening, D. L. Greene, and C. Difiglio, "Energy efficiency and consumption - the rebound effect-a survey," Energy policy, vol. 28,no. 6, pp. 389-401, 2000.

[127] R. M. Margolis and D. M. Kammen, "Evidence of Under-investment in Energy R\&D in the United States and the Impact of Federal Policy," Energy Policy, vol. 27, no. 10, pp. 575-584, 1999.

[128] J. L. Lewis and R. H. Wiser, "Fostering a renewable energy technology industry: An international comparison of wind industry policy support mechanisms," Energy Policy, vol. 35, no. 3, pp. 1844-1857, 2007.

[129] E. Shove, "Gaps, barriers and conceptual chasms: theories of technology transfer and energy in buildings," Energy Policy, vol. 26,no. 15, pp. 1105-1112, 1998.

[130] A. Purkus and V. Barth, "Geothermal power production in future electricity markets-A scenario analysis for Germany," Energy Policy, vol. 39, no. 1, pp. 349-357, 2011.

[131] R. Parnell and O. P. Larsen, "Informing the development of domestic energy efficiency initiatives," Environment and Behavior, vol. 37, no. 6, pp. 787-807, 2005.

[132] S. Meyers, J. Sathaye, B. Goldberg, D. Renné, A. Kaupp, M. Mendis, J. Ernst, A. Kokorin, and T. Kerr, "International Workshop on Greenhouse-Gas Mitigation Technologies and Measures-Summary," Applied Energy, vol. 56, no. 3-4, pp. $203-$ 223, 1997.

[133] D. G. Ockwell, J. Watson, G. MacKerron, P. Pal, and F. Yamin, "Key policy considerations for facilitating low carbon technology transfer to developing countries," Energy Policy, vol. 36, no. 11, pp. 4104-4115, 2008.

[134] K. S. Gallagher, "Limits to leapfrogging in energy technologies? Evidence from the Chinese automobile industry," Energy policy, vol.34, no. 4, pp. 383-394, 2006.

[135] P. Söderholm and M. Pettersson, "Offshore wind power policy and planning in Sweden,” Energy Policy, vol. 39, no. 2, pp. 518-525, 2011.

[136] W. Van der Gaast, K. Begg, and A. Flamos, "Promoting sustainable energy technology transfers to developing countries through the CDM," Applied Energy, vol. 86, no. 2, pp. 230-236, 2009. 
[137] D. Roessner, "Quantitative and qualitative methods and measures in the evaluation of research," Research Evaluation, vol. 9, no. 2, pp. 125-132, 2000.

[138] K. Ehrhardt-Martinez and J. A. Laitner, "Rebound, technology and people: Mitigating the rebound effect with energy-resource management and people-centered initiatives," Proceedings of the 2010 ACEEE Summer Study on Energy Efficiency in Buildings, 2010.

[139] D. Kaya, "Renewable energy policies in Turkey," Renewable and Sustainable Energy Reviews, vol. 10, no. 2, pp. 152-163, 2006.

[140] E. Luiten, H. van Lente, and K. Blok, "Slow technologies and government intervention: Energy efficiency in industrial process technologies," Technovation, vol. 26, no. 9, pp. 1029-1044, 2006.

[141] R. Wüstenhagen, M. Wolsink, and M. J. Bürer, "Social acceptance of renewable energy innovation: An introduction to the concept," Energy policy, vol. 35, no. 5, pp. 2683-2691, 2007.

[142] A. Mallett, "Social acceptance of renewable energy innovations: The role of technology cooperation in urban Mexico," Energy policy, vol.35, no. 5, pp. 27902798, 2007.

[143] J. C. Stephens, E. J. Wilson, and T. R. Peterson, "Socio-Political Evaluation of Energy Deployment (SPEED): An integrated research framework analyzing energy technology deployment," Technological Forecasting and Social Change, vol. 75, no. 8, pp. 1224-1246, 2008.

[144] J. Noailly and S. Batrakova, "Stimulating energy-efficient innovations in the Dutch building sector: Empirical evidence from patent counts and policy lessons," Energy Policy, vol. 38, no. 12, pp. 7803-7817, 2010.

[145] J. C. J. . van den Bergh, A. Faber, A. M. Idenburg, and F. H. Oosterhuis, "Survival of the greenest: evolutionary economics and policies for energy innovation," Environmental Sciences, vol. 3, no. 1, pp. 57-71, 2006.

[146] H. Herring and R. Roy, "Technological innovation, energy efficient design and the rebound effect," Technovation, vol. 27, no. 4, pp. 194-203, 2007.

[147] J. I. Lewis, "Technology acquisition and innovation in the developing world: Wind turbine development in China and India," Studies in Comparative International Development (SCID), vol. 42, no. 3, pp. 208-232, 2007.

[148] V. K. Upadhyay, P. Sikka, and D. K. Abrol, "Technology dissemination programmes and extramural R\&D support in India," The Journal of Technology Transfer, vol. 35, no. 6, pp. 680-690, 2010.

[149] V. Kathuria, "Technology transfer for GHG reduction: a framework with application to India," Technological Forecasting and Social Change, vol. 69, no. 4, pp. 405-430, 2002.

[150] H. De Coninck, F. Haake, and N. Van Der Linden, "Technology transfer in the Clean Development Mechanism," Climate Policy, vol. 7, no. 5, pp. 444-456, 2007.

[151] E. Worrell, R. Van Berkel, Z. Fengqi, C. Menke, R. Schaeffer, and R. O Williams, "Technology transfer of energy efficient technologies in industry: a review of trends and policy issues," Energy Policy, vol. 29, no. 1, pp. 29-43, 2001.

[152] Q. Shujing, "The Analysis on Barriers of Low Carbon Technology Transfer," Energy Procedia, vol. 14, pp. 1398-1403, 2012. 
[153] N. Kok, M. McGraw, and J. M. Quigley, "The diffusion of energy efficiency in building," The American Economic Review, vol. 101, no.3, pp. 77-82, 2011.

[154] S. Jacobsson and A. Johnson, "The diffusion of renewable energy technology: an analytical framework and key issues for research," Energy policy, vol. 28, no. 9, pp. 625-640, 2000.

[155] S. Jacobsson and V. Lauber, "The politics and policy of energy system transformation - explaining the German diffusion of renewable energy technology," Energy policy, vol. 34, no. 3, pp. 256-276, 2006.

[156] J. Bessant, “The rise and fall of [] Supernet': a case study of technology transfer policy for smaller firms," Research Policy, vol. 28, no. 6, pp. 601-614, 1999.

[157] D. Toke, "The UK offshore wind power programme: A sea-change in UK energy policy?," Energy Policy, vol. 39, no. 2, pp. 526-534, 2011.

[158] S. K. Markham, S. J. Ward, L. Aiman-Smith, and A. I. Kingon, "The valley of death as context for role theory in product innovation," Journal of Product Innovation Management, vol. 27, no. 3, pp. 402-417, 2010.

[159] S. Jacobsson and A. Bergek, "Transforming the energy sector: the evolution of technological systems in renewable energy technology," Industrial and corporate change, vol. 13, no. 5, pp. 815-849, 2004.

[160] H. A. Linstone, Decision making for technology executives: using multiple perspectives to improved performance. Artech House Norwood, MA, 1999.

[161] Jenkins, J and Mansur, S., "Bridging the Clean Energy Valleys of Death", Breakthrough Institute, November 2011

[162] Kyoto Protocol, Available: http://www.kyotoprotocal.com

[163] http://seekingalpha.com/article/224005-crossing-the-biotech-valley-ofdeath-frominnovation-to-cure, 09/06/2010, Jason Chew

[164] Available: http://www.pnnl.gov/business/techtransfer/documents/TechComm Overview-singlepgs.pdf

[165] Available: http://www.pnnl.gov/business/techtransfer/documents/TechComm Overview-singlepgs.pdf

[166] Panel discussion: TT: So Much Research, So Few Good Products CHI 96 Conference Available:

http://www.sigchi.org/chi96/proceedings/panels/Isaacs/eai_tech.html

[167] Pisano, Gary, "Creating an R\&D Strategy", Harvard Business School, 2012; Available: http://www.hbs.edu/faculty/Publication\%20Files/12-095_fb1bdf97-e0ec4a82-b7c0-42279dd4d00e.pdf

[168] Available: HCS, //techcrunch.com/2011/10/04/why-did-solyndra-fail-sospectacularly/

[169] Abbas, Mustafa, "Consistency Analysis for Judgment Quantification in Hierarchical Decision Model”, Ph.D. dissertation, ETM, PSU, Portland, OR 2016 [170] NSF Proposal Evaluation Criteria:

http://www.nsf.gov/bfa/dias/policy/merit_review/

[171] NIH Proposal Evaluation Criteria:

http://grants.nih.gov/grants/peer_review_process.htm\#scoring2 
[172] P. Gerdsri, "A Systematic Approach to Developing National Technology Policy and Strategy for Emerging Technologies," Portland State University, 2009.

[173] J. Wallenius, J. S. Dyer, P. C. Fishburn, R. E. Steuer, S. Zionts, K. Deb, J. S. Dyer, P. C. Fishburn, and R. E. Steuer, "Multiple Criteria Decision Making, Multiattribute Utility Theory : Recent Accomplishments and What Lies Ahead," Manage. Sci., no. June 2016, 2008.

[174] D. Sheskin, Handbook of Parametric and Nonparametric Statistical Procedures. Chapman\&Hall/CRC Publisher, 2007.

[175] Shrout. P.E. and Fleiss. J.L., "Intraclass Correlation: Uses In Assessing Rater Reliability,"

Psychological Bulletin, vol. 86, pp. 420-428, 1979. 
APPENDIX A: PROPOSAL EVALUATION CRITERIA

\section{Appendix A1: Proposal Evaluation Criteria: EERE}

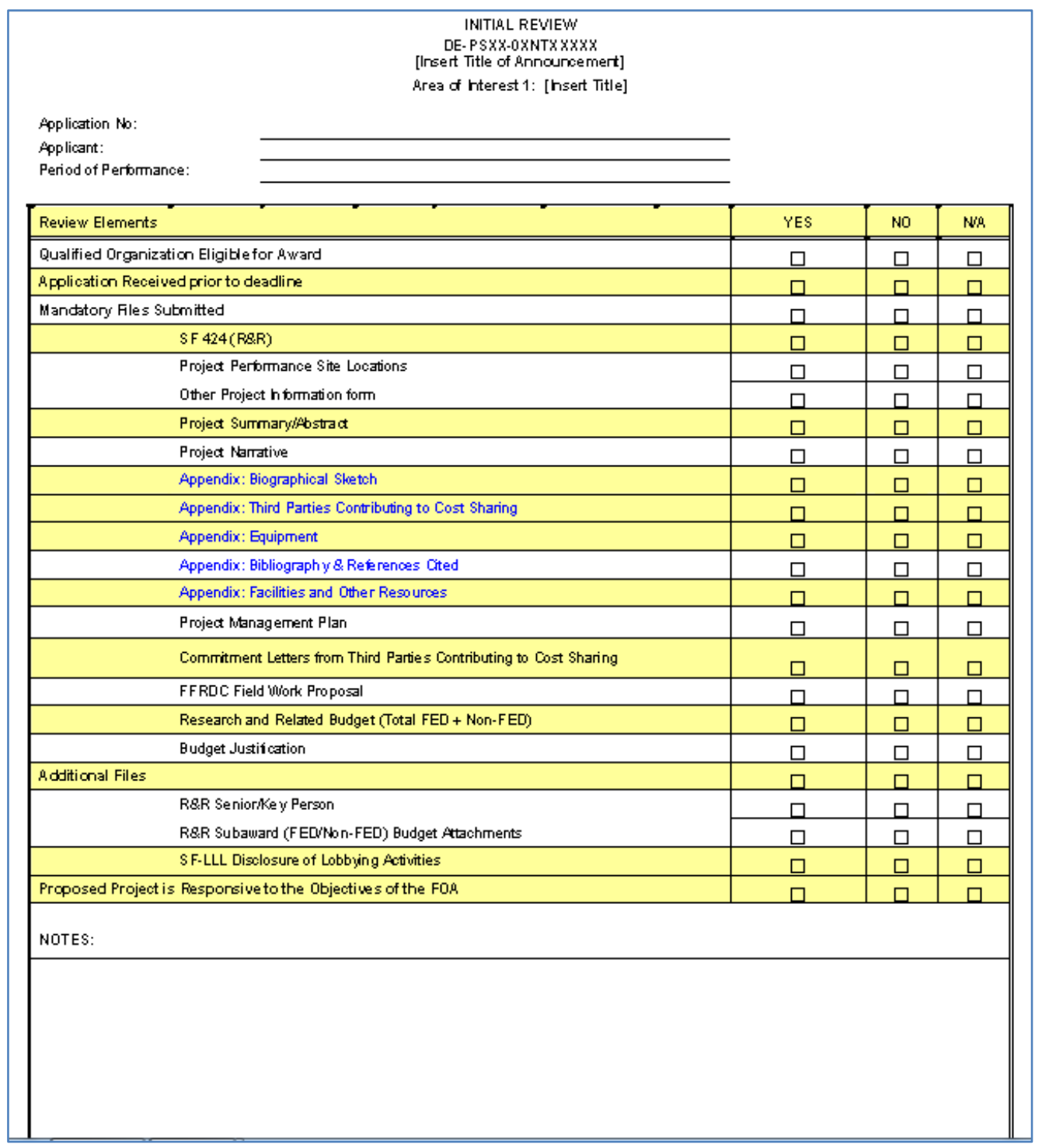




\section{Appendix A2: Proposal Evaluation Criteria: BPA}

\begin{tabular}{|l|l|}
\hline \multicolumn{1}{|c|}{ Criteria } & \multicolumn{1}{|c|}{ BPA Objective } \\
\hline $\begin{array}{l}\text { The degree to which the } \\
\text { project strengthens BPA's } \\
\text { existing portfolio of projects }\end{array}$ & The right portfolio \\
\hline $\begin{array}{l}\text { The degree to which project } \\
\text { scope addresses the R\&D } \\
\text { Program(s) identified in the } \\
\text { Technology Roadmap(s) }\end{array}$ & The right research \\
\hline $\begin{array}{l}\text { The quantitative or qualitative } \\
\text { expected benefits as applied } \\
\text { system-wide, assuming this } \\
\text { project is a technical success }\end{array}$ & $\begin{array}{l}\text { Magnitude of benefits to BPA } \\
\text { commensurate with risks }\end{array}$ \\
\hline $\begin{array}{l}\text { Team members have } \\
\text { sufficient experience and are } \\
\text { qualified to carry out the } \\
\text { project }\end{array}$ & The right mix of talent \\
\hline $\begin{array}{l}\text { The probability of the project } \\
\text { being a technical success }\end{array}$ & $\begin{array}{l}\text { Achieving successful project } \\
\text { results }\end{array}$ \\
\hline $\begin{array}{l}\text { The probability of near or } \\
\text { long term successful } \\
\text { application to BPA }\end{array}$ & $\begin{array}{l}\text { Successful application to } \\
\text { BPA business challenges }\end{array}$ \\
\hline $\begin{array}{l}\text { The degree to which } \\
\text { proposed Stage Gates } \\
\text { (go/stop decision points) } \\
\text { reflect real options/choices } \\
\text { for project decisions, and } \\
\text { relate to real } \\
\text { discovery/science/achieveme } \\
\text { nt thresholds }\end{array}$ & The right decision points \\
\hline $\begin{array}{l}\text { Cost share which exceeds the } \\
\text { minimum requirement, e.g. } \\
\text { greater than 50\% }\end{array}$ & The right leverage \\
\hline $\begin{array}{l}\text { The percentage of cost share } \\
\text { which is a cash contribution }\end{array}$ & The right leverage \\
\hline
\end{tabular}




\section{Appendix A3: Proposal Evaluation Criteria: CEC}

\section{STAGE ONE: APPLICATION SCREENING CHECKLIST}

\begin{tabular}{|l|l|}
\hline \multicolumn{1}{|c|}{ SCREENING CRTERLA } & Pass/Fail \\
The Application must pass ALL crteria to progress to Stage Two. & \\
\hline 1. The application is recein bed by the Energy Commission's \\
Contracts, Grants, and Loans Office by the due date and time \\
specified in the "Key Activities Schedule" in Part I of this \\
solicitation.
\end{tabular}

When comparing the stage 2 criteria to the other organizations considered in this response, the CEC criteria is much more comprehensive and quantitative. The stage 2 
checklist is provided below:

\section{F. STAGE TWO: APPLICATION SCORING}

Proposals that pass A.LL Stage One Screening Criteria will be evaluated based on the Scoring Criteria on the next page and the Scoring Scale below (with the exception of criteria 7 and 8 , which will not use the Scoring Scale). Each criterion has an assigned number of possible points, and is divided into multiple sub-criteria. The sub-criteria are not equally meighted. The Project Narrative (Attachm ent 4) must respond to each sub-criterion, unless otherwise indicated.

- The scores for criteria 7 (ratio of unloaded labor rates to loaded labor rates) and 8 (match funding) will be calculated as described in each criterion.

- The total minim um passing score is $\mathbf{7 0 . 0 0}$ out of $\mathbf{1 0 0}$ points.

- The minim urn passing score for criteria 1-4 is 49.00 points. The points for criteria 5-8 will only be applied to proposals that achieve the minimum score for criteria 1-4.

\section{SCORING SCALE}

\begin{tabular}{|c|c|c|}
\hline $\begin{array}{c}\text { \% of Possible } \\
\text { Points }\end{array}$ & Interpretation & Explanation for Percentage Points \\
\hline $0 \%$ & $\begin{array}{l}\text { Not } \\
\text { Responsive }\end{array}$ & $\begin{array}{l}\text { - The response fails to addressthe criteria. } \\
\text { - The omissions, flaws, or defects are significant and } \\
\text { unacoeptable. }\end{array}$ \\
\hline $10-30 \%$ & $\begin{array}{l}\text { Minimally } \\
\text { Responsive }\end{array}$ & $\begin{array}{l}\text { - The response minimally addressesthe criteria. } \\
\text { - The omissions, flaws, or defects are significant and } \\
\text { unacoeptable. }\end{array}$ \\
\hline $40-60 \%$ & Inadequate & $\begin{array}{l}\text { - The response addresses the criteria. } \\
\text { - There are one or more omissions, flaws, or defeds or the } \\
\text { criteria are addressed in a limited may that results in a low } \\
\text { degree of confidence in the proposed solution. }\end{array}$ \\
\hline $70 \%$ & Adequate & $\begin{array}{l}\text { - The response adequately addresses the criteria. } \\
\text { - Any ornissions, flaws, or defects are inconsequential and } \\
\text { acceptable. }\end{array}$ \\
\hline $80 \%$ & Good & $\begin{array}{l}\text { - The response fully addresses the criteria with a good } \\
\text { degree of confidence in the applicant's response or } \\
\text { proposed solution. } \\
\text { - There are no identified om issions, flaws, or defects. Any } \\
\text { identified meaknesses are minimal, inconsequential, and } \\
\text { acceptable. }\end{array}$ \\
\hline $90 \%$ & Excellent & $\begin{array}{l}\text { - The response fully addresses the criteria with a high } \\
\text { degree of confidence in the applicant's response or } \\
\text { proposed solution. } \\
\text { - The applicant offers one or more enhancing features, } \\
\text { methods, or approachesthat exceed basic expectations. }\end{array}$ \\
\hline $100 \%$ & Exceptional & $\begin{array}{l}\text { - All criteria are addressed with the highest degree of } \\
\text { confidence in the applicant's response or proposed } \\
\text { solution. } \\
\text { - The response exceeds the requirements in providing } \\
\text { multiple enhancing features, a creative approach, or an } \\
\text { exceptional solution. }\end{array}$ \\
\hline
\end{tabular}


The Projed Narraive (Attachment 4) must respond to each criterion below, unless othe muise indicated. Any estimates of energy savings or GHG impact must be calculated as specified in the References for Calculaing Bectricity End-Use, Bectricity Demand, and GHG Emissions (Attachment 12).

\begin{tabular}{|l|c|}
\hline \multicolumn{1}{|c|}{ Scoing Criteria } & $\begin{array}{c}\text { Maximum } \\
\text { Points }\end{array}$ \\
\hline 1. Technical Mrit and Need & 20
\end{tabular}

a. Provides a dear and concise description of the goak, objectives, technological or scientific knowledge advancement, and innouation in the proposed project.

b. Explains how the proposed project mill lead to technological aduancement and breakthroughs that overcome barriers to achieving the state's statutony energy goak.

c. Summarizes the current status of the relevant technology andior scientific knowledge, and explairs how the proposed project will aduance, supplement, andior replace current technology andior scientific knowledge.

d. Justifies the need for EPIC funding, including an explanation of why the proposed work is not adequately supported by competitive or regulated markets.

e. Discusses the degree to which the proposed work is technicalty feasible and achievable.

f. Provides a clear and plausible test plan that describes how energy savings and other benefits specified in the application will be determined and measured.

2. Technical Approach

a. Describes the technique, approach, and methods to be used in providing performing the work described in the Scope of Work. Highlights any outtanding features.

b. Describes how tasks will be executed and coordinated with various participants and te am members.

c. Identifies and discusses factors critical for success, in addition to riłs. barriers, and limitations. Provides a plan to address them.

d. Describes how the knowledge gained, experimental results, and lessors learned will be made available to the public and key decision makers. 


\begin{tabular}{|c|c|}
\hline Scoring Criteria & $\begin{array}{l}\text { Maximum } \\
\text { Points }\end{array}$ \\
\hline $\begin{array}{l}\text { 3. Impacts and Benefits for Califomia IOU Ratepayers } \\
\text { a. Explains how the proposed project will benefit California Investor-Owned } \\
\text { Utility (IOU) ratepayers wh respect to the EPIC goals of greater } \\
\text { reliability, lower costs, andior increased safety). } \\
\text { b. Provides clear, plausible, and justifiable quantitative estim ates of } \\
\text { potential benefits for California IOU eledricity ratepayers, induding the } \\
\text { following (as appicabbe). annual electricity and thermal savings (kilowatt- } \\
\text { hour and thems), peak load reduction andior shifting, energy cost } \\
\text { reductions, greenhouse gas emission reductions, air emission reductions } \\
\text { (e.g., NOx), and water use andior cost redudions. } \\
\text { c. States the timeframe, assumptions, and calculations for the estimated } \\
\text { benefits, and explains their reasonableness. } \\
\text { d. Identifies impacted market segments in California, including size and } \\
\text { penetration or deployment rates, with underlyng assumptions. } \\
\text { e. Discusses any qualitative or intangible benefits to California IOU } \\
\text { electricity ratepayers, induding timeframe and assumptions. } \\
\text { t. Provides a costbenefit analysis that compares projed costs to } \\
\text { anticipated benefits. Explains how costs and benefits will be calculated } \\
\text { and quantified, and identifies any underlying assumptions. }\end{array}$ & 20 \\
\hline 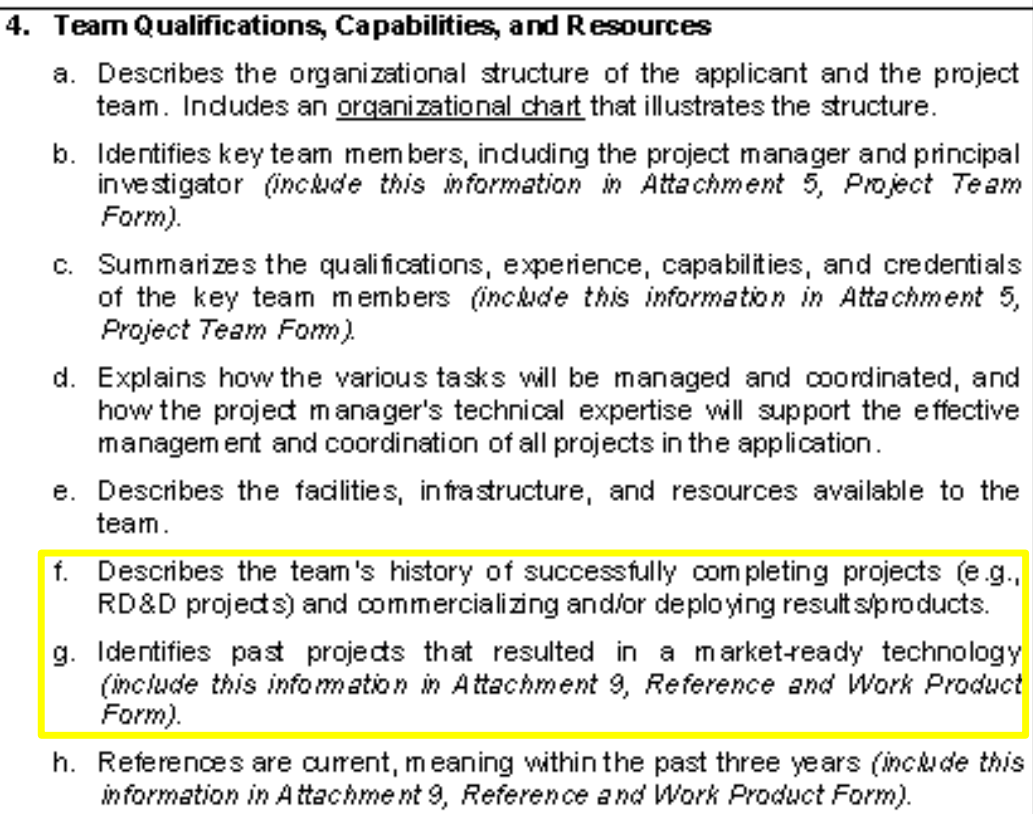 & 10 \\
\hline
\end{tabular}




\begin{tabular}{|c|c|}
\hline Scoring Criteria & $\begin{array}{l}\text { Maximum } \\
\text { Points }\end{array}$ \\
\hline $\begin{array}{l}\text { i. Identifies any collaborations with utilities, industries, or others. Explains } \\
\text { the nature of the collaboration and what each collaborator will contribute. }\end{array}$ & \\
\hline $\begin{array}{l}\text { j. Demonstrates that the applicant has the financial ability to complete the } \\
\text { project, as indicated by the responses to the following questions: } \\
\text { - Has your organization been involved in a lawsuit or government } \\
\text { investigation within the past ten years? } \\
\text { - Does your organization have overdue taxes? } \\
\text { - Has your organization ever filed for or does it plan to file for } \\
\text { bankruptcy? } \\
\text { - Has any party that entered into an agreement with your } \\
\text { organization terminated it, and if so for what reason? } \\
\text { - For Energy Commission agreements listed in the application that } \\
\text { were executed (i.e, approved at a Commission business meeting } \\
\text { and signed by both parties) within the past five years, has your } \\
\text { organization ever failed to provide a final report by the date } \\
\text { indicated in the agreement? } \\
\text { k. Support or commitment letters (for match funding, test sites, or project } \\
\text { partners) indicate a strong level of support or commitment for the project. }\end{array}$ & \\
\hline $\begin{array}{l}\text { Total Possible Points for criteria 1-4 } \\
\text { (Minimum Passing Score for criteria } 1.4 \text { is } 49.00 \text { ) }\end{array}$ & 70 \\
\hline 5. Budget and Cost-Effectiveness & 10 \\
\hline $\begin{array}{l}\text { a. Justifies the reasonableness of the requested funds relative to the project } \\
\text { goals, objectives, and tasks. }\end{array}$ & \\
\hline $\begin{array}{l}\text { b. Justifies the reasonableness of costs for direct labor, non-labor (e.g., } \\
\text { indirect overhead and general and administrative costs, and } \\
\text { subcontractor profit), and operating expenses by task. }\end{array}$ & \\
\hline $\begin{array}{l}\text { c. Explains why the hours proposed for personnel and subcontractors are } \\
\text { reasonable to accomplish the actwities in the Scope of Work (Attachment } \\
\text { 6). }\end{array}$ & \\
\hline $\begin{array}{l}\text { d. Explains how the applicant will maximize funds for technical tasks and } \\
\text { minimize expenditure of funds for program administration and overhead. }\end{array}$ & \\
\hline
\end{tabular}




\begin{tabular}{|c|c|c|}
\hline \multicolumn{2}{|c|}{ Scoring Criteria } & $\begin{array}{l}\text { Maximum } \\
\text { Points }\end{array}$ \\
\hline \multirow{3}{*}{\multicolumn{2}{|c|}{$\begin{array}{l}\text { 6. EPIC Funds Spent in Califomia } \\
\text { Projeds that spend EPIC funds in California will receive points as indicated in the } \\
\text { table below. "Spent in California" means that: (1) Funds under the "Dired Labor" } \\
\text { category and all categories calculated based on direct labor in the B-4 budget } \\
\text { attadnments (Prime and Subcontrador Labor Rates) are paid to individuals who } \\
\text { pay California state income taxes on mages received for work performed under } \\
\text { the agreement; and (2) Business transactions (e.g., material and equipment } \\
\text { purchases, leases, rentals, and contradual mork) are entered into with a } \\
\text { business located in California. } \\
\text { Airline ticket purchases and payments made to out-of-state morkers are not } \\
\text { considered funds "spent in Califomia." However, funds spent by out-of-state } \\
\text { workers in California (e.g., hotel and food) are considered funds "spent in } \\
\text { California." }\end{array}$}} & \multirow{9}{*}{15} \\
\hline & & \\
\hline & & \\
\hline $\begin{array}{l}\text { Percentage of EPIC funds spent in Ca } \\
\text { (derived rom budget attachment } \mathrm{B}-2 \text { ) } \\
\end{array}$ & Percentage of Possitle Poirts & \\
\hline$>60 \%$ & $20 \%$ & \\
\hline \begin{tabular}{|l|l|}
7702 \\
\end{tabular} & $40 \%$ & \\
\hline \begin{tabular}{|l|l|}
$>80 \%$ \\
\end{tabular} & $60 \%$ & \\
\hline & & \\
\hline \begin{tabular}{|l|l|l|}
$>100 \%$ \\
\end{tabular} & \begin{tabular}{|l|l|}
$100 \%$ \\
\end{tabular} & \\
\hline \multicolumn{2}{|c|}{$\begin{array}{l}\text { 7. Ratio of Direct Labor and Fringe Benefit Rates to Loaded Labor Rates } \\
\text { The score for this criterion will derive from the Rates Summary worksheet } \\
\text { (Tab B-8) in the budget forms, which compares the weighted direct labor and } \\
\text { fringe benefits rate to the meighted loaded rate. This ratio, as a percentage, is } \\
\text { multiplied by the possible points for this criterion. }\end{array}$} & 5 \\
\hline \multicolumn{2}{|l|}{$\begin{array}{l}\text { Total Possible Points } \\
\text { (Minimum Passing Score is } \mathbf{7 0} \text { ) }\end{array}$} & 100 \\
\hline \multicolumn{2}{|c|}{$\begin{array}{l}\text { 8. Match Funding (Optional) } \\
\text { - E ach match funding contributor m ust submit a commitment letter that } \\
\text { meets the requirements of Attachment } 11 \text {. Failure to meet these } \\
\text { requirements will disqualify the proposal from consideration for match } \\
\text { funding points. } \\
\text { - Any match funding pledged in Attachment } 1 \text { must be consistent with the } \\
\text { amount or dollar value de suribed in the commitment letter( } s \text { ) (e.g., if } \\
\$ 5,000 \text { "cash in hand" tunds are pledged in a commitment letter, } \\
\text { Attachment } 1 \text { must match this amount). Failure to meet this requirement } \\
\text { will disqualify the proposal from consideration for match funding points. } \\
5 \text { points for this criterion will be awarded based on the percentage of } \\
\text { match funds relative to the EPIC funds requested. This ratio will be } \\
\text { multiplied by } 5 \text { to yield the points, and rounded to the nearest whole } \\
\text { number. } \\
\text { For example: If requested EPIC funds are } \$ 1,000,000 \text { and match funds }\end{array}$} & 10 \\
\hline
\end{tabular}




\begin{tabular}{|l|l|}
\hline \multicolumn{1}{|c|}{ Scoring Criteria } & $\begin{array}{c}\text { Maximum } \\
\text { Points }\end{array}$ \\
\hline are $\$ 500,000$, the match funding ratio is 0.50 . The proposal will be \\
awarded 3 points $(5 \times 0.50=2.5$, rounded to the nearest whole number $=$ & \\
3 ). & \\
The remaining 5 points for this criterion will be based on the level of \\
commitment, dollar value justification, and funding replacement strategy \\
described in the match funding commitment letter (see Attachment 11$)$. \\
The proposal scoring scale in Section $F$ will be used to evaluate these \\
criteria.
\end{tabular}




\title{
Appendix A5: Proposal Evaluation Criteria: NSF
}

\section{Excerpt from NSF site:}

\author{
http://www.nsf.gov/pubs/policydocs/pappguide/nsf16001/gpg_3.jsp\#IIIA
}

\section{A. Merit Review Principles and Criteria}

The National Science Foundation strives to invest in a robust and diverse portfolio of projects that creates new knowledge and enables breakthroughs in understanding across all areas of science and engineering research and education. To identify which projects to support, NSF relies on a merit review process that incorporates consideration of both the technical aspects of a proposed project and its potential to contribute more broadly to advancing NSF's mission "to promote the progress of science; to advance the national health, prosperity, and welfare; to secure the national defense; and for other purposes." NSF makes every effort to conduct a fair, competitive, transparent merit review process for the selection of projects.

\section{Merit Review Principles}

These principles are to be given due diligence by PIs and organizations when preparing proposals and managing projects, by reviewers when reading and evaluating proposals, and by NSF program staff when determining whether or not to recommend proposals for funding and while overseeing awards. Given that NSF is the primary federal agency charged with nurturing and supporting excellence in basic research and education, the following three principles apply:

- All NSF projects should be of the highest quality and have the potential to advance, if not transform, the frontiers of knowledge.

- NSF projects, in the aggregate, should contribute more broadly to achieving societal goals. These broader impacts may be accomplished through the research itself, through activities that are directly related to specific research projects, or through activities that are supported by, but are complementary to, the project. The project activities may be based on previously established and/or innovative methods and approaches, but in either case must be well justified.

- Meaningful assessment and evaluation of NSF funded projects should be based on appropriate metrics, keeping in mind the likely correlation between the effect of broader impacts and the resources provided to implement projects. If the size of the activity is limited, evaluation of that activity in isolation is not likely to be meaningful. Thus, assessing the effectiveness of these activities may best be done at a higher, more aggregated, level than the individual project. 
With respect to the third principle, even if assessment of Broader Impacts outcomes for particular projects is done at an aggregated level, PIs are expected to be accountable for carrying out the activities described in the funded project. Thus, individual projects should include clearly stated goals, specific descriptions of the activities that the PI intends to do, and a plan in place to document the outputs of those activities.

These three merit review principles provide the basis for the merit review criteria, as well as a context within which the users of the criteria can better understand their intent.

\section{Merit Review Criteria}

All NSF proposals are evaluated through use of two National Science Board approved merit review criteria. In some instances, however, NSF will employ additional criteria as required to highlight the specific objectives of certain programs and activities.

The two merit review criteria are listed below. Both criteria are to be given full consideration during the review and decision-making processes; each criterion is necessary but neither, by itself, is sufficient. Therefore, proposers must fully address both criteria. (GPG Chapter II.C.2.d.(i) contains additional information for use by proposers in development of the Project Description section of the proposal.) Reviewers are strongly encouraged to review the criteria, including GPG Chapter II.C.2.d.(i), prior to the review of a proposal.

When evaluating NSF proposals, reviewers will be asked to consider what the proposers want to do, why they want to do it, how they plan to do it, how they will know if they succeed, and what benefits could accrue if the project is successful. These issues apply both to the technical aspects of the proposal and the way in which the project may make broader contributions. To that end, reviewers will be asked to evaluate all proposals against two criteria:

- Intellectual Merit: The Intellectual Merit criterion encompasses the potential to advance knowledge; and

- Broader Impacts: The Broader Impacts criterion encompasses the potential to benefit society and contribute to the achievement of specific, desired societal outcomes.

The following elements should be considered in the review for both criteria:

1. What is the potential for the proposed activity to:

a. Advance knowledge and understanding within its own field or across different fields (Intellectual Merit); and 
b. Benefit society or advance desired societal outcomes (Broader Impacts)?

2. To what extent do the proposed activities suggest and explore creative, original, or potentially transformative concepts?

3. Is the plan for carrying out the proposed activities well-reasoned, well-organized, and based on a sound rationale? Does the plan incorporate a mechanism to assess success?

4. How well qualified is the individual, team, or organization to conduct the proposed activities?

5. Are there adequate resources available to the PI (either at the home organization or through collaborations) to carry out the proposed activities?

\section{Merit Review Process}

Click the square buttons to find out more information about the review process.

Download a printable version of the Merit Review Process Illustration. PDF (21K)

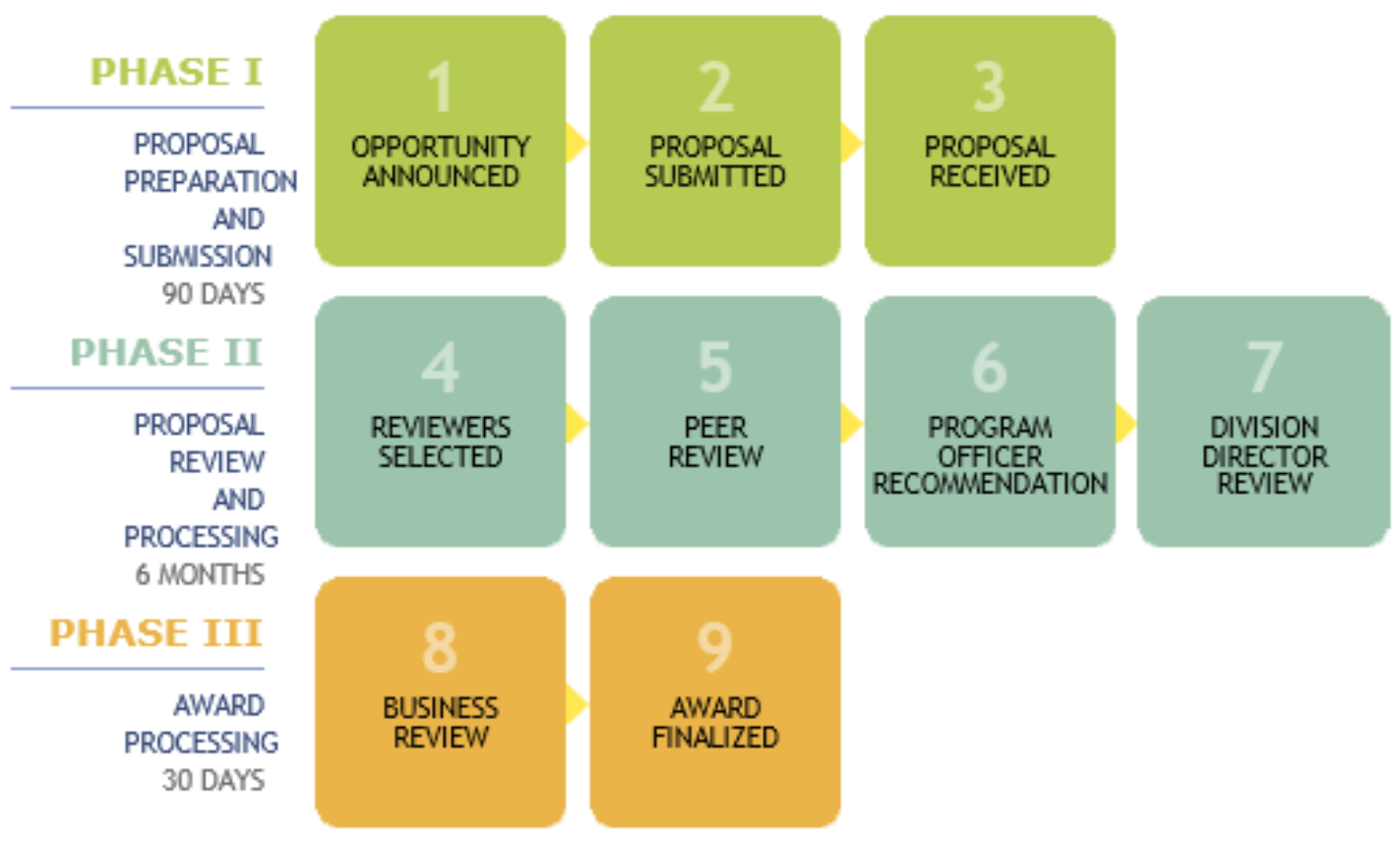




\section{APPENDIX B: DEFINITIONS OF REISMAN'S TAXONOMY}

\section{Key 1: Actors}

\subsection{Transferors}

1.1.1. Scientific disciplines

1.1.2. Professions

1.1.3. Corporate or institutional entities

1.1.4. Industries

1.1.5. Economic sectors

1.1.6. Geographic regions

1.1.7. Societies/countries.

\subsection{Transferees}

1.2.1. Scientific disciplines

1.2.2. Professions

1.2.3. Corporate or institutional entities

1.2.4. Industries

1.2.5. Economic sectors

1.2.6. Geographic regions

1.2.7. Societies/countries.

\section{Key 2: Transaction Types}

\subsection{External Transfers}

2.1.1. Information exchange

2.1. 1.1 Programs: (Sabbaticals, scholarship programs such as the

Fulbright awards, work study arrangements, internships)

2.1.1.2 Conferences and Symposia

2.1.1.3 Technical Correspondence

2.1. 1.4 Free Technical Services

2.1.1.5 Professional-Journal Publications

2.1. 1.6 Software programs

2.1.1.7 Internet/Web usage related exchanges

\subsubsection{Sales}

2.1.2.1 Sales of Equipment and/or Intellectual Properties: (A single piece of equipment or an entire system such as a factory, turn-key projects, etc., a formula, new designs. drawings, blueprints, procedures, market surveys, demographic statistics)

2.1.2.2 Sales of Services: (Consulting assistance, user manuals, equipment maintenance)

2.1.3 Cooperative agreement

2.1.3.1 Co-production: (The GE (USA) - SNECMA (French)) collaboration in the aerospace industry

2.1.3.2 Co-research (the U.S. Human Genome Project. a 13-year effort coordinated by the Department of 
Energy and the National Institutes of Health)

2.1.3.3 Co-design (Arrow anti- missile system (USA and Israel), The UK

Watch-keeper' unmanned spy plane project (UK, USA, Israel)

2.1.4 Arm's length licensing

2.1.4.1 Licensing: Conveyance of manuals, blueprints, design drawings or data: provision of technical and managerial assistance.

2.1.4.2 Cross licensing: (same as above)

2.1.5 Franchising (McDonald's hamburgers in USSR. Holiday Inn Hotels in USA).

2.1.6 Joint venture

2.1.6.1 Equity Joint Venture:

2.1.6.2 Contractual Joint Venture

\subsection{Internal Transfers}

2.2.1 Internal information exchange

2.2.1.1 Meetings:

2.2.1.2 Correspondence:

2.2.1.3 Publications:

2.2.2 Cooperative agreement

2.2.3 Arm's length licensing

2.2.4 Internal joint venture

2.2.5 Wholly owned subsidiary

2.3 Time duration

2.3.1 Short term

2.3.2 Long term

2.4 Payment requirement

2.4.1 None

2.4.2 Required

\subsection{Network}

2.5.1 Two nodes

2.5.2 Multi nodal

\subsection{Flow}

2.6.1 Unidirectional

2.6.2 Bi-directional

2.6.3 Multi-directional

\subsection{Nature of TT}

2.7.1 Proprietary

2.7.2 Non- Proprietary

\section{Key 3 Motivations}

\subsection{Economic Factors}

3.1.1 Cost savings

3.1.2 Economic growth 
3.1.3 Increased earnings in hard currency

3.1.4 Generation of foreign exchange (other than hard currency)

3.1.5 Improved balance of trade

3.1.6 Generation of exports

3.1.7 More equitable trade agreements

3.1.8 Increased tax revenues

3.1.9 Increased sales

3.1.10 Taking advantage of tax and tariff laws

3.1.11 Increased royalties

3.1 .12 Increased sales of technology

3.1.13 Improved profitability

3.1.14 Improved knowledge/database

\subsection{Social Factors}

3.2.1 Improved quality of life

3.2.2 Improved physical health status

3.2.3 Increased employment

3.2.4 Elevation of social or political status

3.2.5 Cultural enrichment, cultural evolution

3.2.6 Advancement of society

3.2.7 Improved environment through improved/new technology

3.2.8 Improved crime-fighting capabilities

\subsection{Operational Factors}

3.3.1 Changes in scale of production or service

3.3.2 Improved input material

3.3.3 Improved reliability of delivery dates

3.3.4 More efficient use of capital and labor

3.3.5 Upgraded labor skills

3.3.6 Access to alternative sources of supply

3.3.7 Increased production capacity

3.3.8 Working out trade deals under constraints

3.3.9 Reducing risk of over-demand forecast

3.3.10 Improved problem solving skills

3.3.11 Better purchasing capability

3.3.12 Increased mechanization/automation

3.3.13 Improved process yields

3.3.14 Changing from intermittent to mass flow processes

3.3.15 Improved communication capabilities

3.3.16 Temporal improvement: ability to do work faster

3.3.17 moving towards standardization

3.3.18 Long-term arrangements that feed technology enhancement

3.3.19 designing for market segments

3.3.20 Long-term arrangements that feed technology enhancements

3.3.21 larger market for participating multinational companies

3.3.22 Improved R\&D

3.3.23 Vertical and horizontal integration of an industry 
3.3.24 Improved access to new technology and know-how

3.3.25 Exposure to future technical innovations

3.3.26 Improved sales opportunities

3.3.27 Gaining access to new markets

3.3.28 Accelerated introduction of a new product model

3.3.29 Opportunity to start new business

3.3.30 Productivity gains

3.3.31 Improved user satisfaction

3.3.32 Improved process innovation

3.3.33 Improved quality of conformance

3.3.34 Greater degree of computerization resulting in higher accuracy and speed

3.3.35 Improved communications (e.g. in satellite technology transfer)

3.3.36 Improved Internet or web hosting capabilities

\subsection{Strategic Factors}

3.4.1 Improved product and service quality of design

3.4.2 Improved product innovation

3.4.3 Entry into international market

3.4.4 Improved volume flexibility

3.4.5 Improved product/service flexibility

3.4.6 Improved managerial flexibility

3.4.7 Improved handling customer complaints after sales service

3.4.8 Improved agility: reduction in idea, to-market time

3.4.9 Improved product and service design

3.4.10 Improved physical properties of the product

3.4.11 Improved performance characteristics of products/services

3.4.12 Entry barrier mitigation through Internet

3.4.13 Technology management (10 respond to changes)

3.4.14 Web-enabled services

\subsection{Global factors}

3.5.1 Improved reconnaissance capabilities

3.5.2 Improved war/defense capabilities

3.5.3 Improved space technological capabilities

3.5.4 Improved transportation capabilities

3.5.5 Improved political image

3.5.6 Enhanced influence

\subsection{Personal Factors}

3.6.1 Benefits from learning

3.6.2 Gratification from teaching/sharing knowledge

3.6.3 Quid pro quo with colleagues

3.6.4 Enhanced status in the discipline/profession

3.6.5 Enhanced marketability

3.6.7 Improved personal benefits-higher personal income

3.6.8 Enhanced travel opportunities 
Key 4 Disciplines and Professions

\subsection{Economics}

4.1.1 Vertical $n$

4.1.2 Horizontal $n$

4.1.3 Physical item $n$

4.1.4 Information $n$

4.1.5 Industry- industry $n$

4.1.6 Sector-sector TT

4.1.7 Region-.region $n$

4.1.8 Domestic $n$

4.1.9 International TT

4.1.9.1 West-East

4.1.9.2 North-South TT

\subsection{Anthropology Cross-cultural TT}

4.2.1 Group program

4.2.2 Community program

4.2.3 Village program

4.2.4 Rural program

4.2.5 Urban program

\subsection{Sociology}

4.3.1 Diffusion of innovation

4.3.2 Adoption 01 Innovation

4.3.3 Diffusion 01 social technology

4.3.4 Diffusion of non-social technology

4.3.5 Centralized diffusion

4.3.6 Decentralized diffusion

\subsection{Management engineering and other professions}

4.4.1 Vertical TT

4.4.2 Horizontal $n$

4.4.3 Physical item $n$

4.4.4 Information $n$

4.4.5 Industry-industry TT

4.4.6 Sector-sector TT

4.4.7 Region-region IT

4.4.8 Domestic TT

4.4.9 International TT

4.4.10 Material TT

4.4.11 Design TT

4.4.12 Capacity TT

4.4.13 imparts operational capability

4.4.14 TT imparts duplicative capability

4.4.15 TT imparts innovative capability

4.4.16 Markel level IT

4.4.17 Production level IT

4.4.18 R\&D level TT 


\author{
4.4.19 Inter-firm IT \\ 4.4.20 Intra-firm TT \\ 4.4.21 Internal TT \\ 4.4.22 Arms-Length TT \\ 4.4.23 TT to wholly owned subsidiary \\ 4.4.24 TT to joint venture \\ 4.4.25 TT to independent company \\ 4.4.26 Web-based Innovations \\ 4.4.27 Web-based customer interactions
}




\section{APPENDIX C: MODEL VALIDATION ASSESSMENT TOOL MODEL VALIDATION}

Thank you very much for agreeing to participate in my research. Please answer the 5 questions to complete the content validation assessment. The assessment aims to capture your judgment on a number of proposed assessment variables.

The objective of this assessment tool is to validate the preliminary hierarchical model that was developed based on a comprehensive literature review. The following questions are intended to capture your judgment of the suitability of the proposed perspectives and success attributes, and identify those that might have gone undetected during my literature review. Your input will be used to help finalize my model.

The model is presented below in its entirety. Individual questions will address specific levels of the model for you to assess. Also, each question includes a definition of the perspective and corresponding success attributes as appropriate. You are NOT being asked to comment on desirability curves (indicated as "DC" in the diagram). Note: This research defines technology transfer as moving from Technology Readiness Levels 7-9 into application at an organization.

Thank you again for your time and for providing your expert opinion - it will make a significant difference in the quality of my research. I would appreciate it if you would provide responses at your earliest convenience.

Sincerely,

Judith Estep

PMO, Technology Innovation, BPA

PhD Candidate, Dept of Engineering and Technology Management, PSU

[MODEL GRAPH WAS INSERTED] 


\section{QUESTION 1 WAS OMITTED TO MAINTAIN EXPERT ANONIMITY}

\section{QUESTION 2}

A comprehensive literature review was used to develop four major perspectives when considering technology transfer. A definition of each perspective is provided.

Organizational: This perspective refers to the strategies developed between the research organization and the technology recipient. Strategies consider how similar the research partners are, in terms of organizational structure, their location, and how many stakeholders are involved in the technology transfer transaction. For the purposes of this proposal the research organizations include 5 likely partners: Universities, Collaborative Partnerships (EPRI, CEATI, etc.), National Labs (LBNL, PNNL, etc.), Industry Partners (Intel, IBM, etc.), and other utilities (So Cal Edison, Consolidated Edison, etc.).

Technological: This perspective considers actions related to the technology as important for successful technology transfer. Actions include the researcher's previous cooperative experience and ability to demonstrate the technology, understanding of the recipient's technology needs, and the existence of and ability of the Technology Transfer Office to be effective at marketing the technology.

Social: The emphasis on social strategies is how to develop and maintain a relationship between the researchers and recipients such that technology transfer is more likely to occur. This perspective and associated success attributes identify the necessary activities to facilitate a successful technology transfer.

Market: This perspective assesses the market's readiness to accept the new technology - has a market-pull be sufficiently created such that it (the market) has a need established and assessed for the technology? The success attributes that support this perspective include: a business plan has been created, financial feasibility has been confirmed, common standards exist, there is an appropriate level of support from management, and government incentives exist to make the technology more appealing to use or be adopted on a larger scale.

Please indicate whether the proposed perspectives are valid for developing a technology transfer score.

$\begin{array}{lll}\text { Organizational } & \text { Yes } & \text { No } \\ \text { Technological } & \text { Yes } & \text { No } \\ \text { Social } & \text { Yes } & \text { No } \\ \text { Market } & \text { Yes } & \text { No }\end{array}$

Please use this space to comment on additional perspectives that should be included when considering technology transfer. 


\section{QUESTION 3}

A comprehensive literature review was used to identify attributes of the Organizational perspective that contribute to successful technology transfer. A definition of each success attribute is provided.

Budget Cost-Share: The ability to have budget flexibility is preferred for successful technology transfer. In this context budget flexibility is defined as allowing budget to move between fiscal years, amount of discretionary funding, and the personnel level that is authorized to release funding (e.g. a council is required to approve funding versus devolving to the R\&D managers for budget assignment)

Geographic Proximity: Refers to the geographic proximity between the researcher and technology recipient. Proposed categories would be local (within the same geographic region, e.g. Pacific Northwest), National (within the same country), or International (researcher and technology recipient reside in different countries). Literature implies that technology transfer is more successful when the organizations are geographically close.

Organizational Homogeneity: Homogeneity describes the similarities between the research and technology recipient organizations. Examples include the size of the firm, strategic alignment, similar motivations for doing research, the organizational structures (matrix, etc.), and similar expectations for success. Proposed units of measure include no homogeneity, some, or very homogenous. The more homogeneity there is between research and technology recipient organizations, the better for technology transfer success.

Time to Contract: This attribute considers the level of detail and duration of setting up agreements/contracts between the researchers and technology recipients. Higher levels of bureaucracy inhibit technology transfer.

Technical and Stakeholder Complexity: This attribute refers to the number technology characteristics and the number of impacted stakeholders/project team. The proposed units of measure would be few, some, or high number of impacted stakeholders. The implication is that the higher number of stakeholders, the more communication and coordination that is necessary, therefore the technology would be more challenging to transfer.

Please indicate whether the proposed success attributes, associated with the Organizational perspective are valid for developing a technology transfer score.

$\begin{array}{lll}\text { Budget Cost-Share } & \text { Yes } & \text { No } \\ \text { Geographic Proximity } & \text { Yes } & \text { No } \\ \text { Organizational Homogeneity } & \text { Yes } & \text { No } \\ \text { Time to Contract } & \text { Yes } & \text { No } \\ \text { Tech/Stakeholder Complexities } & \text { Yes } & \text { No }\end{array}$

Please use this space to comment on additional success attributes that should be included when considering technology transfer. 


\section{QUESTION 4}

A comprehensive literature review was used to identify success attributes of the Technological perspective that contribute to successful technology transfer. A definition of each success attribute is provided.

Generally the success attributes for Technology Elements refer to the research organizations experience working cooperatively, knowledge of the technology and recipient needs, and the ability to "sell" the technology to the market.

Combined Research Experience: How much experience does the researcher have working with others? Are they new (no cooperative experience) or are they very familiar working with other organizations on $R \& D$. More cooperative experience implies higher likelihood of technology transfer because they are familiar with potential barriers based on their previous experience.

Technology Publications: How many successful technology demonstrations or publications does the organization have (for the case study)? As an example, assuming the case study is for demand response technologies, how many demonstrations or publications of heat pump water heaters has the researcher been involved with? More technology demonstrations or publications are better for successful technology transfer.

Personnel Assigned to the Technology Transfer Office (TTO): Does the research organization have a dedicated TTO that can coordinate activities between the researcher and the technology recipient?

Technology Benefits: How familiar is the research organization with the customer requirements and/or market needs?

Budget Allocated to TT: Literature suggests that the TTO should be staffed with personnel who have marketing experience. Indicators/Units of measure would be the percent of budget allocated to marketing activities or the number of personnel with a technology marketing background.

Please indicate whether the proposed success attributes, associated with the Technological perspective, are valid for developing a technology transfer score.

$\begin{array}{lll}\text { Combined Research Experience } & \text { Yes } & \text { No } \\ \text { Technology Publications } & \text { Yes } & \text { No } \\ \text { Personnel Assigned to the TTO } & \text { Yes } & \text { No } \\ \text { Technology Benefits } & \text { Yes } & \text { No } \\ \text { Budget Allocated to TT } & \text { Yes } & \text { No }\end{array}$

Please use this space to comment on additional success attributes that should be included when considering technology transfer. 


\section{QUESTION 5}

A comprehensive literature review was used to identify the Social perspective attributes that contribute to successful technology transfer. A definition of each success attribute is provided.

Generally, these success attributes consider the personnel relationships and activities that facilitate technology transfer both at the research organization and technology recipient's organization.

Diversity Events: Personnel that are more aware of and have more experience interacting with different cultures are more successful at technology transfer. Potential units of measure are the organizations have none, some, a lot of diversity/cultural training opportunities.

Personnel Dedicated to TT: This attribute refers to the degree that researchers are involved in the hand-off process. When do the researchers start to consider technology transfer and start to involve end-users/technology recipients (e.g. as part of the $R \& D$ process or after the research is complete)?

Project Meetings: Fundamental to successful technology transfer is establishing a trusting relationship between the research and technology recipient. This can be accomplished by frequent communication, structured project management/meetings, cooperative risk assessments, etc.

Personnel Loan Policy: The willingness to "loan" researchers to help with technology transfer was cited as necessary for technology transfer.

Successful TT Experiences: Does the research or technology recipient organization have systems in place to recognize innovative thinking? Literature suggests that having a reward system in place facilitates technology transfer.

Please indicate whether the proposed success attributes, associated with the Social perspective are valid for developing a technology transfer score.

$\begin{array}{lll}\text { Diversity Events } & \text { Yes } & \text { No } \\ \text { Personnel Dedicated to TT } & \text { Yes } & \text { No } \\ \text { Project Meetings } & \text { Yes } & \text { No } \\ \text { Personnel Loan Policy } & \text { Yes } & \text { No }\end{array}$

Please use this space to comment on additional success attributes that should be included when considering technology transfer. 


\section{QUESTION 6}

A comprehensive literature review was used to identify attributes of the Market perspective that contribute to successful technology transfer. A definition of each success attribute is provided.

Generally, these success attributes refer to how ready is the market to receive the technology. Has the technical and financial feasibility been verified? Are incentives in place to encourage technology transfer (e.g. rebates, common standards, etc.)? Also, does the recipient organization have a structure in place to accept the technology?

Use Case: Does a comprehensive business plan exist that supports the technology in the recipient organization?

Organizational Champion: Literature suggests that a dedicated champion in the recipient organization is fundamental to successful technology transfer. The champion can shepherd the technology through organizational barriers; a sense of ownership is created.

Level of Top Management Support: Similar to an organizational champion, the top management in the organization needs to see the value of the technology. Their support is required for successful technology transfer.

Government Incentives: Incentives are seen as a way to entice a market to invest in technology. Examples include rebates for purchasing LED lightbulbs or tax credits for wind farms.

Common Technology Standards: Common standards help to facilitate the introduction of multiple but similar technologies into the market. Common communication protocols are examples of standards that help to facilitate demand response technologies.

ROI: Similar to the business plan, has financial feasibility been determined? Examples include, price point of solar panels for the residential market have not been completely realized and is seen as one of the barriers to their widespread adoption in the US.

Please indicate whether the proposed success attributes, associated with the Market perspective, are valid for developing a technology transfer score.

$\begin{array}{lll}\text { Use Case } & \text { Yes } & \text { No } \\ \text { Organizational Champion } & \text { Yes } & \text { No } \\ \text { Level of Top Mgmt Support } & \text { Yes } & \text { No } \\ \text { Government Incentives } & \text { Yes } & \text { No } \\ \text { Common Tech Standards } & \text { Yes } & \text { No } \\ \text { ROI } & \text { Yes } & \text { No }\end{array}$


Please use this space to comment on additional success attributes that should be included when considering technology transfer. 
APPENDIX D: MODEL QUANTIFICATION ASSESSMENT TOOLS

Appendix D1: Quantification Tool for Perspective Level

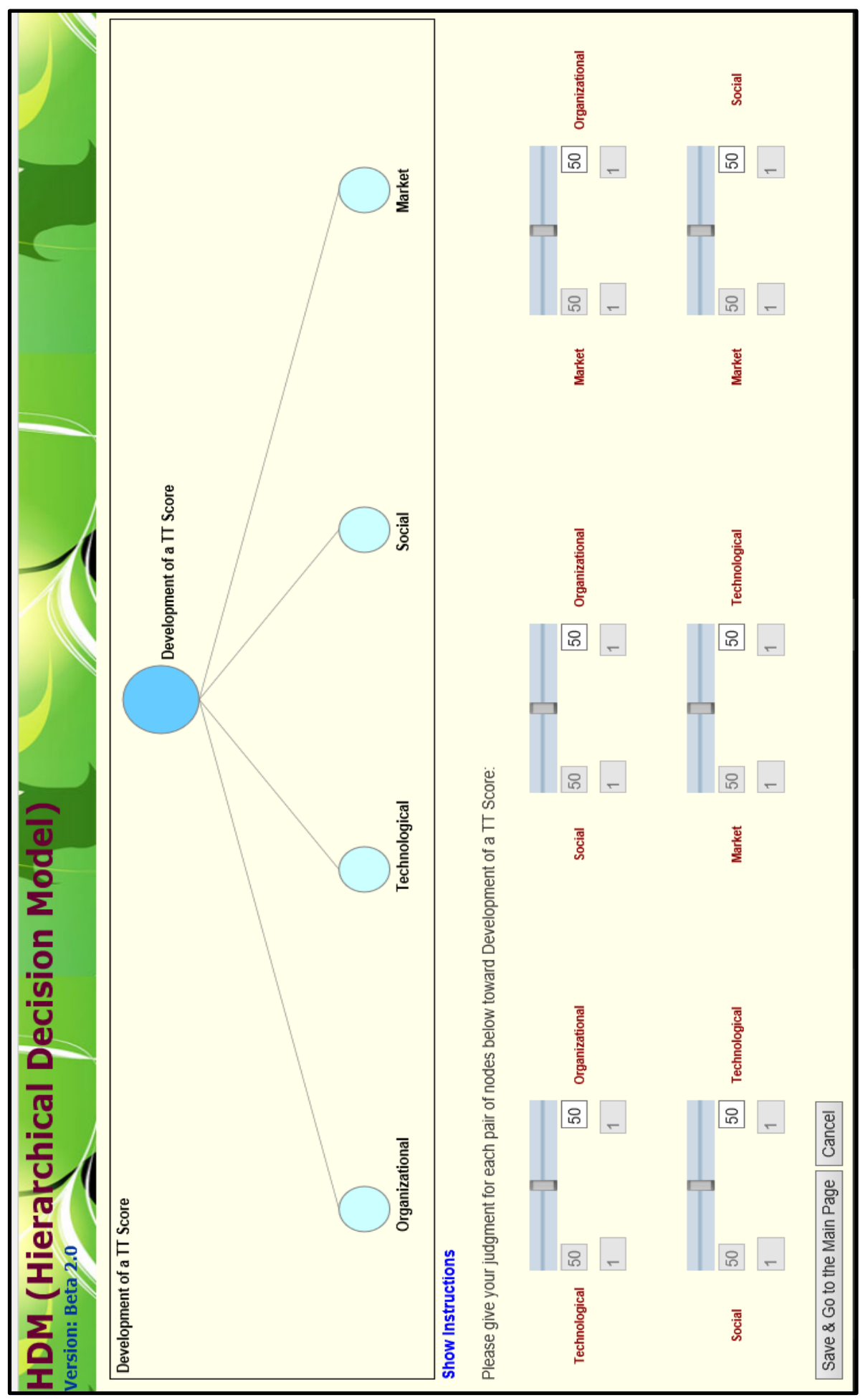


Appendix D2: Quantification Tool for Organizational Success Attributes

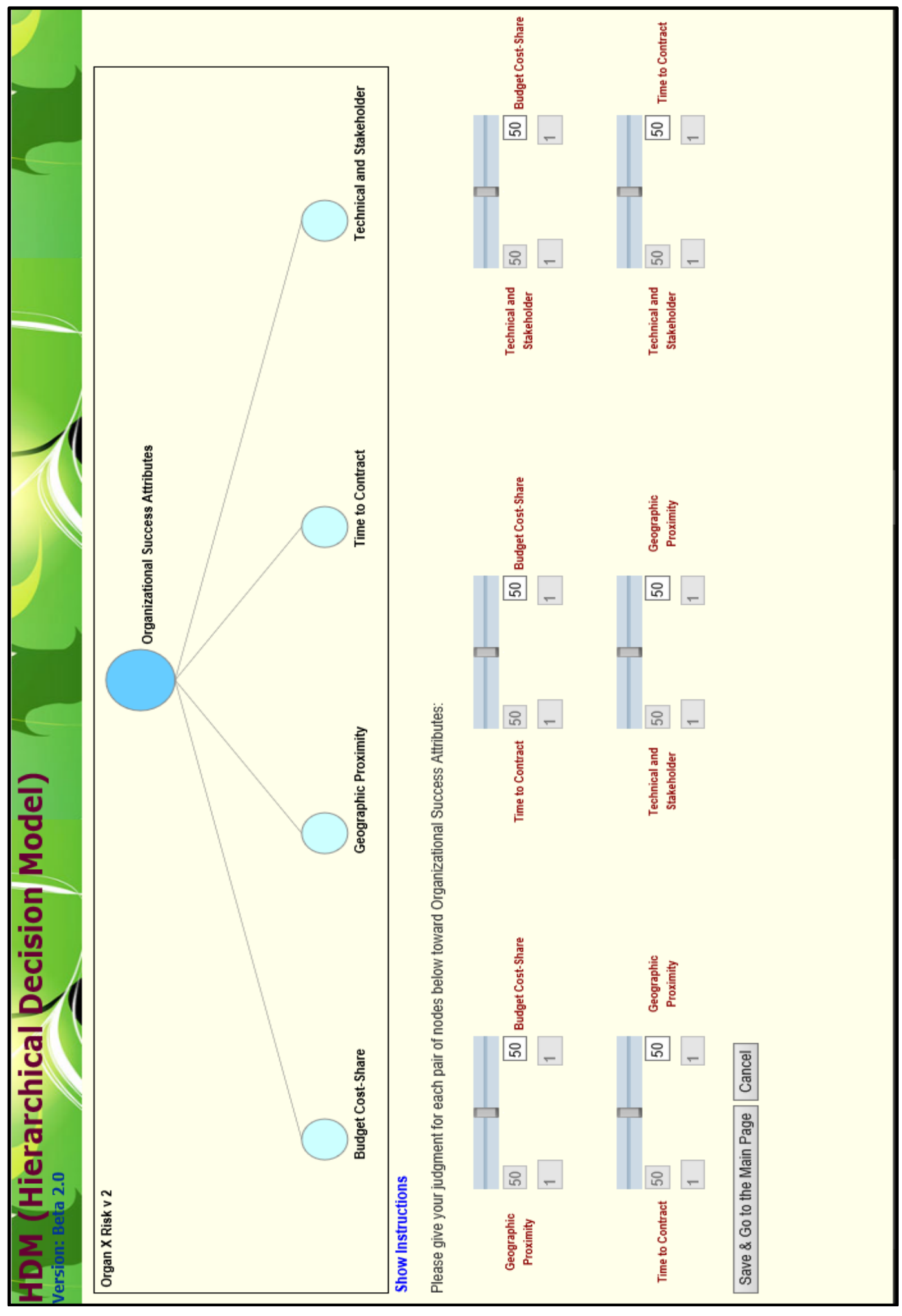


Appendix D3: Quantification Tool for Technological Success Attributes

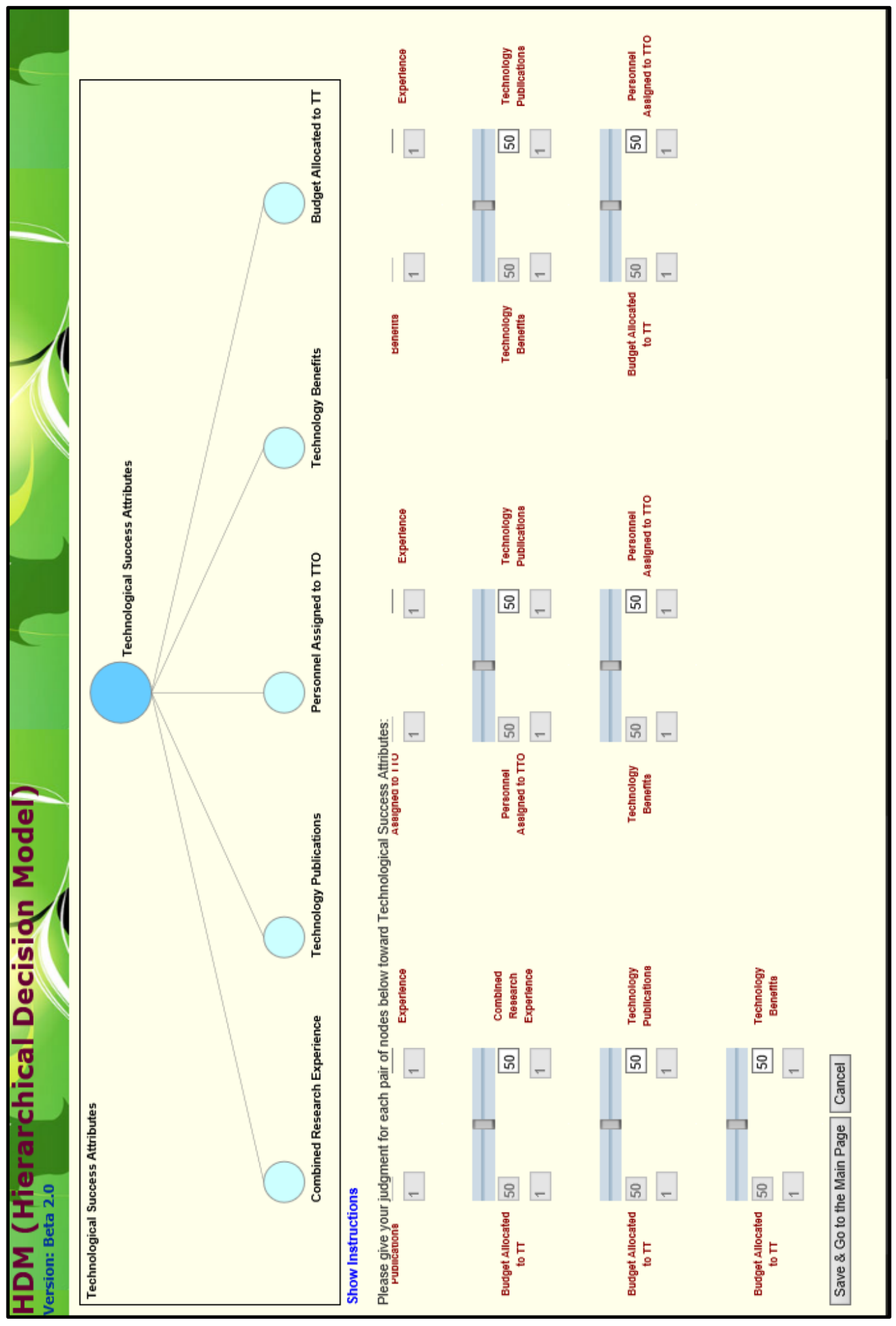


Appendix D4: Quantification Tool for Social Success Attributes

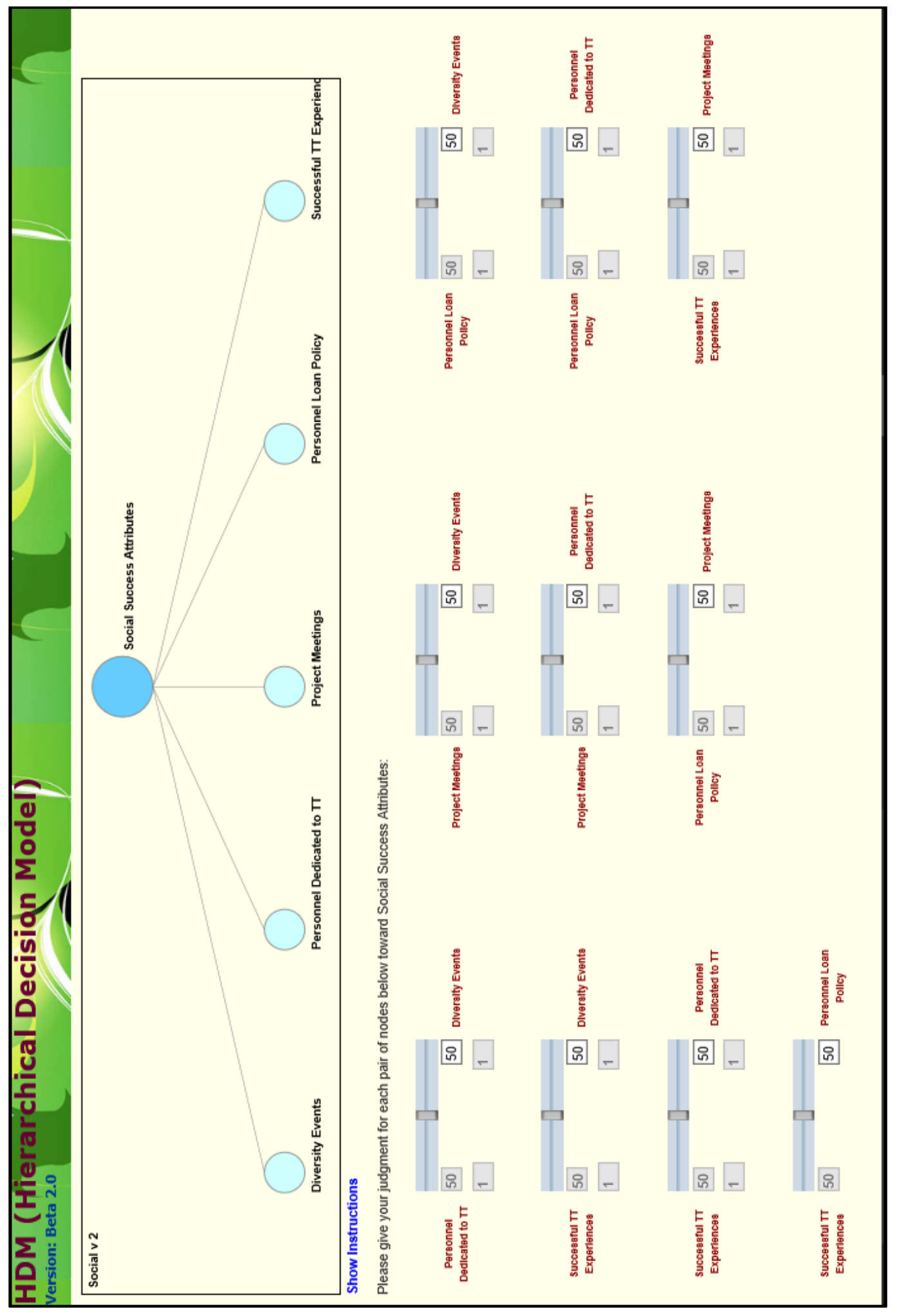


Appendix D5: Quantification Tool for Market Success Attributes

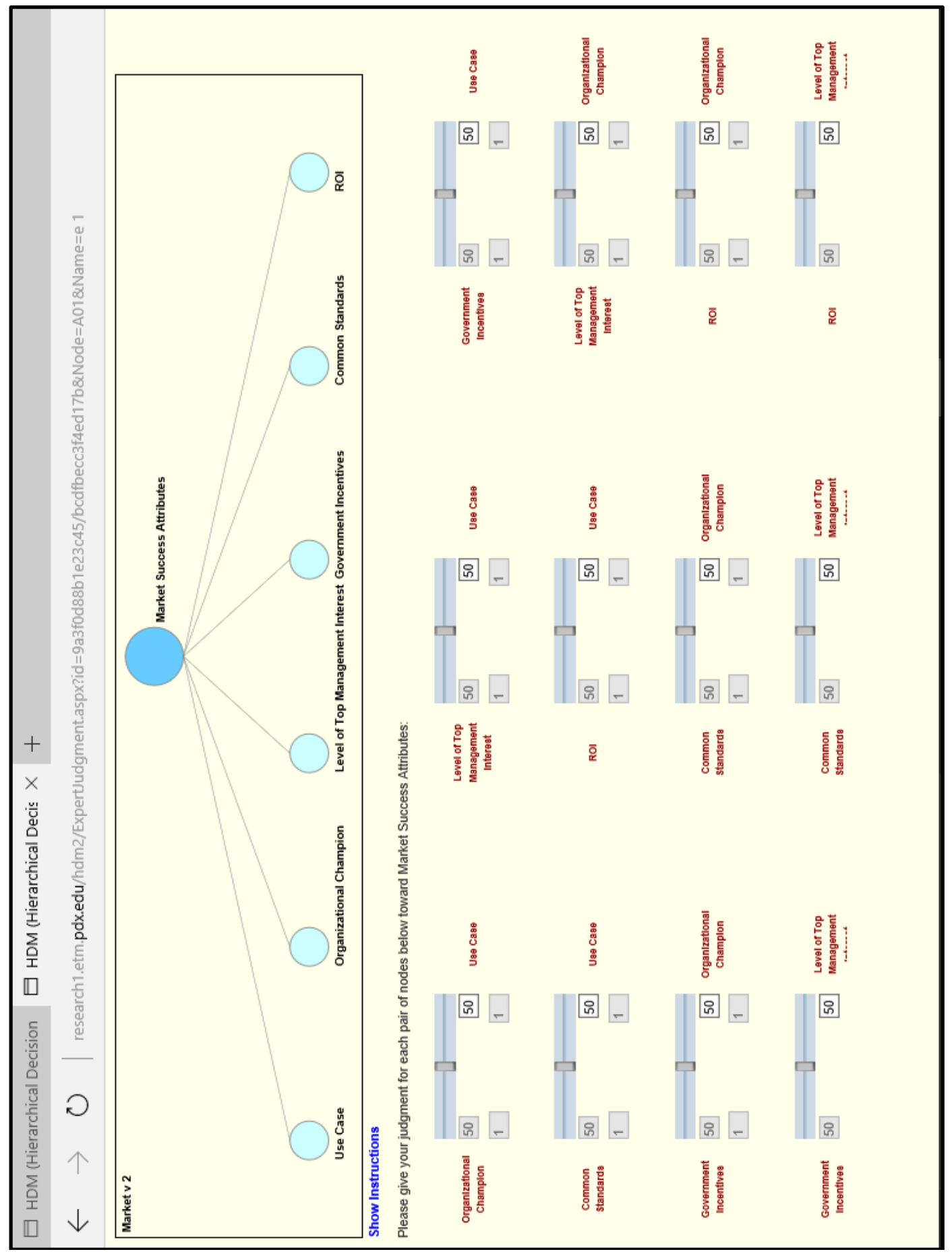




\section{APPENDIX E: MODEL VALIDATION RESULTS}

\section{Appendix E1: Validation of Perspective Level}

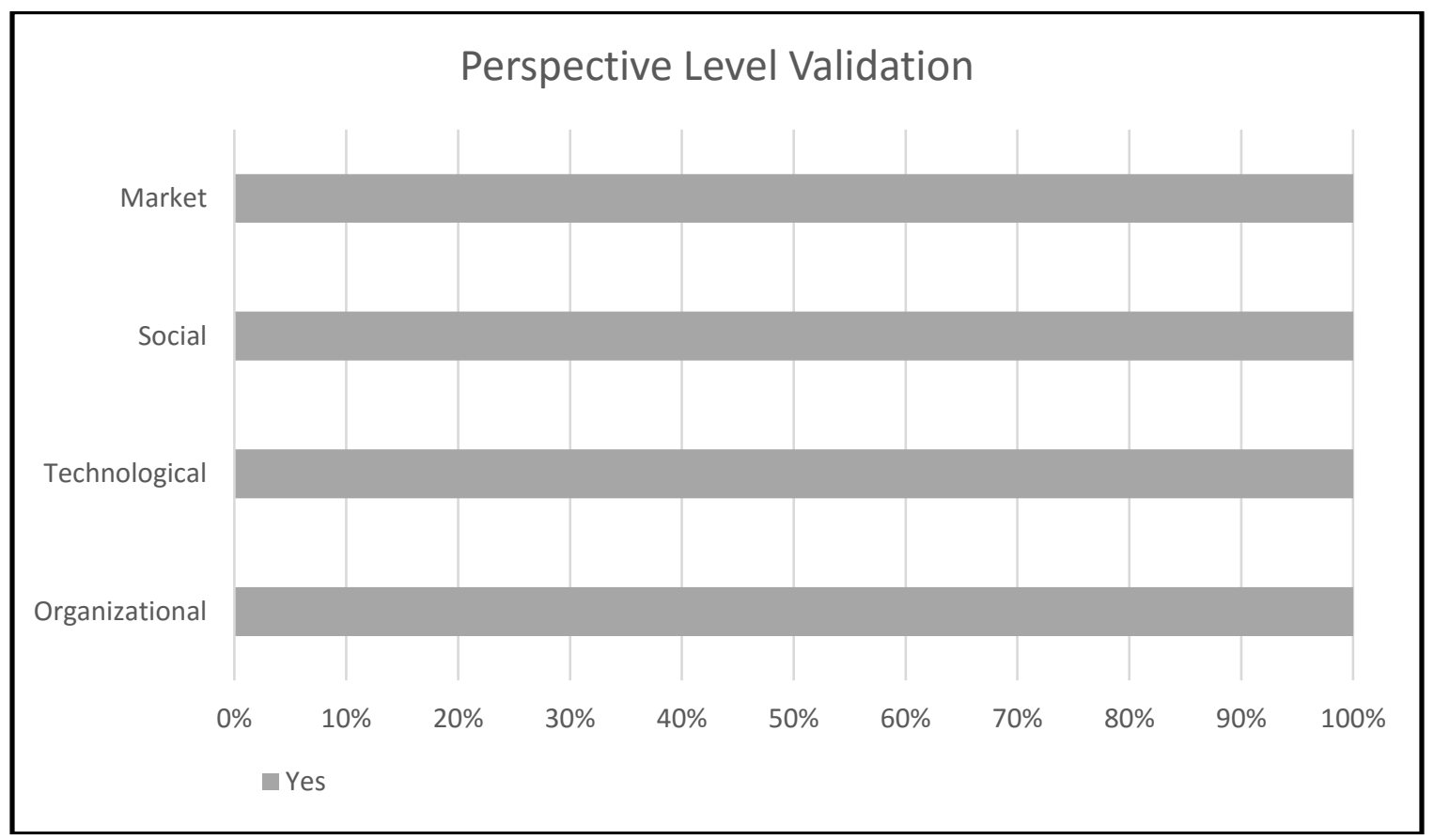

Outcome: All experts agreed that the four perspectives were appropriate for assessing technology transfer potential. 


\section{Appendix E2: Validation of Organizational Perspective Success Attributes}

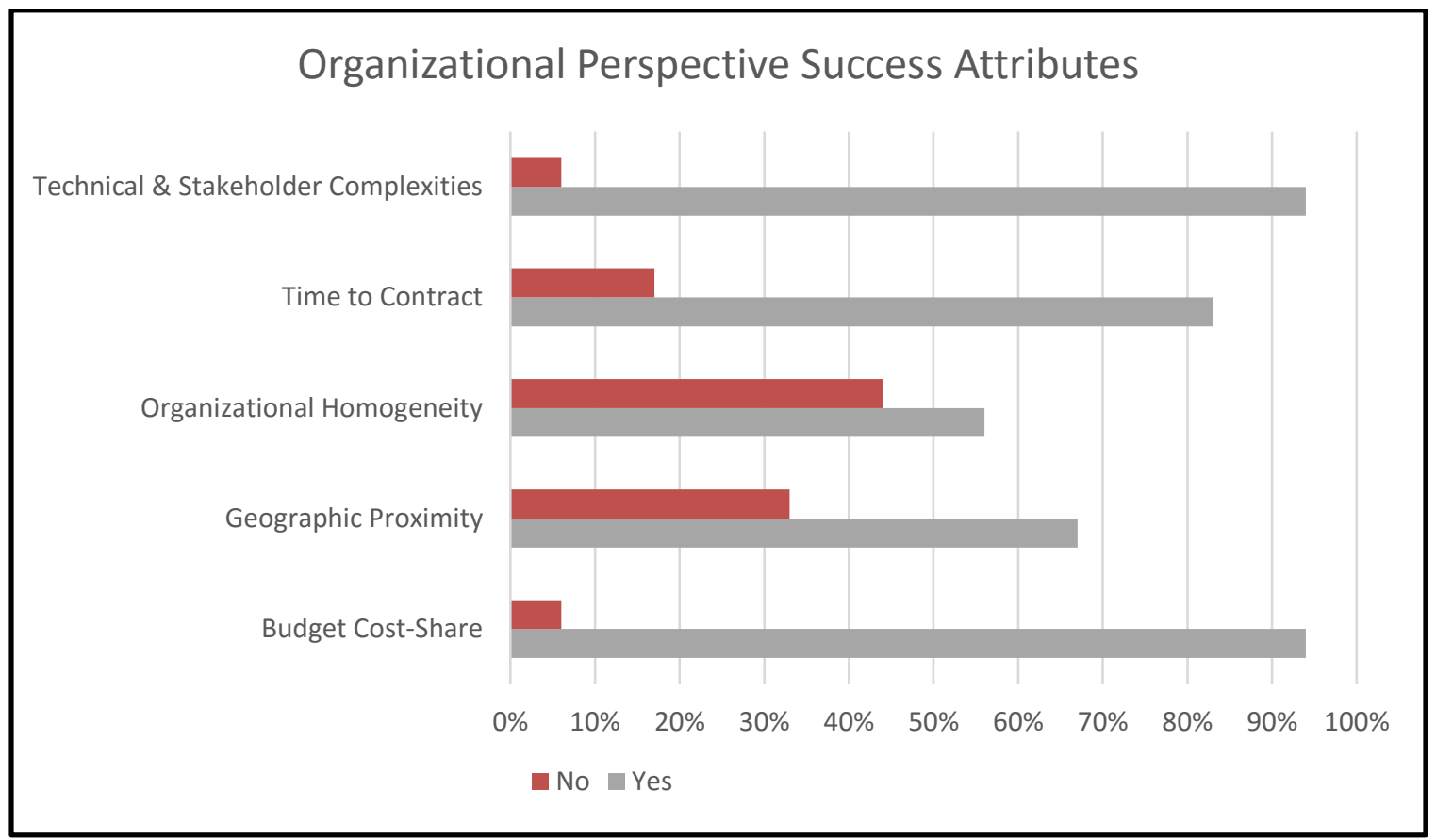

Verbatim Feedback:

- Geographic proximity is a matter of convenience but with today's technology barriers are easier to overcome.

- First adopter: Consider the willingness of the recipient to be the first one to use a new product. Some organizations are conservative and insist only on commercially available technologies

- Regarding stakeholders - a large number of stakeholders may create a market pull

Outcome:

- Less than $67 \%$ of experts thought that Organizational Homogeneity was valid for developing a TT score 
○ "...the organization taking technology to market should be very different than the R\&D organization. They have a much different purpose and may be much smaller..." [Expert 7]

○ "...sometimes I have observed that large organizations have trouble working with each other. The organizations can have established processes, cultures, etc. that are not easily changed..." [Expert 1]

- The success attribute was removed from the final model

\section{Appendix E3: Validation of Technological Perspective Success Attributes}

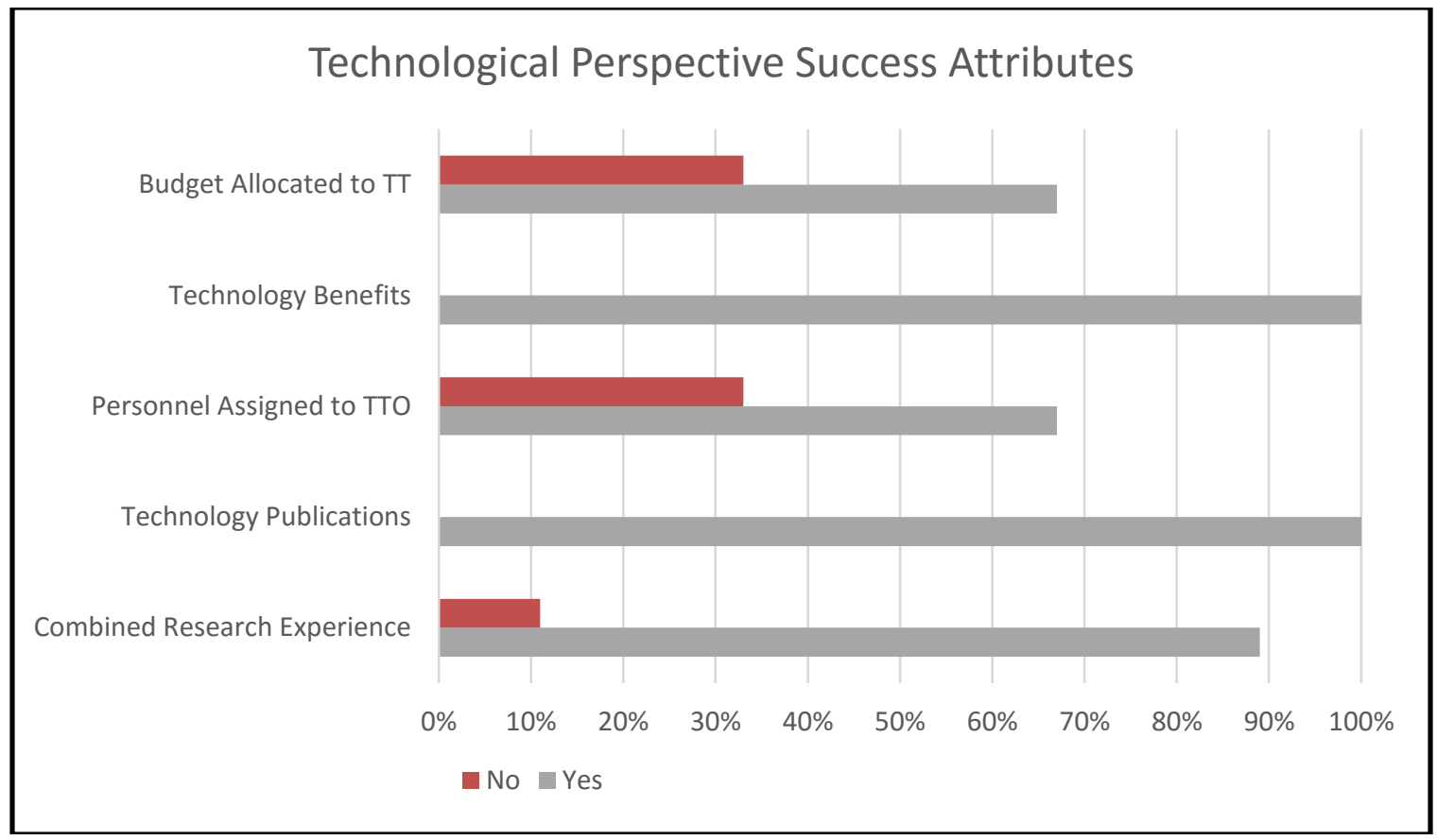

Outcome: All success attributes were determined to be appropriate for developing a technology transfer score. 


\section{Appendix E4: Validation of Social Perspective Success Attributes}

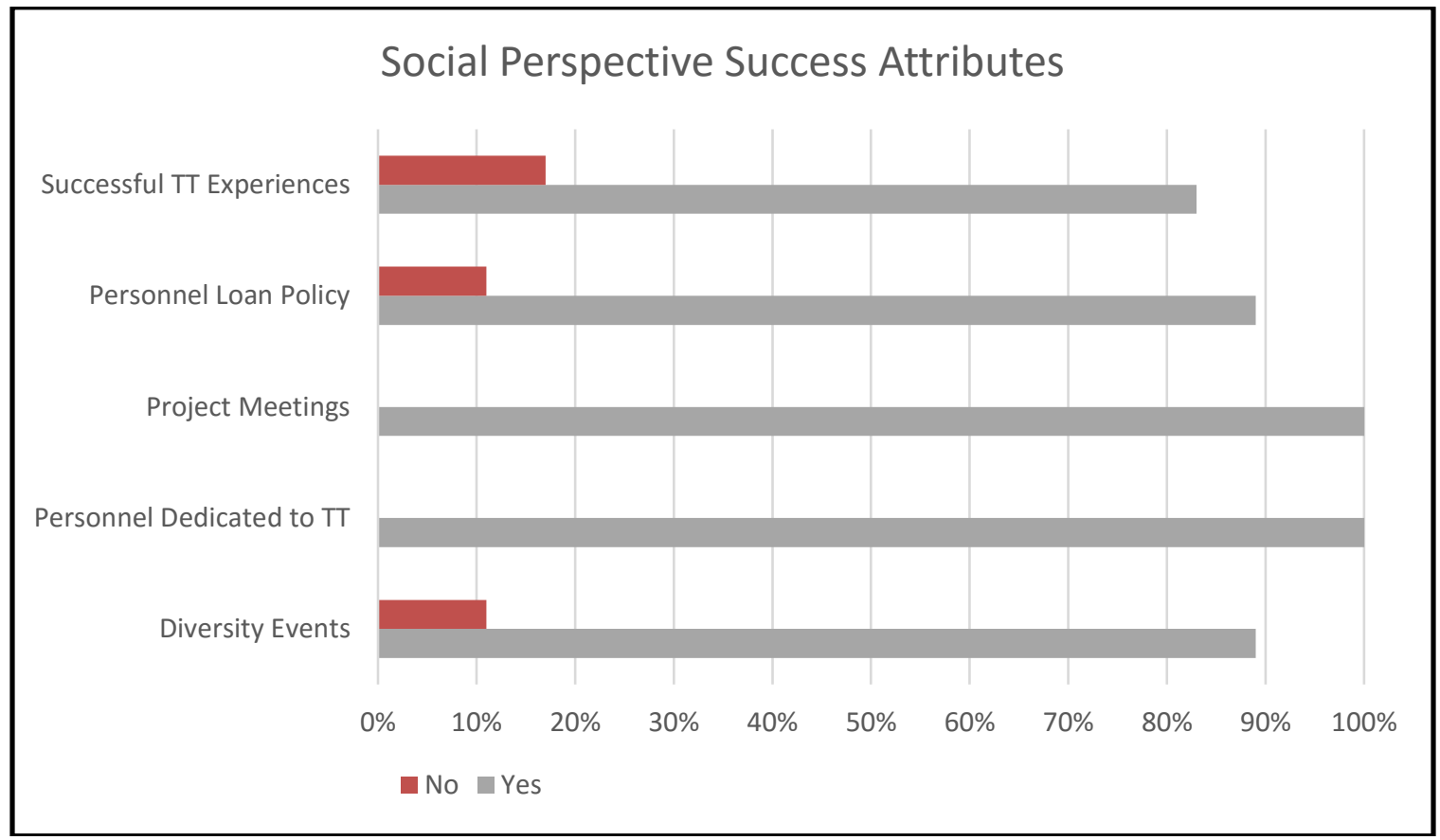

Outcome: All success attributes were determined to be appropriate for developing a technology transfer score. 


\section{Appendix E5: Validation of Market Perspective Success Attributes}

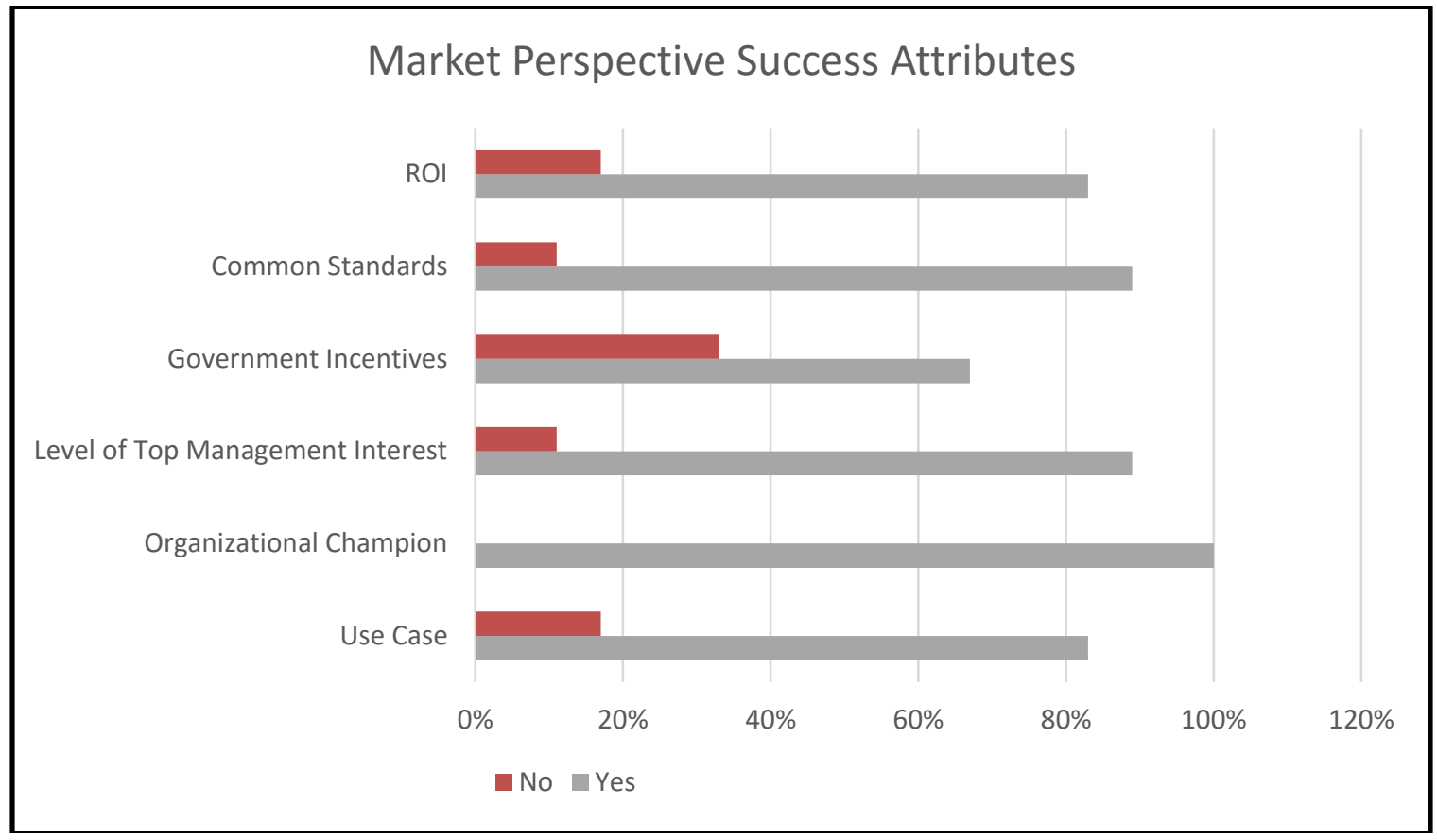

Outcome: All success attributes were determined to be appropriate for developing a technology transfer score. 


\section{APPENDIX F: PAIRWISE COMPARISON RESULTS}

\section{Appendix F1: Perspective Level Pairwise Comparisons}

\begin{tabular}{|l|c|c|c|c|c|c|}
\hline Expert & $\mathrm{A}: \mathrm{B}$ & $\mathrm{A}: \mathrm{C}$ & $\mathrm{A}: \mathrm{D}$ & $\mathrm{B}: \mathrm{C}$ & $\mathrm{B}: \mathrm{D}$ & $\mathrm{C}: \mathrm{D}$ \\
\hline Expert 1 & 20 & 50 & 20 & 85 & 65 & 20 \\
\hline Expert 2 & 40 & 90 & 50 & 90 & 50 & 20 \\
\hline Expert 3 & 60 & 70 & 40 & 60 & 30 & 20 \\
\hline Expert 4 & 65 & 30 & 30 & 20 & 20 & 40 \\
\hline Expert 5 & 60 & 50 & 30 & 70 & 30 & 30 \\
\hline Expert 6 & 25 & 25 & 25 & 50 & 30 & 30 \\
\hline Expert 7 & 60 & 50 & 50 & 70 & 40 & 40 \\
\hline Expert 8 & 50 & 40 & 30 & 30 & 20 & 40 \\
\hline Expert 9 & 35 & 50 & 25 & 70 & 45 & 15 \\
\hline Expert 10 & 40 & 35 & 30 & 60 & 35 & 40 \\
\hline Expert 11 & 20 & 50 & 20 & 60 & 50 & 40 \\
\hline
\end{tabular}
A: Organizational
B: Technological
C: Social
D: Market 


\section{Appendix F2: Organizational Pairwise Comparisons}

\begin{tabular}{|l|c|c|c|c|c|c|}
\hline Expert & $\mathrm{A}: \mathrm{B}$ & $\mathrm{A}: \mathrm{C}$ & $\mathrm{A}: \mathrm{D}$ & $\mathrm{B}: \mathrm{C}$ & $\mathrm{B}: \mathrm{D}$ & $\mathrm{C}: \mathrm{D}$ \\
\hline Expert 21 & 40 & 20 & 50 & 30 & 60 & 70 \\
\hline Expert 22 & 75 & 40 & 35 & 25 & 25 & 30 \\
\hline Expert 23 & 60 & 65 & 20 & 50 & 30 & 35 \\
\hline Expert 24 & 75 & 70 & 60 & 40 & 35 & 60 \\
\hline Expert 25 & 40 & 35 & 15 & 60 & 20 & 10 \\
\hline Expert 26 & 75 & 50 & 50 & 25 & 15 & 50 \\
\hline Expert 27 & 25 & 25 & 75 & 75 & 50 & 50 \\
\hline Expert 28 & 40 & 70 & 50 & 65 & 45 & 25 \\
\hline Expert 29 & 40 & 50 & 40 & 70 & 35 & 60 \\
\hline Expert 30 & 80 & 40 & 30 & 20 & 20 & 50 \\
\hline Expert 31 & 60 & 85 & 35 & 70 & 35 & 50 \\
\hline Expert 32 & 75 & 75 & 35 & 70 & 50 & 5 \\
\hline Expert 33 & 65 & 40 & 50 & 35 & 35 & 50 \\
\hline
\end{tabular}
A: Budget Cost-Share
B: Geographic Proximity
C: Average Time to Contract
D: Technical/Stakeholder Complexities 


\section{Appendix F3: Technological Pairwise Comparisons}

\begin{tabular}{|l|c|c|c|c|c|c|c|c|c|c|}
\hline Expert & $\mathrm{A}: \mathrm{B}$ & $\mathrm{A}: \mathrm{C}$ & $\mathrm{A}: \mathrm{D}$ & $\mathrm{A}: \mathrm{E}$ & $\mathrm{B}: \mathrm{C}$ & $\mathrm{B}: \mathrm{D}$ & $\mathrm{B}: \mathrm{E}$ & $\mathrm{C}: \mathrm{D}$ & $\mathrm{C}: \mathrm{E}$ & $\mathrm{D}: \mathrm{E}$ \\
\hline Expert 34 & 35 & 50 & 20 & 50 & 75 & 40 & 70 & 30 & 75 & 85 \\
\hline Expert 35 & 40 & 60 & 50 & 50 & 70 & 50 & 75 & 40 & 50 & 50 \\
\hline Expert 36 & 50 & 75 & 20 & 75 & 75 & 35 & 65 & 10 & 40 & 75 \\
\hline Expert 37 & 90 & 60 & 60 & 50 & 60 & 50 & 65 & 50 & 70 & 50 \\
\hline Expert 38 & 35 & 25 & 25 & 50 & 40 & 50 & 60 & 70 & 90 & 90 \\
\hline Expert 39 & 80 & 80 & 50 & 80 & 60 & 20 & 50 & 20 & 50 & 80 \\
\hline Expert 40 & 25 & 25 & 50 & 75 & 40 & 60 & 75 & 75 & 75 & 60 \\
\hline Expert 41 & 45 & 40 & 10 & 60 & 60 & 40 & 75 & 40 & 80 & 90 \\
\hline Expert 42 & 25 & 50 & 25 & 50 & 75 & 50 & 60 & 25 & 50 & 75 \\
\hline Expert 43 & 60 & 60 & 40 & 70 & 50 & 30 & 60 & 30 & 60 & 80 \\
\hline Expert 54 & 20 & 65 & 20 & 50 & 80 & 40 & 80 & 15 & 35 & 75 \\
\hline
\end{tabular}
A: Cooperative Experience
B: Technology Publications
C: Personnel Dedicated to TTO
D: Technology Benefits
E: Percent Budget Allocated to TT 


\section{Appendix F4: Social Pairwise Comparisons}

\begin{tabular}{|l|c|c|c|c|c|c|c|c|c|c|}
\hline Expert & $\mathrm{A}: \mathrm{B}$ & $\mathrm{A}: \mathrm{C}$ & $\mathrm{A}: \mathrm{D}$ & $\mathrm{A}: \mathrm{E}$ & $\mathrm{B}: \mathrm{C}$ & $\mathrm{B}: \mathrm{D}$ & $\mathrm{B}: \mathrm{E}$ & $\mathrm{C}: \mathrm{D}$ & $\mathrm{C}: \mathrm{E}$ & $\mathrm{D}: \mathrm{E}$ \\
\hline Expert 21 & 10 & 30 & 10 & 65 & 60 & 50 & 80 & 35 & 75 & 80 \\
\hline Expert 22 & 75 & 50 & 60 & 40 & 40 & 35 & 25 & 60 & 50 & 40 \\
\hline Expert 23 & 15 & 20 & 25 & 35 & 55 & 65 & 70 & 60 & 65 & 60 \\
\hline Expert 24 & 30 & 20 & 40 & 35 & 20 & 60 & 40 & 75 & 50 & 45 \\
\hline Expert 25 & 40 & 30 & 60 & 40 & 50 & 70 & 80 & 75 & 75 & 50 \\
\hline Expert 26 & 40 & 40 & 50 & 35 & 30 & 60 & 60 & 70 & 70 & 40 \\
\hline Expert 27 & 25 & 25 & 75 & 75 & 50 & 99 & 99 & 99 & 99 & 50 \\
\hline Expert 28 & 30 & 70 & 50 & 75 & 60 & 80 & 80 & 65 & 80 & 50 \\
\hline Expert 29 & 40 & 50 & 30 & 60 & 50 & 60 & 70 & 70 & 70 & 50 \\
\hline Expert 30 & 40 & 50 & 25 & 50 & 70 & 70 & 70 & 50 & 70 & 50 \\
\hline Expert 31 & 35 & 40 & 45 & 40 & 45 & 50 & 40 & 55 & 60 & 40 \\
\hline Expert 32 & 30 & 5 & 15 & 5 & 50 & 50 & 30 & 75 & 50 & 50 \\
\hline Expert 33 & 25 & 35 & 40 & 30 & 55 & 60 & 60 & 50 & 60 & 45 \\
\hline
\end{tabular}
A: Diversity Events
B: Personnel Dedicated to TT
C: Project Team Communications
D: Personnel Loan Policy
E: Successful TT Experiences 


\section{Appendix F5: Market Pairwise Comparisons}

\begin{tabular}{|l|l|l|l|l|l|l|l|l|l|l|l|l|l|l|l|}
\hline $\begin{array}{l}\text { Exper } \\
\text { t }\end{array}$ & $\begin{array}{l}\text { A: } \\
\text { B }\end{array}$ & $\begin{array}{l}\text { A: } \\
\text { C }\end{array}$ & $\begin{array}{l}\text { A: } \\
\text { D }\end{array}$ & $\begin{array}{l}\text { A: } \\
\text { E }\end{array}$ & $\begin{array}{l}\text { A: } \\
\text { F }\end{array}$ & $\begin{array}{l}\text { B: } \\
\text { C }\end{array}$ & $\begin{array}{l}\text { B: } \\
\text { D }\end{array}$ & $\begin{array}{l}\text { B: } \\
\text { E }\end{array}$ & $\begin{array}{l}\text { B: } \\
\text { F }\end{array}$ & $\begin{array}{l}\text { C: } \\
\text { D }\end{array}$ & $\begin{array}{l}\text { C: } \\
\text { E }\end{array}$ & $\begin{array}{l}\text { C: } \\
\text { F }\end{array}$ & $\begin{array}{l}\text { D: } \\
\text { E }\end{array}$ & $\begin{array}{l}\text { D: } \\
\text { F }\end{array}$ & $\begin{array}{l}\text { E: } \\
\text { F }\end{array}$ \\
\hline E12 & 50 & 50 & 80 & 80 & 30 & 50 & 80 & 80 & 30 & 80 & 80 & 30 & 40 & 10 & 10 \\
\hline E13 & 55 & 45 & 60 & 35 & 40 & 40 & 35 & 25 & 35 & 75 & 40 & 50 & 25 & 50 & 55 \\
\hline E14 & 75 & 65 & 95 & 70 & 50 & 45 & 80 & 50 & 30 & 90 & 70 & 40 & 20 & 10 & 20 \\
\hline E15 & 30 & 30 & 75 & 40 & 50 & 20 & 60 & 25 & 50 & 75 & 50 & 65 & 20 & 40 & 60 \\
\hline E17 & 10 & 10 & 5 & 5 & 10 & 50 & 20 & 20 & 25 & 15 & 5 & 40 & 60 & 75 & 50 \\
\hline E18 & 30 & 30 & 70 & 35 & 30 & 50 & 70 & 60 & 35 & 70 & 60 & 30 & 30 & 20 & 35 \\
\hline E19 & 25 & 25 & 80 & 80 & 50 & 45 & 80 & 75 & 50 & 90 & 85 & 70 & 40 & 25 & 25 \\
\hline E20 & 60 & 90 & 50 & 80 & 20 & 10 & 50 & 40 & 50 & 60 & 50 & 50 & 40 & 80 & 60 \\
\hline E2 & 60 & 70 & 80 & 80 & 50 & 60 & 80 & 90 & 40 & 85 & 90 & 40 & 50 & 30 & 10 \\
\hline
\end{tabular}

A: Comprehensiveness of Use Case

B: Credibility of the Organizational Champion

C: Level of Top Management Interest

D: Government Incentives

E: Common Standards

F: ROI 


\section{APPENDIX G: DESIRABILITY CURVES FOR CASE STUDY - ACTUAL}

VALUES

\section{Appendix G1: Summary of Desirability Curves}

\begin{tabular}{|c|c|c|c|}
\hline \multirow{5}{*}{ 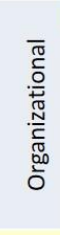 } & Success Attributes & Units of Measurement & Source \\
\hline & Budget Cost-Share & $\%$ cost share required to fund research & Research Proposal \\
\hline & Geographic Proximity & relative proximity (distance) between research and recipient & Research Proposal \\
\hline & Time to Contract & time to execute a contract & $\begin{array}{l}\text { Recipient Contracting } \\
\text { Office }\end{array}$ \\
\hline & Technical \& Stakeholder Complexity & $\begin{array}{l}\text { \# of technical characteristics identified in proposal and \# of } \\
\text { impacted stakeholders }\end{array}$ & Research Proposal \\
\hline \multirow{5}{*}{$\frac{\bar{\pi}}{\overline{0}}$} & Diversity Events & \# of diversity events to create cultural awareness & Research Organization \\
\hline & Personnel Dedicated to TT & \# of people dedicated to support TT & Research Organization \\
\hline & Project Meetings & \# of comms described in the project communication plan & Research Proposal \\
\hline & Personnel Loaned to Recipient & time that researchers are loaned to help with TT & Research Organization \\
\hline & Successful TT Experiences & \# of previous successful TT & Research Organization \\
\hline \multirow{5}{*}{ 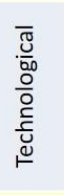 } & Combined Research Experience & \# years of combined research experience of principles & Research Proposal \\
\hline & Technology Publications & \# publications about technology & Research Proposal \\
\hline & Personnel Assigned to TTO & \# of personnel assigned to TTO & Research Organization \\
\hline & Technology Benefits & \# technology benefits identified in the research proposal & Research Proposal \\
\hline & Budget Allocated to TT & \% R\&D budget dedicated to TTO activities/marketing & Research Proposal \\
\hline \multirow{6}{*}{ 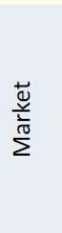 } & Comprehensive Use Case & How well is the Use Case Defined & Technology Recipient Org \\
\hline & Credibility of Organizational Champion & Credibility of the Organizational Champion & Technology Recipient Org \\
\hline & Level of Top Management Interest & Level of Organizational Support for TT & Technology Recipient Org \\
\hline & Government Incentives & $\#$ and type of government incentives & Publically Available \\
\hline & Common Technology Standards & How are common standards supported & Publically Available \\
\hline & $\mathrm{ROI}$ & ROI & Technology Recipient Org \\
\hline
\end{tabular}




\section{Appendix G2: Success Attributes for Case Studies}

\begin{tabular}{|c|c|c|c|c|c|c|c|}
\hline & \multirow{5}{*}{ 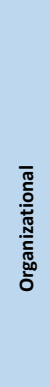 } & Success Attributes & Units of Measurement & Proposal 1 & Proposal 2 & Proposal 3 & Proposal 4 \\
\hline & & Budget Cost-Share & $\begin{array}{l}\% \text { cost share required to } \\
\text { fund research }\end{array}$ & $62 \%$ & $50 \%$ & $50 \%$ & $50 \%$ \\
\hline & & Geographic Proximity & $\begin{array}{l}\text { proximity between } \\
\text { research and recipient }\end{array}$ & $\begin{array}{l}250 \text { - } 1500 \text { mile } \\
\text { separation }\end{array}$ & $\begin{array}{l}250 \text { - } 1500 \text { mile } \\
\text { separation }\end{array}$ & $\begin{array}{l}250 \text { - } 1500 \text { mile } \\
\text { separation }\end{array}$ & $\begin{array}{l}1500-3000 \text { mile } \\
\text { separation }\end{array}$ \\
\hline & & Average Time to Contract & $\begin{array}{l}\text { average time to execute a } \\
\text { contract }\end{array}$ & 4 months & 1.5 months & 1.5 months & 4 months \\
\hline & & $\begin{array}{l}\text { Technical \& Stakeholder } \\
\text { Complexity }\end{array}$ & $\begin{array}{l}\text { \# of technical characteristics } \\
\text { identified in proposal and \# } \\
\text { of impacted stakeholders }\end{array}$ & $\begin{array}{l}2 \text { technology } \\
\text { characteristics and } \\
3 \text { stakeholders }\end{array}$ & $\begin{array}{c}1 \text { technology } \\
\text { characteristic and } \\
\text { stakeholders }\end{array}$ & $\begin{array}{c}2 \text { technology } \\
\text { characteristics and } \\
7 \text { stakeholders }\end{array}$ & $\begin{array}{c}5 \text { technology } \\
\text { characteristics and } 2 \\
\text { stakeholder }\end{array}$ \\
\hline \multirow{5}{*}{\multicolumn{2}{|c|}{$\begin{array}{l}0 \\
0 \\
0 \\
0 \\
0 \\
0 \\
0 \\
0\end{array}$}} & Diversity Events & $\begin{array}{l}\text { \# of diversity events to } \\
\text { create cultural awareness }\end{array}$ & 0 & 0 & recommended & 0 \\
\hline & & $\begin{array}{l}\text { Personnel Dedicated to } \\
\text { Support TT }\end{array}$ & $\begin{array}{c}\text { \# of people dedicated to } \\
\text { support TT }\end{array}$ & 0.5 & 0.5 & 0 & 1 \\
\hline & & Project Meetings & $\begin{array}{l}\text { \# of comms described in the } \\
\text { comm project plan }\end{array}$ & monthly meetings & weekly and site visits & weekly & monthly meetings \\
\hline & & $\begin{array}{l}\text { Personnel Loaned to } \\
\text { Recipient }\end{array}$ & $\begin{array}{l}\text { time that researchers are } \\
\text { loaned to help with TT }\end{array}$ & 0 & 0 & 1 year & 1 week \\
\hline & & Successful TT Experiences & $\begin{array}{c}\# \text { of previous successful TT } \\
\text { experiences }\end{array}$ & 0 & 0 & 0 & 4 \\
\hline \multirow{5}{*}{\multicolumn{2}{|c|}{ 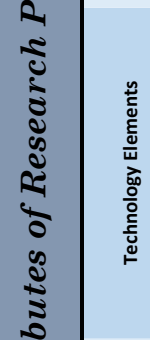 }} & $\begin{array}{l}\text { Combined Research } \\
\text { Experience }\end{array}$ & $\begin{array}{l}\text { \# years of combined } \\
\text { research experience of } \\
\text { principles }\end{array}$ & 47 years & 38 years & 46 years & 44 years \\
\hline & & Technology Publications & $\begin{array}{c}\text { \# publications about } \\
\text { technology }\end{array}$ & 45 publications & 23 publications & 16 publications & 16 publications \\
\hline & & Personnel Assigned to TTO & $\begin{array}{c}\text { \# of personnel assigned to } \\
\text { TTO }\end{array}$ & 0 & 3 & 3 & 0 \\
\hline & & Technology Benefits & $\begin{array}{l}\text { \# technology benefits } \\
\text { identified in the research } \\
\text { proposal }\end{array}$ & 10 & 7 & 4 & 7 \\
\hline & & Budget Allocated to TT & $\begin{array}{c}\text { \% R\&D budget dedicated to } \\
\text { TTO activities }\end{array}$ & 0 & 5 & 0 & 0 \\
\hline$\sum_{\substack{\pi \\
T}}^{\pi}$ & \multirow{6}{*}{ 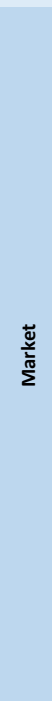 } & $\begin{array}{l}\text { Comprehensiveness of Use } \\
\text { Case }\end{array}$ & $\begin{array}{c}\text { How well is the use Case } \\
\text { Defined }\end{array}$ & none & none & none & none \\
\hline & & $\begin{array}{l}\text { Credibility of Organizational } \\
\text { Champion }\end{array}$ & $\begin{array}{c}\text { Credibility of the } \\
\text { Organizational Champion }\end{array}$ & $\begin{array}{c}\text { The champion has } \\
\text { technical expertise } \\
\text { and is recognized } \\
\text { within the region as an } \\
\text { expert }\end{array}$ & $\begin{array}{l}\text { The champion has } \\
\text { technical expertise } \\
\text { and is recognized } \\
\text { within the region as } \\
\text { an expert }\end{array}$ & $\begin{array}{l}\text { The champion has } \\
\text { technical expertise } \\
\text { and is recognized } \\
\text { within the region as } \\
\text { an expert }\end{array}$ & $\begin{array}{l}\text { The champion has } \\
\text { technical expertise } \\
\text { and is recognized } \\
\text { within the } \\
\text { organization as an } \\
\text { expert }\end{array}$ \\
\hline & & $\begin{array}{l}\text { Level of Top Management } \\
\text { Interest }\end{array}$ & $\begin{array}{l}\text { Level of Organizational } \\
\text { Support for TT }\end{array}$ & $\begin{array}{c}\text { There is some support by } \\
\text { middle management but } \\
\text { their engagement and } \\
\text { support is not consistent }\end{array}$ & $\begin{array}{c}\text { Executives are aware of } \\
\text { the technology but } \\
\text { their engagment is not } \\
\text { consistent }\end{array}$ & $\begin{array}{c}\text { Executives are aware of } \\
\text { the technology but their } \\
\text { engagment is not } \\
\text { consistent }\end{array}$ & $\begin{array}{c}\text { There is some support } \\
\text { by middle management } \\
\text { but their engagement } \\
\text { and support is not } \\
\text { consistent }\end{array}$ \\
\hline & & Government Incentives & $\begin{array}{l}\text { \# and type of government } \\
\text { incentives }\end{array}$ & $\begin{array}{l}\text { No incentives for energy } \\
\text { pods used at utility scale }\end{array}$ & $\begin{array}{c}\text { No incentives exists to } \\
\text { encourage technology } \\
\text { transfer }\end{array}$ & $\begin{array}{c}\text { No incentives exists to } \\
\text { encourage technology } \\
\text { transfer }\end{array}$ & $\begin{array}{c}\text { transient stability } \\
\text { modeling important - } 1 \\
\text { regulatory incentive }\end{array}$ \\
\hline & & $\begin{array}{l}\text { Common Technology } \\
\text { Standards }\end{array}$ & $\begin{array}{c}\text { How are common standards } \\
\text { supported }\end{array}$ & $\begin{array}{l}\text { There are no common } \\
\text { standards or codes for } \\
\text { the technology }\end{array}$ & $\begin{array}{l}\text { Communication } \\
\text { standards (CEA 2045, } \\
\text { WiFi, radio, etc.) - } \\
\text { Supported by a } \\
\text { consortium }\end{array}$ & $\begin{array}{l}\text { Communication } \\
\text { standards (CEA 2045, } \\
\text { WiFi, radio, etc.) - } \\
\text { Supported by a } \\
\text { consortium }\end{array}$ & $\begin{array}{l}\text { IEEE Standards for PMU data } \\
\text { used with modeling - } \\
\text { Supported by a consortium - } \\
\text { more generalized support and } \\
\text { awareness by a community } \\
\text { but there is no formal } \\
\text { requirement in place }\end{array}$ \\
\hline & & $\mathrm{ROI}$ & ROI & 0 & 0 & 0 & $\begin{array}{c}>20 \% \text { but less than } \\
50 \% \text { ROI }\end{array}$ \\
\hline
\end{tabular}




\section{Appendix G3: Corresponding Desirability Curve Values}

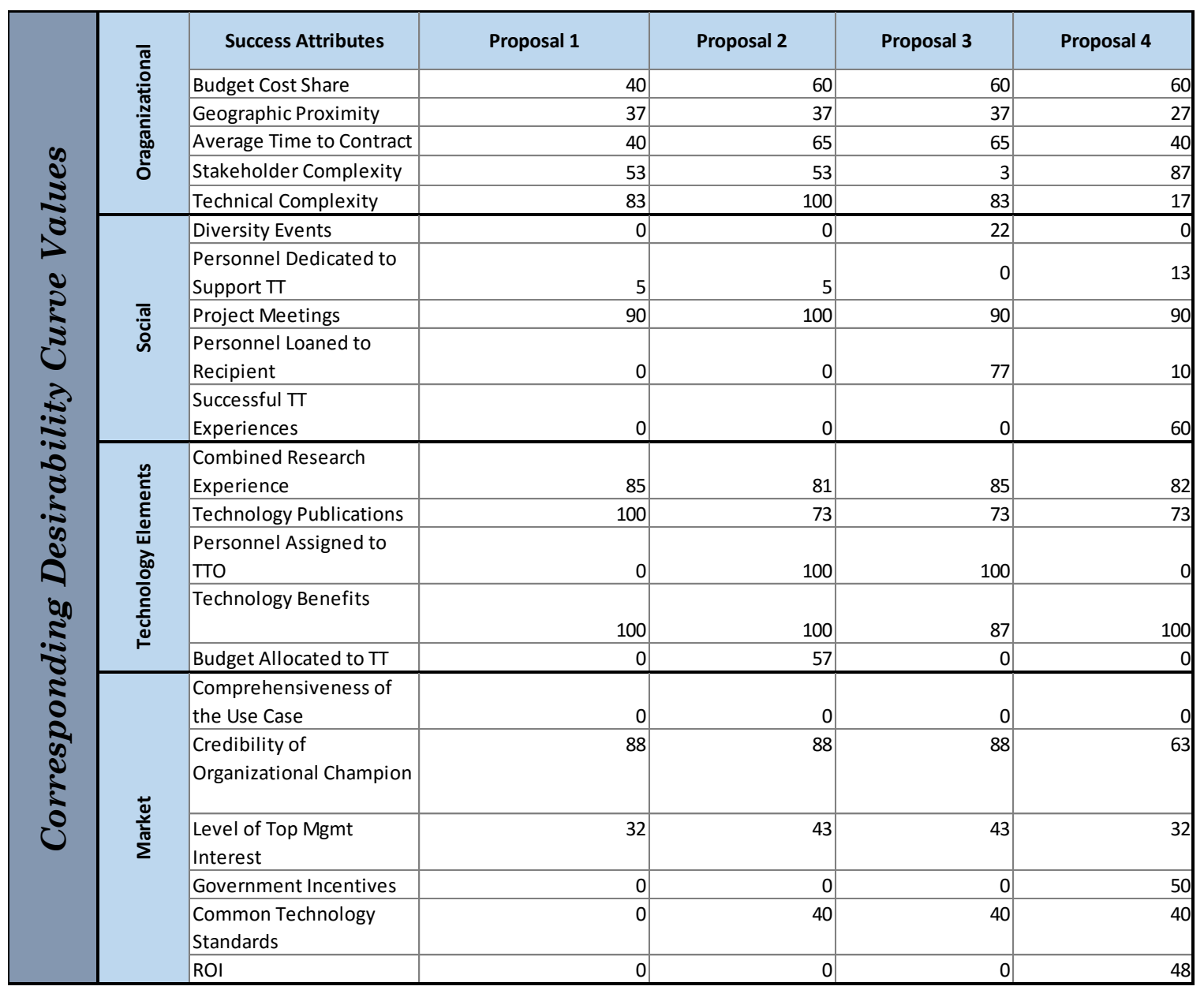

